\author{
Monograph \\ urn:lsid:zoobank.org:pub:F8DAFD36-2878-438D-B7C0-B8D05531EC5C
}

\title{
Euro-Mediterranean fauna of Campodeinae (Campodeidae, Diplura)
}

\author{
Alberto SENDRA ${ }^{1, *} \&$ Ana Sofia P.S. REBOLEIRA ${ }^{2}$ \\ ${ }^{1}$ Coleccions Torres-Sala i Siro de Fez, Servei de Patrimoni Històric, \\ Ajuntament de València, València, Spain. \\ ${ }^{2}$ Natural History Museum of Denmark, University of Copenhagen, Universitetsparken 15, \\ DK-2100 København Ø, Denmark. \\ ${ }^{2}$ Centre for Ecology, Evolution and Enviromental Changes (cE3c), Faculdade de Ciências, \\ Universidade de Lisboa, Lisbon, Portugal. \\ *Corresponding author: alberto.sendra@uv.es \\ ${ }^{2}$ Email: asreboleira@fc.ul.pt \\ ${ }^{1}$ urn:lsid:zoobank.org:author:11636BAE-AE66-4898-A7C8-35B329E7E3A8 \\ ${ }^{2}$ urn:lsid:zoobank.org:author:338DE845-4839-4EF5-B684-587C021F076C
}

\begin{abstract}
Campodeinae is the most diverse subfamily of Campodeidae diplurans and inhabits soils and subsurface ecosystems. These are distributed in the Palearctic area, clearly rarifying towards northern latitudes. The major taxonomic characters are chaetotaxy, shape and complexity of pretarsal structures, and secondary sexual characters. This monograph provides a taxonomic revision of the subfamily Campodeinae in the Euro-Mediterrnean region, based on extensive literature review and new material studied. It comprises detailed morphological descriptions and illustrations together with habitat and distribution data of 161 species and 14 subspecies from 10 genera: Campodea Westwood, 1842, Edriocampa Silvestri, 1933, Eutrichocampa Silvestri, 1902, Helladocampa Condé, 1984, Libanocampa Condé, 1955, Litocampa Silvestri, 1933, Oreocampa Condé, 1950, Podocampa Silvestri, 1932, Remycampa Condé 1952, and Spaniocampa Silvestri, 1933. With 116 species Campodea is the most diverse and widely distributed genus in the studied area.
\end{abstract}

Keywords. Dipluran, soil, cave fauna, troglobiont, Europe, Mediterranean basin.

Sendra A. \& Reboleira A.S.P.S. 2020. Euro-Mediterranean Fauna of Campodeinae (Campodeidae, Diplura). European Journal of Taxonomy 728: 1-130. https://doi.org/10.5852/ejt.2020.728.1181

We dedicate this revision to the memory of Professor Bruno Conde in recognition of his extensive contribution to the taxonomy of Campodeidae.

\section{Table of contents}

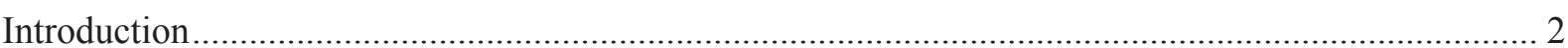

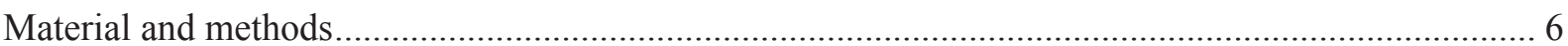

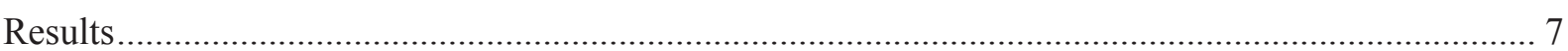

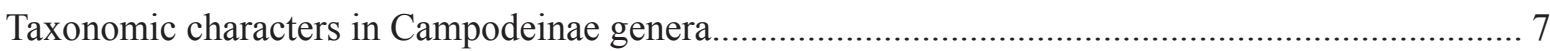




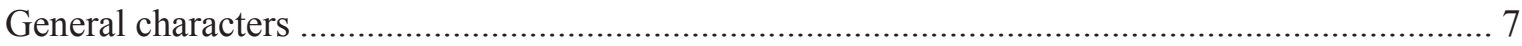

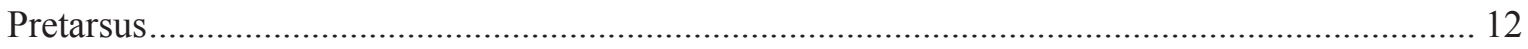

Labium .

Sexual characters

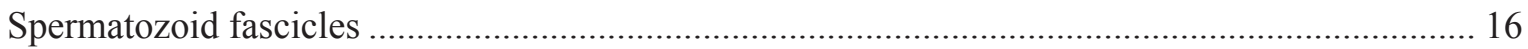

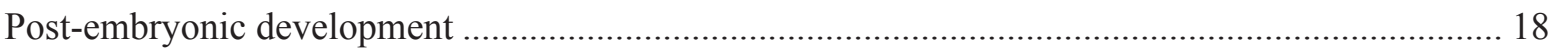

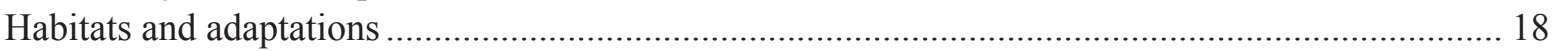

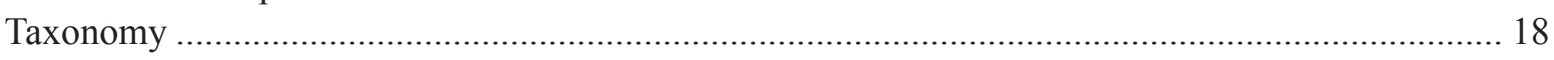

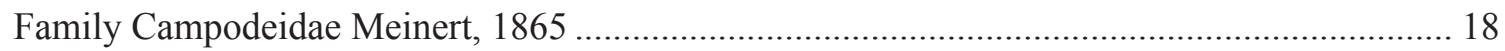

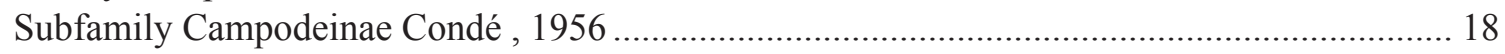

Taxonomic key for genera and subgenera of the subfamily Campodeinae (including species of

Eutrichocampa and Remycampa) from the Euro-Mediterranean region........................................ 19

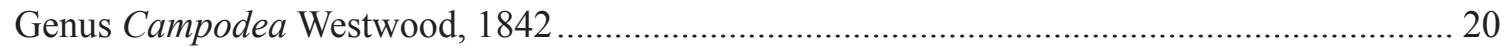

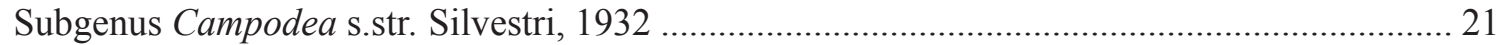

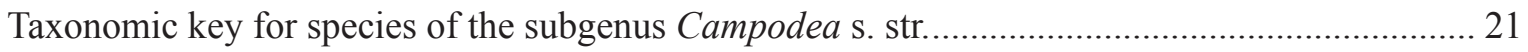

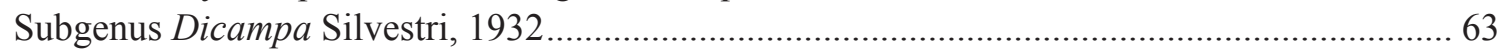

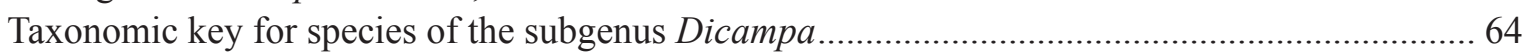

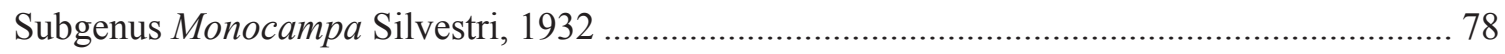

Taxonomic key for species of the subgenus Monocampa ….................................................... 79

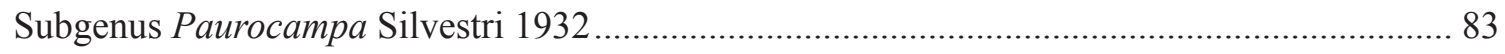

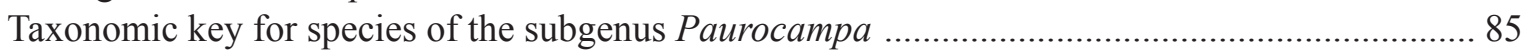

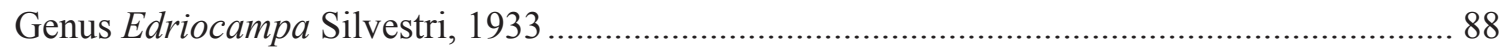

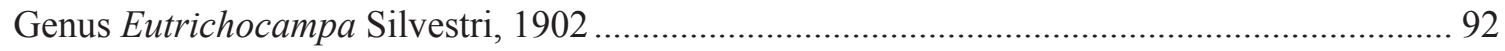

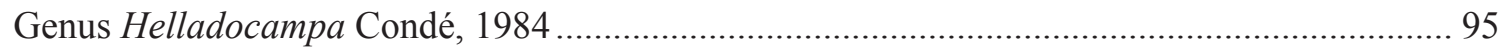

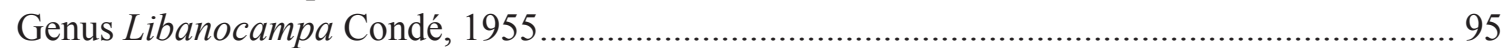

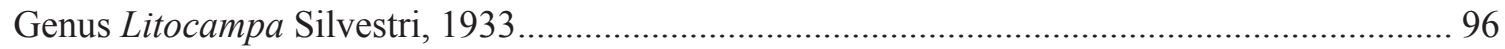

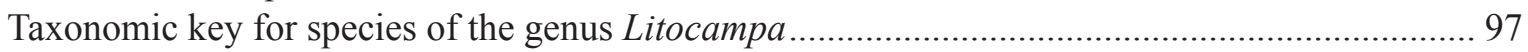

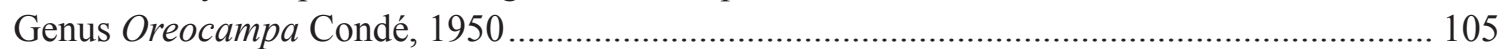

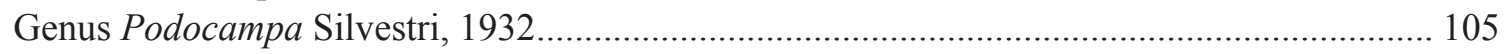

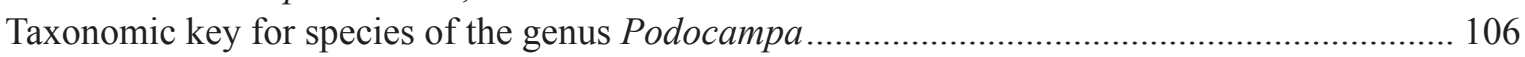

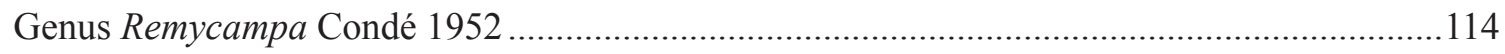

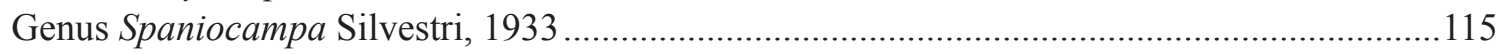

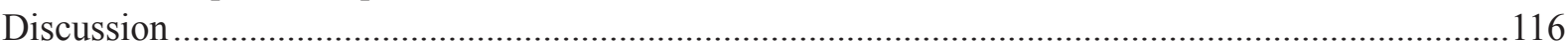

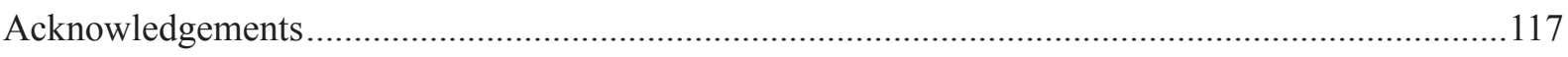

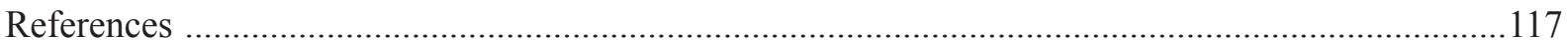

\section{Introduction}

Diplura Börner, 1904 are considered the sister group to insects, and are part of basal hexapods together with Protura Silvestri, 1907 and Collembola Lubbock, 1871 (Blanke \& Machida 2016). Diplurans, commonly known as two-pronged or bristletail doubletails, are distributed in terrestrial ecosystems across the planet, except in the polar regions, and nearly 1000 species have been described. They play an important role in the degradation of organic matter in leaf litter and are able to colonize caves and other subterranean habitats.

The tagmatization of diplurans is organized into a round flat head, three well-delimited thoracic segments, ten abdominal segments, and two cerci (Figs 1, 5-6). The cephalic capsule has enthognathous mouthparts and antennae with independent articular anennomeres, but no eyes. Each of the three thoracic segments has one pair of locomotory legs with two apical claws (Denis 1949; Condé \& Pagés 1991; Bareth 2006). 
Secretory glands with communication and reproductive functions are located on the sternal side of the first abdominal segment (Pagés 1967a; Bareth 1968). Two articulated appendages with setae, named styli (Pagés 1967a), and two exsertil water absorbent vesicles are present on the second to the seventh abdominal segments (Weyda 1976). The eighth abdominal segment has a simple genital papilla with

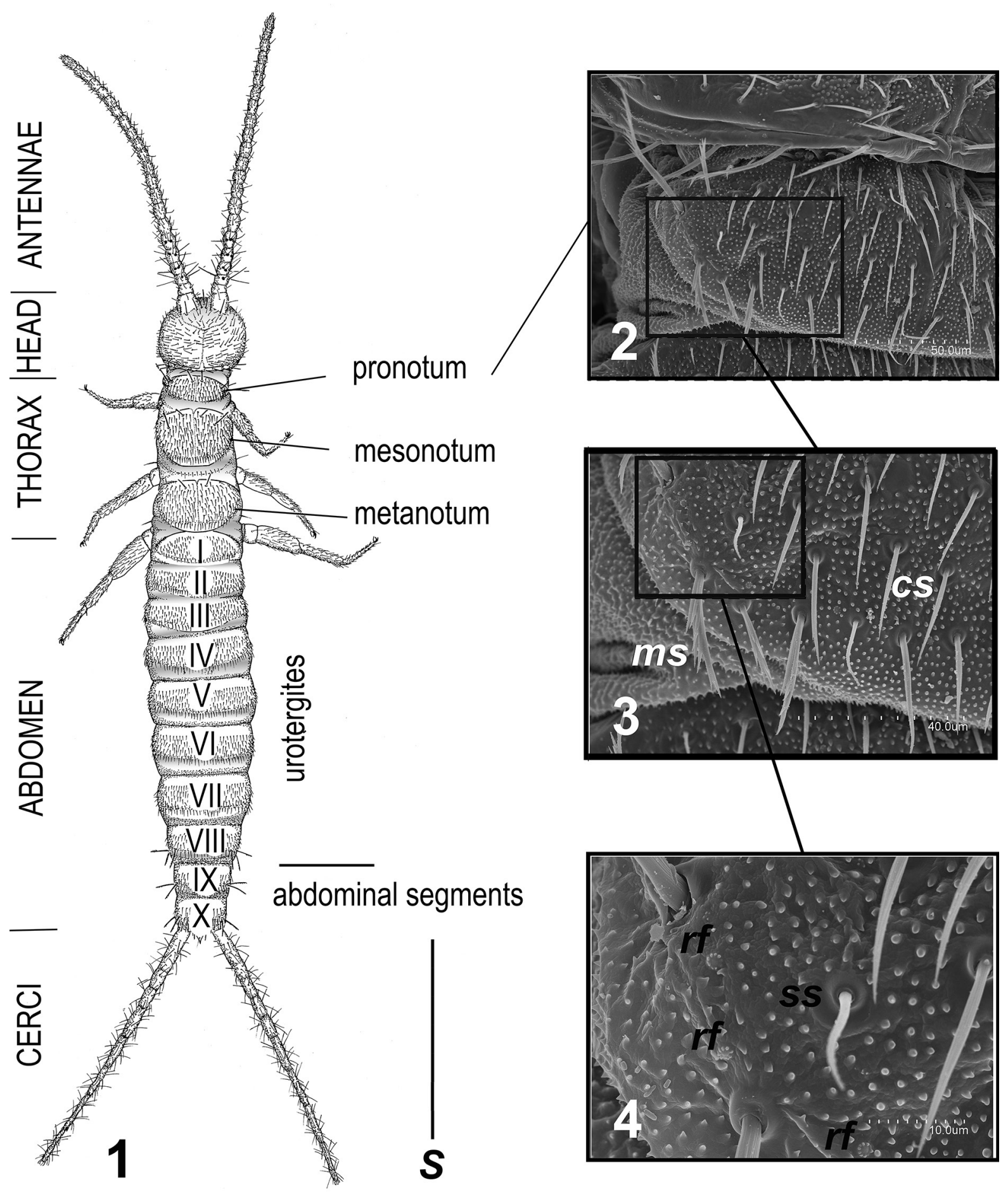

Figs 1-4. Campodea (Dicampa) catalana Denis, 1930. 1. Habitus with terminology of body parts. 2. Pronotum left side. 3. Lateral posterior detail of the pronotum left side. 4. Detail of lateral posterior of the pronotum left heminotum. Abbreviations: see Material and methods. 

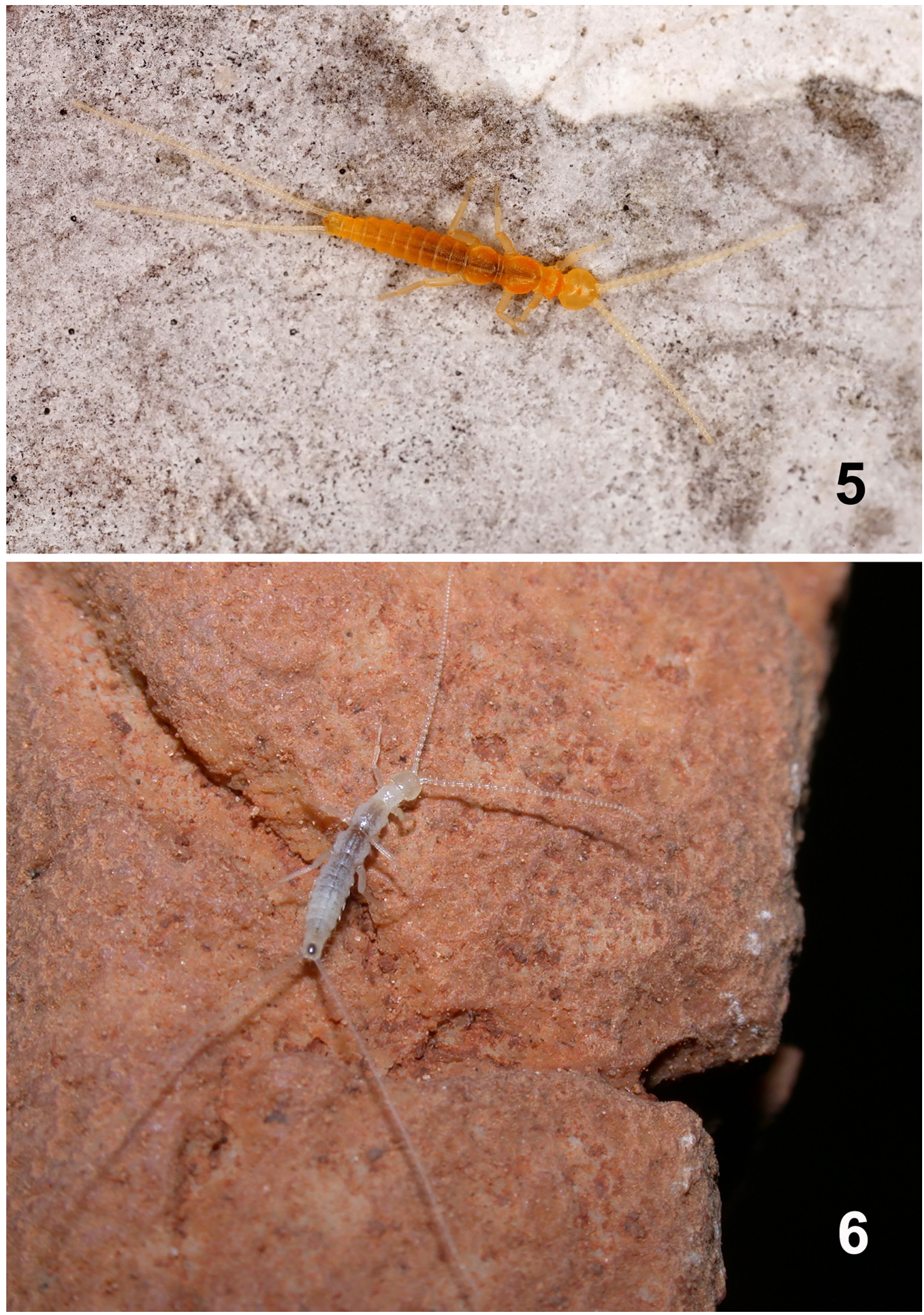

Figs 5-6. Campodeidae in their natural environment. 5. Campodea (Campodea) tuxeni Wygodzinsky, 1944, Hartelsgraben valley, Hieflau, Styria, Austria (photograph by Christian Komposch). 6. Campodea (Campodea) maestrazgoensis Sendra \& Escolà, 2004 in Cova del Mas Nou cave, Coves de Virrromà, Castellò, Iberican Mounta in Range, East of the Iberian Peninsula (photograph by Sergio Montagud). 
similar morphology across families (Pagés 1961). The two cerci at the end of the abdomen, from which the order gets the common name two-pronged or bristletail doubletails, are diagnostic for the ten families of diplurans. They exhibit a wide variety of shapes, from simple forceps to elongate, mutiarticular cerci, with or without sclerotized structures, secretory glands and various shapes of mechanoreceptors (Paclt 1957; Pagés 1959, 1961).

Campodeidae Meinert, 1865 and Japygidae Haliday, 1864 are well-known families of Diplura. Japygids have strong cerci in the form of forceps or pincers that also appear in the large-sized Heterojapygidae Womersley, 1939 or the small-sized Parajapygidae Womersley, 1939 (Sendra 2015). Species of heterojapygids and japygids can reach a body length of up to five centimeters (Denis 1949; Condé \& Pagés 1991) or even more, while campodeids rarely exceed one centimeter. However, the entire length of a campodeid, measured with antennae and cerci, can be five times the trunk length (Sendra et al. 2017b).

Campodeidae is the most diverse family of diplurans with about 450 species (for Diplura diversity see Sendra 2015). A considerable part of this diversity is attributable to the subfamily Campodeinae Condé, 1956 that is widespread over all continents except Antarctica (Condé 1956a). The threadlike cerci of the Campodeidae are composed of one basal article plus up to 27 articles with characteristic setation (Sendra et al. 2017b).

The classification of the family Campodeidae requires a molecular analysis to better understand its evolution (Condé 1956a; Paclt 1957). Not all higher taxa proposed in Campodeidae fit into a natural classification, as they appear to also have a strong geographical support, which is clear for the diplurans of the Holarctic region but not so clear for those outside this region or near its borders. Chaetotaxy, shape and complexity of pretarsal structures, and secondary sexual characters are the major characters used for this group, although they are insufficient for proper phylogenetic clarity (Sendra et al. 2012).

Campodeidae are divided in five subfamilies: Lepidocampinae Condé, 1956, Hemicampinae Condé, 1956, Syncampinae Paclt, 1957, Plusiocampinae Paclt, 1957, and Campodeinae, in addition to the peculiar tachycampoide lineage (Condé 1956a; Paclt 1957; Bareth \& Condé 1981; Sendra et al. 2020a). Lepidocampinae and Syncampinae have scales on the thorax and abdomen or only on the abdomen (Hemicampinae). Plusiocampinae is likely to be a paraphyletic taxon whose only diagnosic character are the extra lateral posterior pronotal macrosetae with equal or more than $1+1$ medial anterior, $1+1$ lateral anterior and 2+2 lateral posterior macrosetae (Sendra et al. 2020a). The tachycampoid group also lacks synapomorphies; all species share the reduction of the number of notal macrosetae and mostly the absence of dorsal femoral macrosetae and lateral crests on the claws (Bareth \& Condé 1981; Sendra et al. 2016, 2020a). The subfamily Campodeinae is characterized by the pronotal macrosetae formula up to $1+1$ medial anterior, 1+1 lateral anterior and 1+1 lateral posterior, one pair of medial anterior and lateral anteriorurotergal macrosetae, and one or two pairs (exceptionally three) of lateral posterior urotergal macrosetae.

Species of Campodeidae live from the soil layers down to cave habitats. The monotypic Syncampinae occur in soil habitats in China (Silvestri 1931c), the four species of Hemicampinae live in soils in the southern USA, Mexico and Guyana (Condé 1956a; Condé \& Geeraert 1962; Sendra et al. 2020c). Species of Lepidocampinae are known from tropical and subtropical soils around the world, with three species reported only from caves (Condé 1956a; Sendra et al. 2017b). Campodeinae, the most diverse and abundant subfamily in soils in every continent except Antarctica (Condé 1956a), are widely distributed from humid areas to deserts and also tropical forests. Only 36 out of the 300 species of Campodeinae colonize cave habitats, in contrast to the Plusicampinae and the tachycampoid lineage, in which most of the species show adaptations to cave habitats in karst and volcanic territories (Sendra et al. 2016, 2017c, 2020a; Sendra \& Weber 2018). 
A loose aggregation behavior is recognized in campodeids (Gunn 1992), while japygids are known to be territorial (Pagés 1967b), probably due to their predatory life-style (Pagés 1967a). Campodeids - and Campodeinae in particular - preferably feed on fungal spores and mycelia, decaying organic matter and corpses, but can also predate (Carpenter 1988; Christian \& Bauer 2005). A carvivorous diet has been observed in the digestive tube of cave-dwelling Campodeinae (Sendra pers. obs.).

Diplurans reproduce by indirect sperm transfer, and in campodeids it was observed that males deposit spermatophores on the substrate, which are picked up by females (Orelli 1956; Bareth 1963; Pagés 1967a). The female produces a mass of 4 to 40 spherical eggs ( $0.4 \mathrm{~mm}$ diameter) that is attached to the substrate by a short stalk, from where a juvenile hatches wrapped in a sac-shaped cuticle (Orelli 1956; Bareth 1963; Bareth \& Condé 1965). In campodeids this pre-imaginal development lasts around two weeks, while in japygids the hatching period lasts six weeks, the juvenile goes through two 'larvae' instars clearly different from the adults (Pagés 1967a) and the females guard their eggs and juveniles, whereas campodeids leave them alone (Pagés 1967a). Diplurans can live at least a year, continuously moulting after reaching sexual maturity and increasing slightly in size (Orelli 1956). A clear seasonal variation of abundance has been recorded in soil-dwelling campodeids, related to the reduction or absence of reproduction during the winter season (Orelli 1956; Bareth 1968; Blesić 1987; Sendra et al. 2017a). Such variation is not observed in cave-adapted campodeids (Sendra et al. 2017b).

The subfamily Campodeinae was proposed by John O. Westwood (1842) to accomodate the genus Campodea, and revised later by Frederik V.A. Meinert (1865). In-depth studies on diplurans during the first half of the $20^{\text {th }}$ century are scarce, e.g., Condé (1956a) and Paclt (1957), but several relevant regional taxonomic contributions were made (e.g., Bagnall 1915, 1918a, 1918b, 1918c; Stach 1920, 1928; Denis 1924, 1930, 1932a, 1932b, 1949; Womersley 1927; Agrell 1944; Ionescu 1951, 1955; Pagés 1951; Arevad 1957; Palissa 1964; Rusek 1964, 1965a, 1965b, 1965c). The Italian entomologist Filippo Silvestri settled the current taxonomy of Diplura (Silvestri 1912). The first and unique taxonomic key of European campodeid species was proposed by Peter Wygodzinsky (1941a), while Paclt (1957) proposed the only generic key of Diplura to date. The French entomologist Bruno Condé dedicated his life to the study of Campodeidae (Condé 1956a), publishing 138 articles about diplurans, with the descriptions of 172 species, 32 subspecies and 15 genera (see Bareth 2007b). Contributions on the reproduction and postembryonic development of campodeids were made by Camille Bareth (1968) and Marcus von Orelli (1956).

Here, we revise all species of Euro-Mediterranean Campodeinae, providing detailed descriptions and illustrations of relevant morphological characters, as well as data on habitats and distribution, based on collections and newly sampled material. Furthermore, we provide a taxonomic key to genera, subgenera and species of Campodeinae genera from the Euro-Mediterranean region.

\section{Material and methods}

The material studied includes a total of 2592 specimens deposited in the National Museum of Natural History, Paris (Supplementary file 2), 3361 specimens from the Geneva Zoological Museum, the Zoological Museum of Barcelona, the Natural History Museum of Denmark, the collection of the first author (Sendra coll.) and other material collected by different zoologists and naturalists (Supplementary file 2).

Specimens were washed using distilled water, mounted with Marc André II solution on glass slides and studied under a phase-contrast optical microscope (Leica DMLS) with camera lucida. Measurements of the body length were taken from the base of the distal macrochaeta of the frontal process to the tip of the supra-anal valve. Some specimens were critical point-dried in a Tousimis Autosamdi 815, series A, coated with palladium-gold and studied under Hitachi S-4100 and JEOL JSM-6335F scanning electronic microscopes (SEM). 
The taxonomic keys to genera, subgenera and species of Campodeinae were generated in the DELTA database (Dallwitz 2005) and modified to improve readability. Each taxon includes a diagnosis, and a habitat and distribution section. Taxonomic notes and character illustrations are provided for the 26 revised species based on new material studied. The overall taxa distribution and life-style are summarized in Table 1 and in Supplementary file 1. The ecological classification of the species follows that previously used in Sendra et al. (2020a).

A complete database including the species localities was built to produce the distribution maps (Figs 5862) following the methodology previously used in Sendra et al. (2020a).

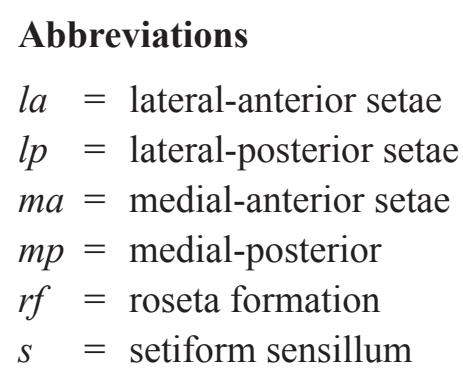

\section{Results}

\section{Taxonomic characters in Campodeinae genera}

The interspecific differences in Campodeinae are mostly based on the position, shape and size of the mechanoreceptor setae, which vary from simple clothing setae to more distinguishable macrosetae inserted in a fixed position. The pretarsal and claw shape and its outer lateral process are also of relevant taxonomic significance.

\section{General characters}

\section{Integument}

The cuticle is thin with a smooth epicuticle frequently covered with microdenticles perceptible at $100 \mathrm{x}$ magnifications in optical microscopy (Figs 2-12). Reticulation (Fig. 11) and microdenticles (Figs 2-12) of the cuticle are only visible in SEM. Unicellular secretory glands are present randomly on the cuticle, constituing micropores, called roseta formations, and correspond to the opening of the gland, which is surrounded by a crown of microspheres characteristic to Campodeinae (Figs 4, 8, 10, 16) (Bareth 1963; Bareth \& Juberthie-Jupeau 1996; Sendra et al. 2018, 2020b).

\section{Mechanoreceptors and sensilla}

Mechanoreceptors setae and the sensorial formations detailed below are important taxonomic characters in Campodeinae (Condé 1956a; Bareth 1968).

\section{Clothing setae}

These are small simple sensorial setae covering the whole body (Figs 2-3), appendages included, and increase in number during growth. Their surface is usully smooth, sometimes with a simple apical barb and rarely covered by barbs.

\section{Marginal setae}

These are simple setae positioned along the border of the notal and urotergal tergites (Fig. 3). They are usually thicker, longer and more barbed than clothing setae. 
Table 1 (continued on next three pages). Euro-Mediterranean fauna of Campodeinae Condé, 1956 per country and habitat. Abbreviation: MSS = mesovoid shallow substratum.

\begin{tabular}{|c|c|c|}
\hline Species & Country & Habitat \\
\hline Campodea (Campodea) alfierii Wygodzinsky, 1942 & Israel & Soil \\
\hline Campodea (Campodea) alluvialis Sendra, 2017 & Spain & MSS \\
\hline Campodea (Campodea) anae Sendra \& Teruel, 2010 & Turkey & Soil \\
\hline Campodea (Campodea) anavyi Condé, 1955 & Lebanon & Soil \\
\hline Campodea (Campodea) apennina Ramellini, 1998 & Italy & Soil \\
\hline Campodea (Campodea) arrabidae Wygodzinsky, 1944 & Portugal, Spain & Soil \\
\hline Campodea (Campodea) augens Silvestri, 1936 & $\begin{array}{l}\text { Austrai, Bosnia and Herzegovina, Czech Republic, } \\
\text { Poland, Russia, Serbia, Turkey }\end{array}$ & Soil \\
\hline Campodea (Campodea) basiliensis Wygodzinsky, 1941 & France, Germany, Switzerland & Soil \\
\hline Campodea (Campodea) blandinae blandinae Condé, 1948 & France, Italy & Cave \\
\hline Campodea (Campodea) blandinae ichnusa Condé, 1956 & Italy & Cave \\
\hline Campodea (Campodea) blandinae virgolae Condé, 1948 & France & Cave \\
\hline Campodea (Campodea) chardardi cephalonica Condé, 1947 & Greece & Soil \\
\hline Campodea (Campodea) chardardi chardardi Condé, 1947 & France & Soil \\
\hline Campodea (Campodea) chionea Rusek, 1966 & Czech Republic, Germany, Poland, Slovakia & Soil \\
\hline Campodea (Campodea) coniphora Wygodzinsky, 1941 & France, Switzerland & Soil \\
\hline Campodea (Campodea) consobrina Condé \& Mathieu, 1957 & France, Italy & Soil \\
\hline Campodea (Campodea) cossetana Sendra \& Escolà, 2004 & Spain & Cave \\
\hline Campodea (Campodea) cyrnea alethae Condé, 1948 & France & Cave \\
\hline Campodea (Campodea) cyrnea cyrnea Condé, 1946 & France & Cave \\
\hline Campodea (Campodea) delamarei Condé \& Mathieu, 1957 & France & Soil \\
\hline Campodea (Campodea) donensis Rusek, 1965 & Russia, Turkey & Soil \\
\hline Campodea (Campodea) egena Condé, 1951 & Spain & Cave \\
\hline Campodea (Campodea) epirotica Condé, 1984 & Greece & Soil \\
\hline Campodea (Campodea) aff. fragilis Meinert, 1865 & Turkey & Soil \\
\hline Campodea (Campodea) fragilis Meinert, 1865 & $\begin{array}{l}\text { Algeria, Austria, Belgium, Czech Republic, Denmark, } \\
\text { France, Germany, Greece, Hungary, Ireland, Italy, } \\
\text { Macedonia, Morocco, Norway, Poland, Romania, Serbia, } \\
\text { Slovakia, Spain, Sweden, Switzerland, United Kingdom }\end{array}$ & Soil \\
\hline Campodea (Campodea) franzi Condé, 1954 & Austria, Czech Republic, Germany, Poland & Soil \\
\hline Campodea (Campodea) frascajensis Condé, 1946 & France & Soil \\
\hline Campodea (Campodea) aff. galilaea Wygodzinsky, 1942 & Italy & Soil \\
\hline Campodea (Campodea) galilaea Wygoszinsky, 1942 & Israel, Lebanon, Turkey & Soil \\
\hline Campodea (Campodea) ghilarovi Rusek, 1965 & Abkhazia, Ukranie & Soil \\
\hline Campodea (Campodea) giardi Silvestri, 1912 & France, Spain, United Kingdom & Soil \\
\hline Campodea (Campodea) grallesiensis Sendra \& Condé, 1987 & Spain & Cave \\
\hline Campodea (Campodea) grassii Silvestri, 1912 & Algeria, France, Italy, Spain & Soil \\
\hline Campodea (Campodea) ilixonis Denis, 1932 & France, Spain & Soil \\
\hline Campodea (Campodea) kasiki Rusek, 1964 & Montenegro, Slowakia, Turkey & Soil \\
\hline Campodea (Campodea) kervillei Denis, 1932 & France, Spain & Soil \\
\hline Campodea (Campodea) lankesteri Silvestri, 1912 & $\begin{array}{l}\text { Austria, Belgium, Denmark, France, Germany, Ireland, } \\
\text { Luxembourg, Sweden, United Kingdom }\end{array}$ & Soil \\
\hline Campodea (Campodea) leclerci Bareth, 1985 & France & Cave \\
\hline Campodea (Campodea) lubbocki Silvestri, 1912 & $\begin{array}{l}\text { Austria, Belgium, France, Germany, Italy, Luxembourg, } \\
\text { Norway, Switzerland, Sweden, United Kingdom }\end{array}$ & Soil \\
\hline Campodea (Campodea) machadoi Condé, 1951 & Portugal & Soil \\
\hline Campodea (Campodea) maestrazgoensis Sendra \& Escolà, 2004 & Spain & Cave \\
\hline Campodea (Campodea) magna Ionescu, 1955 & Austria, Romania, Turkey & Soil \\
\hline Campodea (Campodea) majorica interjecta Condé, 1955 & Spain & Cave \\
\hline Campodea (Campodea) majorica majorica Condé, 1955 & Spain & Cave \\
\hline Campodea (Campodea) majorica sicula Condé, 1957 & Italy & Cave \\
\hline Campodea (Campodea) majorica valentina Sendra \& Moreno, 2004 & Spain & Cave \\
\hline Campodea (Campodea) meinerti Bagnall, 1918 & Belgium, France, United Kingdom & Soil \\
\hline Campodea (Campodea) minor Wygodzinsky, 1944 & Portugal and Spain & Soil \\
\hline Campodea (Campodea) monspessulana Condé, 1953 & France & Soil \\
\hline
\end{tabular}


Table 1 (continued).

\begin{tabular}{ll}
\hline Species & Country \\
\hline Campodea (Campodea) navasi Sendra \& Moreno 2004 & Spain \\
Campodea (Campodea) olivieri Condé, 1955 & Lebanon \\
Campodea (Campodea) oredonensis Condé, 1951 & France \\
Campodea (Campodea) patrizii Condé, 1953 & Italy \\
Campodea (Campodea) pempturochaeta Silvestri, 1912 & Algeria, Italy, Spain, Turkey \\
Campodea (Campodea) pieltaini Silvestri, 1932 & France, Spain \\
Campodea (Campodea) plusiochaeta Silvestri, 1912 & Abkhazia, Algeria, Austria, Belgium, Bosnia- \\
& Herzegovina, Croatia, Czech Republic, Denmark, \\
& Finland, France, Germany, Greece, Italy, Luxembourg, \\
& Macedonia, Montenegro, Morocco, Norway, Poland, \\
& Russia, Serbia, Slovakia, Spain, Switzerland, Turkey,
\end{tabular}

Campodea (Campodea) portacoeliensis Sendra \& Jiménez, 1986

Spain

Campodea (Campodea) posterior Silvestri, 1932

Campodea (Campodea) procera Condé, 1948

Campodea (Campodea) pseudofragilis Condé, 1984

Campodea (Campodea) pusilla Condé, 1950

Campodea (Campodea) redii Silvestri, 1912

Campodea (Campodea) remyi Denis, 1930

Campodea (Campodea) rhopalota Condé, 1948

Campodea (Campodea) sarae Sendra \& Teruel, 2010

Campodea (Campodea) aff. sardiniensis Bareth, 1980

Campodea (Campodea) sardinensis Bareth, 1980

Campodea (Campodea) sensillifera Condé \& Mathieu, 1958

Campodea (Campodea) silvestrii Bagnall, 1918

Campodea (Campodea) silvicola Wygodzinsky, 1940

Campodea (Campodea) staphylinus Westwood, 1842

Campodea (Campodea) subdives Silvestri, 1932

Campodea (Campodea) aff. taunica Marten, 1939

Campodea (Campodea) taunica Marten, 1930

Campodea (Campodea) tuxeni Wygodzinsky, 1941

Campodea (Campodea) vihorlatensis Paclt, 1961

Campodea (Campodea) wallacei Bagnall, 1918

Campodea (Campodea) westwoodi Bagnall, 1918

Campodea (Campodea) aff. zuluetai Silvestri, 1932

Campodea (Campodea) zuluetai Silvestri, 1932

Campodea (Dicampa) aemula Condé, 1953

Campodea (Dicampa) apula Silvestri, 1912

Campodea (Dicampa) aristotelis Silvestri, 1912

Campodea (Dicampa) azkarraga Sendra, 2006

Campodea (Dicampa) blancae Sendra \& Moreno, 2006

Campodea (Dicampa) boneti Silvestri, 1932

Campodea (Dicampa) campestris Ionescu, 1955

Campodea (Dicampa) catalana Denis, 1930

Campodea (Dicampa) caucasica Rusek, 1965

Campodea (Dicampa) codinai Silvestri, 1932

Campodea (Dicampa) condei Rusek, 1965

Campodea (Dicampa) crimeaensis Rusek, 1965

France

Greece, Romania

France

France, Italy, Spain

Habitat

Soil

Soil

Soil

Cave

Soil

Soil

Soil

Belgium, Bosnia-Herzegovina, France, Germany,

Luxembourg, Switzerland

Austria, France, Switzerland Soil

Turkey Soil

Spain Soil

Italy Soil

France Soil

Austria, Bosnia-Herzegovina, Czech Republic, Soil

Denmark, France, Germany, Greece, Hungary, Ireland, Italy, Poland, Serbia, Slovakia, Switzerland, Sweden,

United Kingdom

Germany, France, Serbia, Switzerland Soil

Belgium, France, Germany, Italy, Poland, United Soil

Kingdom

Algeria, Greece, Luxembourg, Spain, Turkey Soil

France, Turkey Soil

France, Germany, Romania, Serbia, Switzerland, Turkey Soil

Austria, Czech Republic, Romania, Slovenia Soil

Italy, Romania, Slovakia Soil

Belgium, Czech Republic, France, Germany, Italy, Soil

Luxembourg, Macedonia, Montenegro, Poland, Serbia,

Slovenia, Slovakia, Sweden, Switzerland, United

Kingdom

France, United Kingdom Soil

Italy Soil

France, Italy, Spain Soil

Morocco, Spain Soil

Abkhazia, Italy, Poland, Romania, Slovakia Soil

Greece, Turkey Soil

Turkey Soil

Spain Soil

Spain Soil

Bulgaria, Montenegro, Romania, Serbia Soil

Italy, Spain Soil

Russia Soil

Italy, Spain Soil

Russia Soil

Crimean Peninsula, Turkey $\quad$ Soil 
Table 1 (continued).

\begin{tabular}{|c|c|c|}
\hline Species & Country & Habitat \\
\hline Campodea (Dicampa) davidi Condé, 1952 & Algeria, Morocco, Spain & Soil \\
\hline Campodea (Dicampa) egreria Condé, 1953 & Morocco & Soil \\
\hline Campodea (Dicampa) escalerai Silvestri, 1932 & Spain & Soil \\
\hline Campodea (Dicampa) frenata Silvestri, 1931 & $\begin{array}{l}\text { Bosnia-Herzegovina, Bulgaria, Romania, Serbia, } \\
\text { Slovakia }\end{array}$ & Soil \\
\hline Campodea (Dicampa) aff. gestroi Silvestri, 1912 & Italy & Soil \\
\hline Campodea (Dicampa) gestroi Silvestri, 1912 & Italy & Soil \\
\hline Campodea (Dicampa) imeretinensis Chevrizov, 1976 & Crimean Peninsula, Georgia, Turkey & Soil \\
\hline Campodea (Dicampa) insulana Condé, 1952 & France & Soil \\
\hline Campodea (Dicampa) aff. jolyi Condé, 1948 & Portugal & Soil \\
\hline Campodea (Dicampa) jolyi Condé, 1947 & France, Italy & Soil \\
\hline Campodea (Dicampa) kocheri Condé, 1954 & Algeria, Morocco & Soil \\
\hline Campodea (Dicampa) lusitana Wygodzinsky, 1944 & Portugal, Spain & Soil \\
\hline Campodea (Dicampa) malpighii Silvestri, 1912 & Italy, Romania, Serbia & Soil \\
\hline Campodea (Dicampa) melici Sendra, 2015 & Spain & Cave \\
\hline Campodea (Dicampa) merceti Silvestri, 1932 & Algeria, France, Spain & Soil \\
\hline Campodea (Dicampa) neuherzi Condé, 1995 & Romania & Cave \\
\hline Campodea (Dicampa) neusae Sendra \& Moreno, 2006 & Spain & Soil \\
\hline Campodea (Dicampa) pagesi Condé \& Mathieu, 1957 & France & Soil \\
\hline Campodea (Dicampa) pardoi Silvestri, 1932 & Spain & Soil \\
\hline Campodea (Dicampa) aff. plagiaria Silvestri, 1932 & Morocco & Cave \\
\hline Campodea (Dicampa) plagiaria Silvestri, 1932 & Morocco, Spain & Soil \\
\hline Campodea (Dicampa) propinqua Silvestri, 1932 & Spain & Soil \\
\hline Campodea (Dicampa) silvicola Ionescu, 1955 & Romania, Serbia & Soil \\
\hline Campodea (Dicampa) sprovieri sprovieri Silvestri, 1933 & Bulgaria, Greece, Romania, Turkey & Soil \\
\hline Campodea (Dicampa) sprovieri vardousiae Condé, 1984 & Greece & Soil \\
\hline Campodea (Dicampa) taurica Silvestri, 1949 & Crimean Peninsula, Russia & Cave \\
\hline Campodea (Monocampa) aurunca Ramellini, 1990 & Italy & Soil \\
\hline Campodea (Monocampa) denisi Wygodzinsky, 1940 & Austria, Czech Republic, France, Italy, Switzerland & Soil \\
\hline Campodea (Monocampa) devoniensis Bagnall, 1918 & $\begin{array}{l}\text { Austria, Croatia, France, Italy, Morocco, Portugal, } \\
\text { Slovakia, Spain, United Kingdom }\end{array}$ & Soil \\
\hline Campodea (Monocampa) emeryi algira Condé, 1948 & Algeria & Soil \\
\hline Campodea (Monocampa) emeryi emeryi Silvestri, 1912 & France, Italy & Soil \\
\hline Campodea (Monocampa) emeryi spelaea Condé, 1978 & Italy & Cave \\
\hline Campodea (Monocampa) goursati Condé, 1950 & France & Soil \\
\hline Campodea (Monocampa) hauseri Condé, 1978 & Greece & Soil \\
\hline Campodea (Monocampa) navasi Silvestri, 1932 & Andorra, France, Spain & Soil \\
\hline Campodea (Paurocampa) corsica Condé, 1946 & France, Italy & Soil \\
\hline Campodea (Paurocampa) aff. pretneri I Condé, 1974 & Slovenia & Cave \\
\hline Campodea (Paurocampa) aff. pretneri II Condé, 1974 & Italy. Montenegro, Slovenia & Cave \\
\hline Campodea (Paurocampa) pretneri Condé, 1974 & Italy, Slovenia & Cave \\
\hline Campodea (Paurocampa) ribauti Silvestri, 1912 & France, Spain & Soil \\
\hline Campodea (Paurocampa) rocasolanoi Silvestri, 1932 & France, Macedonia, Montenegro, Serbia, Spain & Soil \\
\hline Campodea (Paurocampa) ruseki Condé, 1966 & Austria & Soil \\
\hline Campodea (Paurocampa) speleaea Ionescu, 1955 & Romania, Serbia & Cave \\
\hline Campodea (Paurocampa) suensoni Tuxen, 1930 & $\begin{array}{l}\text { Austria, Bosnia-Herzegovina, Bulgaria, Croatia, Czech } \\
\text { Republic, Greece, Italy, Montenegro, Romania, Serbia, } \\
\text { Slovakia, Slovenia }\end{array}$ & Soil \\
\hline Edriocampa ghigii Silvestri, 1933 & Greece, Turkey & Soil \\
\hline Eutrichocampa aegea Silvestri, 1933 & Egypt, Greece, Israel, Lebanon, Turkey & Soil \\
\hline Eutrichocampa collina collina Ionescu, 1955 & Bosnia-Herzegovina, Romania, Serbia & Soil \\
\hline Eutrichocampa collina ithacesia Condé, 1984 & Greece & Soil \\
\hline Eutrichocampa helvetica Wygodzinsky, 1941 & Switzerland & Soil \\
\hline Eutrichocampa hispanica Silvestri, 1932 & Portugal, Spain & Soil \\
\hline Eutrichocampa paurociliata Loksa, 1960 & Hungary & Soil \\
\hline
\end{tabular}


Table 1 (continued).

\begin{tabular}{|c|c|c|}
\hline Species & Country & Habitat \\
\hline Eutrichocampa remyi Condé, 1947 & Bosnia-Herzegovina, Greece, Montenegro, Serbia & Soil \\
\hline Eutrichocampa thamugadensis Condé, 1948 & Algeria, France, Italy, Turkey & Soil \\
\hline Helladocampa mahnerti Condé, 1984 & Greece & Soil \\
\hline Libanocampa coiffaiti Condé, 1955 & Lebanon, Turkey & Soil \\
\hline Litocampa bourgoini (Condé, 1948) & France, Switzerland & Cave \\
\hline Litocampa aff. cognata (Condé, 1948) & Italy & Soil \\
\hline Litocampa cognata (Condé, 1948) & France & Cave \\
\hline Litocampa coiffaiti (Condé, 1948) & France, Spain & Cave \\
\hline Litocampa drescoi (Condé, 1949) & France, Spain & Cave \\
\hline Litocampa aff espanoli (Condé, 1949) & Spain & Cave \\
\hline Litocampa espanoli (Condé, 1949) & Spain & Cave \\
\hline Litocampa henryi Condé, 1991 & France & Cave \\
\hline Litocampa hubarti Bareth, 1999 & Belgium & Cave \\
\hline Litocampa humilis comani Condé, 1991 & Romania & Cave \\
\hline Litocampa humilis humilis Condé, 1948 & Belgium, France, Luxemburg, Romania & Cave-Soil \\
\hline Litocampa mendesi Sendra \& Reboleira, 2010 & Portugal & Cave \\
\hline Litocampa montana (Ionescu, 1955) & Romania & Soil \\
\hline Litocampa quadrisetigera Bareth, 2001 & France & Cave \\
\hline Litocampa sollaudi (Denis, 1930) & France, Switzerland & Cave \\
\hline Litocampa tuzetae (Condé, 1947) & France & Cave-Soil \\
\hline Litocampa vandeli (Condé, 1946) & France, Spain & Cave \\
\hline Litocampa aff. zaldivarae Sendra, Salgado \& Monedero, 2003 & Spain & Cave \\
\hline Litocampa zaldivarae Sendra, Salgado \& Monedero, 2003 & Spain & Cave \\
\hline Oreocampa aff. minutella (Silvestri, 1918) & Russia & Soil \\
\hline Podocampa aff. asturiana I Sendra, Salgado \& Monedero, 2003 & Spain & Cave \\
\hline Podcampa aff. asturiana II Sendra, Salgado \& Monedero, 2003 & Spain & Cave \\
\hline Podocampa asturiana asturiana Sendra, Salgado \& Monedero, 2003 & Spain & Cave \\
\hline Podocampa asturiana riberiensis Sendra, Salgado \& Monedero, 2003 & Spain & Cave \\
\hline Podocampa brolemanni Denis, 1932 & France & Soil \\
\hline Podocampa cardini (Silvestri, 1932) & Portugal, Spain & Soil \\
\hline Podocampa aff. ceballosi (Silvestri, 1932) & Spain & Cave \\
\hline Podocampa ceballosi (Silvestri, 1932) & Algeria, Marroco, Portugal, Spain & Soil \\
\hline Podocampa cerruti Condé, 1975 & Italy & Cave \\
\hline Podocampa cerruti kahmanni Condé, 1975 & Italy & Soil \\
\hline Podocampa fragiliformis Condé, 1953 & Morocco & Soil \\
\hline Podocampa aff. fragiloides (Silvestri, 1932) & Portugal, Spain & Cave-Soil \\
\hline Podocampa fragiloides (Silvestri, 1932) & Morocco, Portugal, Spain & Soil \\
\hline Podocampa aff. iglesiasi (Silvestri, 1932) & Spain & Soil \\
\hline Podocampa iglesiasi (Silvestri, 1932) & Portugal, Spain & Soil \\
\hline Podocampa jeanneli (Condé, 1947) & France, Spain & Cave \\
\hline Podocampa jorgei (Wygodzinsky, 1944) & Portugal & Soil \\
\hline Podocampa mauritanica (Silvestri, 1932) & Morocco & Soil \\
\hline Podocampa moroderi (Silvestri, 1932) & Spain & Soil \\
\hline Podocampa rifiana Silvestri, 1932 & Morocco & Soil \\
\hline Podocampa seabrai (Wygodzinsky, 1944) & Portugal & Soil \\
\hline Podocampa serbica Karaman \& Blesić, 1983 & Serbia & Soil \\
\hline Podocampa simonini Condé, 1956 & Spain & Cave \\
\hline Remycampa erbanica Sendra \& Oromí, 2020 & Spain & Cave \\
\hline Remycampa launeyi Condé, 1952 & Morocco, Spain & Soil \\
\hline Spaniocampa relicta Sendra \& López, 2020 & Spain & MSS \\
\hline
\end{tabular}




\section{Macrosetae}

These are large mechanoreceptor setae with a large base in upright position (Figs 2, 7, 9), occupying a fixed position during growth (Orelli 1956). They are longer and thicker, with larger bases, and usually with more barbs than other setae. Exceptionally, these macrosetae can be substituted by submacrosetae, which are thinner, shorter and less barbed than normal macrosetae. The macrosetal length is useful for taxonomy; however, the ratios should account for body size, as these increase in length during growth (Sendra 1988). Three main macrosetae formulas (notal, urotergal and urosternal) are used to charaterize most of the genera and species in Campodeinae (Condé 1956a, Paclt 1957), in addition to the number of macrosetae on appendages. Notal macrosetae formula: macrosetae can occupy three different positions in each notum: pronotum from $0+0$ up to $3+3 m a$, $l a$, $l p$; mesonotum from $0+0$ up to $3+3 m a, l a$, $l p$ (with the exceptions of 4+4 ma, la, $l p_{2,3}$ in Eumesocampa Silvestri, 1933 and 5+5 ma, la, $l p_{1,2,3}$ in Mexicampa Wygodzinsky, 1944) and metanotum from $0+0$ up to $2+2 m a, l p$ (with the exception of $4+4 m a, l p_{12,3}$ in Mexicampa). Urotergal macrosetae formula: macrosetae can occupy four different positions in each urotergite: $m a, m p$, la and $l p$. Three regions can be differentiated (Condé 1956a): (1) first and second urotergites with $0+0$ or $1+1 m a$ or $m p$ macrosetae; (2) from third to seventh urotergites with $0+0$ or $1+1 m a$ or $m p$ macrosetae, $0+0$ or $1+1$ la macrosetae and from $0+0$ to $3+3 l p_{l, 2,3}$ macrosetae; (3) eighth urotergite and ninth adominal segment with $0+0$ or $1+1 m a$ or $m p$ macrosetae and with $2+2$ to $6+6 l p$ macrosetae. Urosternal macrosetae formula: urosternite I with $6+6$ (up to 9+9) macrosetae; urosternite II-VII with 4+4-5+5 macrosetae and urosternite VIII with $1+1$ macrosetae. For the macrosetae on appendages, the most relevant charcater is the presence or absence of one dorsal femoral macrosetae, an important character to differentiate species and genera; the presence or absence of one to three ventral tibial macroseta; and the macrosetae present in the cerci that can be sparse or abundant or can have a wide variety of shapes and length (long to short, setiform, spiniform or claviform).

\section{Sensillum of the third antennomere}

Isolated sensillum on the third antennomere, of subcylindrical or spheroidal shape that can occupy dorsal or ventral positions, among the crown of macrosetae, which encircle the antennomere. To define the position of this sensillum, the $a$ macrosetae is located between the two trichobotria, the $b$ macrosetae is laterad, followed by the $c, d, e, f$ (etc.) around the antennomere (Condé 1956a).

\section{Cupuliform organ}

Invagination of the integument at the end of the apical antennomere filled with olfactory chemoreceptors, each made up of a multiperforated cuticular layer of spheroidal shape with a large apical pore (JuberthieJupeau \& Bareth 1980). In soil-dwelling species the spheroidal receptor has one simple fold and their number of sensilla in the cupuliform organ range from 4 to 6 (Figs 15, 17-18). On the other hand, olfactory receptors of cave-dwelling species are more numerous than in soil-dwelling species and have at least two or three folds (Figs 17-18) (Condé 1956a: Juberthie-Jupeau \& Bareth 1980; Sendra et al. 2020b).

\section{Trochanteral sensilla}

It has a mechanical and chemoreceptor function and is only present in a few species of Campodeinae with usually just one trochanteral sensilla, or two or three in a few species, and exceptionally in C. sensillifera with up to 26 per trochanter (Juberthie-Jupeau \& Bareth 1989).

\section{Pretarsus}

The shape of the pretarsus with two claws, each one with a typical lateral process, has been used as a specific and generic taxonomical character. Two main shapes of claws predominate: a subequal smooth regularly curved one and another with elbow-like with lateral crests (Figs 23-28). The lateral processes are variable from setiform to laminar, with a short to long pubescence or dense barbs. Intraspecific variation of the lateral process is observed in some species of Podocampa and in Parallocampa spenceri Silvestri, 1931 from North America (Condé 1959; Sendra et al. 1986). 

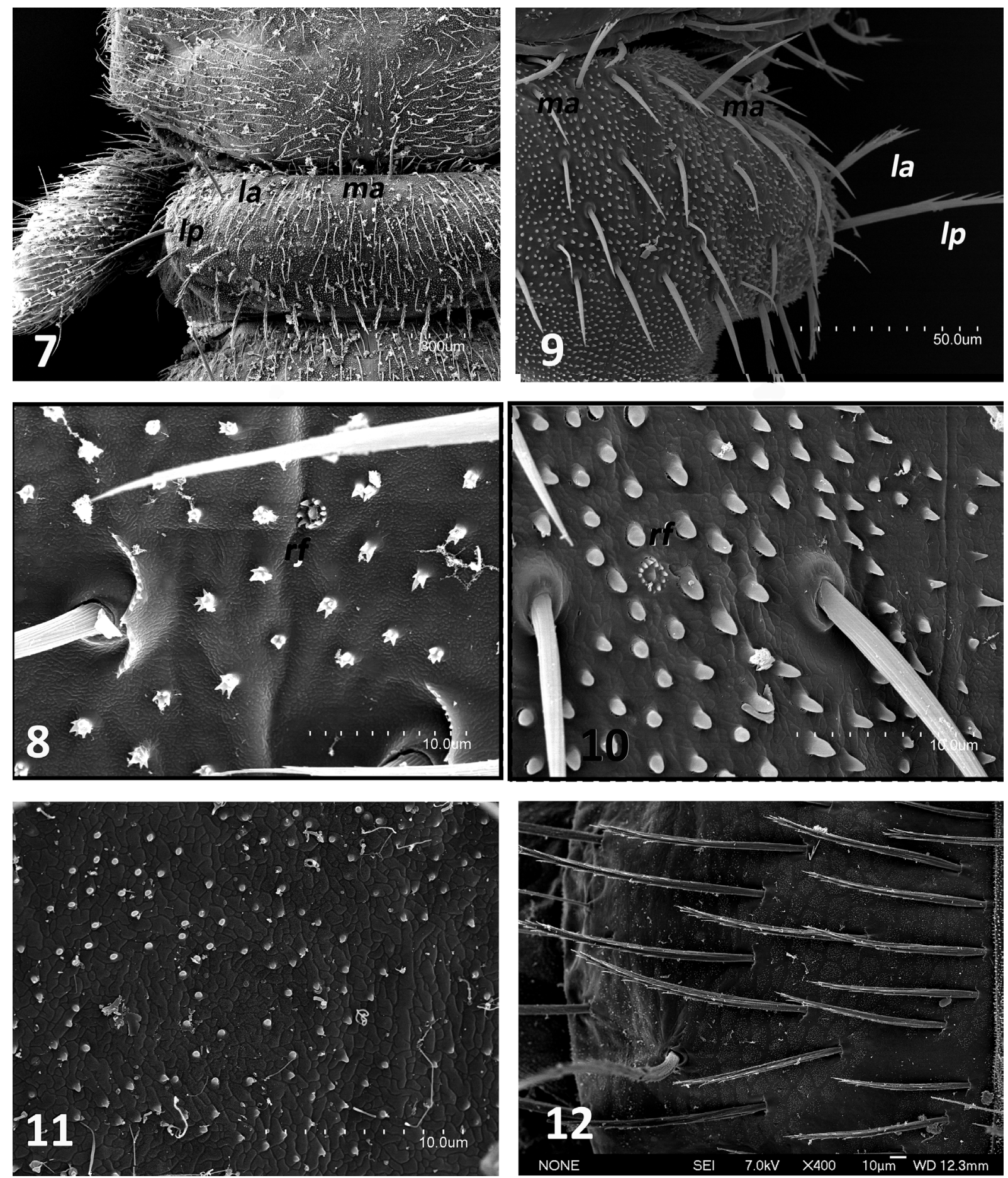

Figs 7-12. - 7-8. Campodea (Campodea) pieltaini Silvestri, 1932. 7. Pronotum, left side. 8. Detail pronotum. - 9-10. Campodea (Paurocampa) suensoni Tuxen, 1930. 9. Pronotum, right side. 10. Detail pronotum. - 11. Campodea (Campodea) maestrazgoensis Sendra \& Escolà, 2004, detail mesonotum. - 12. Podocampa aff. fragiloides from Portugal caves, detail mesonotum. Abbreviations: see Material and methods. 


\section{Labium}

The labium has small differences across dipluran families, but it is homogeneous within them (Bitsch 1952). The position of the labial pieces is uniform in Campodeidae (Figs 19-21), with a few exceptions: species of Remycampa and the American Podocampa labedosa Condé \& Geeraert, 1962 have an atypical labium (Condé 1953b; Condé \& Geeraert 1962; Sendra et al. 2020b).
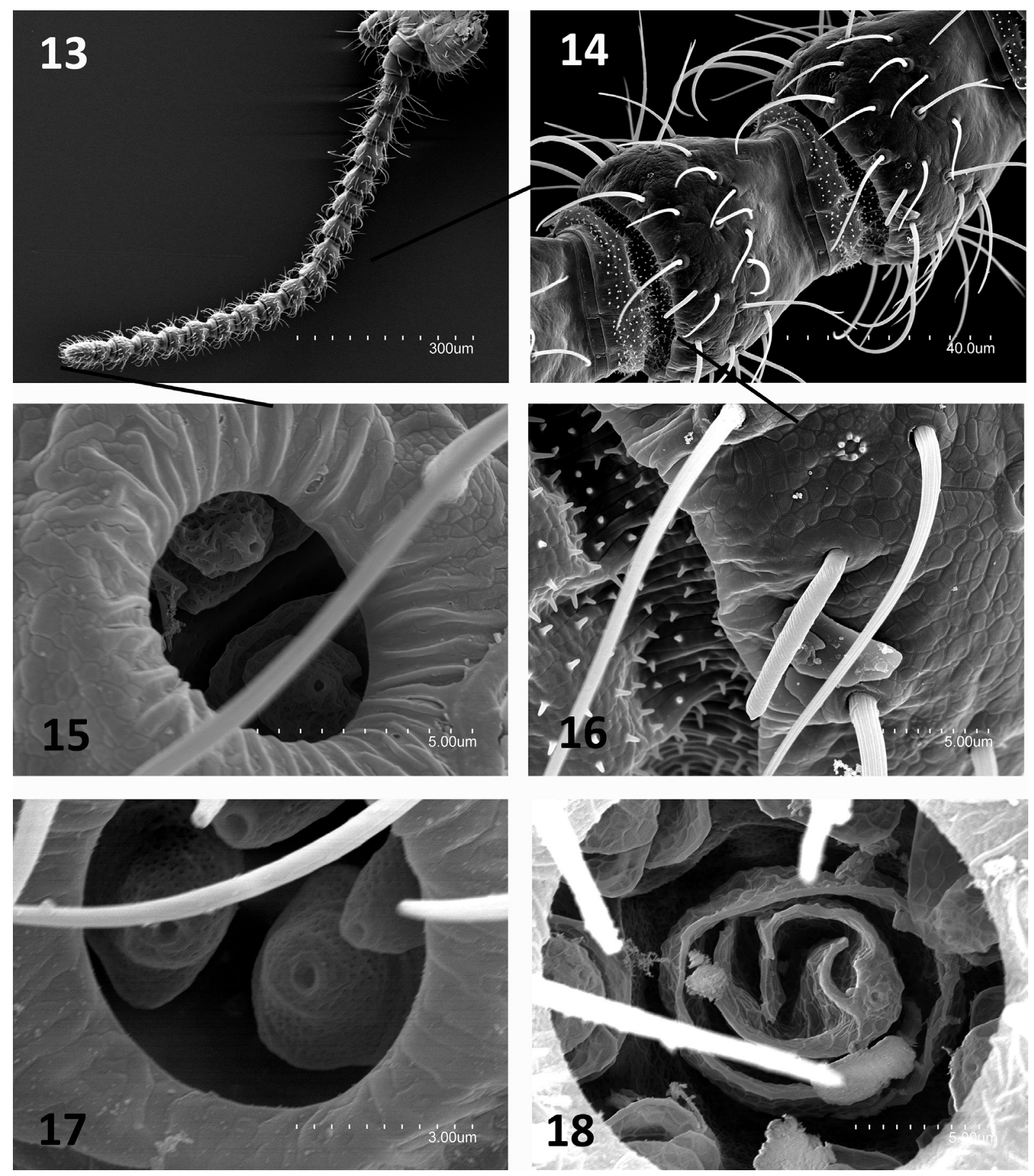

Figs 13-18. - 13-16. Campodea (Monocampa) devoniensis Bagnall, 1918. 13. Antenna. 14. Medial antennomeres. 15. Cupuliform organ. 16. Detail distal antennomere. - 17. Campodea (Paurocampa) suensoni Tuxen, 1930, cupuliform organ. - 18. Campodea (Campodea) egena Condé, 1951, cupuliform organ. 


\section{Sexual characters}

Sexual secondary characters are present in the first urosternite (Figs 29-34). In Campodea (Dicampa) escalerai Silvestri, 1932, sexual dimorphism is also observed in the cerci: males and females have it covered with different macrosetae and clothing setae (Sendra 1989b).

\section{Glandular $g_{1}$ setae on the first urosternite}

Present in males (Fig. 33), with one known exception in females of Campodea franzi Condé, 1954. The $g_{l}$ are grouped in one, occasionally two, areas on the posterior margin of the urosternite between the appendages.

\section{Appendages of the first urosternite}

Located in both latero-posterior edges, it is subcylindrical in females and subtrapezoidal in males (Figs 29-31, 33). Variation may occour at specific and generic level.

\section{Glandular $a_{2}$ setae on the appendages of the first urosternite}

Grouped on the ventral side, proximal to the ubiquitous area of the glandular $a_{l}$ setae, and has variable numbers, higher in males than in females (Figs 32, 34).
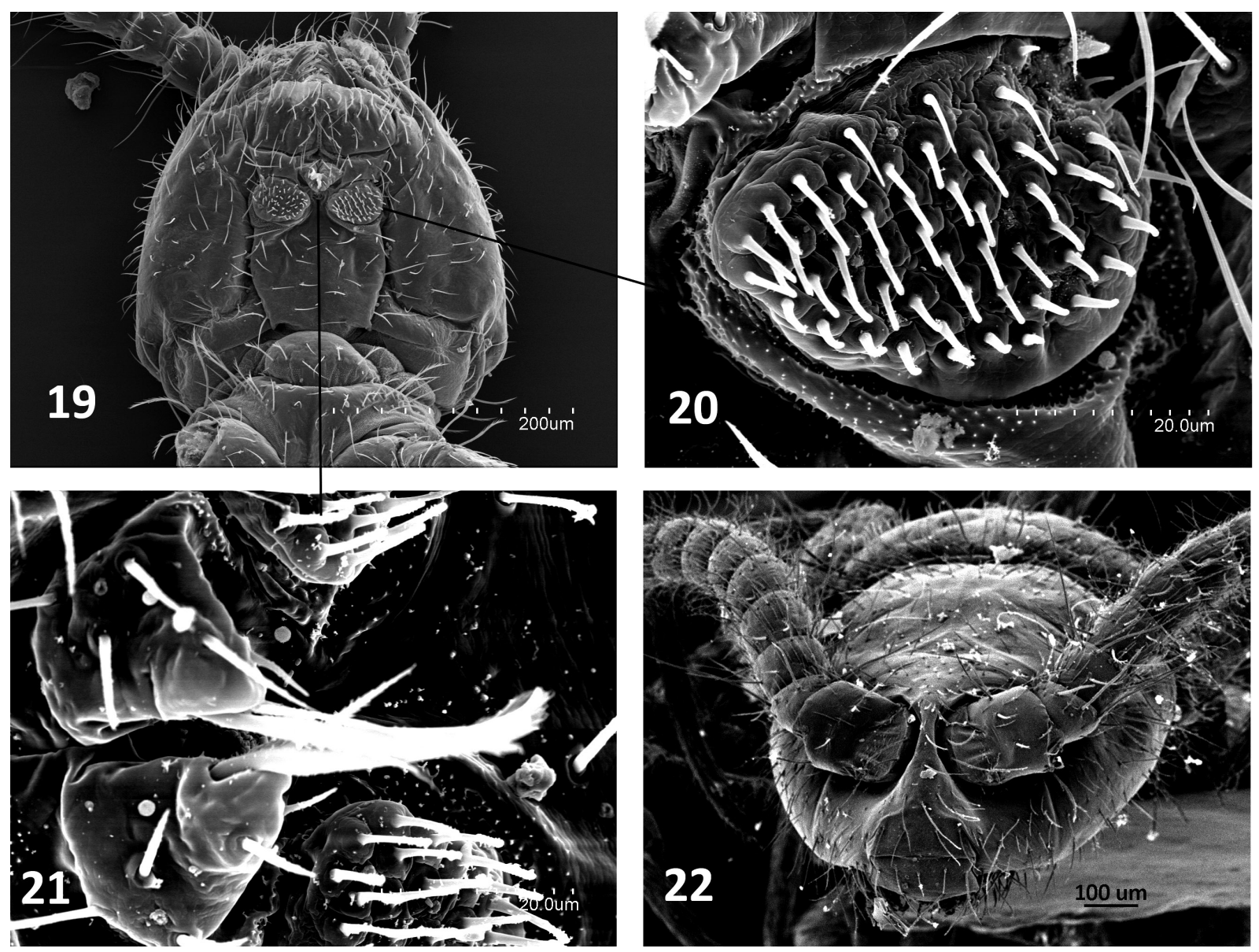

Figs 19-22. Campodea (Dicampa) catalana Denis, 1930. 19. Head ventral side. 20. Labial palp. 21. Palpiform palps. 22. Head frontal view. 


\section{Spermatozoid fascicles}

They are produced by the pair of testes located in the abdomen of males, and are the result of a packed group of spermatozoans in a spiral structure, which can vary in length, size and shape (Bareth 2000b).
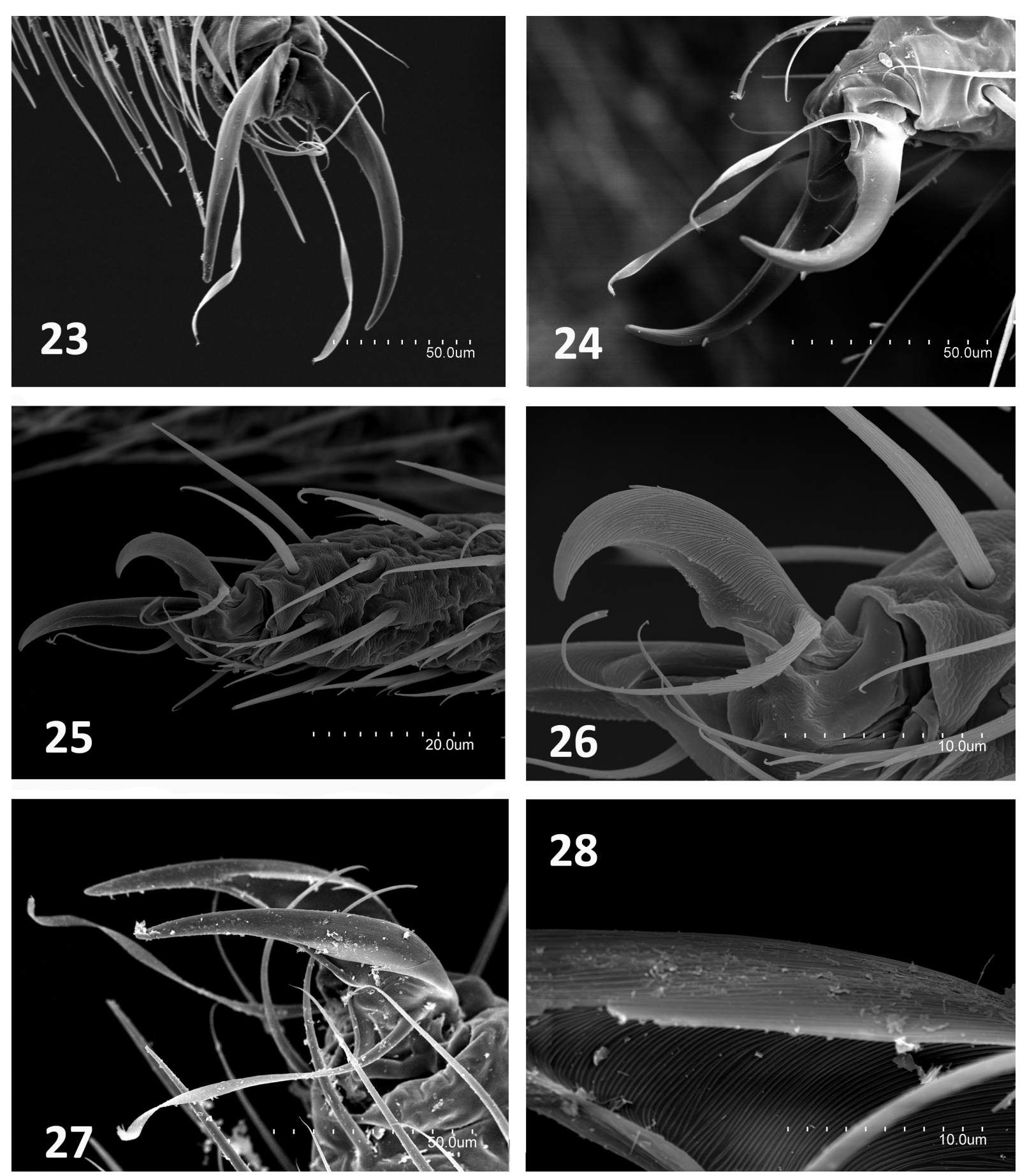

Figs 23-28. - 23. Campodea (Campodea) maestrazgoensis Sendra \& Escolà, 2004, pretarsus, metathoracic leg. - 24. Campodea (Campodea) pieltaini Silvestri, 1932, pretarsus, metathoracic leg. 25-26. Campodea (Monocampa) devoniensis Bagnall, 1918. 25. Pretarsus, metathoracic leg. 26. Detail pretarsus, metathoracic leg. - 27-28. Litocampa espanoli (Condé, 1949). 27. Pretarsus, metathoracic leg. 28. Detail pretarsus, metathoracic leg. 
One or few spermatozoid fascicles are grouped into spermatophores, deposited in the substrate during the reproduction period (Bareth 1968).
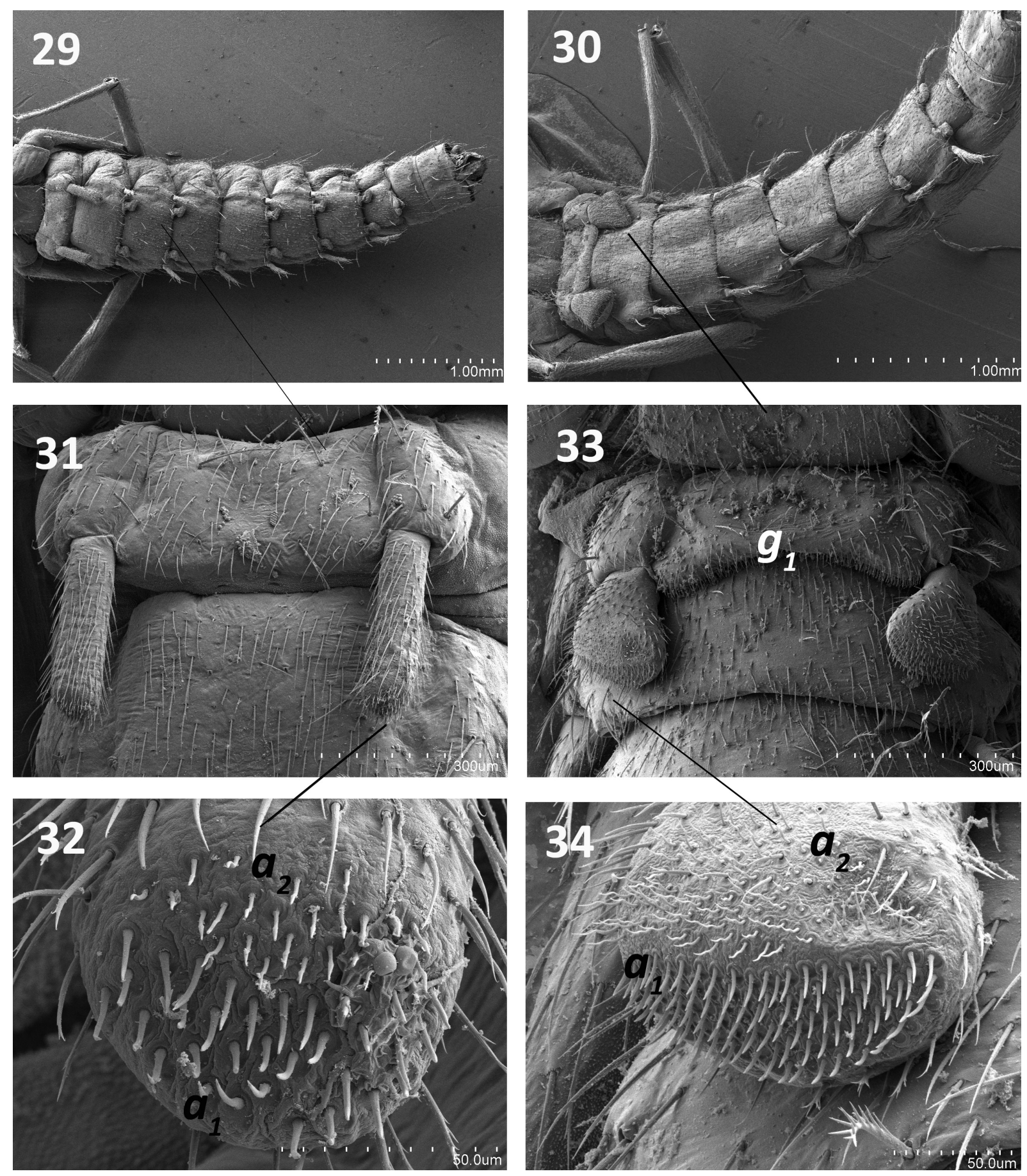

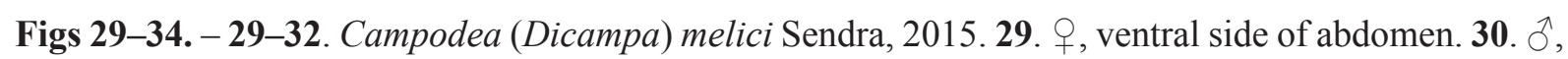
ventral side of abdomen. 31. + , first urosternite. 32. + , apical portion of first urosternite appendage. -

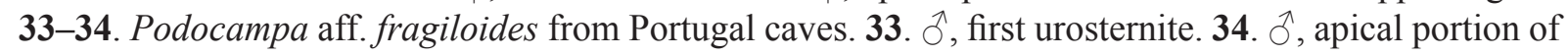
a first urosternite appendage. Abbreviations: $a_{1}, a_{2}, g_{1}=$ glandular setae. 


\title{
Post-embryonic development
}

From the egg hatches a 'prelarva', which has a thin cuticle and small evaginations where setae will develop (Bareth \& Condé 1965). This 'prelarva' is inside a cuticular sac attached to the egg, that moults into a first juvenile instar a few minutes after hatching. This instar already presents the specific macrosetal chaetotaxy and some clothing and marginal setae, but no trichobotria which will appear in the next instar. A preliminary genital papilla appears in the second instar in males or in the third in females, and several moults are needed to reach reproductive maturity (Bareth 1968). The epimorphic development occurs throughout life, increasing the size and length of appendages and macrosetae, and the growing rate may be variable (Sendra 1988). The glandular $g_{1}$ and $a_{1}, a_{2}$ setae appear and increase in number, but they may also disappear seasonally (Bareth 1968). The increment in the number of cercal articles during growth is clear in all species, but the same is not so clear for the increment of antennomeres with the exception of the subfamily Lepidocampinae (Condé 1956a).

\section{Habitats and adaptations}

Campodeids live in the leaf litter, within the soil and in caves (Sendra et al.2020c). They rarely dig in the soil, as opposed to japygids that have a certain hability to excavate (Bareth 1986). They have a positive thigmotaxis, i.e., they seek permanent contact with the substrate, and they exhibit a remarkable grooming behavior that involves at least fourteen cleaning positions (Kühnelt 1957; Valentine \& Glorioso 1978). Endogean campodeids mainly living in B horizons of the soil have a smaller size and shorter appendages than species occurring more frequently in O and A horizons (Condé 1956a; Sendra et al. 2017a). A similar trend is observed in other soil-dwelling hexapods such as Collembola (Bernard 2008) and endogean beetles (Coiffait 1958). In the C horizon, populations of some species (e.g., Campodea grassii Silvestri, 1912 and Campodea catalana Denis, 1930) have larger bodies and longer appendages than populations inhabiting the upper soil horizons (Sendra et al. 2017a). Many species of campodeids have adaptated to a life in caves and exhibit specific traits as a result of selective environmental pressure. These species have elongated bodies and appendages, higher number of antennomeres and cercal articles, and sensilla with higher complexity (Condé 1956a; Juberthie-Jupeau \& Bareth 1980; Sendra et al. 2017b). Caveadapted diplurans are also found in the mesovoid shallow substratum (MSS) or the C edaphic horizon when there are good connections with caves (Bareth 1983; Sendra et al. 2017a).

\section{Taxonomy}

\author{
Class Diplura Börner, 1904 \\ Family Campodeidae Meinert, 1865 \\ Subfamily Campodeinae Condé, 1956
}

Campodeinae Condé, 1956a: 94.

Diagnosis (Condé 1956a)

Epicuticle reticulated apparently smooth in optical microscopy, with microdenticles; presence of roseta formations; body covered with smooth to well-barbed macrosetae and setae; sensillum of third antennomere in dorsal or ventral position; labial pieces typical or slightly rotated in Remycampa ssp.; pronotal macrosetae formula up to $1+1$ medial anterior, $1+1$ lateral anterior, $1+1$ lateral posterior; with or without trochanteral sensilla; with or without one dorsal femoral macrosetae; tibia with up to three short ventral macrosetae, usually only one; subequal simple claws without medial unguiculus except in Eutrichocampa hispanica Silvestri, 1932; claws with lateral crests in the genus Litocampa; one pair of medial anterior and lateral anterior urotergal macrosetae at most and one or two pairs of lateral posterior urotergal macrosetae (exceptionaly three). 


\section{Habitat and distribution}

Almost $75 \%$ of the campodeid species belongs to Campodeinae. The 300 species of Campodeinae are grouped in 28 genera (Condé 1956a; Paclt 1957; Sendra 2015). They are distributed across nearly every terrestrial subsurface habitat, except in the polar regions or those under permafrost influence. Most species of Campodeinae inhabit more-or-less humid soils, but 34 occur in cave habitats, for which they show particular adapations (= troglomorphic traits).

Taxonomic key for genera and subgenera of the subfamily Campodeinae (including species of Eutrichocampa and Remycampa) from the Euro-Mediterranean region

1. Lateral process of the pretarsus laminar and with a unique subtrapezoidal extreme; labium

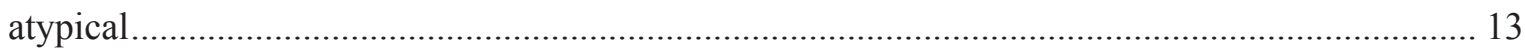

- Different shape of lateral process of the pretarsus, labium typical................................................ 2

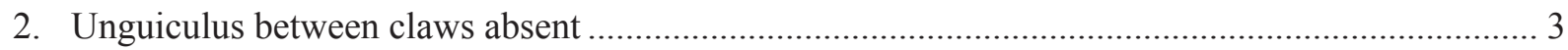

- Unguiculus between claws present ................................... Eutrichocampa hispanica Silvestri, 1932

3. Laminar lateral telotarsal process with short barbs on ventral side.

Eutrichocampa thamugadensis Condé, 1947

- Lateral telotarsal process with side-shoot sharp .............. Oreocampa aff. minutella (Silvestri, 1918)

- Subtrapezoidal laminar lateral telotarsal process with ending with or without pubescence

Libanocampa coiffaiti Condé, 1955

- Laminar lateral telotarsal process with long barbs on ventral side.

- Setiform and barbed lateral telotarsal process ............Eutrichocampa helvetica Wygodzinsky, 1941

- Laminar lateral telotarsal process with barbed both sides ............ Edriocampa ghigii Silvestri, 1933

- Polymorphic lateral telotarsal process ..................................................Podocampa Silvestri, 1932

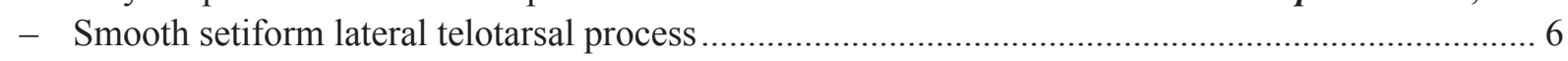

4. Lateral posterior mesonotal macrosetae $1+1$; medial anterior metanotal macrosetae $1+1$; medial anterior mesonotal macrosetae $1+1$; lateral posterior macrosetae in some urotergites $1+1$

Eutrichocampa aegea Silvestri, 1933

- Lateral posterior mesonotal macrosetae $0+0$; medial anterior metanotal macrosetae $0+0$; medial anterior mesonotal macrosetae $0+0$; without lateral posterior macrosetae in urotergite ................... 5

5. Lateral anterior mesonotal macrosetae $1+1$; urosternite I $7+7$ macrosetae; urosternites II-VII 4+4 macrosetae

Eutrichocampa remyi Condé, 1947

- Without lateral anterior mesonotal macrosetae; urosternite I 4+4 macrosetae; urosternites II-VII 3+3 macrosetae

Eutrichocampa collina Ionescu, 1955

6. Elbow-like claws

Litocampa Silvestri, 1933

- Regularly curved claws.

7. One dorsal femoral macrosetae

Podocampa Silvestri, 1932

- Without dorsal femoral macrosetae

8. Lateral posterior mesonotal macrosetae $1+1$

- Lateral posterior mesonotal macrosetae $0+0$

9. Lateral posterior macrosetae in some urotergites $2+2$............ Helladocampa mahnerti Condé, 1984

- Lateral posterior macrosetae at least in urotergites $1+1$ or $0+0 \ldots \ldots . .$. Campodea s. str. Silvestri, 1932 
10. Medial anterior metanotal macrosetae $1+1$; medial anterior mesonotal macrosetae $1+1$

Dicampa Silvestri, 1932

- Without medial anterior metanotal macrosetae; without medial anterior mesonotal macrosetae ....11

11. Lateral anterior mesonotal macrosetae $1+1$

Monocampa Silvestri, 1932

- Without lateral anterior mesonotal macrosetae.....

12. With $1+1$ medial anterior, $1+1$ lateral anterior and $1+1$ lateral posterior pronotal macrosetae

- Without pronotal macrosetae

Spaniocampa relicta Sendra \& López, 2020

13. Lateral posterior macrosetae on metanotum; $1+1$ lateral posterior macrosetae on third and fourth urotergites Remycampa launeyi Condé, 1952

- Without lateral posterior macrosetae on metanotum and no lateral posterior macrosetae on third and fourth urotergites; cave-adapted traits Remycampa herbanica Sendra \& Oromí, 2020

Genus Campodea Westwood, 1842

Campodea Westwood, 1842: 71.

\section{Diagnosis}

Notal formula with $1+1$ medial anterior, $1+1$ lateral anterior, $1+1$ lateral posterior macrosetae on pronotum or more, and up to $1+1$ medial anterior, $1+1$ lateral anterior, $1+1$ lateral posterior macrosetae on mesonotum and up to $1+1$ medial anterior, $1+1$ lateral posterior on metanotum; without dorsal femoral macrosetae; with one short ventral tibial macroseta; smooth subequal slightly curved claws with smooth setiform telotarsal process; not more than one pair of medial anterior macrosetae on I-VII urotergites and up to one pair of lateral anterior and lateral posterior on III-VII urotergites; with or without medial anterior or medial posterior macrosetae on VIII urotergite and IX abdominal segment; $3+3(2+2)$ lateral posterior macrosetae on VIII urotergite and $5+5(4+4)$ lateral posterior macrosetae on IX abdominal segment; first urosternite with $6+6$ macrosetae (with $1+1$ extra smaller thiner macrosetae in Libanocampa coiffaiti Condé, 1955), 4+4 on II-VII and 1+1 on VIII; male first urosternite with area of continuous glandular $g_{l}$-setae (split in two or absent in some species), subtrapezoidal appendages with glandular $a_{1}$ and $a_{2}$-setae (only $a_{1}$ in a few species); females without $g_{1}$-glandular setae (exception: C. (C.) franzi) with subcylindrical appendages with $a_{1}$-glandular setae. Cercal articles covered with whorls of macrosetae and setae in most species.

The genus Campodea is divided into five subgenera: Campodea s. str., Dicampa, Indocampa Silvestri, 1933, Monocampa and Paurocampa. The monotypic subgenus Hypercampa Silvestri, 1933, with Campodea (Hypercampa) essigi Silvestri, 1933 from California (USA), is excluded from the genus Campodea due to its thick and barbed telotarsal process.

\section{Habitat and distribution}

Most species of Campodea (128 out of 143) live in edaphic habitats, from the upper layers of the leaf litter to the microvoids within the A and B horizons (endogean environment) and the largest voids of $\mathrm{C}$ horizon. Notwithstanding this, hitherto 15 species of Campodea (plus some undescribed, Sendra unpublish data) have colonized cave-ecosystems showing cave-related traits. This genus extends across the Holarctic Region, being well known in the Euro-Mediterranean area and in North America, with its northernmost distribution near the Artic circle in Norway (Lie-Pettersen, 1898) and the southernmost reaching Mexico (Silvestri 1912; Wygodzinsky 1944b; Allen 1994, 1995). Other species live in Cuba 
and the subgenus Indocampa is distributed in Oriental and Australian ecozones (Silvestri 1931a, 1933d; Bareth \& Condé 1977; Condé 1980; Bareth 1992).

Subgenus Campodea s. str. Westwood, 1842

Campodea s. str. Westwood, 1842: 71.

\section{Diagnosis}

Notal formula with $1+1$ medial anterior, $1+1$ lateral anterior, 1+1 lateral posterior macrosetae on pronotum and mesonotum, 1+1 medial anterior, 1+1 lateral posterior on metanotum, besides a few species with $1+1$ medial anterior, $1+1$ lateral posterior or $1+1$ lateral anterior, $1+1$ lateral posterior on mesonotum and/or 1+1 lateral posterior or $0+0$ macrosetae on metanotum; dorsal and lateral tarsal setae smooth; $0+0$ or $1+1$ lateral posterior macrosetae on IV-VII urotergites; from 0 to $1+1$ lateral anterior macrosetae on IV-VII urotergites; $0+0$ or $1+1$ medial anterior or medial posterior macrosetae on I-IX urotergites; $3+3$ lateral posterior macrosetae on VIII urotergite and 5+5 lateral posterior macrosetae on IX abdominal segment; first urosternite of the male with an area of continuous (in a few species slipt in two) glandular $g_{I}$-setae (absent in a few species and in seasonal periods), subtrapezoidal appendages with glandular $a_{1}$ and $a_{2}$-setae ( $a_{2}$-glandular setae absent in a few species); females without $g_{1}$-glandular setae (with the exception of $C$. (C.) franzi) with subcylindrical appendages with $a_{1}$-glandular setae.

\section{Habitat and distribution}

The subgenus Campodea encompasses 92 described species spread across Europe and the Mediterranean Region, around the $60^{\circ}$ parallel in the Scandinavian Peninsula (Lie-Pettersen, 1898; Reuter 1895) to some spots of humid soils in North Africa (Condé 1956a; Paclt 1957; Condé 1953b; Silvestri 1932b) (Fig. 58). Only nine species colonize cave ecosystems distributed in karst regions on the East coast of the Iberian Peninsula and in the Western Mediterranean Islands (Condé 1956a; Sendra \& Moreno 2004). Most inhabit the soil and are well adapted to upper and lower soil horizons. The distribution of Campodea subgenus outside this region is poorly known but in the Middle East true Campodea have been observed in Iran (Azadbakhsh \& Nozari 2016). In Nearctic ecozone, Campodea subgenus is well distributed with a total of 13 species described in North America and Mexico (Allen 1994, 1995; Condé 1956a; Condé \& Geeraert 1962; Palacios-Vargas \& García-Gómez 2014).

\section{Taxonomic key for species of the subgenus Campodea s. str.}

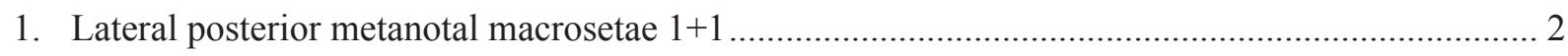

- Without lateral posterior metanotal macrosetae …........................................................................... 52

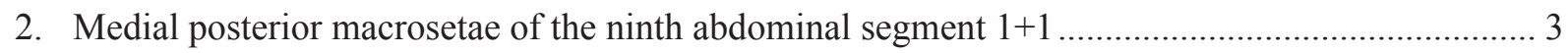

- Without medial posterior macrosetae of the ninth abdominal segment.......................................... 18

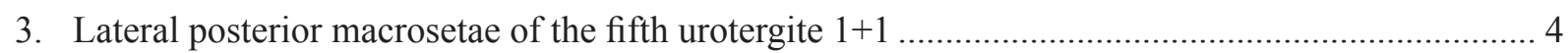

- Without lateral posterior macrosetae of the fifth urotergite........................................................... 14

4. Medial posterior macrosetae of the seventh urotergite $1+1$

Campodea (Campodea) giardi Silvestri, 1912

- Without medial posterior macrosetae of the seventh urotergite ..................................................... 5

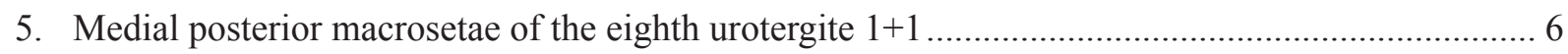

- Without medial posterior macrosetae of the eighth urotergite 
6. Lateral posterior macrosetae of the fourth urotergite $1+1$

.. Campodea (Campodea) sardiniensis Bareth, 1980

- Without lateral posterior macrosetae of the fourth urotergite.

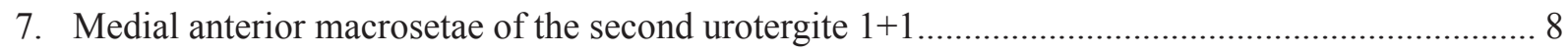

- Without medial anterior macrosetae of the second urotergite ...................................................... 13

8. Cerci pilosity with thin macrosetae and smooth or with one to three apical tiny barbs

Campodea (Campodea) sensillifera Condé \& Mathieu, 1957

- Cerci pilosity with long poorly barbed macrosetae, shorter smooth clothing setae .......................... 9

- Cerci pilosity with latero interior swollen macrosetae in proximal articles .................................... 10

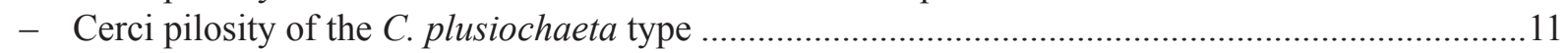

9. Male $g_{1}$ glandular setae present but separated; sensillum of the cupuliform organ simple; notal macrosetae short (medial anterior, lateral anterior) and long barbed lateral posterior; body shape not cave adapted.

Campodea (Campodea) oredonensis Condé, 1951

- Male $g_{1}$ glandular setae present and continuous; sensillum of the cupuliform organ complex; notal macrosetae middle sized, robust, barbed; body shape cave adapted

..Campodea (Campodea) procera Condé, 1948

10. Male $g_{1}$ glandular setae present but separated; female without $a_{2}$ glandular setae; notal macrosetae short (medial anterior, lateral anterior) and long poorly barbed lateral posterior; marginal setae short smooth or with a few small distal barbs

Campodea (Campodea) ilixonis Denis, 1932

- Male $g_{1}$ glandular setae present and continuous; female with $a_{2}$ glandular setae; notal macrosetae short (medial anterior, lateral anterior) and long barbed lateral posterior; marginal setae short with apical long barbs

Campodea (Campodea) meinerti Bagnall, 1918

11. Notal macrosetae long barbed; marginal setae long barbed.

Campodea (Campodea) zuluetai Silvestri, 1932

- Notal macrosetae long robust barbed; marginal setae long thin pine cone .................................... 12

- Notal macrosetae short (medial anterior, lateral anterior) and long barbed lateral posterior; marginal setae short with apical long barbs Campodea (Campodea) lecreci Bareth, 1985

12. Medial anterior submacrosetae of the first urotergite $1+1$; medial anterior submacrosetae of the second urotergite $1+1$; medial anterior submacrosetae of the third urotergite $1+1$; male without $g_{1}$ glandular setae

Campodea (Campodea) egena Condé, 1951

- Without medial anterior submacrosetae of the first urotergite; without medial anterior submacrosetae of the second urotergite; without medial anterior submacrosetae of the third urotergite; male $g_{1}$ glandular setae present and continuous ..Campodea (Campodea) cossetana Sendra \& Escolà, 2004

13. Male $g_{l}$ glandular setae absent; medial anterior submacrosetae of the first urotergite $1+1$; medial anterior submacrosetae of the second urotergite 1+1; medial anterior submacrosetae of the third urotergite $1+1$.

Campodea (Campodea) egena Condé, 1951

- Male $g_{1}$ glandular setae present and continuous; without medial anterior submacrosetae of the first urotergite; wout medial anterior submacrosetae of the second urotergite; without medial anterior submacrosetae of the third urotergite.

Campodea (Campodea) maestrazgoensis Sendra \& Escolà, 2004

14. Medial posterior macrosetae of the eighth urotergite $1+1$

- Without medial posterior macrosetae of the eighth urotergite. 
15. Lateral posterior metanotal short like marginal setae; sensillum of the cupuliform organ complex; one ventral sensilla on the third antennomere; body shape cave-adapted

Campodea (Campodea) grallesiensis Sendra \& Condé, 1987

- Lateral posterior metanotal long to middle sized; sensillum of the cupuliform organ simple; one dorsal sensilla on the third antennomere; body shape not cave adapted

16. Lateral anterior macrosetae of the fifth urotergite $1+1$; male $g_{1}$ glandular setae area present but separated in two; cerci pilosity with latero interior swollen macrosetae in proximal articles......... 17

- Without lateral anterior macrosetae of the fifth urotergite; male $g_{l}$ glandular setae present and continuous; cerci pilosity with long, barbed macrosetae and a few short smooth setae..

Campodea (Campodea) arrabidae Wygodzinsky, 1944

17. Notal macrosetae short (medial anterior, lateral anterior) and long (lateral posterior) robust barbed; marginal setae short with thin pine cone shape

Campodea (Campodea) rhopalota Denis, 1930

- Notal macrosetae middle sized, robust, poorly barbed; marginal setae with a long thin and pine cone shape

Campodea (Campodea) kervillei Denis, 1932

18 Lateral posterior macrosetae of the fifth urotergite $1+1$

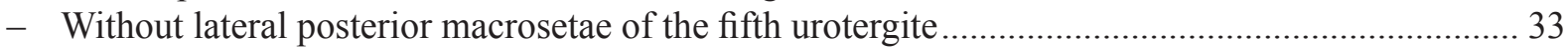

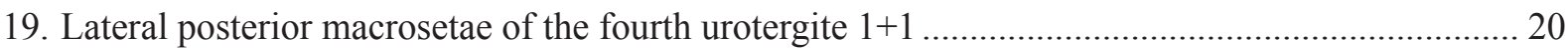

- Without lateral posterior macrosetae of the fourth urotergite......................................................... 24

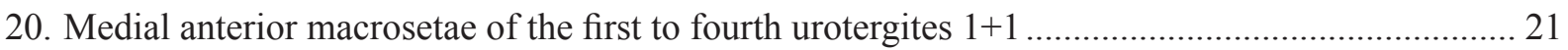

- Without medial anterior macrosetae of the first to fourth urotergites.............................................. 23

21. Medial anterior macrosetae of the eighth urotergite $1+1$; medial anterior macrosetae of the ninth abdominal segment $1+1$; epicuticle with microdenticles.

Campodea (Campodea) lankesteri Silvestri, 1912

- Without medial anterior macrosetae of the eighth urotergite; without medial anterior macrosetae of the ninth abdominal segment; epicuticle without microdenticles.

22. Lateral anterior macrosetae of the fourth to seventh urotergites $1+1$

Campodea (Campodea) kasiki Rusek, 1964

- Without lateral anterior macrosetae of the fourth to seventh urotergites.

Campodea (Campodea) portacoeliensis Sendra \& Jiménez, 1986

23. Lateral anterior macrosetae of the fourth urotergite 1+1; notal macrosetae short (medial anterior, lateral anterior) and long barbed lateral posterior; marginal setae short with apical long barbs

Campodea (Campodea) subdives Silvestri, 1933

- Without lateral anterior macrosetae of the fourth urotergite; notal macrosetae long thin barbed; marginal setae long barbed.

Campodea (Campodea) redii Silvestri, 1912

24. Without swollen sensilla (Pagés' setae) on labium

- With swollen sensilla (Pagés' setae) on labium.

Campodea (Campodea) chardardi Condé, 1947

25. Medial anterior macrosetae of the first to fourth urotergites $1+1$

- Without medial anterior macrosetae of the first fourth urotergites

26. Lateral posterior metanotal short like marginal setae; lateral posterior mesonotal short like marinal setae; cerci pilosity with latero-interior swollen macrosetae in proximal articles..... 
- Lateral posterior metanotal long to middle sized; lateral posterior mesonotal large to middle sized; cerci pilosity with long, barbed macrosetae and a few short smooth setae

27. Medial anterior macrosetae of the ninth urotergite $1+1$; marginal setae short thick with a few barbs

- Without medial anterior macrosetae of the ninth urotergite; marginal setae short, smooth or with a few small distal barbs Campodea (Campodea) epirotica Condé, 1984

28. Male $g_{1}$ glandular setae absent; 26-30 antennomeres; male $a_{2}$ glandular setae absent; notal macrosetae long, robust and barbed... Campodea (Campodea) delamarei Condé \& Mathieu, 1957

- Male $g_{1}$ glandular setae present and continuous; 16-20 antennomeres; male $a_{2}$ glandular setae present; notal macrosetae long, robust and poorly barbed

Campodea (Campodea) frascajensis Condé, 1946

29. Lateral anterior macrosetae in the fifth urotergite $1+1$ 30

- Without lateral anterior macrosetae in the fifth urotergite 32

30. Clothing setae short thick with barbs or smooth; notal macrosetae long robust barbed; marginal setae short, thin and pine cone shape

Campodea (Campodea) tuxeni Wygodzinsky, 1941

- Clothing setae long, thin and smooth; notal macrosetae long thin barbed; marginal setae long thin barbed

Campodea (Campodea) wallacei Bagnall, 1918

- Clothing setae short to middle sized, smooth or with a few small apical barbs; notal macrosetae short (medial anterior, lateral anterior) and long barbed lateral posterior; marginal setae short with apical long barbs. 31

31. Cerci pilosity with long, barbed macrosetae and a few short smooth setae

Campodea (Campodea) plusiochaeta Silvestri, 1912

- Cerci pilosity with short macrosetae and dense short smooth setae.

Campodea (Campodea) pempturochaeta Silvestri, 1912

32. Lateral anterior macrosetae of the sixth and seventh urotergites $1+1$; cerci pilosiy with long barbed macrosetae and a few short smooth setae; notal macrosetae short (medial anterior, lateral anterior), and long and barbed lateral posterior macrosetae.

Campodea (Campodea) anae Sendra \& Teruel, 2010

- Without lateral anterior macrosetae of the sixth and seventh urotergites; cerci pilosity with long, thin, smooth macrosetae; notal macrosetae long, robust and barbed

Campodea (Campodea) ghilarovi Rusek, 1965

33. Medial anterior mesonotal and metanotal macrosetae $1+1$

- Without medial anterior mesonotal and metanotal macrosetae.

Campodea (Campodea) patrizii Condé, 1953

34. Female $g_{l}$ glandular setae absent

- Female $g_{l}$ glandular setae present Campodea (Campodea) franzi Condé, 1954

35. Labium type Pagés' sensilla absent

- Labium type Pagés's sensilla present.....

Campodea (Campodea) chardardi Condé, 1947

36. Without lateral posterior metanotal macrosetae

Campodea (Campodea) coniphora Wygodzinsky, 1941

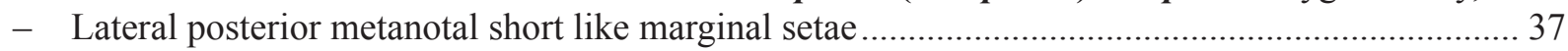

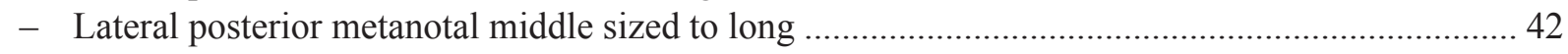


37. Medial anterior macrosetae of the first urotergite 1+1; medial anterior macrosetae of the second urotergite $1+1$; medial anterior macrosetae of the third urotergite $1+1$; medial anterior macrosetae of the fourth urotergite $1+1$

- Without medial anterior macrosetae of the first urotergite; without medial anterior macrosetae of the second urotergite; without medial anterior macrosetae of the third urotergite; without medial anterior macrosetae of the fourth urotergite.

38. Lateral posterior mesonotal as short as marginal setae.

- Lateral posterior mesonotal middle sized to long

Campodea (Campodea) machadoi Condé, 1951 (specimens from Braga)

39. Clothing setae short and thick with barbs or smooth; with short macrosetae and abundant short, smooth setae; notal macrosetae short, thick and poorly barbed; marginal setae short thick with a few barbs.

Campodea (Campodea) lubbockii Silvestri, 1912

- Clothing setae short to middle sized, smooth or with a few small apical barbs; cerci pilosity with latero-interior swollen macrosetae in proximal articles; notal macrosetae short (medial anterior, lateral anterior) and long barbed lateral posterior; marginal setae short, smooth or with a few small distal barbs Campodea (Campodea) minor Wygodzinsky, 1944

40. Cerci pilosity with long and poorly barbed macrosetae, shorter smooth clothing setae 41

- Cerci covered with whorls of thin macrosetae bent forward and backward, and surrounded by a few clothing setae

Campodea (Campodea) westwoodi Bagnall, 1918

41. Lateral anterior macrosetae of the fifth urotergite $1+1$; smooth clothing setae short to middle sized or with a few small apical barbs; epicuticle without microdenticles; trochanteral sensillum none.....

Campodea (Campodea) coniphora Wygodzinsky, 1941

- Without lateral anterior macrosetae of the fifth urotergite; clothing setae short and thick with barbs or smooth; epicuticle with microdenticles; trochanteral sensillum one.

Campodea (Campodea) grassii Silvestri, 1912

42. Lateral posterior macrosetae of the sixth and seventh urotergites $1+1$

- Without lateral posterior macrosetae of the sixth and seventh urotergites

Campodea (Campodea) vihorlatensis Paclt, 1961

43. Medial anterior macrosetae of the first to fourth urotergites $1+1$

Campodea (Campodea) basiliensis Wygodzinsky, 1940

- Without medial anterior macrosetae of the first to fourth urotergites............................................... 44

44. Cerci pilosity long and poorly barbed macrosetae; shorter, smooth clothing setae.......

- Cerci bearing one complete whorl of short macrosetae with one apical barb and numerous short clothing setae for each article

Campodea (Campodea) pseudofragilis Condé, 1984

- Cerci pilosity with latero interior swollen macrosetae in proximal articles.

Campodea (Campodea) taunica Marten, 1939

- Cerci pilosity with long and barbed macrosetae and a few short smooth setae .............................. 48

- Cerci pilosity with short macrosetae and abundant short smooth setae .

Campodea (Campodea) fragilis Meinert, 1865

45. Lateral anterior macrosetae of the sixth and seventh urotergites $1+1$

- Without lateral anterior macrosetae of the sixth and seventh urotergites

Campodea (Campodea) pieltaini Silvestri, 1932 
46. Lateral anterior macrosetae of the fifth urotergite 1+1; epicuticle without microdenticles.

Campodea (Campodea) coniphora Wygodzinsky, 1941

- Without lateral anterior macrosetae of the fifth urotergite; epicuticle with microdenticles ..... 47

47. Clothing setae thin pine cone shape; notal macrosetae middle sized, robust, barbed; marginal setae long thin pine cone shape; without trochanteral sensillum.

Campodea (Campodea) monspessulana Condé, 1953

- Clothing setae short to middle sized, smooth or with a few small apical barbs; notal macrosetae middle sized, robust and poorly barbed; marginal setae short thin pine cone shape; one trochanteral sensillum

Campodea (Campodea) magna Ionescu, 1955

48. Lateral anterior macrosetae of the fifth urotergite $1+1$

- Without lateral anterior macrosetae of the fifth urotergite......

49. Male $a_{2}$ glandular setae absent; notal macrosetae short (medial anterior, lateral anterior) and long barbed lateral posterior; marginal setae short with apical long barbs.

Campodea (Campodea) silvestrii Bagnall, 1918

- Male $a_{2}$ glandular setae present; notal macrosetae long, thin, smooth or poorly barbed; marginal setae short, smooth or with a few small distal barbs

Campodea (Campodea) silvicola Wygodzinsky, 1940

50. Lateral anterior macrosetae of the sixth urotergite 1+1; lateral anterior macrosetae of the seventh urotergite $1+1$

- Without lateral anterior macrosetae of the sixth urotergite; without lateral anterior macrosetae of the seventh urotergite. Campodea (Campodea) sarae Sendra \& Teruel, 2010

51. Clothing setae thin with pine cone shape ......Campodea (Campodea) monspessulana Condé, 1953

- Clothing setae short with apical barbs Campodea (Campodea) augens Silvestri, 1936

- Clothing setae short to middle sized, smooth or with a few small apical barbs

Campodea (Campodea) posterior Silvestri, 1932

52. Lateral posterior macrosetae of the fifth urotergite $1+1$

- Without lateral posterior macrosetae of the fifth urotergite

53. Lateral anterior macrosetae of the sixth and seventh urotergites $1+1$; cerci pilosity with latero interior swollen macrosetae in proximal articles.

- Without lateral anterior macrosetae of the sixth and seventh urotergites; cerci pilosity with long, barbed macrosetae and a few short smooth setae ... Campodea (Campodea) alluvialis Sendra, 2017

54. Lateral anterior macrosetae of the fifth urotergite $1+1$; male $g_{I}$ glandular setae absent.

Campodea (Campodea) galilaea Wygodzinsky, 1942

- Without lateral anterior macrosetae of the fifth urotergite; male $g_{l}$ glandular setae present and continuous Campodea (Campodea) galilaea (Sardinia form)

55. Medial anterior mesonotal macrosetae $1+1$; medial anterior metanotal macrosetae $1+1$

- Without medial anterior mesonotal macrosetae; without medial anterior metanotal macrosetae ........ Campodea (Campodea) remyi Denis, 1930

56. Lateral anterior mesonotal macrosetae $1+1$

- Without lateral anterior mesonotal macrosetae.. Campodea (Campodea) apennina Ramellini, 1998 
57. Lateral posterior macrosetae of the sixth urotergite $1+1$

- Without lateral posterior macrosetae of the sixth urotergite.

Campodea (Campodea) majorica Condé, 1955

58. Lateral anterior macrosetae of the fifth urotergite $1+1$

Campodea (Campodea) blandinae Condé, 1948

Without lateral anterior macrosetae of the fifth urotergite

59. Lateral anterior macrosetae of the sixth urotergite $1+1$; lateral anterior macrosetae of the seventh urotergite $1+1$

- Without lateral anterior macrosetae of the sixth urotergite; without lateral anterior macrosetae of the seventh urotergite. Campodea (Campodea) navasi Sendra \& Moreno, 2004

60. Male $g_{1}$ glandular setae absent; cerci pilosity with long barbed macrosetae and a few short smooth setae; notal macrosetae middle size, barbed; marginal setae short thin pine cone shape

Campodea (Campodea) cyrnea Condé, 1946

- Male $g_{1}$ glandular setae present and continuous; cerci pilosity with long poorly barbed macrosetae and short smooth setae; notal macrosetae short (medial anterior, lateral anterior) and long barbed lateral posterior; marginal setae short with apical long barbs

Campodea (Campodea) staphylinus Westwood, 1842

Campodea (Campodea) alfierii Wygodzinsky, 1942

Campodea (Campodea) alfierii Wygodzinsky, 1942: 31, figs 1-9.

\section{Differential diagnosis}

This species differs from those in the $C$. plusiochaeta group by cerci macrosetae with 6-9 thin barbs (Wygodzinsky 1942).

\section{Habitat and distribution}

Soil-dwelling species recorded from a single locality in Degania, Israel (Wygodzinsky 1942).

Campodea (Campodea) alluvialis Sendra, 2017

Campodea (Campodea) alluvialis Sendra, 2017a: 73, fig 3, table 4.

Diagnosis (Sendra et al. 2017a)

Body length 2.2-2.5 mm; epicuticle with microdenticles; short and smooth clothing setae; antennae with 21-22 antennomeres in juveniles, 23-25 antennomeres in adults; sensillum of third antennomere small, in ventral position; $1+1 \mathrm{ma}$ macrosetae on metanotum; short ( $m a, l a)$ and long $(l p)$ barbed notal macrosetae; short with apical long barbs marginal setae; $1+1 l p$ on V-VII urotergites, $3+3 l p$ on VIII urotergite and $5+5 \mathrm{lp}$ on IX abdominal segment; cerci base followed by up to 10 short primary articles, each bearing two whorls of macrosetae with barbs on distal two-thirds, mixed from proximal to distal articles with one to three whorls of smooth setae; distal end of each article bearing a whorl of smooth microsetae.

\section{Habitat and distribution}

Known distribution in several alluvial non-flooded spots around watersheds in eastern Prebaetic Mountains, east of the Iberian Peninsula: Guadalest-Bolulla, Xaló, Girona, Serpis, and Xúquer (Sendra et al. 2017a). It is found in non-flooded spots of channel rivers and is almost exclusively located in alluvial debris and MSS. 
Campodea (Campodea) anae Sendra \& Teruel, 2010

Campodea (Campodea) anae Sendra \& Teruel in Sendra et al., 2010: 43, figs 1-2.

Diagnosis (Sendra et al. 2010)

Body length 2.5-3.7 mm; epicuticle with small microdenticles; short, smooth clothing setae; antennae 22-25 antennomeres; sensillum of third antennomere in ventral position; short ( $m a$, la) and long (lp) barbed notal macrosetae; short with apical long barbs marginal setae; $1+1 l p$ macrosetae on $\mathrm{V}$ urotergite, $1+1 l a, 1+1 l p$ on VI-VII urotergites, $3+3 l p$ on VIII urotergite and $5+5 l p$ on IX abdominal segment; cerci covered in thin macrosetae with barb along distal third and a few thin clothing setae.

\section{Habitat and distribution}

Soil-dwelling species found in four localities in the Turkish Black Sea region, around the Pontic Mountains in the Anatolian Peninsula (Sendra et al. 2010).

\section{Campodea (Campodea) anavyi Condé, 1955}

Campodea (Campodea) anavyi Condé, 1955a: 402, fig. 1f-i.

Differential diagnosis from C. plusiochaeta species (Condé 1955a)

Antennae with 26-30 antennomeres; cupuliform organ with four to seven olfactory chemoreceptors; marginal setae with numerous barbs well differentiated from clothing setae.

\section{Habitat and distribution}

Cave-dwelling species found in Batara cave, Lebanon (Condé 1955a).

\section{Campodea (Campodea) apennina Ramellini, 1998}

Campodea (Campodea?) apennina Ramellini, 1998: 21, figs 1-11.

\section{Diagnosis (Ramellini 1998)}

Body length 3.0-3.8 mm; epicuticle with microdenticles; short smooth or with a few thin apical barbs clothing setae; antennae with 22-25 antennomeres; sensillum of third antennomere in dorsal position; 1+1 ma, 1+1 lp macrosetae on mesonotum, 1+1 ma on metanotum; short ( $m a, l a)$ and long (lp) barbed notal macrosetae; thin pine cone shape marginal setae; one trochanteral sensillum; $1+1 l p$ macrosetae on VII urotergite, $3+3 l p$ on VIII urotergite and $5+5 l p$ on IX abdominal segment.

\section{Habitat and distribution}

Soil-dwelling species collected in two localities in Abruzzo National Park, Lazio, Italy (Ramellini 1998).

Campodea (Campodea) arrabidae Wygodzinsky, 1944

Campodea (Campodea) arrabidae Wygodzinsky, 1944a: 504, figs 10-22.

Diagnosis (Wygodzinsky 1944a)

Body length 3.0-4.5 mm; epicuticle with microdenticles; short with a few thin apical barbs clothing setae; antennae with 21-27 antennomeres; sensillum of third antennomere in dorsal position (between $b-c$ and $a-b$ macrosetae); short ( $m a, l a)$ and long $(l p)$ barbed notal macrosetae; thin pine cone marginal setae; $1+1 l a, 1+1 l p$ macrosetae on VI-VII urotergites; $1+1 m p, 3+3 l p$ on VIII urotergite and $1+1 m p$, $5+5 \mathrm{l} p$ on IX abdominal segment; cerci covered in macrosetae with 1-4 thin distal barbs (only 1-2 in the latero-interior macrosetae) and a few clothing setae. 


\section{Habitat and distribution}

Soil-dwelling species distributed around the western regions of the Iberian Peninsula (Condé 1951d; Wygodzinsky 1944a; Sendra \& Moreno 2004). The presence of C. (C.) arrabidae in southeastern Europe (Rusek 1965a) needs to be revised.

Campodea (Campodea) augens Silvestri, 1936

Campodea (Campodea) augens Silvestri, 1936: 529, tables IX 1-10, X 11-17.

Diagnosis (Silvestri 1936; Condé 1953a; Rusek 1964)

Body length 4.0-5.0 mm; epicuticle with microdenticles; clothing setae short with small apical barbs; antennae with 25 antennomeres; sensillum of third antennomere in dorsal position; middle sized, robust notal macrosetae covered with short barbs; $l p$ mesonotal longer than $l p$ metanotal; short thin pine cone notal marginal; setae one trochanteral sensillum; $1+1 l a, 1+1$ lp macrosetae on VI-VII urotergites; $3+3$ $l p$ on VIII urotergite and $5+5 l p$ on IX abdominal segment; cerci longer than body with 10 articles covered in smooth thin macrosetae or with distal barb and sparse clothing setae.

\section{Habitat and distribution}

Soil-dwelling species that inhabits the upper layer of forest soil. It is distributed from the Alps to the Carpathian Mountains (Paclt 1951, 1954, 1956; Rusek 1964, 1965c; Condé 1984) and also in southern Serbia (Blesić 1984: D0358). The records for the Western Caucasus (Rusek 1965a) and the Pontic Mountains (Sendra et al. 2006) should be revised, along with a study of intraspecific variability across its distribution areas.

\section{Campodea (Campodea) basiliensis Wygodzinsky, 1941}

Campodea (Campodea) basiliensis Wygodzinsky, 1941a: 127, figs 34-39.

Diagnosis (Wygodzinsky 1941a; Condé \& Mathieu 1957)

Body length $2.5 \mathrm{~mm}$; short, smooth clothing setae; antennae with 19-24 antennomeres; sensillum of third antennomere in dorsal position; thin, middle-sized barbed notal macrosetae; $l p$ metanotal much shorter than $l p$ mesonotal; short with apical long barbs notal marginal setae; $1+1 \mathrm{ma}$ macrosetae on IVII urotergites, $1+1$ la on $\mathrm{V}, 1+1 l a, 1+1$ l $p$ on VI-VII urotergites, $3+3 l p$ on VIII urotergite and $5+5 l p$ on IX abdominal segment; cerci shorter than body with 10-11 articles covered in long macrosetae with barbs and a few clothing setae, but with swollen latero-interior macrosetae in proximal articles.

\section{Habitat and distribution}

Soil-dwelling species found scattered from the Basin of Paris to the French Pyrenees (Condé 1947d, 1947h, 1951a; Condé \& Mathieu 1957), as well as in eastern Germany and the Swiss Alps (Wygodzinsky 1941a; Christian 2003).

Campodea (Campodea) blandinae blandinae Condé, 1948

Campodea (Campodea) cyrnea blandinae Condé, 1948c: 64, figs c, e, g.

Diagnosis (Condé 1948c)

Cave-adapted species; body length 3.3-8.0 mm; short, thick with one to three small, thick apical barbs; antennae with 37-46 antennomeres; cupuliform organ with eight thick complex olfactory chemoreceptors; 1+1 ma macrosetae on metanotum; thick, short well-barbed notal macrosetae; thin pine cone marginal 
setae; $1+1$ la macrosetae on V urotergite, $1+1$ la $1+1$ l $p$ on VI-VII urotergites, $3+3$ lp on VIII urotergite and $5+5 l p$ on IX abdominal segment; cerci $2 \frac{1}{2}$ times as long as body covered with middle-sized barbed macrosetae arranged in several whorls and forming one (on basal articles) to several (on medial and distal articles) whorls of smooth short setae.

\section{Campodea (Campodea) blandinae virgolae Condé 1948}

Campodea (Campodea) cyrnea virgolae Condé 1948c: 64, figs d, f, h.

Differential diagnosis from the f. typ. (Condé 1948c)

Thinner $l p$ mesonotal macrosetae than in f. typ.

Campodea (Campodea) blandinae ichnusa Condé, 1957 nom. nud.

Campodea (Campodea) blandinae ichnusa Condé, 1957: 140.

\section{Remarks}

Condé (1956b) quoted several specimens from Sardinian caves as Campodea s. str. A year later, Condé (1957) named them as C. (C.) blandinae ichnusa without any formal description, therefore we suggest that this subspecies should be a nomen nudum.

\section{Habitat and distribution}

Cave-adapted species inhabiting caves in the Nebbio and Golo karst regions on Corsica Island (Condé 1948c) and the undescribed subspecies C. (C.) blandinae ichnusa from a cave in Sardinia Island (Condé 1957).

Campodea (Campodea) chardardi chardardi Condé, 1947

Campodea (Campodea) augens chardardi Condé, 1947d: 86, fig. 1.

Diagnosis (Condé 1947d; 1984; Pagés 1951; Bareth 2006)

Body length 4.0-6.7 mm; epicuticle microdenticles; short clothing setae with one apical barb; antennae with 24-28 antennomeres; sensillum of third antennomere in ventral or dorsal position; sternal face of labium with some 'Pagés' setae (swollen sensilla); mid-size robust notal macrosetae almost covered with short barbs; thin pine cone notal marginal setae; $1+1$ la $1+1$ lp macrosetae on VI-VII urotergites; $3+3 l p$ on VIII urotergite and 5+5 lp on IX abdominal segment; cerci shorter than body with 6-8 articles long, worn macrosetae with 1-2 distal barbs and a few clothing setae; small spermatozoid fascicles 26 $\mu \mathrm{m}$ diameter and $5 \mu \mathrm{m}$ wide; spiral filament with $2 \frac{1}{2}$ spirals, $150-180 \mu \mathrm{m}$ long and $1 \mu \mathrm{m}$ diameter.

\section{Campodea (Campodea) chardardi cephalonica Condé, 1984}

Campodea (Campodea) chardardi cephalonica Condé, 1984: 179, fig. 2.

Differential diagnosis from the f. typ. (Condé 1984)

From 28 to 32 antennomeres, sensillum of third antennomere in dorsal position; notal macrosetae shorter and with a few barbs; $1+1$ la macrosetae on $\mathrm{V}$ urotergite.

\section{Taxonomic notes}

Although $C$. (C.) chardardi cephalonica was described from Greece with two key differences from the f. typ., the large and dorsal position of sensillum of the third antennomere and the presence of $1+1 \mathrm{la}$ macrosetae on the fifth urotergite, Condé (1984) also described several specimens from Greece with 
the same position on the sensillum of the third antennomere but no macrosetae on the fifth urotergite. In some specimens from Greek populations (Supplementary file 2), we found a much higher variability of the fifth urotetergal macrosetae, but in all cases a dorsal sensillum on the third antennomere without macrosetae as in the type form, but with $1+1 l a$ and $1+1 l p$ macrosetae.

\section{Habitat and distribution}

Soil-dwelling species spreading from the Basin of Paris to the Central Massif of France (Conde 1947d; 1947h; Pagés 1951; Bareth \& Condé 1998). The records of this species from the southwestern Balkan Peninsula and Crete Island should be attributed to C. chardardi cephalonica (Condé 1984).

\section{Campodea (Campodea) chionea Rusek, 1966}

Campodea (Campodea) chionea Rusek, 1966: 364, figs 86-105.

\section{Diagnosis (Rusek 1966)}

No taxonomic characters differentiate C. chionea from C. plusiochaeta in its description (Rusek 1966; Szeptycki 1974). Therefore, the study of the type material is required to clarify its taxonomic status.

\section{Campodea (Campodea) coniphora Wygodzinsky, 1941}

Campodea (Campodea) coniphora Wygodzinsky, 1941b: 64, fig. 1a-m.

Diagnosis (Wygodzinsky 1941b; Bareth 2006)

Body length $5.5 \mathrm{~mm}$; epicuticle without microdenticles; short, slightly thick, smooth clothing setae; antennae with 26-27 antennomeres; long, thin barbed notal macrosetae; thin pine cone marginal setae; $1+1$ la macrosetae on V urotergite; $1+1$ la, $1+1$ lp on VI-VII urotergites, $3+3 l p$ on VIII urotergite and $5+5$ lp on IX abdominal segment; cerci covered in generally long, smooth macrosetae, sometimes with one thin distal barb, and sparse clothing setae.

\section{Taxonomic notes}

Specimens collected in Geneva (Supplementary file 2) have two noticeable differences from those originaly described: the thick notal and urotergal macrosetae having long barbs over all its length, and swollen latero-interior cercal macrosetae.

\section{Habitat and distribution}

Soil-dwelling species collected in a few localities in the Cévennes Mountains located in southern central France (Wygodzinsky 1941b; Condé 1948a), and a distinct population from Geneva (Switzerland).

Campodea (Campodea) consobrina Condé \& Mathieu, 1957

Campodea (Campodea) consobrina Condé \& Mathieu, 1957: 459, figs VIII(27-30), IX(31-35).

Diagnosis (Condé \& Mathieu 1957)

Body length 2.0-3.2 mm; epicuticle with microdenticles; short, thick, smooth clothing setae smooth or with a few thin distal barbs; antennae with 19-21 antennomeres; cupuliform organ with four to six simple olfactory chemoreceptors; sensillum of third antennomere in ventral position; short, thick notal macrosetae smooth or with a few tiny barbs; $l p$ metanotal very short slightly longer than marginal setae; short with apical small barbs marginal setae; one trochanteral sensillum. 1+1 thick short ma macrosetae on I-VII urotergites, $1+1 l a, 1+1 l p$ on V-VII urotergites, $1+1$ short, thick $m a, 3+3 l p$ on VIII urotergite 
and $1+1$ short, thick $m a$ in backward position (almost $m p$ ), $5+5 l p$ on IX abdominal segment; cerci with 9-10 articles covered in abundant short macrosetae with barbs and clothing setae, but latero-interior macrosetae almost smooth on proximal articles.

\section{Habitat and distribution}

Soil-dwelling species from several localities in the central and eastern Pyrenees (Condé \& Mathieu 1957), one locality in the Italian Piedmont and two on the Island of Sardinia.

Campodea (Campodea) cossetana Sendra \& Escolà, 2004

Campodea (Campodea) cossetana Sendra \& Escolà, 2004: 894, figs 1(a-g), 2-3, 4(a-c), tables I-IV.

Diagnosis (Sendra \& Escolà 2004)

Cave-adapted species; body length 3.8-6.5 mm; smooth epicuticle; clothing setae with short, smooth or a few thin apical barbs; antennae with 36-46 antennomeres; cupuliform organ with four to nine complex olfactory chemoreceptors; sensillum of third antennomere in ventral position; long, robust and barbed notal macrosetae; long, robust and barbed marginal setae; $1+1$ short $m a$ on I-III urotergites and $1+1$ long ma macrosetae on IV-VII urotergites; $1+1$ la, $1+1$ lp on V-VII urotergites; $1+1 m p, 3+3 l p$ on VIII urotergite and $1+1 \mathrm{mp}, 5+5 \mathrm{lp}$ on IX abdominal segment; cerci longer than body, with 13 articles covered in long macrosetae with barbs along distal two-thirds and a few clothing setae; large spermatozoids fascicles with $70-80 \mu \mathrm{m}$ diameter and $17 \mu \mathrm{m}$ thick, spiral filament with 1 to $1 \frac{11 / 4}{4}$ turns, $165 \mu \mathrm{m}$ long and round, $3.5 \mu \mathrm{m}$ at widest section.

\section{Habitat and distribution}

Cave-dwelling species found in several caves of the Serra de Montsant, Catalonian Mountain Chain in eastern Iberian Peninsula, including a mine (Sendra \& Escolà 2004).

Campodea (Campodea) cyrnea cyrnea Condé, 1946

Campodea (Campodea) cyrnea cyrnea Condé, 1946b: 4, fig. 2a-h.

Diagnosis (Condé 1946b, 1948c)

Cave-adapted species; body length 5.0-6.5 mm; short, smooth clothing setae; antennae with 35-43 antennomeres; cupuliform organ with eight or more complex olfactory chemoreceptors; $1+1 \mathrm{ma}$ macrosetae on metanotum; middle-sized notal macrosetae almost completely covered with short barbs; thin pine cone marginal setae; $1+1$ la $1+1 l p$ macrosetae on VI-VII urotergites, $3+3 l p$ on VIII urotergite and $5+5 \mathrm{lp}$ on IX abdominal segment; male without glandular $g_{1}$-setae.

\section{Campodea (Campodea) cyrnea alethae Condé, 1948}

Campodea (Campodea) cyrnea alethae Condé, 1948c: 63, fig. b.

Differential diagnosis from the f. typ. (Condé 1948c)

Notal macrosetae longer and thinner than f. typ.

\section{Habitat and distribution}

Cave-adapted species located in several caves in Cap Corse, Corsica Island (Condé 1946b, 1948c). 
Campodea (Campodea) delamarei Condé \& Mathieu, 1957

Campodea (Campodea) delamarei Condé \& Mathieu, 1957: 456, figs V(18-20), VI(21-23), VII(24-26).

Diagnosis (Condé \& Mathieu 1957; Bareth 2006)

Body length $5.5 \mathrm{~mm}$; short, smooth clothing setae; antennae with 29 antennomeres; cupuliform organ with six simple olfactory chemoreceptors; sensillum of third antennomere in ventral position; long, robust and barbed notal macrosetae; marginal setae short, thick with a few tiny barbs; $1+1$ short $m a$ macrosetae on I-VII urotergites, $1+1$ la, $1+1 l p$ on V-VII urotergites, $1+1$ short $m a, 3+3 l p$ on VIII urotergite and $1+1$ short $m a, 5+5 \mathrm{lp}$ on IX abdominal segment; male has neither glandular $g_{1}$-setae on first urosternite nor $a_{2}$-setae on appendages due to perhaps seasonal disappearance; cerci covered in long macrosetae with barbs along distal half.

\section{Habitat and distribution}

Soil-dwelling species, only one male has been found in a beech forest in Banyuls-sur-Mer, eastern Pyrenees (Condé \& Mathieu 1957).

Campodea (Campodea) donensis Rusek, 1965

Campodea (Campodea) donensis Rusek, 1965a: 1346, pl. 1 figs 1-19.

Differential diagnosis from C. plusiochaeta species (Rusek 1965a)

Thinner and shorter notal macrosetae.

\section{Habitat and distribution}

Collected in the soil at two localities along the northern Black Sea (Rusek 1965a) and in the centre of the Anatolian Peninsula (Sendra et al. 2010).

Campodea (Campodea) egena Condé, 1951

Fig. 17

Campodea (Campodea) egena Condé, 1951b: 52, fig. 1.

\section{Diagnosis (Condé 1951b)}

Cave-adapted species; body length 4.0-6.9 mm; epicuticle with small microdenticles visible at high magnifications; clothing setae smooth or with a few small apical barbs; antennae with 36-50 antennomeres; sensillum of third antennomere in ventral position; cupuliform organ with seven to nine complex olfactory chemoreceptors; long, robust and barbed notal macrosetae; long thin pine cone notal marginal setae; $1+1$ sma submacrosetae on I-VII urotergites; $1+1 l a, 1+1 l p$ on V-VII urotergites; $1+1 \mathrm{mp}, 3+3 \mathrm{lp}$ on VIII urotergite; $1+1 \mathrm{mp}, 5+5 \mathrm{lp}$ on IX abdominal segment; males without glandular $g_{1}$-setae; cerci longer than body with 9 to 20 articles covered in long macrosetae with thin barbs along distal half to two-thirds and a few clothing setae.

A different population, C. (C.) aff. egena in Sendra \& Escolà 2004, has no ma submacrosetae on urotergites I-VII, but glandular $g_{1}$-setae in males. This population is distributed along caves throughout the coastal mountain range on the eastern Iberian Peninsula (Bareth \& Condé 1981; Sendra \& Escolà 2004). 


\section{Habitat and distribution}

Cave-dwelling species endemic to the Montserrat Massif in the Catalonian Mountain Range, northeast Iberian Peninsula (Condé 1951b; Sendra 1990b; Sendra \& Escolà 2004), whereas Campodea (C.) aff. egena is distributed south of the f. typ.

Campodea (Campodea) epirotica Condé, 1984

Campodea (Campodea) epirotica Condé, 1984: 182, figs 3a-e, 4a.

\section{Diagnosis (Condé 1984)}

Body length 2.0-2.5 mm; epicuticle without microdenticles; smooth clothing setae; antennae 21-22 antennomeres; sensillum of third antennomere in ventral position; short ( $m a, l a)$ and long $(l p)$, poorly barbed notal macrosetae; marginal setae short with apical barb or smooth; $1+1$ short ma macrosetae on I-VIII urotergites, $0+0-1+1$ la on IV urotergite, $1+1 l a, 1+1 l p$ on V-VII urotergites, $3+3 l p$ on VIII urotergite and $5+5 \mathrm{lp}$ on IX abdominal segment; cerci covered with macrosetae with thin barbs along distal half to two-thirds and a few clothing setae.

\section{Habitat and distribution}

Soil-dwelling species collected at two sites: in Epirus, Greece and the eastern Balkan Peninsula (Condé 1984).

\section{Campodea (Campodea) fragilis Meinert, 1865}

Campodea (Campodea) fragilis Meinert, 1865: figs 12-22, table 14.

Diagnosis (Silvestri 1912; Bareth 2006)

Body length 3.0-5.0 mm; epicuticle with microdenticles; clothing setae short to middle sized, smooth or with apical barbs; antennae with 18-22 antennomeres; large sensillum of third antennomere in dorsal position; short $(m a, l a)$ and long $(l p)$ poorly barbed notal macrosetae; short marginal setae with long apical barbs; $1+1$ la macrosetae on V urotergite; $1+1 l a, 1+1 l p$ on VI-VII urotergites, $3+3 l p$ on VIII urotergite and $5+5 \mathrm{lp}$ on IX abdominal segment; cerci shorter than body with 9-13 articles bearing two to four whorls of short macrosetae with one apical barb and numerous short clothing setae; small spermatozoid fascicles, $35 \mu \mathrm{m}$ diameter and 15-20 $\mu \mathrm{m}$ wide, spiral filament with 4 spirals, $450 \mu \mathrm{m}$ long and $1-1.5 \mu \mathrm{m}$ in diameter.

\section{Habitat and distribution}

Species with a strong preference for beds in watercourses, up to the level of the water. It has been collected in alluvial subsurface habitats (Sendra et al. 2017a). C. (C.) fragilis is a widespread species, in Europe alone it has been quoted from 400 localities (Supplementary file 1). It occurs from the EuroMediterranean zone to North America (Silvestri 1933b; Condé, 1956a, 1973; Bareth \& Condé 1958; Condé \& Geeraert 1962). In the northern territories, it has been found in the British Isles (Bagnall 1918b) and in the southern Scandinavian Peninsula (Silvestri 1912; Börset 1968; Olsen 1996); in continental Europe from France to Poland (Denis 1930; Wygodzinsky 1941b; Condé 1947h; Paclt 1956, 1961a; Stach 1964), in the Pyrenees (Condé \& Mathieu 1957), in the Iberian Peninsula (Sendra \& Moreno 2004), in the Italian Peninsula (Ramellini 1995, 2000), in the Anatolian Peninsula (Sendra et al. 2006), and, finally, in N Africa (Algeria; Condé 1947g) and the Canary Islands (Sendra \& Baez 1986). 
Campodea (Campodea) franzi Condé, 1954

Campodea (Campodea) franzi Condé, 1954: 645, fig. a.

Diagnosis (Condé 1954; Rusek 1964)

Body length $5.0 \mathrm{~mm}$; short ,smooth clothing setae; antennae with 19-22 antennomeres; sensilla of third antennomere in dorsal position; short $(m a, l a)$ and long, $(l p)$ poorly barbed notal macrosetae; marginal setae with short and thick apical barbs; $1+1$ la macrosetae on V urotergite; $1+1 l a, 1+1 l p$ on VI-VII urotergites, $3+3 l p$ on VIII urotergite, $5+5 l p$ on IX abdominal segment; female with continuous area of glandular $g_{1}$-setae and enlarged appendages with glandular $a_{l}$-setae; cerci similar to $C$. $(C$.) silvestrii but observed cerci incomplete.

\section{Habitat and distribution}

Soil-dwelling species distributed from the Alps to the Carpathian Mountains (Austria, Germany and the Czech Republic) (Condé 1954; Rusek 1964; Christian 2003).

Campodea (Campodea) frascajensis Condé, 1946

Campodea (Campodea) frascajensis Condé, 1946b: 3, fig. 1(1-v).

Diagnosis (Condé 1946b; Bareth 2006)

Body length 2.5-3.0 mm; short, smooth clothing setae; antennae with 17-20 antennomeres; long, robust, poorly barbed notal macrosetae; short, thick marginal setae with a few apical barbs; $1+1$ short $m a$ macrosetae on proximal urotergites and longer ma macrosetae in distal ones, on I-IX urotergites, $1+1$ la, $1+1 l p$ on V-VII urotergites, $3+3$ lp on VIII urotergite and 5+5 lp on IX abdominal segment; cerci with 8-9 articles covered in macrosetae with barbs along distal half and a few clothing setae, latero-interior macrosetae smooth or with 1-3 distal barbs on proximal articles.

\section{Taxonomic notes}

Specimens probably belonging to $C$. frascajensis were collected in a cave in La Feuillade (France) (Supplementary file 2) showing some noticeable features, some of which can be used to separate this cave population from the type species: body size $2.5-4.7 \mathrm{~mm}$; epicuticle without microdenticles in juveniles, but with tiny microdenticles in adults; sensillum of third antennomere in ventral position; antennae with 28 antennomeres and six olfactory chemoreceptors in cupuliform organ; notal macrosetae with a few thin and tiny barbs.

\section{Habitat and distribution}

Soil-dwelling species found at two localities in Niolo, a region in the central northwestern part of Corsica Island (Condé 1946b). The record of this species from a cave in continental France, near La Feuillade, should be clarified.

\section{Campodea (Campodea) galilaea Wygodzinsky, 1942}

Campodea (Campodea) galilaea Wygodzinsky, 1942: 32, figs 10-19.

Diagnosis (Wygodzinsky 1942; Sendra et al. 2010)

Body length $3.5 \mathrm{~mm}$; short clothing setae; antennae with 24-25 antennomeres; sensilla of third antennomere in ventral position; $1+1 m a$ macrosetae on metanotum; short $(m a, l a)$ and long $(l p)$, barbed notal macrosetae; short marginal setae with a few barbs; $1+1 l a, 1+1$ lp macrosetae on V-VII 
urotergites, $3+3 l p$ on VIII urotergite and $5+5 l p$ on IX abdominal segment; male without glandular $g_{I^{-}}$ setae, appendages with glandular $a_{1}$ and $a_{2}$-setae; cerci covered in long barbed macrosetae and a few clothing setae, but latero-inside macrosetae slightly enlarged, a bit swollen.

\section{Taxonomic notes}

A close related form of C. (C.) galilaea, named as C. (C.) aff. galilaea, has been described from Sardinia Island (Bareth 1980) and found in Liguria, NW Italy (Supplementary file 2) characterized by less antennomeres (19-21), with 1+1 lp macrosetae on V urotergite and a complete area of glandular $g_{I}$-setae; nevertheless, more samples would be needed to confirm the separation of this Sardinian population from the f. typ.

\section{Habitat and distribution}

Soil-dwelling species found at three localities in the southeast of the Mediterranean region: Degania, near the Galilea Sea (Israel, former Palestine) (Wygodzinsky 1942); Lebanon (Condé 1947f) and DiyarbakIr (Turkey) (Sendra et al. 2010). A different form is known from Sardinia Island (Bareth 1980) and northwestern Italy.

Campodea (Campodea) ghilarovi Rusek, 1965

Figs 35-36

Campodea (Campodea) ghilarovi Rusek, 1965a: fig. 2(1-22).

Diagnosis (Rusek 1965a)

Body length 2.5-4.5 mm; epicuticle without microdenticles; smooth clothing setae; antennae with 24-26 antennomeres; large sensillum third antennomere in dorsal position; long robust barbed notal macrosetae; short thin pine cone notal marginal setae; $1+1 l p$ macrosetae (from submedial position to more lateral) on V-VII urotergites, $3+3$ lp on VIII urotergite and 5+5 lp on IX abdominal segment; cerci covered in smooth thin macrosetae.

\section{Taxonomic notes}

Nota (Fig. 35) and male first urosternite (Fig. 36) were studied from new material (Supplementary file 2).

\section{Habitat and distribution}

Soil-dwelling species found in the extreme west of the Caucasus Mountains (Rusek 1965a).

Campodea (Campodea) giardi Silvestri, 1912

Campodea (Campodea) giardi Silvestri, 1912: 120, fig. VIII.

Diagnosis (Silvestri 1912; Bareth 2006)

Body length 3.5-4.5 mm; long, thin, smooth clothing setae; antennae with 22-29 antennomeres; sensillum of third antennomere in ventral position plus 1-4 sensilla on IV to VII antennomeres (in a few specimens these extra sensilla are absent); notal macrosetae long, thin and smooth or with 1-2 barbs; marginal setae long, poorly barbed with 1-2 barbs; one sensillum trochanteral; $1+1$ long ma urotergal macrosetae with insertion backward towards marginal setae from urotergites I to VII; $1+1 l a, 1+1 l p$ on V-VII urotergites; $1+1 \mathrm{mp}, 3+3$ lp on VIII urotergite and $1+1 \mathrm{mp}, 5+5 \mathrm{lp}$ on IX abdominal segment; cerci covered in macrosetae with some barbs and a few clothing setae; middle-sized spermatozoid fascicles, 

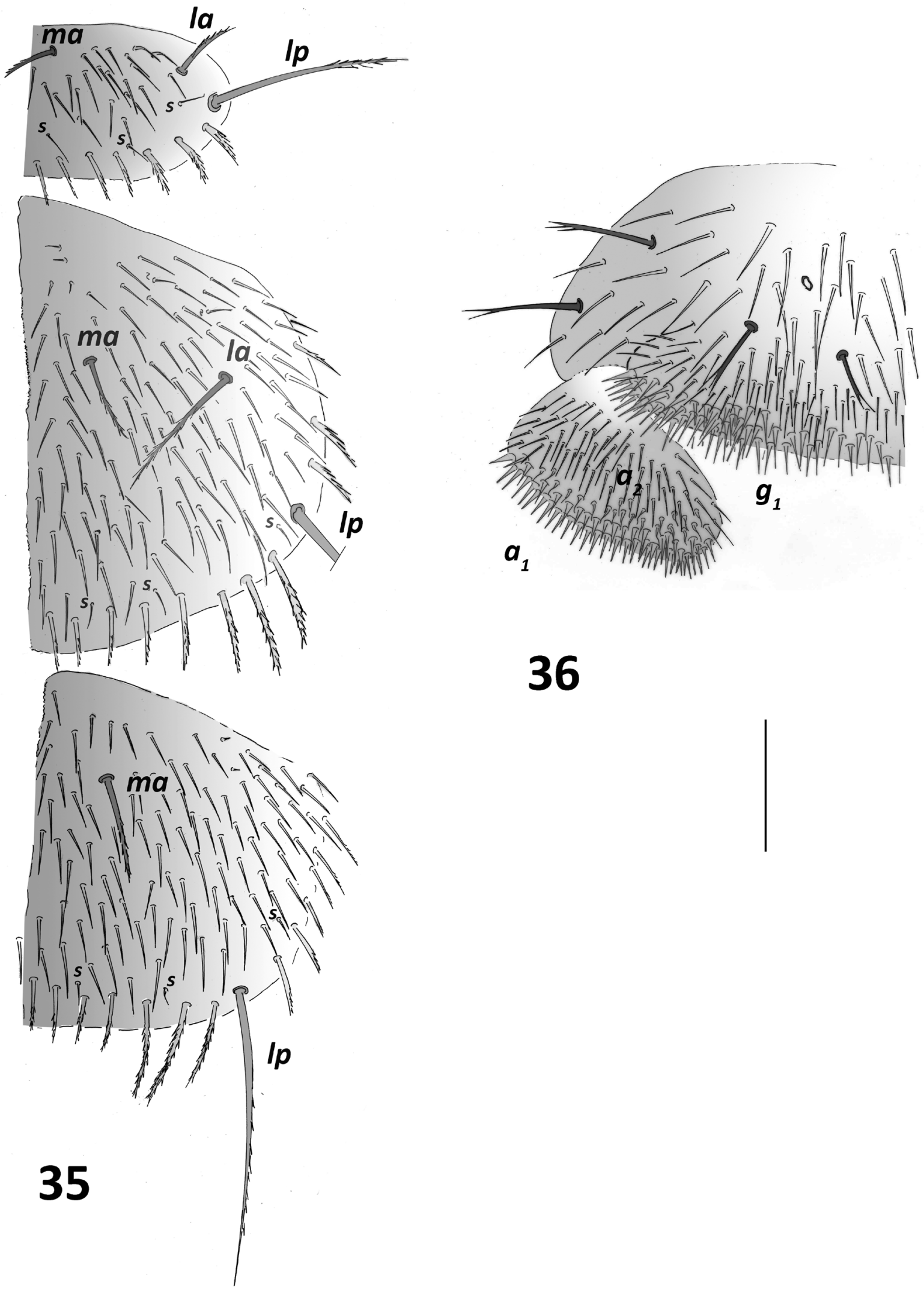

36

Figs 35-36. Campodea (Campodea) ghilarovi Rusek, 1965. 35. ㅇ, $2.5 \mathrm{~mm}$, pronotum, mesonotum and metanotum, right side, from Abkhazia. 36. $\hat{\jmath}, 2.8 \mathrm{~mm}$, first urosternite, right side, from Abkhazia. Abbreviations: $a_{1}, a_{2}, g_{1}=$ glandular setae; see Material and methods. Scale bar: $0.1 \mathrm{~mm}$. 
55-60 $\mu \mathrm{m}$ diameter and $25 \mu \mathrm{m}$ wide, spiral filament with 2-3 spirals, $240-360 \mu \mathrm{m}$ long and $2.8-3.3 \mu \mathrm{m}$ diameter in round section.

\section{Habitat and distribution}

Soil-dwelling species with a preference for mountain habitats. It was collected from the central and eastern Pyrenees (Denis 1930; Condé \& Mathieu 1957; Sendra \& Jiménez 1986). Outside the Pyrenees, C. giardi is cited from two localities at Durham, NE England (Bagnall 1915) and from two further localities in France: a mine of Gard and in a humid cave near Nancy (Husson 1946), but Condé (1956a) considered that they needed to be revised.

Campodea (Campodea) grallesiensis Sendra \& Condé, 1987

Campodea (Campodea) grallesiensis Sendra \& Condé, 1987: 55, figs 1a-c, 2, 3a-b.

Diagnosis (Sendra \& Condé 1987)

Cave-adapted species; body length $4.0-8.3 \mathrm{~mm}$; epicuticle with microdenticles; thick and short clothing setae with barbs; antennae with 34-40 antennomeres; cupuliform organ with eight to ten complex olfactory chemoreceptors; sensillum of third antennomere in ventral position; middle-sized, robust notal macrosetae almost completely covered with short barbs; la mesonotal similar to clothing setae and $l p$ metanotal similar to marginal setae; short thin pine cone marginal setae; $1+1$ la macrosetae on V urotergite; $1+1 l a, 1+1 l p$ on VI-VII urotergites; $1+1 \mathrm{mp}, 3+3 \mathrm{lp}$ on VIII urotergite and $1+1 \mathrm{mp}, 5+5$ $l p$ on IX abdominal segment; male without glandular $g_{I}$-setae; cerci twice as long as body with 15-17 articles, covered with long macrosetae with thin barbs along distal half to two-thirds and a few clothing setae.

\section{Habitat and distribution}

Cave-dwelling species endemic from the Caroig Massif, a karst region in the eastern Iberian Peninsula (Sendra \& Condé 1987; Sendra \& Moreno 2004).

Campodea (Campodea) grassii Silvestri, 1912

Campodea (Campodea) grassii Silvestri, 1912: 122, figs IX-XI.

Diagnosis (Silvestri 1912; Condé 1955b; Condé \& Mathieu 1957; Bareth 2006)

Body length 4.0-7.0 mm; epicuticle with abundant microdenticles; short, thick clothing setae with a few apical barbs; antennae with 24-36 antennomeres; cupuliform organ with four to six simple olfactory chemoreceptors; sensillum of third antennomere in dorsal and ventral position; $1+1 \mathrm{ma}, 1+1$ lp macrosetae on metanotum; middle-sized, robust notal macrosetae almost completely covered with barbs; $l p$ metanotal so short in adults that it is difficult or impossible to differentiate from thin pine cone marginal setae; one trochanteral sensillum; $1+1 l a, 1+1$ lp macrosetae on VI-VII urotergites, $3+3 l p$ on VIII urotergite and $5+5 \mathrm{l} p$ on IX abdominal segment; cerci covered in long thin macrosetae with small distal and thin barbs and a few clothing setae; small spermatozoid fascicles $35 \mu \mathrm{m}$ in diameter and 10 $\mu \mathrm{m}$ wide, spiral filament turns around $2.5 \times$, is $170-200 \mu \mathrm{m}$ long and $1 \mu \mathrm{m}$ in diameter.

\section{Habitat and distribution}

Soil-dwelling species with a clear preference for the upper layers of soil (O and A horizons). It is frequently found near springs or moisty sites and has been found in the entrance or twilight zones in caves (Sendra \& Moreno 2004), and in MSS habitats (Sendra et al. 2017a). Distributed in the West- 
Mediterranean region, it has been sampled in the Iberian and Italian peninsulas (Silvestri 1912; Condé \& Mathieu 1957; Ramellini 2000; Sendra \& Moreno 2004), in N Africa (Algeria; Condé 1947g); in Corsica (Condé 1947e), Sardinia (Bareth 1980), Sicily (Silvestri 1912) and Ponza Island (Condé 1978b).

Campodea (Campodea) ilixonis Denis, 1932

Campodea colladoi Silvestri, 1932a.

Campodea (Campodea) ilixonis Denis, 1932b: 599, figs 1-3, table I.

Diagnosis (Denis 1932b; Bareth 2006)

Body length 2.4-4.0 mm; epicuticle with microdenticles; middle-sized, smooth clothing setae; antennae with 20-23 antennomeres; sensillum of third antennomere in dorsal position; short ( $m a, l a)$ and long $(l p)$, poorly barbed notal macrosetae; marginal setae short and smooth or with a few apical barbs; $1+1$ short ma macrosetae on I-VII urotergites, $1+1$ la, $1+1 l p$ on V-VII urotergites, $1+1 m p, 3+3 l p$ on VIII urotergite and $1+1 \mathrm{mp}, 5+5 \mathrm{lp}$ on IX abdominal segment; male with two separated areas of glandular $g_{I}$-setae; cerci covered in long macrosetae with distal barbs and a few clothing setae but with swollen latero-interior macrosetae on proximal articles.

\section{Habitat and distribution}

Soil-dwelling species with a preference for the upper layers of the soil ( $\mathrm{O}$ and A horizons). It extends from the centre and west of the Pyrenees towards the Basque and the Cantabrian Mountains (Denis 1932b; Condé \& Mathieu 1957; Sendra \& Jiménez 1983). The presence of this species outside those regions should be further revised with new material (Blesić 1984, 1987, 1988, 1992, 1997b, 1998a, 1998b, 2000b; Ionescu 1955; Christian 2003).

Campodea (Campodea) kasiki Rusek, 1964

Campodea (Campodea) kasiki Rusek, 1964: 140, figs 57-77.

Diagnosis (Rusek 1964)

Body length $3.5 \mathrm{~mm}$; short, smooth clothing setae; midle-sized, thin, barbed notal macrosetae with a few thin and long barbs; long smooth notal marginal setae; smooth marginal setae; $1+1 \mathrm{ma}$ macrosetae on I-VII urotergites, $1+1 l a, 1+1 l p$ on IV-VII urotergites, $3+3 l p$ on VIII urotergite and $5+5 l p$ on IX abdominal segment.

\section{Taxonomic notes}

Anatolian specimens quoted by Sendra et al. (2006) show some features that have not been described by Rusek (1964) (Supplementary file 2): epicuticle without microdenticles; 23-25 antennomeres with sensillum of the third antennomere in dorsal position; and one trochanteral sensillum. The female from Montenegro studied doesn't have microsenticles and no trochanteral sensillum has been seen either, but the antennae are completely regenerated.

\section{Habitat and distribution}

Soil-dwelling species collected in three isolated regions, in the Tatra Mountains of Slovakia (Rusek 1964), at a single locality in Montenegro and in the central and eastern Anatolian Peninsula (Sendra et al. 2006). 
Campodea (Campodea) kervillei Denis, 1932

Campodea (Campodea) kervillei Denis, 1932a: 75, figs 1-10.

Diagnosis (Denis 1932a; Condé \& Mathieu 1957; Bareth 2006)

Body length 4.0-5.0 mm; epicuticle with thin microdenticles; short clothing setae with a few small apical barbs; antennae 19-29 antennomeres; sensillum of third antennomere in dorsal position; middle sized, poorly barbed, robust notal macrosetae; long, robust and barbed notal marginal setae; $1-0$ trochanteral sensillum; $1+1$ la on V urotergite, $1+1$ la $1+1$ l $p$ on VI-VII urotergites, $1+1 \mathrm{mp}, 3+3$ lp on VIII urotergite and $1+1 \mathrm{mp}, 5+5 \mathrm{lp}$ on IX abdominal segment; male with two separated areas of glandular $g_{I}$-setae; cerci with 7-9 articles covered in long macrosetae with distal barbs but swollen latero-interior macrosetae and a few clothing setae; spermatozoid fascicle 50-55 $\mu \mathrm{m}$ diameter and 15-20 $\mu \mathrm{m}$ thick, spiral filament $300-400 \mu \mathrm{m}$ long in 2-3 whorls and 3-4 $\mu \mathrm{m}$ diameter with one sharp extreme.

\section{Habitat and distribution}

Soil-dwelling species sometimes found in the MSS (Bareth 1983) or in caves (Denis 1932a; Condé \& Mathieu 1957) but without exhibiting cave-adaptated traits. It is abundant around the Pyrenees and neigbouring areas, except its eastern border (Denis 1932b; Condé 1947c; Condé \& Mathieu 1957; Sendra \& Moreno 2004).

Campodea (Campodea) lankesteri Silvestri, 1912

Campodea (Campodea) lankesteri Silvestri, 1912: 118, figs VI-VII.

Diagnosis (Silvestri 1912; Bareth 2006)

Body length 5.0-7.0 mm; epicuticle with thick microdenticles; long, thin, smooth clothing setae; antennae with 26-28 antennomeres; sensillum of third antennomere in ventral position; middle-sized, robust notal macrosetae poorly barbed; long, poorly barbed marginal setae; $1+1$ long ma macrosetae on I-IX urotergites, $1+1 l a, 1+1 l p$ on IV-VII urotergites, $3+3 l p$ on VIII urotergite and $5+5 l p$ on IX abdominal segment; cerci with $8-9$ articles covered in long, strong macrosetae with distal barbs and a few clothing setae; large spermatozoids fascicles with $60 \mu \mathrm{m}$ in diameter and $30 \mu \mathrm{m}$ thick, spiral filament with 9 spirals and $1000 \mu \mathrm{m}$ long, flattened filament of 3-4 $\mu \mathrm{m}$ in larger side and cylindrical void inside.

\section{Habitat and distribution}

Soil-dwelling species also collected in a few natural and artificial caves (Leleup 1948; Bareth 2000a; Sendra et al. 2013). It has been found in the North of Europe on the the British Isles (Bagnall 1915, 1918b; Good et al. 1989) and spreads throughout continental Europe from eastern France (Condé 1947d; Condé \& Barbier 1965), Belgium (Bareth 2000a) to the Jutland Peninsula and the southern extreme of the Scandinavian Peninsula (Agrell 1944), and across Central Europe (Marten 1939; Christian 1992, 2003).

Campodea (Campodea) leclerci Bareth, 1985

Campodea (Campodea) leclerci Bareth, 1985: 47, figs a-g.

Diagnosis (Bareth 1985, 2006)

Slightly cave-adapted species; body length 3.2-4.5 mm; short, smooth clothing setae; antennae with 30-31 antennomeres; cupuliform organ with six to seven olfactory chemoreceptors; sensillum of third antennomere in ventral position; short $(m a, l a)$ and long $(l p)$ barbed notal macrosetae; short notal marginal setae with long apical barbs; $1+1 \mathrm{ma}$ macrosetae from short to longer from I to VII urotergites, 
$1+1 l a, 1+1 l p$ on V-VII urotergites, $1+1 \mathrm{mp} 3+3 \mathrm{lp}$ on VIII urotergite and $1+1 \mathrm{mp} 5+5 \mathrm{lp}$ on IX abdominal segment; male without glandular $g_{1}$-setae; cerci longer than body with 12 articles covered in long macrosetae with thin barbs and a few clothing setae; spermatozoid fascicles $43-47 \mu \mathrm{m}$ in diameter and 21-22 $\mu \mathrm{m}$ thick, spiral filament with 4 spirals, $240 \mu \mathrm{m}$ long and $1.3 \times 0.7 \mu \mathrm{m}$ in its elliptical section.

\section{Habitat and distribution}

Cave-dwelling species found in the Grotte Puechredon, Gard, South of France (Bareth 1985).

Campodea (Campodea) lubbockii Silvestri, 1912

Figs $37-41$

Campodea (Campodea) lubbockii Silvestri, 1912: 116, figs IV-V.

Diagnosis (Silvestri 1912; Bareth 2006, 2007a)

Body length 3.5-5.0 mm; epicuticle with microdenticles visible up to $400 \times$; short thick clothing setae with thin apical barb, ventral side with short, thin and smooth clothing setae; antennae with 20-23 antennomeres; small sensillum of third antennomere in ventral position; short thick notal macrosetae with a few tiny barbs; $l p$ meso and metanotal similar to marginal setae; short, thick marginal setae with a few tiny barbs; one trochanteral sensillum; $1+1$ short swollen $m a$ macrosetae on I-VII urotergites, $1+1$ la on V urotergite, $1+1$ la, $1+1$ lp on VI-VII urotergites, $1+1$ short swollen $m a, 3+3$ lp on VIII urotergite and $1+1$ short swollen $m a, 5+5 \mathrm{lp}$ on IX abdominal segment; cerci as long as body length with 9 to 15 articles covered in short macrosetae and abundant clothing setae, distalmost articles show remarkable subdivisions, up to nine in apical article; small spermatozoid fascicles with diameter of $30 \mu \mathrm{m}$ and $10-12 \mu \mathrm{m}$ thick, spiral filament with $2 \frac{1}{2}$ to 3 turns, $180-200 \mu \mathrm{m}$ long and $1.5-2 \mu \mathrm{m}$ in diameter.

\section{Taxonomic notes}

Nota (Fig. 37), urotergites (Fig. 38), male and female first urosternites (Figs 40-41), and cerci (Fig. 39) were drawn from the studied material (Supplementary file 2).

\section{Habitat and distribution}

Soil-dwelling species also found in mines and MSS habitats (Bareth 2000a, 2007a; Sendra et al. 2013). It has beeen found across England (Bagnall 1915, 1918b), on the southern border of the Scandinavian Peninsula (Agrell 1944; Olsen 1996), eastern France (Denis 1924; Condé 1947h; Condé \& Mathieu 1957; Condé \& Bareth 1998), Belgium (Bareth 2000a, 2007a), Germany (Christian 2003), Switzerland (Wygodzinsky 1941a) and Austria (Christian 1992). Its presence in Lazio, Italy (Ramellini 1990) should be reviewed.

\section{Campodea (Campodea) machadoi Condé, 1951}

Campodea (Campodea) machadoi Condé, 1951d: 7, figs a-g.

\section{Diagnosis (Condé 1951d)}

Body length $4.5 \mathrm{~mm}$; clothing setae smooth or with small apical barb; antennae with 17 antennomeres; short $(m a, l a)$ and long $(l p)$ barbed notal macrosetae, $l p$ macrosetae on metanotum similar to marginal setae; thin pine cone notal marginal setae; $1+1$ short ma macrosetae on I-VII urotergites; $1+1$ la on V urotergite, $1+1 l a, 1+1 l p$ on VI-VII, $1+1$ short $m a, 3+3 l p$ on VIII urotergite and $1+1 m p, 5+5 l p$ on IX abdominal segment; cerci almost $2 \frac{1}{2}$ shorter than body with 11 articles covered in macrosetae with barbs along distal $2 / 3$ on proximal articles, and macrosetae with one apical barb on distal articles and a few clothing setae along complete cerci. Sendra \& Moreno (2004) described a juvenile female of $2.1 \mathrm{~mm}$ 

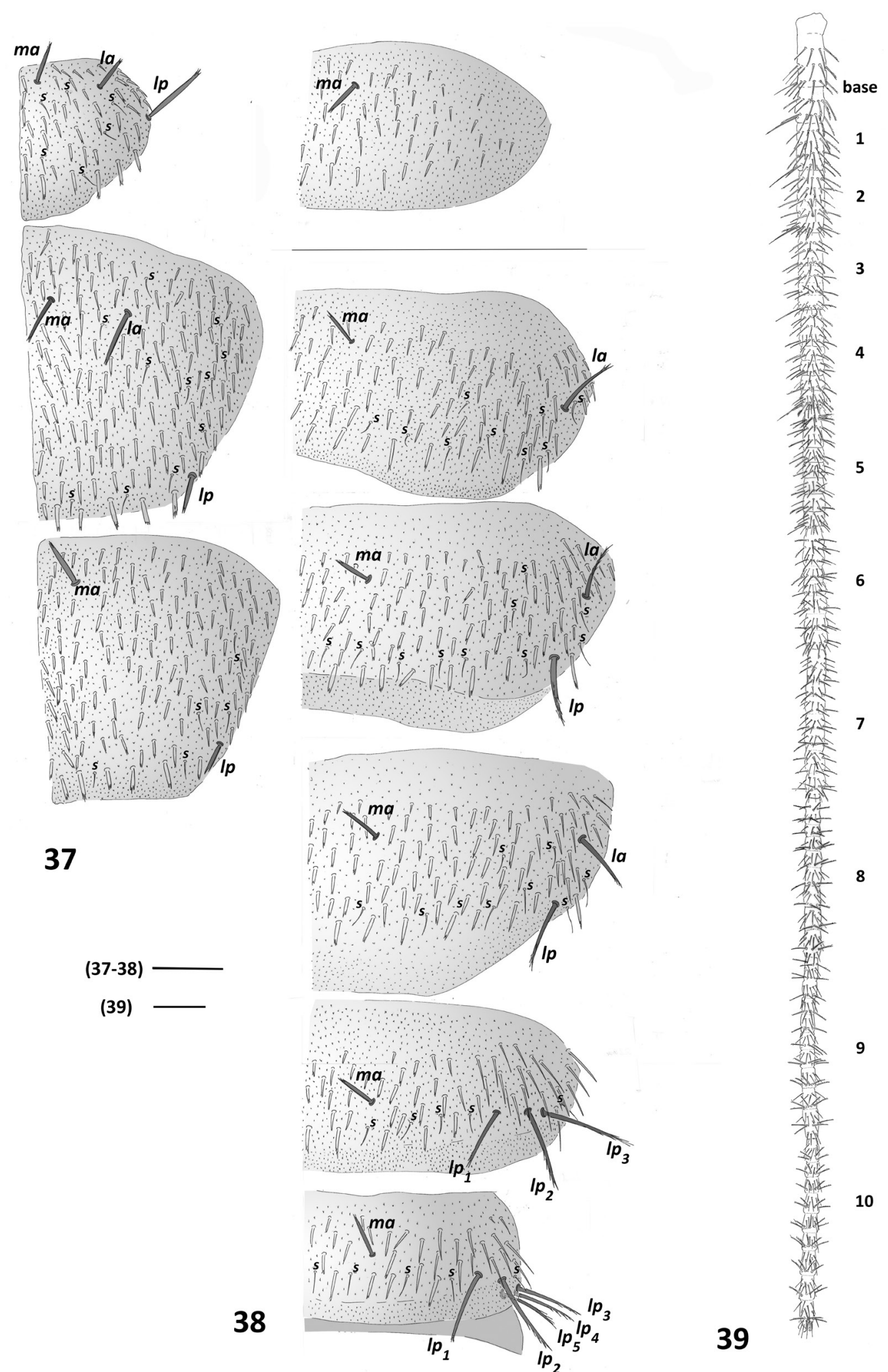

Figs 37-39. Campodea (Campodea) lubbockii Silvestri, 1912. 37. $९$, 4 mm, from Geneva, Switzerland, pronotum, mesonotum and metanotum, right side. 38. Urotergites I, V-VIII and abdominal segment IX, right side. 39. $\odot$, $4.1 \mathrm{~mm}$, from Pichoy, France, right cercus. Abbreviations: see Material and methods. Scale bars: $0.2 \mathrm{~mm}$. 
from Celorico de Bastos (Braga, Portugal) similar to the original description of C. (C.) machadoi, but with two important differences: the presence of $1+1 \mathrm{ma}$ macrosetae on IX abdominal segment and the absence of the la macrosetae on $\mathrm{V}$ urotergite.

\section{Habitat and distribution}

Soil-dwelling species described with one female collected in Paços de Sousa, near Oporto, Portugal (Condé 1951d).
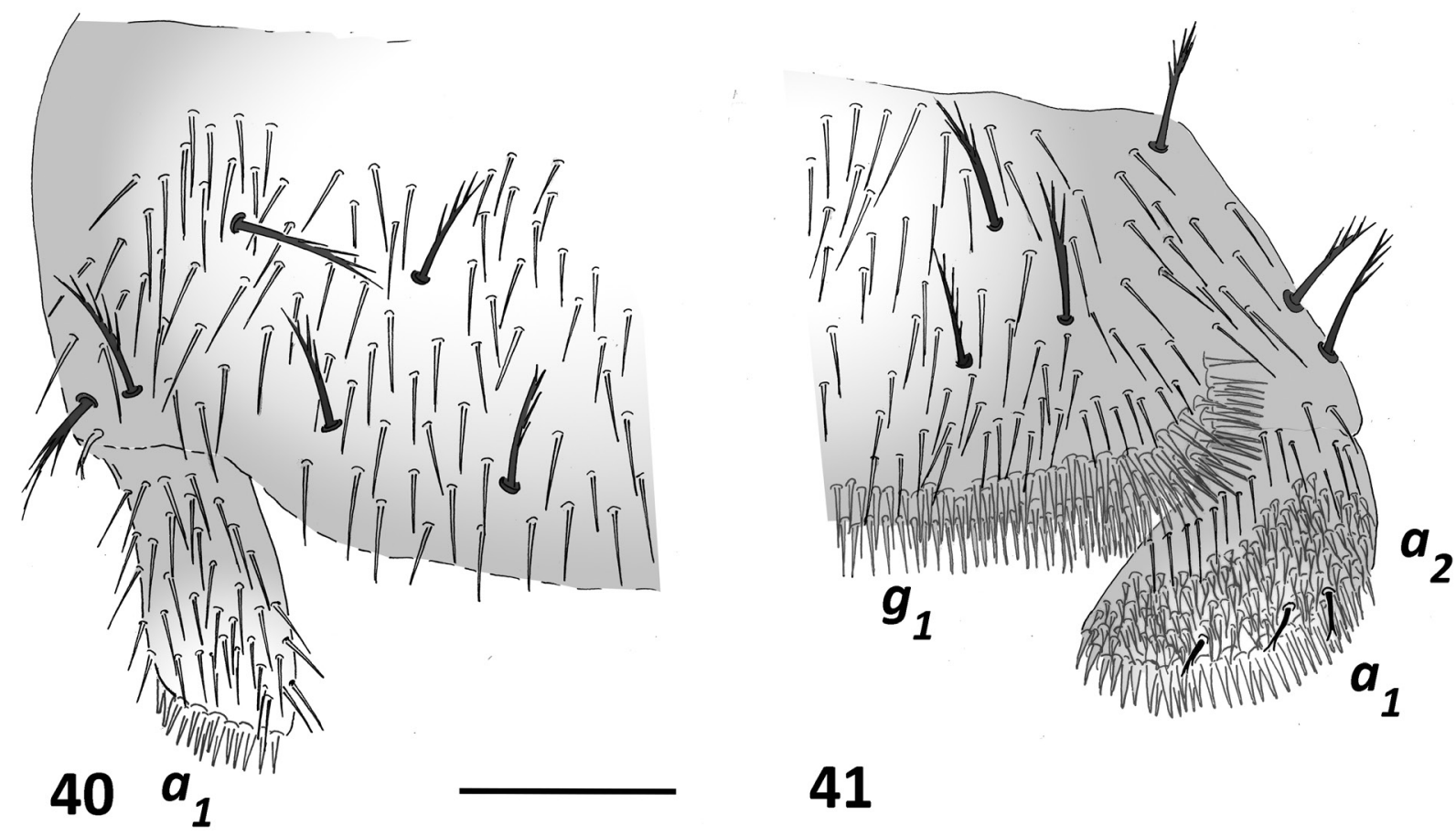

Figs 40-41. Campodea (Campodea) lubbockii Silvestri, 1912, from Pichoy, France. 40. $q, 5 \mathrm{~mm}$, first

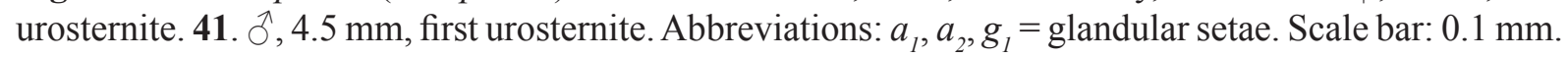

Campodea (Campodea) maestrazgoensis Sendra \& Escolà, 2004 Figs $6,11,23$

Campodea (Campodea) maestrazgoensis Sendra \& Escolà, 2004: 902, figs 5-6, 7a-b.

Diagnosis (Sendra \& Escolà 2004)

Cave-adapted species; body length 3.8-6.1 mm; epicuticle without microdenticles under optical microscope but visible above $1000 \times$; long, thin, smooth clothing setae; antennae with 36-37 antennomeres; cupuliform organ with seven to eight complex olfactory chemoreceptors with two folds; long, large sensillum of third antennomere in ventral position; long, thin barbed notal macrosetae; long, barbed notal marginal setae; $1+1 m a$ macrosetae on IV-VII urotergite; $1+1$ la $1+1$ lp on V-VII urotergites; $1+1 \mathrm{mp}, 3+3 \mathrm{lp}$ on VIII urotergite and $1+1 \mathrm{mp}, 5+5 \mathrm{lp}$ on IX abdominal segment; cerci twice longer than body, with 13 articles covered in long macrosetae with barbs almost from their base and a few clothing setae. 


\section{Taxonomic notes}

The studied material (Supplementary file 2) has allowed to photograph some structures under SEM (Figs 6, 11, 23).

\section{Habitat and distribution}

Cave-dwelling species found in caves around the Maestrazgo, a mountain region in the south of the Aragonese Mountain Branch of the Iberian Mountains Range, eastern Iberian Peninsula (Sendra \& Escolà 2004).

\section{Campodea (Campodea) magna Ionescu, 1955}

Campodea (Campodea) magna Ionescu, 1955: 31.

Diagnosis (Ionescu 1955; Sendra et al. 2012)

Body length 5.5-7.0 mm; epicuticle with microdenticles; short, smooth clothing setae; antennae with 27-31 antennomeres; sensillum of third antennomere in dorsal position; middle-sized, robust and poorly barbed notal macrosetae; $l p$ mesonotal longer than $l p$ metanotal; slightly thin pine cone notal marginal setae; one trochanteral sensillum; $1+1$ la, $1+1 l p$ macrosetae on urotergites VI-VII, $3+3 l p$ on VIII and $5+5$ lp on IX abdominal segment.

\section{Taxonomic notes}

Cerci with thin smooth macrosetae in Austrian specimens, Supplementary file 2.

\section{Habitat and distribution}

Soil-dwelling species found in several localities from southern Carpathians Mountains (Ionescu 1955; Sendra et al. 2012).

Campodea (Campodea) majorica majorica Condé, 1955

Campodea (Campodea) majorica majorica Condé, 1955b: 121, fig. 1a-b.

\section{Diagnosis (Condé 1955b)}

Cave-adapted species; body length 5.0-9.0 mm; epicuticle with abundant microdenticles; thin pine cone clothing setae; antennae with 41-44 antennomeres; cupuliform organ with 12-19 complex olfactory chemoreceptors; sensillum of third antennomere in ventral position; 1+1 ma macrosetae on metanotum; middle sized, robust notal macrosetae almost completely covered with short barbs; thin pine cone notal marginal setae; $1+1$ la macrosetae on VI urotergite, $1+1$ la and $1+1 l p$ on VII urotergite, $3+3 l p$ on VIII urotergite and $5+5 \mathrm{l} p$ on IX abdominal segment; cerci longer than the body with long barbed macrosetae.

\section{Campodea (Campodea) majorica interjecta Condé, 1955}

Campodea (Campodea) majorica interjecta Condé, 1955b: 122, fig. 1c.

Differential diagnosis from the f. typ. (Condé 1955b)

Urotegite VI with $1+1$ or $0+1$ lp macrosetae.

Campodea (Campodea) majorica sicula Condé, 1957

Campodea (Campodea) majorica sicula Condé, 1957: 138, fig. 1.

Differential diagnosis from the f. typ. (Condé 1957)

Notal macrosetae longer and thinner than the f. typ. 
Campodea (Campodea) majorica valentina Sendra \& Moreno, 2004

Campodea (Campodea) majorica valentina Sendra \& Moreno, 2004: 30, figs 11-12, tables IV-VII.

Differential diagnosis from the f. typ. (Sendra \& Moreno 2004)

Thick sensilla of third antennomere in dorsal position; $1+1$ la $, 0,1+0,1+1$ lp macrosetae on VI urotergite.

\section{Habitat and distribution}

This is a cave-adapted species inhabiting the cave environment in Majorca Island for C. (C.) majorica majorica and C. (C.) majorica interjecta, Sicily Island for C. (C.) majorica sicula (Condé 1955b, 1957), and caves of a small karst area inland on the northeastern border of the Prebaetic Mountains, East Iberian Peninsula for C. (C.) majorica valentina (Sendra \& Moreno 2004).

\section{Campodea (Campodea) meinerti Bagnall, 1918}

Figs 42-45

Campodea (Campodea) meinerti Bagnall, 1918a: 157.

Diagnosis (Bagnall 1918a; Condé 1951a; Bareth 2006)

Body size 2.5-4.7 mm; epicuticle with microdenticles; smooth, short clothing setae; antennae with 2026 antennomeres; sensillum of third antennomere in dorsal position (between $b-c$ and $c-d$ macrosetae); short $(m a, l a)$ and long $(l p)$ barbed notal macrosetae; lp mesonotal longer than $l p$ metanotal; notal marginal setae short and with long apical barbs; $1+1$ short swollen ma macrosetae on I-VII urotergites, $1+1 l a, 1+1 l p$ on V-VII urotergites, $1+1$ short $m p, 3+3 l p$ on VIII urotergite and $1+1$ short $m p 5+5 l p$ on IX abdominal segment; females with slightly enlarged appendages on first urosternite with glandular $a_{1}$ and $a_{2}$-glandular setae; cerci with ten articles covered in macrosetae and a few clothing setae, but swollen latero-interior macrosetae on proximal articles.

\section{Taxonomic notes}

The studied material (Supplementary file 2) has allowed to draw new figures of the nota (Fig. 42), urotergites (Fig. 43), and male and female first urosternite (Figs 44-45).

\section{Habitat and distribution}

Soil-dwelling species distributed from England (Bagnall 1918a; Womersley 1927; Condé 1951a, 1961) to the Pyrenees (Condé \& Mathieu 1957), throughout eastern French regions (Condé 1947c, 1947h, 1951a).

Campodea (Campodea) minor Wygodzinsky, 1944

Campodea (Campodea) minor Wygodzinsky, 1944a: 503, figs 1-9.

Diagnosis (Wygodzinsky 1944a; Sendra \& Moreno 2004)

Body length 1.3-2.8 mm; epicuticle with microdenticles; short, smooth clothing setae; antennae with 13-19 antennomeres; sensillum of third antennomere in ventral position; short ( $m a$, la) and long (lp pronotal) barbed notal macrosetae; $l p$ mesonotal and metanotal short similar to marginal setae; notal marginal setae short with apical barbs notal; $1+1$ short ma macrosetae on I-VII urotergites; $0+0$ or $1+1$ la on V-VII urotergites, $0+0$ or $1+1$ lp on V-VI urotergites, $1+1 l p$ VII, $1+1$ short $m a, 3+3 l p$ on VIII urotergite, $1+1$ short $m a, 5+5 \mathrm{lp}$ on IX abdominal segment; cerci three times shorter than body with 6 to 7 barrel-shaped articles covered in long macrosetae and a few clothing setae, with three types of latero- 

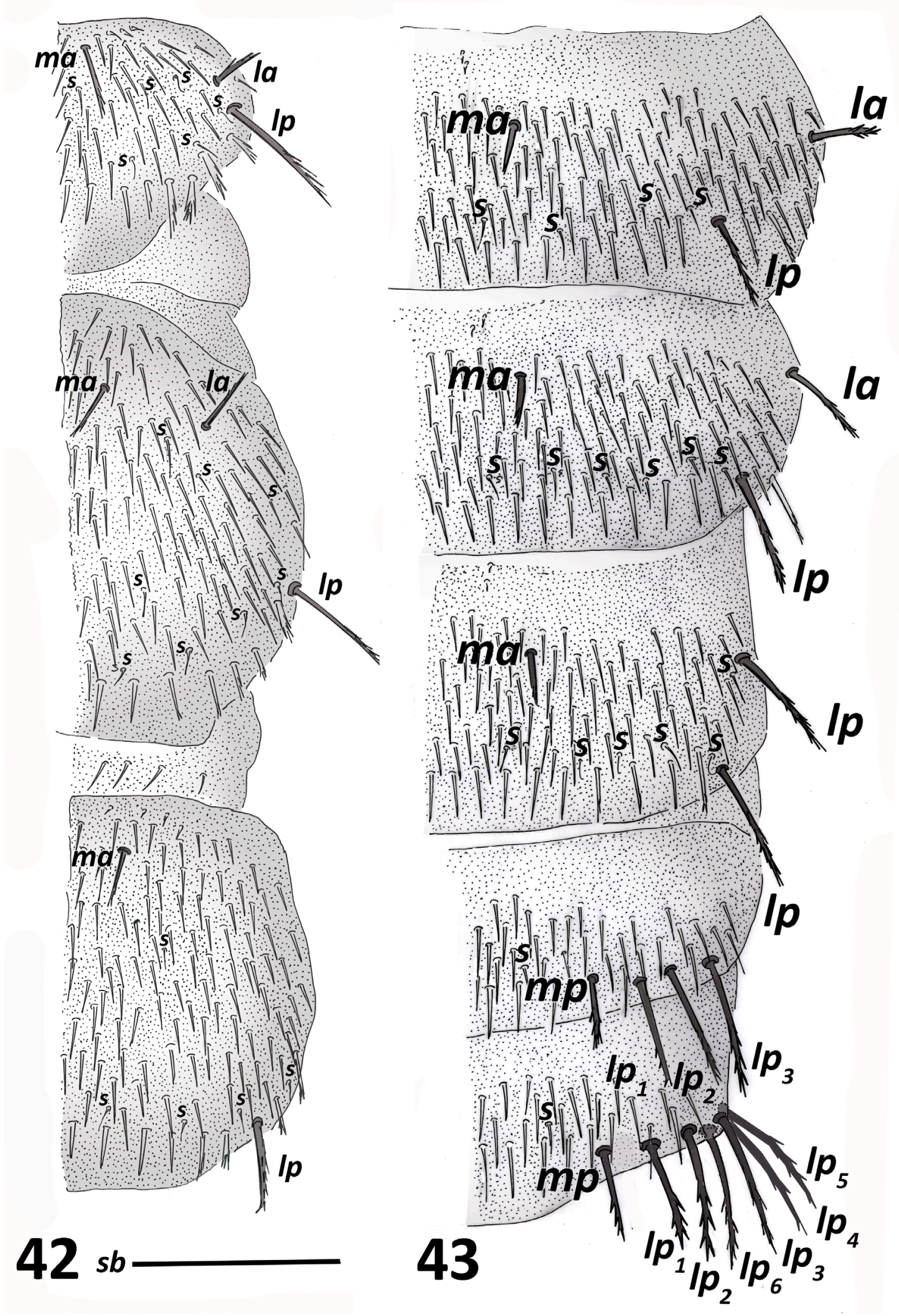

Figs 42-43. Campodea (Campodea) meinerti Bagnall, 1918, $q, 4.4 \mathrm{~mm}$, from Pichoy, France. 42. Pronotum, mesonotum and metanotum. 43. Urotergites V-VII and abdominal segment IX. Abbreviations: see Material and methods. Scale bar: $0.2 \mathrm{~mm}$. 

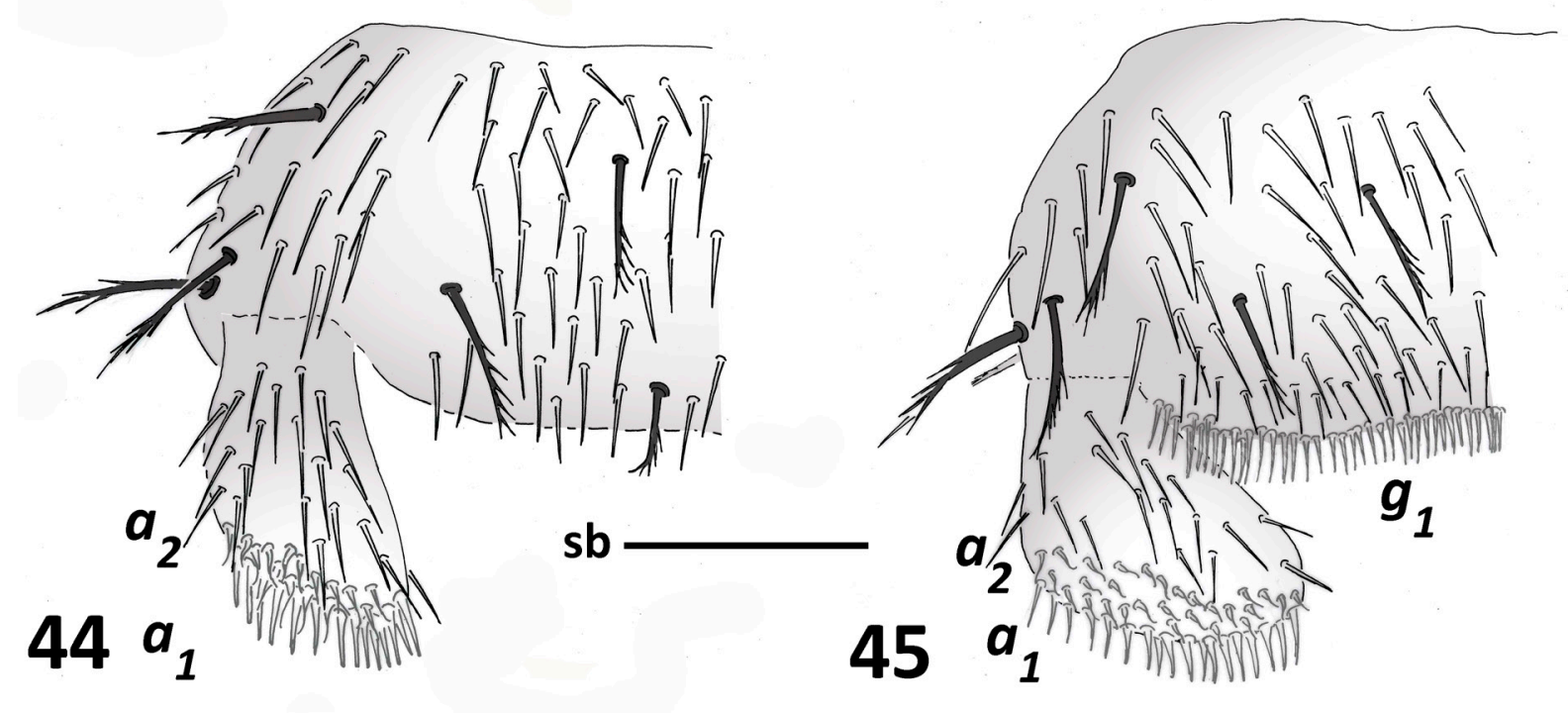

Figs 44-45. Campodea (Campodea) meinerti Bagnall, 1918, from Pichoy, France. 44. $९$, 4.5 mm, first urosternite. 45. $\sigma^{\lambda}, 3.4 \mathrm{~mm}$, first urosternite. Abbreviations: $a_{1}, a_{2}, g_{1}=$ glandular setae. Scale bar: $0.1 \mathrm{~mm}$.

interior cercal macrosetae: smooth macrosetae with a few distal barbs, slightly swollen macrosetae or spine-shape macrosetae.

\section{Habitat and distribution}

Soil-dwelling species well adapted to endogean habitats of B horizon, inhabiting also the crops. Its distribution limits are located around the northwest of the Iberian Peninsula in areas under the Atlantic climatic influence (Sendra \& Moreno 2004).

\section{Campodea (Campodea) monspessulana Condé, 1953}

Campodea (Campodea) monspessulana Condé, 1953: 406, figs a-e.

Diagnosis (Condé 1953a; Bareth 2006)

Body length 5.0-6.4 mm; epicuticle with abundant microdenticles; thin pine cone clothing setae; antennae with 27-29 antennomeres; sensillum of third antennomere in ventral position; middle-sized, robust notal macrosetae, almost completely covered with short barbs; long thin pine cone marginal setae; $1+1 l a, 1+1 l p$ macrosetae on VI-VII urotergites; $3+3 l p$ on VIII and $5+5 l p$ on IX abdominal segment; cerci covered in long macrosetae with barbs (6-20) (1-4 in specimens from San Martino-Genova) along the distal half and a few clothing setae.

\section{Habitat and distribution}

Soil-dwelling species found at a single location in southeast France, near the coast of Mireval, LanguedocRosellón (Condé 1953a).

Campodea (Campodea) navasi Sendra \& Moreno, 2004

Campodea (Campodea) navasi Sendra \& Moreno, 2004: 29, figs 8-9, table III.

Diagnosis (Sendra \& Moreno 2004)

Body length 1.6-2.8 mm; epicuticle with microdenticles; short, smooth clothing setae; antennae with 17-19 antennomeres; sensillum of third antennomere in ventral position; $1+1 \mathrm{ma}$ macrosetae on 
metanotum; short $(m a, l a)$ and long $(l p)$ barbed notal macrosetae; without $l p$ metanotal; short, smooth notal marginal; $1+1 l p$ macrosetae on VI-VII urotergites; $3+3 l p$ on VIII urotergite and $5+5 l p$ on IX abdominal segment; cerci covered in long macrosetae and sparse clothing setae but swollen laterointerior macrosetae.

\section{Habitat and distribution}

Soil-dwelling species located at a few localities in the Pyrenees (Condé \& Mathieu 1957), and frequent in the Basque Mountains, reaching also the North of the Iberian Mountain Range, in the Iberian Peninsula (Sendra \& Moreno 2004).

\section{Campodea (Campodea) olivieri Condé, 1955}

Campodea (Campodea) olivieri Condé, 1955a: 399, figs 1a-e.

Differential diagnosis from C. (C.) plusiochaeta species (Condé 1955a)

Antennae with 24 and 26 antennomeres; cupuliform organ with five to seven olfactory chemoreceptors; notal macrosetae and marginal setae well barbed; cercal macrosetae with barbs along distal two-thirds, but latero-interior macrosetae with one apical thin barb.

\section{Habitat and distribution}

Species found in Biket-Aanjar cave, Lebanon (Condé 1955a).

Campodea (Campodea) oredonensis Condé, 1951

Campodea (Campodea) oredonensis Condé, 1951c: 92, figs b-c.

\section{Diagnosis (Condé 1951c)}

Body length 4.0-5.0 mm; short, smooth clothing setae; antennae with 25-28 antennomeres; sensillum of third antennomere in dorsal position; short $(m a, l a)$ and long $(l p)$ barbed notal macrosetae; thin pine cone notal marginal setae; $1+1 \mathrm{ma}$ macroseta from short to long macrosetae on I to VII urotergites, $1+1$ $l a, 1+1 l p$ on V-VII urotergites, $1+1 \mathrm{mp}, 3+3 \mathrm{lp}$ on VIII urotergite and $1+1 \mathrm{mp}, 5+5 \mathrm{lp}$ on IX abdominal segment; male with two separated areas of glandular $g_{l}$-setae; cerci covered in long thin macrosetae with $1-3$ barbs and a few clothing setae.

\section{Habitat and distribution}

Soil-dwelling species found in a single locality in Oredón Lake, Hautes-Pyrénées, France (Condé 1951c).

Campodea (Campodea) patrizii Condé, 1953

Campodea (Campodea) patrizii Condé, 1953c: 34, fig. $2^{\mathrm{a}}$ c-i.

\section{Diagnosis (Condé 1953c)}

Body length $2.0 \mathrm{~mm}$, in juvenile male; epicuticle with thick microdenticles; clothing setae short, smooth or with a few thin apical barbs, with 0-3 distal barbs; thick sensilla of third antennomere in dorsal position; $1+1$ la, $1+1$ lp macrosetae on mesonotum, $1+1$ lp on metanotum; long barbed notal macrosetae; thin pine cone notal marginal setae; $1+1 l a, 1+1 l p$ macrosetae on VI-VII urotergites, $3+3 l p$ on VIII urotergite and $5+5 \mathrm{l} p$ on IX abdominal segment. It was described from one juvenile male, with broken antennae. The differences with $C$. $(C$.) remyi could be due to age, more samples are needed to redescribe this species, otherwise it should be synonymized. 


\section{Habitat and distribution}

Soil-dwelling species found in a cave located in the southwest of Sardinia Island (Condé 1953c).

Campodea (Campodea) pempturochaeta Silvestri, 1912

Campodea (Campodea) pempturochaeta Silvestri, 1912: 128, figs XV-XVI.

Diagnosis (Silvestri 1912; Sendra \& Moreno 2004)

Body length 2.0-3.5 mm; epicuticle with microdenticles; short, smooth clothing setae; antennae with 18-22 antennomeres; sensillum of third antennomere in ventral position; short $(m a, l a)$ and long $(l p)$ barbed notal macrosetae; short with apical long barbs notal marginal setae; $1+1 l a, 1+1$ lp macrosetae on V-VII urotergites; $3+3 l p$ on VIII urotergite and $5+5 l p$ on IX abdominal segment; cerci shorter than body covered in short macrosetae and numerous clothing setae. Sendra et al. $(2006,2010)$ collected the species at 31 localities in the central and eastern Anatolian Peninsula; these Turkish specimens show two different positions in the sensillum of the third antennomere, in dorsal (more frequent and larger) and ventral position (smaller); antennae with 19-24 antennomeres; variability in the shape of the notal macrosetae; and spermatozoids fascicles observed having 50-80 $\mu \mathrm{m}$ diameter, spiral filament with 3-4 spirals, 600-800 $\mu \mathrm{m}$ long and elliptical shaped with $1.5 \mu \mathrm{m}$ in wider section.

\section{Habitat and distribution}

Soil-dwelling species inhabiting both dry and moisty environments, known from more than 50 localities scattered around the Mediterranean Region: eastern Iberian Peninsula (Sendra \& Moreno 2004), Algeria (Condé 1947g), Sicily, the Italian Peninsula (Silvestri 1912; Wygodzinsky 1941b; Ramellini 1990), and central eastern Anatolian Peninsula (Sendra et al. 2006, 2010).

\section{Campodea (Campodea) pieltaini Silvestri, 1932}

Figs 7-8, 24

Campodea (Campodea) pieltaini Silvestri, 1932: 122, figs III-IV.

Diagnosis (Silvestri 1932a; Bareth 2006)

Body length 5.0-8.0 mm; epicuticle with multi-tip microdenticles, visible above $400 \times$; middle-sized, smooth clothing setae; antennae 24-31 antennomeres; sensillum of third antennomere in dorsal position; cupuliform organ with 6-8 simple olfactory chemoreceptors; long, poorly barbed notal macrosetae almost smooth; long thin pine cone notal marginal setae; $1+1 \mathrm{lp}$ macrosetae in submedial position on VI urotergite; $1+1 l p$ on VII urotergite, $3+3 l p$ on VIII urotergite and $5+5 l p$ on IX abdominal segment; cerci covered in long, smooth macrosetae and a few clothing setae; spermatozoid fascicles with 75-85 $\mu \mathrm{m}$ diameter and $18-20 \mu \mathrm{m}$ thick, spiral filament with $2-2 \frac{1}{2}$ spirals, $350 \mu \mathrm{m}$ long and $2 \mu \mathrm{m}$ diameter.

\section{Taxonomic notes}

The studied material (Supplementary file 2) has allowed to photograph some structures under SEM (Figs 7-8, 24).

\section{Habitat and distribution}

Species living in humid soil, frequently abundant along the Cantabrian Mountains of the Iberian Peninsula, extending its distribution towards the Pyrenees (Condé \& Mathieu 1957; Sendra \& Moreno 2004). 
Campodea (Campodea) plusiochaeta Silvestri, 1912

Fig 46

Campodea gardneri Bagnall, 1918b: 110, figs 5, 7.

Campodea (Campodea) plusiochaeta Silvestri, 1912: 116, fig. III-2.

Diagnosis (Silvestri 1912; Condé \& Bareth 1998; Bareth 2006)

Body length 2.0-4.0 mm; epicuticle with microdenticles; short, smooth clothing setae; antennae with 19-24 antennomeres, up to 27 antennomeres in some Greek specimens (Condé 1984); sensillum of third antennomere in dorsal position (or in ventral position in northern populations form named $C$. $(C$.) gardneri Bagnall, 1918 in Condé \& Bareth 1998: D0431); short (ma,la) and long (lp) barbed notal macrosetae; notal marginal setae short with long apical barbs; $1+1 l a, 1+1$ lp macrosetae on V-VII urotergites, $3+3 l p$ on VIII urotergite and $5+5 l p$ on IX abdominal segment; cerci covered in long, poorly barbed macrosetae and a few clothing setae, latero-interior macrosetae with 1-2 thin barbs; spermatozoid fascicles with 45-50 $\mu \mathrm{m}$ diameter and 20-23 $\mu \mathrm{m}$ thick, spiral filament with 5-6 spirals, 550-600 $\mu \mathrm{m}$ long and hemispheric section 5-6 $\mu \mathrm{m}$ in widest diameter.

\section{Taxonomic notes}

The studied material (Supplementary file 2) has allowed to draw the nota (Fig. 46).

\section{Habitat and distribution}

Soil-dwelling species, living under stones or among the alluvial debris (Condé 1960) and common under bark or moss. It also found in dry environments, burrows of mammals or gardens but as well lives in mountains at high altitude, for instance at 3050 m a.s.l. in Sierra Nevada (Granada, Iberian Peninsula) (Sendra \& Moreno 2004). It is one of the most widespread species, collected at many sites of the Euro-Medianterran region: British Isles (Condé 1961), southern Jutland and southern Scandinavian Peninsulas (Silvestri 1912; Arevad 1957; Olsen 1996), N Africa (Condé 1947g, 1953b), from west to east in the Iberian Peninsula (Sendra \& Moreno 2004), throughout continental Europe including West, central and eastern Europe (Silvestri 1912; Pagés 1951; Rusek 1964; Stach 1964; Wygodzinsky 1941c; Paclt 1965), the Italian Peninsula (Silvestri 1912; Ramellini 1995, 2000), the Balkan Peninsula (Condé 1984) and the Anatolian Peninsula (Sendra et al. 2010). The easternmost localities are in western Russia (Silvestri 1912; Rusek 1965a) close to the $60^{\circ}$ parallel. For the distribution in North America, see Silvestri (1933b), Bareth \& Condé (1958), Condé \& Geeraert (1962) and Condé (1973).

Campodea (Campodea) portacoeliensis Sendra \& Jiménez, 1986

Campodea (Campodea) portacoeliensis Sendra \& Jiménez, 1986: 277, figs 1a-f, 2a-e, 3a-b.

Diagnosis (Sendra \& Jiménez 1986)

Body length 2.4-3.4 mm; epicuticle without microdenticles; long, thin, smooth clothing setae, in small number on dorsal body; antennae with 22-29 antennomeres; sensillum of third antennomere in ventral position; long thin barbed notal macrosetae; mesonotal $l p$ similar to metanotal $l p$; long, thin, poorly barbed notal marginal setae; $1+1 \mathrm{ma}$ long thin macrosetae on I-VII urotergites, $1+1 \mathrm{lp}$ on IVVII urotergites, $3+3 l p$ on VIII urotergite and $5+5 l p$ on IX abdominal segment; cerci covered in long macrosetae with distal barbs and a few clothing setae (at several localities shorter macrosetae with one distal barb, in medial and distal articles).

\section{Habitat and distribution}

Soil-dwelling species showing preferences for moisty sites around mountain areas, distributed in the Turia and Mijares River basins in the eastern Iberian Peninsula (Sendra \& Jiménez 1986; Sendra 1989b; 

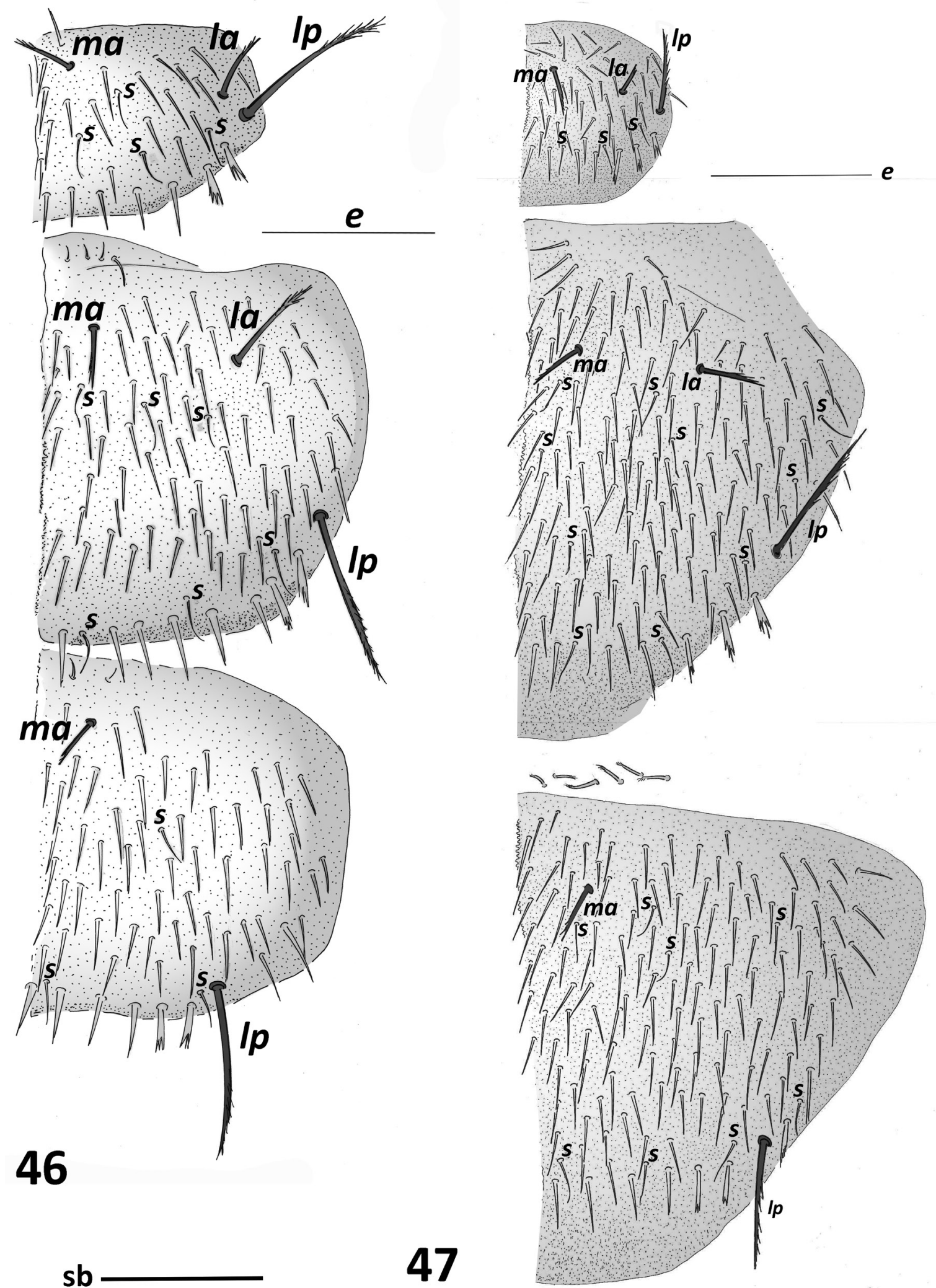

Figs 46-47. - 46. Campodra (Campodea) plusiochaeta Silvestri, 1912, , $3.8 \mathrm{~mm}$, from Geneva, Switzerland, pronotum, mesonotum and metanotum. - 47. Campodea (Campodea) pseudofragilis Condé, 1984,, , $3.7 \mathrm{~mm}$, from Agigea, Romania, pronotum, mesonotum and metanotum. Abbreviations: see Material and methods. Scale bar: $0.1 \mathrm{~mm}$. 
Sendra \& Moreno 2004) and also distributed on the scree slopes in the Guadarrama Mountains in central Spain (Sendra et al. 2017a).

Campodea (Campodea) posterior Silvestri, 1932

Campodea (Campodea) posterior Silvestri, 1932: 119, fig. II.

Diagnosis (Silvestri 1932a; Sendra \& Moreno 2004)

Body length 2.2-4.0 mm; epicuticle with thin microdenticles; middle-sized, smooth clothing setae; antennae with 18-28 antennomeres; sensillum of third antennomere in dorsal position; short ( $\mathrm{ma}$, la) and long $(l p)$ barbed notal macrosetae; $l p$ mesonotal slightly longer than $l p$ metanotal in adults; short thin pine cone notal marginal setae; $1+1 l a, 1+1 l p$ macrosetae on VI-VII urotergites; $3+3 l p$ on VIII urotergite and 5+5 lp on IX abdominal segment; cerci covered with long macrosetae with distal barbs and a few clothing setae.

\section{Habitat and distribution}

Soil-dwelling species, well adapted to different soil conditions, found at low and high altitudes up to $3.200 \mathrm{~m}$ a.s.l. It is distributed under the scree slopes in the Sierra Nevada Massif (Sendra et al. 2017a) and spreads around the Baetic Mountain Range in the southern Iberian Peninsula (Silvestri 1932a; Sendra \& Moreno 2004).

Campodea (Campodea) procera Condé, 1948

Campodea (Campodea) procera Condé, 1948b: 45, fig. 1a-f.

Diagnosis (Condé 1948b, 1997; Bareth 2006)

Cave-adapted species; body length 7.0-8.5 mm; middle-sized, smooth clothing setae; antennae with 3539 antennomeres; cupuliform organ with 10-12 complex olfactory chemoreceptors; sensillum of third antennomere in ventral position; middle-sized, robust notal macrosetae poorly barbed; thin pine cone notal marginal setae; $1+1 \mathrm{ma}$ short macrosetae on I-III urotergites, 1+1 long or short ma macrosetae on or IV-VII urotergites, $1+1 l a, 1+1 l p$ on V-VII urotergites, $1+1 \mathrm{mp}, 3+3 \mathrm{lp}$ on VIII urotergite and $1+1 \mathrm{mp}, 5+5 \mathrm{lp}$ on IX abdominal segment; cerci with 9-10 articles covered in long macrosetae and a few clothing setae, only macrosetae of proximal articles with barbs; large spermatozoid fascicles with $60 \mu \mathrm{m}$ diameter and 36-38 $\mu \mathrm{m}$ wide, spiral filament with 4-18 spirals, 580-1800 $\mu \mathrm{m}$ long and 3-3.5 $\mu \mathrm{m}$ diameter.

\section{Habitat and distribution}

Cave-dwelling species found in several caves of the Grands Causses Natural Park and Cévennes National Park, southern France (Condé 1948b, 1997), also collected under stones in the same region (Condé 1948b).

\section{Campodea (Campodea) pseudofragilis Condé, 1984}

Fig. 47

Campodea (Campodea) pseudofragilis Condé, 1984: 177, figs 1b-c, table II.

\section{Diagnosis (Condé 1984)}

Body length 3.0-3.7 mm; epicuticle with microdenticles; short, smooth clothing setae; antennae with 18-20 antennomeres; small sensillum of third antennomere in dorsal position; short $(\mathrm{ma}, \mathrm{la})$ and long $(l p)$ barbed macrosetae; short with apical long barbs notal marginal setae; $1+1$ la macrosetae on $\mathrm{V}$ urotergite (slightly differentiated in some specimens, can disappear as in Ithaca specimens), 1+1 $l a, 1+1 l p$ macrosetae on VI-VII urotergites, $3+3 l p$ on VIII urotergite and $5+5 l p$ on IX abdominal 
segment; cerci bearing for each article, one complete whorl of short macrosetae with one apical barb and numerous short clothing setae.

\section{Taxonomic notes}

The studied material (Supplementary file 2) has allowed to draw the figure of the nota (Fig. 47).

\section{Habitat and distribution}

Soil-dwelling species found at three localities on the borders of the Balkan Peninsula, on Ithaca Island and Achaea, Greece, and in Agiea, Romania (Condé 1984; Sendra et al. 2012).

\section{Campodea (Campodea) pusilla Condé, 1956}

Campodea (Campodea) pusilla Condé, 1956a: 67.

Differential diagnosis from C. (C.) staphylinus (Condé 1956a; Bareth 2006)

Antennae with 18-20 antennomeres; male unknown; cerci covered in short macrosetae and numerous clothing setae. Campodea (C.) pusilla was proposed by Condé (1956a) with a simple differential feature, without formal description, and based on a single female collected in the soil in the Maritimes Alps, southeast France (Condé 1950a).

\section{Habitat and distribution}

See Condé 1956a and Bareth 2006.

Campodea (Campodea) redii Silvestri, 1912

Campodea (Campodea) redii Silvestri, 1912: 112, fig. 1.

\section{Diagnosis (Silvestri 1912)}

Body length 1.5-3.5 mm; epicuticle without microdentricles in Iberian Peninsula specimens; middlesized, smooth clothing setae; antennae with 21-26 antennomeres; sensilla third antennomere in dorsal position (in ventral position in Iberian Peninsula specimens); long, thin and barbed notal macrosetae; long, barbed marginal setae; claws slightly curved; $1+1 l p$ macrosetae on IV urotergite, $1+1 l a, 1+1 l p$ macrosetae on V-VII urotergites, $3+3 l p$ on VIII urotergite and $5+5 l p$ on IX abdominal segment.

\section{Habitat and distribution}

Soil-dwelling species located at several isolated sites in the West of Europe: North of France (Denis 1930), Calabrian Region, Italy (Silvestri 1912) and in Sierra Nevada, the highest massif of the Baetic Mountains in southern Iberian Peninsula (Sendra \& Moreno 2004).

\section{Campodea (Campodea) remyi Denis, 1930}

\section{Campodea (Campodea) remyi Denis, 1930: 31, figs 14-20.}

Diagnosis (Denis 1930; Bareth 1968, 2006)

Body length 4.0-5.0 mm; epicuticle with thin to thick microdenticles; short, smooth clothing setae; antennae with 27-30 antennomeres; sensillum of third antennomere in dorsal position; $1+1 \mathrm{la}, 1+1 \mathrm{lp}$ macrosetae on mesonotum, without macrosetae on metanotum; short, thick notal macrosetae with a few small barbs; thin pine cone notal marginal setae; one small trochanteral sensillum; $1+1 l a, 1+1$ lp macrosetae on VI-VII urotergites, $3+3 l p$ on VIII urotergite and 5+5 lp on IX abdominal segment; first male urosternite with seasonal glandular $g_{1}$-setae and $a_{2}$-setae; cerci longer than body covered in thin, 
smooth macrosetae and shorter and thin clothing setae; spermatozoid fascicles with 40-50 $\mu$ m diameter and 15-20 $\mu \mathrm{m}$ thick, spiral filament with 6-8 spirals, 550-750 $\mu \mathrm{m}$ long and hemispheric section with two lateral expansions.

\section{Taxonomic notes}

A closely related form, a unique female, of $C$. (C.) remyi has been found in Liguria, NW Italy (Supplementary file 2), characterized by a shorter body, less antennomeres (21) and the presence of 1+1 lateral posterior macrosetae on the fifth urotergite; more samples will be needed to confirm this form the f. typ.

\section{Habitat and distribution}

Soil-dwelling species inhabiting the $\mathrm{O}$ and A horizons of the soil among leaf litter in temperate forests of beech, oak and pine trees (Bareth 1986) and also found in mines (Sendra et al. 2013). It occupies some mountain areas in Central Europe around the Ardennes, Vosges and the Black Forest and throughout the Swiss Alps (Wygodzinsky 1941a; Bockmühl 1956; Orelli 1956; Paclt 1961a). It has also been quoted by Blesić $(1996,2000 b)$ in Bosnia-Herzegovina and Serbia but these records need to be confirmed. The quotation by Ionescu $(1951,1955)$ should be considered a misidentification (Sendra et al. 2012).

Campodea (Campodea) rhopalota Denis, 1930

Figs 30, 48

Campodea (Campodea) rhopalota Denis, 1930: 23, figs 1-6.

Diagnosis (Denis 1930; Bareth 2006)

Body length 4.0-5.0 mm; epicuticle with microdenticles; middle-sized clothing setae with a few barbs; antennae 21-24 antennomeres; sensillum of third antennomere in dorsal position; short $(m a, l a)$ and long $(l p)$ robust barbed notal macrosetae; thin pine cone notal marginal setae; 0 or $1+1$ ma macrosetae or sma submacrosetae on I-VII urotergites; $1+1$ la on V, $1+1$ la, $1+1$ l $p$ on VI-VII, $1+1 m p, 3+3 l p$ on VIII and $1+1 \mathrm{mp}, 5+5 \mathrm{lp}$ on IX abdominal segment; male with two separated areas of glandular $g_{I}$-setae; cerci with 7-8 articles covered in long macrosetae with distal barbs but swollen latero-interior macrosetae on proximal articles and a few clothing setae; spermatozoid fascicles with 55-60 $\mu \mathrm{m}$ diameter and 20-25 $\mu \mathrm{m}$ thick, spiral filament with $2 \frac{1}{2}$ to 3 spirals, $350-400 \mu \mathrm{m}$ long and round section $1.5 \mu \mathrm{m}$ in diameter.

\section{Taxonomic notes}

The studied material (Supplementary file 2) has allowed to draw the nota (Fig. 48).

\section{Habitat and distribution}

Soil-dwelling species spreading from the Langres Plateau in northeast France near the French Pyrenees (Denis 1930; Husson 1946; Condé 1947h; Pagés 1951), through the Swiss to eastern Austrian Alps (Wygodzinsky 1941b; Christian 1992).

Campodea (Campodea) sarae Sendra \& Teruel, 2010

Campodea (Campodea) sarae Sendra \& Teruel in Sendra et al., 2010: 45, figs 3-6.

Diagnosis (Sendra et al. 2010)

Body length 2.8-3.6 mm; epicuticle with microdenticles; short, smooth clothing setae; antennae with 20-21 antennomeres; sensillum of third antennomere in ventral position; short ( $m a, l a)$ and long $(l p)$ barbed notal macrosetae; short notal marginal setae with long apical barbs; $1+1$ lp macrosetae on VI-VII urotergites; $3+3 l p$ on VIII urotergite and $5+5 l p$ on IX abdominal segment; cerci covered in long and barbed macrosetae with a few clothing setae, but the latero-internal with one apical barb. 


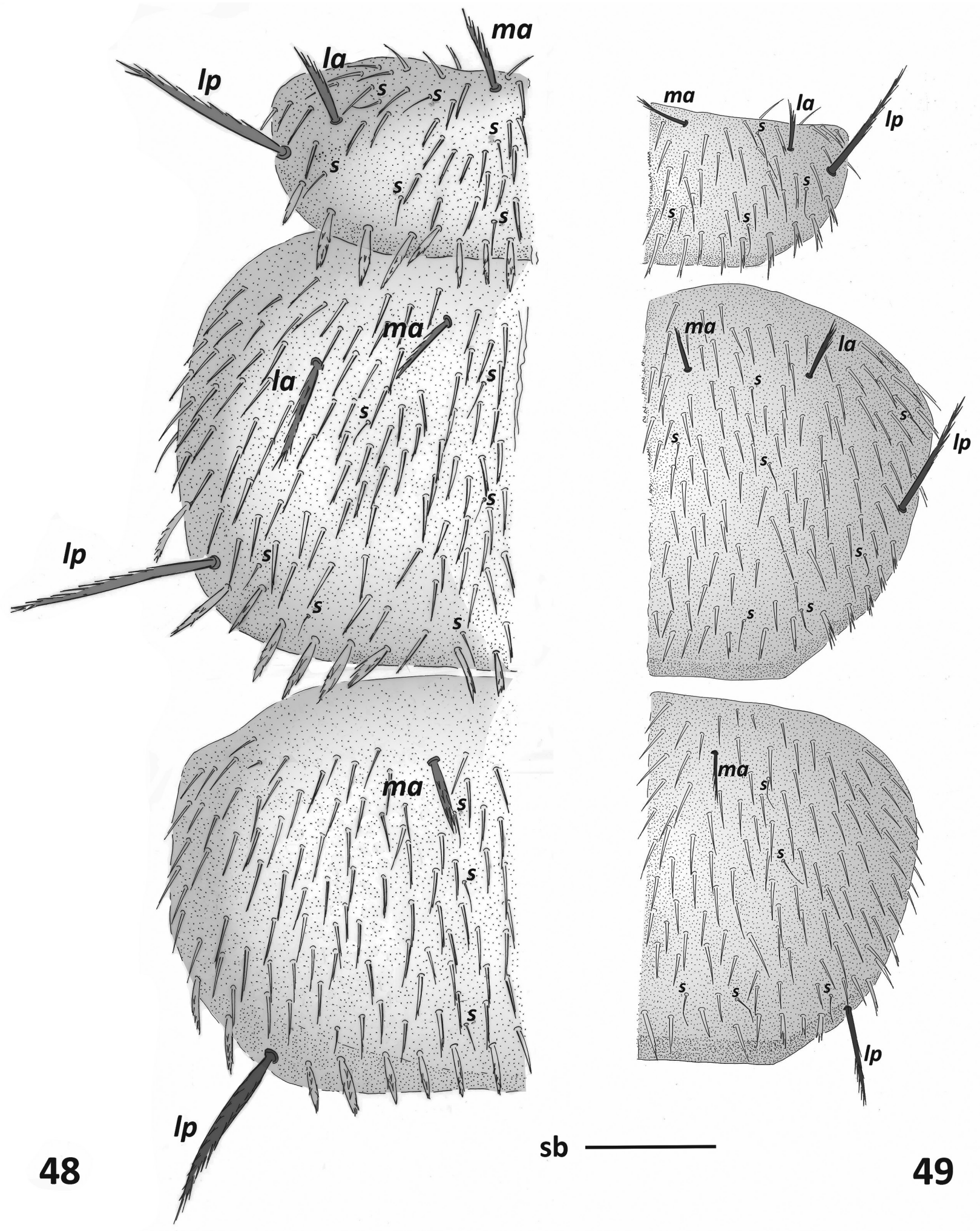

Figs 48-49. - 48. Campodea (Campodea) rhopalota Denis, 1930, ô, $4.0 \mathrm{~mm}$, from Geneva, Switzerland, pronotum, mesonotum and metanotum. - 49. Campodea (Campodea) silvestrii Bagnall, 1918, ㅇ, $2.9 \mathrm{~mm}$, from Greece, pronotum, mesonotum and metanotum. Abbreviations: see Material and methods. Scale bar: $0.1 \mathrm{~mm}$. 


\section{Habitat and distribution}

Soil-dwelling species found at three sites near Denizli in the west of the Anatolian Peninsula (Sendra et al. 2010).

\section{Campodea (Campodea) sardiniensis Bareth, 1980}

Campodea (Campodea) sardiniensis Bareth, 1980: 121, figs Ia-f, IIa-d, IIIa.

\section{Diagnosis (Bareth 1980)}

Body length 2.0-3.5 mm; epicuticle with microdenticles; short, smooth clothing setae; antennae with 20-24 antennomeres; sensillum of third antennomere in ventral position; short ( $\mathrm{ma}$, la) and barbed notal macrosetae; short notal marginal setae with long apical barbs; one trochanteral sensillum; $1+1$ short $m a$ on I-VII urotergites; $1+1 l p$ on IV urotergite, $1+1 l a, 1+1 l p$ on V-VII urotergites; $1+1 \mathrm{mp}, 3+3 l p$ on VIII urotergite and $1+1 \mathrm{mp}, 5+5 \mathrm{lp}$ on IX abdominal segment; cerci covered in short macrosetae similar to clothing setae, but latero-interior macrosetae shorter with distal barb. In the Iberian Peninsula, C. (C.) sardinensis shows some differences to the f. typ. from Sardinia (Sendra \& Moreno 2004): la urotergal macrosetae in backward position; cerci covered in latero-interior macrosetae similar size with others and antennae with 27-31 antennomeres.

\section{Habitat and distribution}

Soil-dwelling species inhabiting humid soils under moss near springs and water zones. The f. typ. has been collected on Sardinia Island (Bareth 1980) but was also quoted in Lazio, Italian Peninsula, by Ramellini (1990). The Iberian population was found between the Aragonese and the coastal Catalan Mountains (Sendra \& Moreno 2004).

Campodea (Campodea) sensillifera Condé \& Mathieu, 1957

Campodea (Campodea) sensillifera Condé \& Mathieu, 1957: 454, figs IV9-17.

Diagnosis (Condé \& Mathieu 1957; Bareth 2006)

Body length 6.0-9.0 mm; clothing setae short with a few thin apical barbs and with 1-2 distal barbs; antennae with 24-30 antennomeres; sensillum of third antennomere in ventral position; five to six simple olfactory chemoreceptors in the cupuliform organ; middle-sized, poorly barbed, robust notal macrosetae; thin pine cone notal marginal setae; until 26 swollen trochanteral sensilla; $1+1$ thick long $m a$ macrosetae on I-VII urotergites; $1+1$ la, $1+1$ l $p$ on V-VII urotergites, $1+1 \mathrm{mp}, 3+3$ lp on VIII urotergite and $1+1 \mathrm{mp}, 5+5 \mathrm{lp}$ on IX abdominal segment; cerci covered in thin macrosetae smooth or with one distal barb and sparse thin clothing setae; large spermatozoid fascicles with 80-100 $\mu$ m diameter, 60-80 $\mu \mathrm{m}$ thick and with spiral filament of 10-14 spirals, 1500-2000 $\mu \mathrm{m}$ long and hemispheric section with lateral expansions of $7-8 \mu \mathrm{m}$ long.

\section{Habitat and distribution}

Soil-dwelling species of large size also inhabiting the MSS habitats in central and western French Pyrenees (Condé \& Mathieu 1957; Bareth 1983).

Campodea (Campodea) silvestrii Bagnall, 1918

Fig. 49

Campodea staphylinus Silvestri, 1912 nec Westwood, 1842: 114, figs II-III.

Campodea (Campodea) silvestrii Bagnall, 1918b: 110, fig. 7a. 
Diagnosis (Silvestri 1912; Bareth 2006)

Body length 2.8-4.1 mm; epicuticle with microdenticles; short, smooth clothing setae; antennae with 19-25 antennomeres; small sensilla of third antennomere in dorsal position; short ( $m a, l a)$ and long $(l p)$ barbed notal macrosetae; short with apical long barbs notal marginal setae; $1+1$ la macrosetae on urotergite $\mathrm{V}, 1+1 l a, 1+1 l p$ on VI-VII urotergites, $3+3 l p$ on VIII urotergite and $5+5 l p$ on IX abdominal segment; males without glandular $a_{2}$-setae; cerci as long as body with 15-17 articles covered in long, thin macrosetae with thin barbs along distal half and a few clothing setae, and latero-inside smooth macrosetae or with one distal barb.

\section{Taxonomic notes}

The studied material (Supplementary file 2) has allowed to draw nota (Fig. 49).

\section{Habitat and distribution}

Soil-dwelling species widely spread from the British Isles (Bagnall 1918b) to the South of the Scandinavian and Jutland peninsulas in the North of Europe (Silvestri 1912; Agrell 1944), throughout Central Europe (Silvestri 1912; Wygodzinsky 1941b; Paclt, 1951, 1956; Condé \& Bareth 1998) and East of Europe (Stach 1928, 1964), including the Dinaric Mountains (Blesić 1984, 1996, 2000b) and towards the south in the Balkan Peninsula (Condé 1984) and to the borders of the Italian Peninsula (Wygodzinsky 1941b).

Campodea (Campodea) silvicola Wygodzinsky, 1941

Fig. 50

Campodea (Campodea) silvicola Wygodzinsky, 1941a: 130, figs 40-49, table 3.

Diagnosis (Wygodzinsky 1941a; Bareth 2006)

Body length 4.0-5.5 mm; epicuticle with microdenticles; clothing setae short and smooth or with tiny distal barb; antennae with 25-27 antennomeres; long subcylindrical sensillum of third antennomere in dorsal position; long, thin, poorly barbed notal macrosetae; short notal marginal setae with a few apical barbs or smooth, slightly different from clothing setae; $1+1$ la macrosetae on V urotergite; $1+1$ la, $1+1$ $l p$ on VI-VII urotergites; $3+3 l p$ on VIII urotergite and $5+5 l p$ on IX abdominal segment; cerci covered in macrosetae with small barbs and sparse clothing setae.

\section{Taxonomic notes}

The studied material (Supplementary file 2) has allowed to draw the nota (Fig. 50).

\section{Habitat and distribution}

Soil-dwelling species found at several sites in the Jura Mountains, Black Forest and Swiss Alps (Wygodzinsky 1941a; Condé 1947h), and possibly in the Dinaric Mountains (Blesić 1984).

Campodea (Campodea) staphylinus Westwood, 1842

Campodea (Campodea) staphylinus Westwood, 1842: 71.

Diagnosis (Bagnall 1918b; Condé \& Bareth 1998; Bareth 2006)

Body length 4.0-5.0 mm; epicuticle with microdenticles; short, smooth clothing setae; antennae with 19-22 antennomeres; sensillum of third antennomere in dorsal or ventral position between $b-c$ and $d-e$ macrosetae; 1+1 ma macrosetae on metanotum; short ( $m a, l a)$ and long $(l p)$ barbed notal macrosetae; short notal marginal setae with long apical setae; one trochanteral sensillum; $1+1 l a, 1+1$ lp macrosetae 


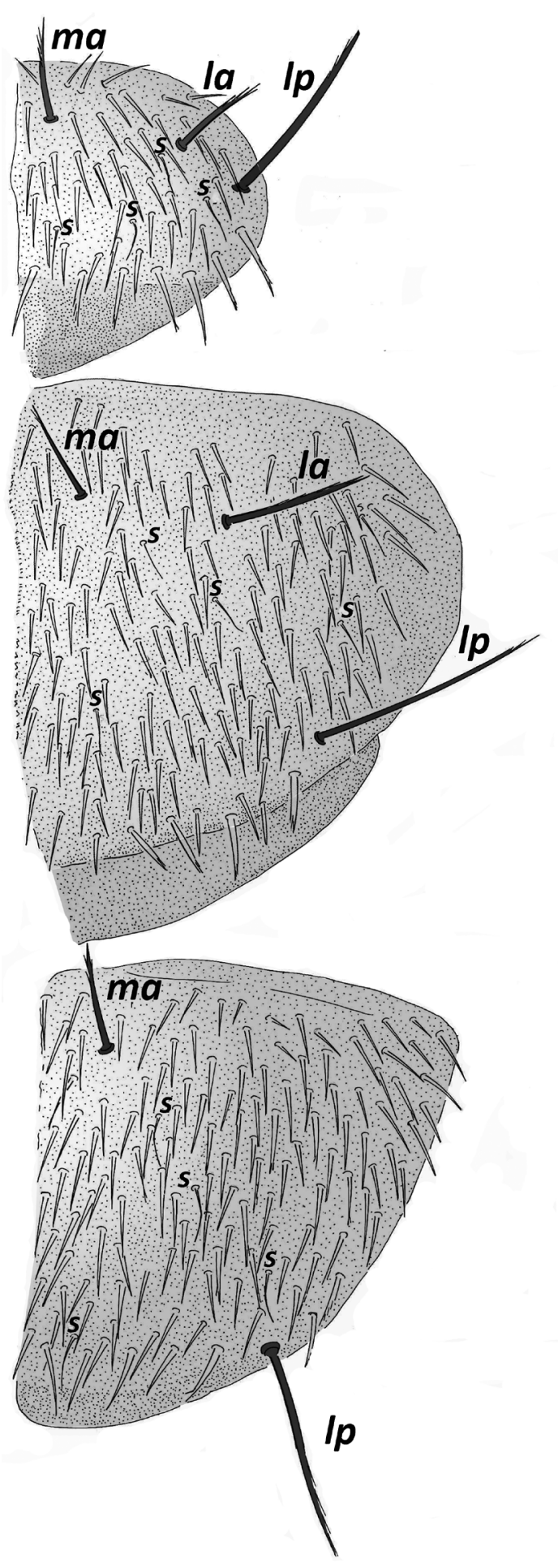

50
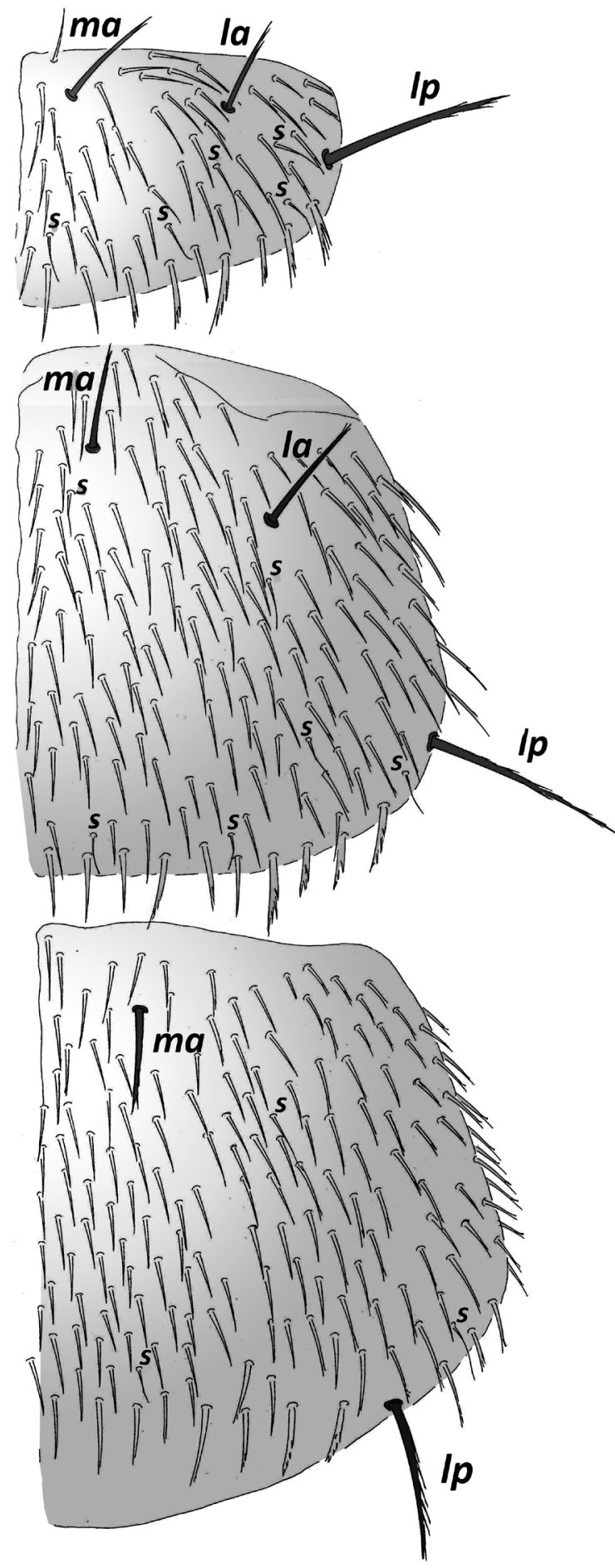

51

Figs 50-51. - 50. Campodea (Campodea) silvicola Wygodzinsky, 1940, đ̂, 4 mm, from Roche Vuti, Switzerland, pronotum, mesonotum and metanotum. - 51. Campodea (Campodea) taunica Marten, 1939, ㅇ, 4.2 mm, from Stâne, Romania, pronotum, mesonotum and metanotum. Abbreviations: see Material and methods. Scale bar: $50=0.2 \mathrm{~mm} ; 51=0.1 \mathrm{~mm}$. 
on VI-VII urotergites, $3+3 l p$ on VIII urotergite and $5+5 l p$ on IX abdominal segment; cerci covered in long macrosetae smooth or with apical barb, on medial and distal articles, and sparse clothing setae; two types of spermatozoid fascicles, in specimens with ventral sensillum of third antennomere: 40-45 $\mu \mathrm{m}$ diameter and 15-20 $\mu \mathrm{m}$ thick, spiral filament with 6-7 spirals, 450-600 $\mu \mathrm{m}$ long and elliptic section 3-4 $\mu \mathrm{m}$ in diameter; in specimens with dorsal sensillum of third antennomere: similar in diameter and thickness but spiral filament turns 10 spirals, is $900-1000 \mu \mathrm{m}$ long and has rectangular section $10 \times 3-4$ $\mu \mathrm{m}$.

\section{Habitat and distribution}

Soil-dwelling species living in the litter of forest soils in the British Isles (Westwood 1842; Bagnall 1918b; Wygodzinsky 1941b; Carpenter 1988) and in the northwestern regions of continental Europe. It occurs in northern and central France from Brittany towards the Central massif (Condé \& Bareth 1998) and reaches its easternmost extension in the Black Forest, Germany (Bockmühl 1956). The reference in Poland by Stach $(1920,1959)$ may be considered a misidentification.

Campodea (Campodea) subdives Silvestri, 1933

Campodea (Campodea) subdives Silvestri, 1933a: 62, figs I-II.

Diagnosis (Silvestri 1933a)

Body length $3.0 \mathrm{~mm}$; epicuticle without microdenticles; short, smooth clothing setae; antennae with 20 to 24 antennomeres (28-29 in female from cave in Mallorca Island; Vadell et al. 2007); sensillum of third antennomere in ventral position; short $(m a, l a)$ and long $(l p)$ barbed notal macorsetae; short with apical long barbs notal marginal setae; $1+1 l a, 1+1 l p$ macrosetae on IV-VII urotergites, $3+3 l p$ on VIII urotergite and $5+5$ lp on IX abdominal segment; cerci from Anatolian specimens covered in long macrosetae on basal articles, short macrosetae on medial and distal articles and numerous clothing; cerci from specimens of cave from Mallorca with long macrosetae with a few clothing setae.

\section{Habitat and distribution}

Soil-dwelling species found in soil habitats at several localities scattered around the Mediterranean Basin: Rhodes Island (Silvestri 1933a), northern Algeria (Condé 1947g), Mallorca Island (Condé 1955c) and southeastern Taurus in the Anatolian Peninsula, Turkey (Sendra et al. 2010). It was also found in an abandoned mine in Luxembourg (Sendra et al. 2013) and a slightly cave-adapted specimen has been collected from a cave in Mallorca Island (Vadell et al. 2007).

Campodea (Campodea) taunica Marten, 1939

Fig. 51

Campodea (Campodea) taunica Marten, 1939: 46.

Diagnosis (Orelli 1956; Bareth 2006; Sendra et al. 2010, 2012)

Body length 4.0-5.0 mm; smooth epicuticle; short, smooth clothing setae; antennae with 19-20 antennomeres; sensillum of third antennomere in dorsal position; short $(m a, l a)$ and long $(l p)$ barbed notal macrosetae; $l p$ mesonotal longer than $l p$ metanotal; slightly thin pine cone marginal setae or only with apical barbs on mesonotum and metanotum; $0+0$ or $1+1$ la macrosetae on $\mathrm{V}$ urotergite, $1+1$ la, $1+1$ $l p$ on VI-VII urotergites, $3+3 l p$ on VIII urotergite and $5+5 l p$ on IX abdominal segment; cerci covered in long macrosetae with several distal barbs but swollen latero-interior macrosetae; small spermatozoid fascicles with $40 \mu \mathrm{m}$ diameter and 8-9 $\mu \mathrm{m}$ thick, spiral filament with 2-3 spirals, $150-230 \mu \mathrm{m}$ long and round section of $1 \mu \mathrm{m}$ diameter. 


\section{Taxonomic notes}

The studied material (Supplementary file 2) allowed to illustrate the nota (Fig. 51).

\section{Habitat and distribution}

Soil-dwelling species spreading around Central Europe: France (Husson 1946; Pagés 1951), central Germany (Paclt 1961a), Swiss Alps (Orelli 1956), and reaching the Romanian Carpathians (Ionescu 1951, 1955; Sendra et al. 2012) and Serbia (Blesić 2000b). Surprisingly, it has not been found yet in the Czech Republic or Slovakia. Outside Central Europe, it has been quoted in the Pontic Mountains, northern Anatolian Peninsula (Sendra et al. 2010).

\section{Campodea (Campodea) tuxeni Wygodzinsky, 1941}

Fig. 5

Campodea (Campodea) tuxeni Wygodzinsky, 1941c: 137, fig. 1.

Diagnosis (Wygodzinsky 1941c)

Body length 3.0-5.5 mm; epicuticle with microdenticles; clothing setae short, thick and smooth or with a few thin distal barbs; antennae with 27-33 antennomeres; large sensillum of third antennomere in dorsal position; long robust barbed notal macrosetae; thin pine cone notal marginal setae; one trochanteral sensillum; $1+1$ la, $1+1$ lp macrosetae on V-VII urotergites, $3+3 l p$ on VIII urotergite and $5+5 l p$ on IX abdominal segment; cerci as long as body covered in long barbed macrosetae and a few clothing setae.

\section{Habitat and distribution}

Should be considered a soil-dwelling species, despite having been recorded for the first time in the Postojana Cave in Slovenia (Tuxen 1930; Wygodzinsky 1941c), this species is spread thourghout the Alps (Condé 1954), Moravia (Rusek 1964) and the Carpathian Mountains (Sendra et al. 2012).

Campodea (Campodea) vihorlatensis Paclt, 1961

Campodea (Campodea) vihorlatensis Paclt, 1961b: 451, figs 1-3, table 1.

Diagnosis (Paclt 1961b)

Body length 1.9-2.3 mm; epicuticle with microdenticles; short, smooth clothing setae; short ( $m a$, la) and long $(l p)$, thin, smooth or with one distal barb notal macrosetae; thin marginal setae smooth or with a tiny and thin distal barb; $1+1$ short $m a$ macrosetae on I-VII urotergites, $3+3 l p$ on VIII urotergite and $5+5 \mathrm{l} p$ on IX abdominal segment; cerci covered in macrosetae with 2-3 distal barbs and a few clothing setae.

\section{Habitat and distribution}

Soil-dwelling species found under stones at different localities of the Slovakian Carpathians (Paclt 1961b; Rusek, 1964) and in Liguria, northwestern Italy.

\section{Campodea (Campodea) wallacei Bagnall, 1918}

Fig. 52

Campodea (Campodea) simulatrix Wygodzinsky, 1941: 68, fig. 2.

Campodea (Campodea) wygodzinskii Rusek, 1966: 364, figs 71-85. Syn. nov.

Campodea (Campodea) wallacei Bagnall, 1918a: 158. 


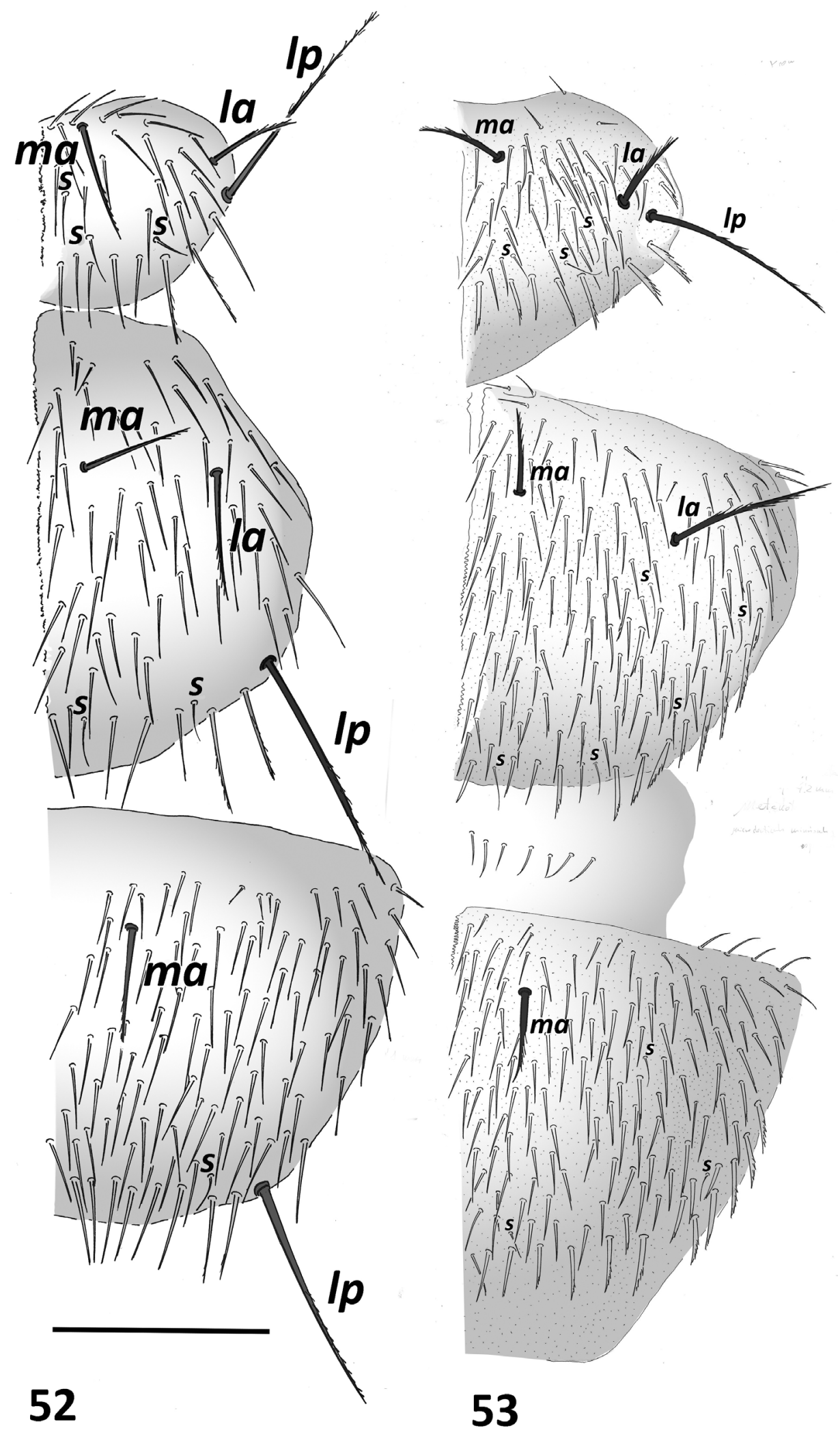

Figs 52-53. - 52. Campodea (Campodea) wallacei Bagnall, 1918, ๆ, 3.9 mm, from Geneva, Switzerland, pronotum, mesonotum and metanotum. - 53. Campodea (Dicampa) frenata Silvestri, 1931, §̂, $4.2 \mathrm{~mm}$, from Sinaia, Romania, pronotum, mesonotum and metanotum. Abbreviations: see Material and methods. Scale bar: $52=0.2 \mathrm{~mm} ; 53=0.1 \mathrm{~mm}$. 
Diagnosis (Bagnall 1918a; Bareth \& Condé 1985; Bareth 2006)

Body length 3.0-4.0 mm; epicuticle without microdenticles; long, thin, smooth clothing setae; antennae with 24-30 (31-32 in specimens found in caves); large sensillum of third antennomere in dorsal position; long, thin barbed notal macrosetae; long, thin barbed notal marginal setae; $1+1 l a, 1+1 l p$ macrosetae on V-VII urotergites, $3+3 l p$ on VIII urotergite and $5+5 l p$ on IX abdominal segment; cerci covered in long macrosetae and a few clothing setae; spermatozoid fascicles 45-50 $\mu$ m diameter and 10-15 $\mu \mathrm{m}$ thick, spiral filament with $4-5$ spirals, $560-600 \mu \mathrm{m}$ long and 3-4 $\mu \mathrm{m}$ elliptic shaped in widest section.

\section{Taxonomic notes}

We propose C. (C.) wygodzinskii Rusek, 1966 as a synonym of C. (C.) wallacei Bagnall, 1966, based on the number of the barbs present in the stylus setae, which are very variable intraspecifically and therefore cannot be used to separate this species. The same is valid for C. (C.) simulatrix Wygodzinsky, 1941, a synonym already proposed by Bareth (2006) due to the poor support to separate this species from $C$. (C.) wallacei based on the reduction of barbs on the notal macrosetae (Fig. 52).

\section{Habitat and distribution}

Soil-dwelling species, which is also found in cave habitats (Condé 1956a, 1962; Sendra et al. 2013). It is distributed in England (Bagnall 1918a), southern Scandinavian Peninsula (Agrell 1944), the Maritime Alps (Bareth \& Condé 1985; Ramellini 2000), France (Condé 1947d, 1947h, 1950a; Pagés 1951), Germany (Christian 2003) and around the Dinaric Mountains (Blesić 1998a, 1998b, 2000b, 2001).

Campodea (Campodea) westwoodi Bagnall, 1918

Campodea (Campodea) westwoodi Bagnall, 1918: 112, figs 1, 9.

Diagnosis (Bagnall 1918b; Condé \& Bareth 1998; Bareth 2006)

Body length 1.8-5.7 mm; epicuticle with tiny microdenticles; clothing setae short and thick with a few apical barbs; antennae with 18-22 antennomeres; sensillum of third antennomere in dorsal position; short, robust notal macrosetae with a few barbs; $l p$ metanotal similar in size and shape to marginal setae; short, thick marginal setae smooth or with 2-3 barbs; one small trochanteral sensillum; 0-1 short la macrosetae on V urotergite, $1+1 l a, 1+1 l p$ on VI-VII urotergites, $3+3 l p$ on VIII urotergite and $5+5 l p$ on IX abdominal segment; cerci with 8-10 articles, each one subdivided in 4-5, covered in whorls of thin macrosetae bent forward and backward and surrounded by a few clothing setae.

\section{Habitat and distribution}

Soil-dwelling species generally found within the litter (Condé \& Bareth 1998). It is known from England (Bagnall 1918b) to northeastern France up to the Paris Basin (Condé \& Bareth 1970, 1998).

Campodea (Campodea) zuluetai Silvestri, 1932

Campodea (Campodea) zuluetai Silvestri, 1932: 128, fig. VI.

Diagnosis (Silvestri 1932a ; Condé \& Mathieu 1957)

Body length 2.5-5.0 mm; epicuticle without microdenticles; long, smooth clothing setae; antennae with 20-29 antennomeres; sensillum of third antennomere in dorsal or ventral position; long, barbed notal macrosetae with barbs along the distal two-thirds distal; marginal setae with long apical barbs; $1+1 \mathrm{ma}$ macrosetae on I-VII urotergites with very variable length (all $m a$ macrosetae short or slightly longer form the anterior urotergites to the posterior ones, the short ma macrosetae less barbed than longer 
ones); $1+1$ la, $1+1 l p$ on V-VII urotergites; $1+1 \mathrm{mp}, 3+3 \mathrm{lp}$ on VIII urotergite and $1+1 \mathrm{mp}, 5+5 \mathrm{lp}$ on IX abdominal segment; cerci covered in long macrosetae almost from basis and a few clothing setae.

Specimens from populations inhabiting cave habitats have antennae with 30-41 antennomeres, and moreover six to eight complex olfactory chemoreceptors inside the cupuliform organ (Condé 1951b; Sendra \& Moreno 2004). Other specimens from different populations collected at several localities in the southeast of the Iberian Peninsula show the la macrosetae on V-VII urotergites in a backward insertion, almost medial posterior position (Sendra 1989b, Sendra \& Moreno 2004). Two types of spermatozoid fascicles in two different populations of $C$. zuluetai have been described: the specimens from Ariège (France) with 24-29 antennomeres, sensillum of third antennomere in ventral position and ma urotergal macrosetae reaching the basis of marginal setae from the IV urotergite, and the specimens from the southeast of the Iberian Peninsula with la macrosetae of urotergites in backward position. Both have similar spermatozoid fascicles: small spermatozoid fascicles with $30-40 \mu \mathrm{m}$ in diameter and $3 \mu \mathrm{m}$ thick, spiral filament with $1 \frac{1 / 2}{2}$ to 2 spirals, 200-250 $\mu \mathrm{m}$ long and round shaped with $1 \mu \mathrm{m}$ in widest section (Bareth 2006; Sendra 1988). It is clear to conclude that such a high degree of variability in different populations in C. zuluetai will need to be throroughly reviewed.

\section{Habitat and distribution}

Inhabits soil and cave environments. It has been collected in caves and found under scree slopes (MSS) in Ariège, Pyrenées (Bareth 1983) and Guadarrama National Park (Sendra et al. 2017a). Some specimens collected in caves show hyperthrophy of the cave-adapted traits. It was also found at high-altitude, $2785 \mathrm{~m}$ a.s.1. in the Cangou peak, Pyrenees (Condé \& Mathieu 1957). It is distributed in a large area in the eastern Iberian Peninsula, from the French Pyrenees to the Baetic Mountains, including the Central System Massif (Condé 1951b; Condé \& Mathieu 1957; Sendra \& Moreno 2004). It was also found in two caves in Menorca, and in Sardinia where it seems to be abundant in the soil (Bareth 1980).

Subgenus Dicampa Silvestri, 1932

Dicampa Silvestri, 1932a: 116.

\section{Diagnosis (Silvestri 1932a; Condé 1956a)}

Notal formula with $1+1 m a, 1+1$ la, $1+1$ lp macrosetae on pronotum; $1+1 m a, 1+1$ la on mesonotum and 1+1 $m a$ on metanotum; epicuticle with microdenticles in all species reviewed with exception in one troglobitic species (C. (D.) melici Sendra, 2015); dorsal and lateral tarsal setae smooth; $0+0$ or $1+1$ lp and $0+0$ or $1+1$ la macrosetae on V-VII urotergites; $3+3(2+2)$ lp macrosetae on VIII urotergite; $5+5$ $(4+4) l p$ macrosetae on IX abdominal segment; $0+0$ or $1+1 \mathrm{ma}$ macrosetae on urotergites I-IX; first urosternite with $6+6$ macrosetae, $4+4$ on II-VII urosternites, $1+1$ on VIII urosternite; first urosternite of male with glandular $g_{1}$-setae, subtrapezoidal appendages with glandular $a_{1}$ and $a_{2}$-setae; female with subcylindrical appendages with glandular $a_{1}$-setae.

\section{Habitat and distribution}

The genus Dicampa includes 33 mostly soil-dwelling species (Condé 1956a), except three caveadapted species: (C. (D.) taurica, C. (D.) neuherzi and C. (D.) melici). It is well distributed around the Mediterranean Basin, three of its islands and the Black Sea territories included (Silvestri 1949; Rusek 1965a; Sendra et al. 2006) (Fig. 59). Its presence outside this distribution area should be reviewed. Species of Dicampa have a preference for territories under influence of the Mediterranean climate, mostly dwelling in the B horizon. In general, species of Dicampa show clear adaptations to the endogean habitat: small body size, short appendages, reduction in the number of antennomeres, cercal articles and presence hick and abundant microdenticles and short clothing setae in the epicuticle (Sendra et al. 2017a). 


\section{Taxonomic key for species of the subgenus Dicampa}

1. Lateral posterior macrosetae of the eighth macrosetae $3+3$; lateral posterior macrosetae of the ninth

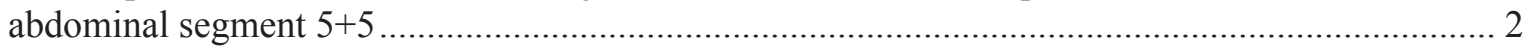

- Lateral posterior macrosetae of the eighth macrosetae $2+2$; lateral posterior macrosetae of the ninth

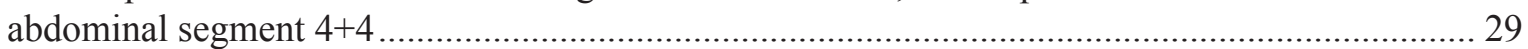

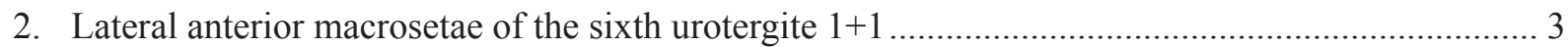

- Without lateral anterior macrosetae of the sixth urotergite............................................................ 19

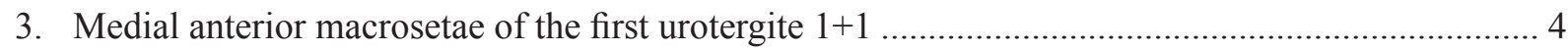

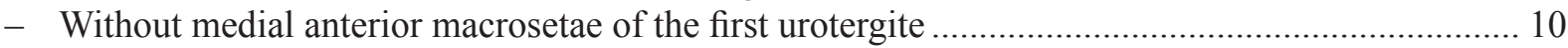

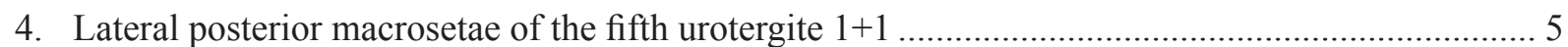

- Without lateral posterior macrosetae of the fifth urotergite ............................................................... 7

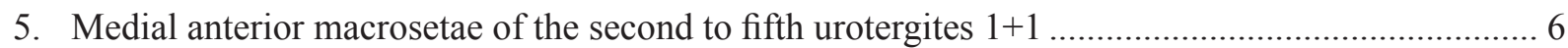

- Without medial anterior macrosetae of the second to fifth urotergites ...........................................

6. Medial anterior macrosetae of the eighth urotergite $1+1$; medial anterior macrosetae of the ninth abdominal segment 1+1; without lateral anterior and lateral posterior macrosetae of the fourth urotergite

Campodea (Dicampa) codinai Silvestri, 1932

- Without medial anterior macrosetae of the eighth urotergite; without medial anterior macrosetae of the ninth abdominal; lateral anterior macrosetae of the fourth urotergite 1+1; lateral posterior macrosetae of the fourth urotergite $1+1$.

Campodea (Dicampa) pardoi Silvestri, 1932

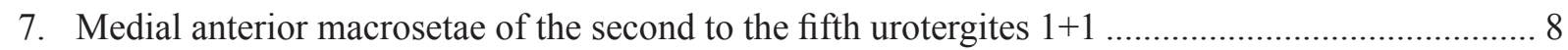

- Without medial anterior macrosetae of the second to the fifth urotergites

Campodea (Dicampa) davidi Condé, 1952

8. Lateral anterior macrosetae of the fifth urotergite $1+1$

Campodea (Dicampa) gestroi Silvestri, 1912

- Without lateral anterior macrosetae of the fifth urotergite

9. Antennomeres 21-25; marginal setae short with long apical barbs .

Campodea (Dicampa) insulana Condé, 1952

- Antennomeres 16-20; marginal setae short smooth or with a few small apical barbs

Campodea (Dicampa) pagesi Condé \& Pagés, 1957

10. Lateral anterior macrosetae of the fifth urotergite $1+1$

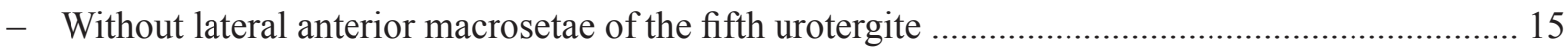

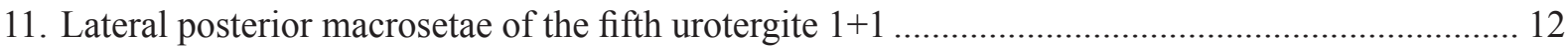

- Without lateral posterior macrosetae of the fifth urotergite........................................................... 13

12. Cerci covered with short barbed macrosetae and abundant short smooth setae; notal macrosetae short barbed (medial anterior and pronotal lateral anterior) and longer barbed (lateral posterior and mesonotal lateral anterior); marginal setae short with long apical barbs

Campodea (Dicampa) aristotelis Silvestri, 1912

- Cerci covered with long barbed macrosetae and a few smooth shorter setae; notal macrosetae short (medial anterior, lateral anterior) with a few barbs and long (lateral posterior) barbed; marginal setae short with a few short apical barbs

Campodea (Dicampa) apula Silvestri, 1912 
- Cerci covered with long barbed macrosetae and a few shorter smooth setae, in adittion to swollen latero-interior macrosetae on the basal articles; notal macrosetae middle sized, thin barbed; marginal setae short smooth or with a few small apical barbs

Campodea (Dicampa) malpighii Silvestri, 1912

13. Lateral posterior macrosetae of the sixth urotergite $1+1$; male $a_{2}$ glandular setae present

- Without lateral posterior macrosetae of the sixth urotergite; male $a_{2}$ glandular setae absent

Campodea (Dicampa) campestris Ionescu, 1955

14. Antennomeres 46-50; marginal setae long, thin, pine cone shaped; cave-adapted features Body shape; cupuliform organ with 11-15 chemoreceptor sensilla......

Campodea (Dicampa) aff. plagiaria Silvestri, 1932

- Antennomeres 26-30; marginal setae short, thin, pine cone shaped; non-cave-adapted body shape; cupuliform organ with 4-5 chemoreceptor sensilla.

Campodea (Dicampa) plagiaria Silvestri, 1932

15. Lateral posterior macrosetae of the fifth urotergite $1+1$

Campodea (Dicampa) neusae Sendra \& Moreno, 2006

- Without lateral posterior macrosetae of the fifth urotergite ........................................................... 16

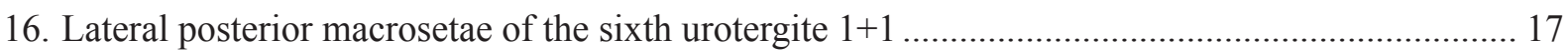

- Without lateral posterior macrosetae of the sixth urotergite.

Campodea (Dicampa) azkarraga Sendra, 2006

17. Notal macrosetae middle sized, barbed

Campodea (Dicampa) sprovieri Silvestri, 1933

- Notal macrosetae middle sized, robust almost covered with barbs

Campodea (Dicampa) frenata Silvestri, 1931

- Notal macrosetae short (medial anterior, lateral anterior) with a few barbs and long (lateral posterior) barbs.....

18. Antennomeres $26-35$

Campodea (Dicampa) egreria Condé, 1953

- Antennomeres 21-25 Campodea (Dicampa) propinqua Silvestri, 1932

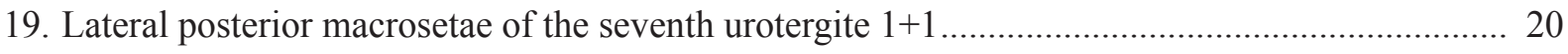

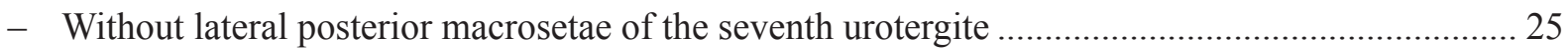

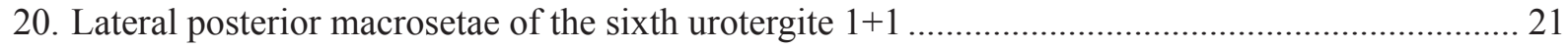

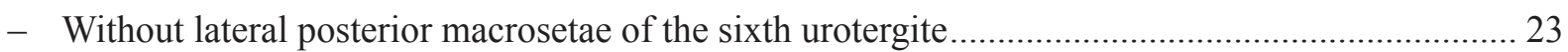

21. Lateral posterior macrosetae of the fifth urotergite $1+1$

Campodea (Dicampa) lusitana Wygodzinsky, 1944

- Without lateral posterior macrosetae of the fifth urotergite

22. Marginal setae short robust completely barbed. Campodea (Dicampa) neuherzi Condé, 1996

- Marginal setae short with a few short apical barb

Campodea (Dicampa) crimeaensis Rusek, 1965 (from type locality)

- Marginal setae short thin pine cone shape Campodea (Dicampa) condei Rusek, 1965 
23. Lateral anterior macrosetae of the seventh urotergite $1+1$

Campodea (Dicampa) caucasica Rusek, 1965

- Without lateral anterior macrosetae of the seventh urotergite 24

24. Notal macrosetae long robust poorly barbed; marginal setae long with a few small apical barbs

Campodea (Dicampa) taurica Silvestri, 1949

- Notal macrosetae middle sized, poorly barbed; marginal setae short smooth or with a few small apical barbs ..... Campodea (Dicampa) imeretinensis Chevrizov, 1976

- Notal macrosetae middle sizre robust almost covered with barbs; marginal setae short thin pine cone shape Campodea (Dicampa) jolyi Condé, 1948

25. Medial anterior macrosetae of the first urotergite $1+1$ 26

- Without medial anterior macrosetae of the first urotergite 28

26. Medial anterior macrosetae of the second to fifth urotergites $1+1$ 27

- Without medial anterior macrosetae from the second to the fifth urotergite

Campodea (Dicampa) aemula Condé, 1953

27. Cerci covered with long barbed macrosetae and a few smooth and shorter setae; notal macrosetae long, robust, poorly barbed; cave-adapted body shape; $a_{2}$ glandular setae present in female

Campodea (Dicampa) melici Sendra, 2015

- Cerci covered with short macrosetae and abundant short, smooth setae; notal macrosetae short (medial anterior, lateral anterior) with a few barbs and long (lateral posterior) barbs; non-caveadapted body shape; $a_{2}$ glandular setae absent in female

Campodea (Dicampa) escalerai Silvestri, 1932

28. $a_{2}$ glandular setae absent in female

Campodea (Dicampa) catalana Denis, 1930

- $a_{2}$ glandular setae present in female Campodea (Dicampa) merceti Silvestri, 1932

29. Medial anterior macrosetae of the first to fourth urotergites $1+1$

Campodea (Dicampa) boneti Silvestri, 1932

- Without medial anterior macrosetae of the first to fourth urotergites

Campodea (Dicampa) blancae Sendra \& Moreno, 2006

Campodea (Dicampa) aemula Condé, 1953

Campodea (Dicampa) aemula Condé, 1953b: 365, fig. 2a-i.

Diagnosis (Condé 1953b; Sendra 1989b)

Body length 2.0-3.0 mm; epicuticle with abundant microdenticles; short, smooth clothing setae; antennae with 17-18 antennomeres; sensillum of third antennomere in ventral position; short ( $m a, l a)$ with a few barbs and long barbed ( $l p$ ) notal macrosetae; $1+1 \mathrm{ma}$ macrosetae on I urotergite, $3+3$ lp on VIII urotergite and $5+5 l p$ on IX abdominal segment; cerci shorter than body covered in short barbed macrosetae and abundant short, smooth setae, in adittion to swollen or truncated latero-interior macrosetae on the basal article.

\section{Habitat and distribution}

A soil-dwelling species adapted to the B horizon of the soil, having a Baetic-Riffean distribution, from East Morocco (Condé 1953b) to the Maestrazgo Massif in the eastern Iberian Mountains (Sendra 1989b; Sendra \& Moreno 2006). 
Campodea (Dicampa) apula Silvestri, 1912

Campodea (Dicampa) apula Silvestri, 1912: 134, fig. XX.

Diagnosis (Silvestri 1912; Paclt 1961a)

Body length 2.6-3.2 mm; short, smooth clothing setae; antennae with 21-25 antennomeres; short ( $\mathrm{ma}$, $l a$ ) with a few barbs and long $(l p)$ barbed notal macrosetae; short, with a few apical barbs notal marginal setae; $1+1 l a, 1+1 l p$ macrosetae on V-VII urotergites, $3+3 l p$ on VIII urotergite and $5+5 l p$ on IX abdominal segment; cerci shorter than body with 10 articles covered in long macrosetae, with barbs and a few shorter smooth setae.

\section{Habitat and distribution}

Soil-dwelling species known from Foggia, Italy (Silvestri 1912), the Carpathian Mountains across Slovakia, Poland and Romania (Ionescu 1951, 1955; Paclt 1961a; Szeptycki 1974), reaching the eastern border of the Caucasus.

Campodea (Dicampa) aristotelis Silvestri, 1912

Campodea (Dicampa) aristotelis Silvestri, 1912: 135, figs XXI-XXII.

Diagnosis (Silvestri 1912 ; Condé 1984; Sendra et al. 2006)

Body length 4-4.5 mm; short, smooth clothing setae; antennae with 19-24 antennomeres; sensillum of third antennomere in dorsal position; short barbed (medial anterior and pronotal lateral anterior) and longer barbed (lateral anterior and mesonotal lateral anterior) notal macrosetae; short, with long apical barbs notal marginal setae; $1+1 l a, 1+1$ lp macrosetae on V-VII urotergites; $3+3 l p$ on VIII urotergite and $5+5 \mathrm{lp}$ on IX abdominal segment; cerci shorter than body covered in short macrosetae with barbs and abundant short smooth setae.

\section{Habitat and distribution}

Soil-dwelling species found in the southern Balkan Peninsula, Ionian Islands included (Condé 1984) and at two localities in the northeast Anatolian Peninsula (Sendra et al. 2006).

Campodea (Dicampa) azkarraga Sendra, 2006

Campodea (Dicampa) azkarraga Sendra, 2006: 699, figs 2-3, 4a-c, tables 3-5.

Diagnosis (Sendra et al. 2006, 2010)

Body length 2.2-2.9 mm; epicuticle with abundant microdenticles; short, smooth clothing setae; antennae with 18-20 antennomeres; sensillum of third antennomere in dorsal position; short ( $m a$, la), poorly barbed and long $(l p)$, barbed macrosetae; short, with long apical barbs to smooth notal marginal setae; $1+1$ la macrosetae on VI urotergite, $1+1$ la, $1+1$ lp on VII urotergite, $3+3$ l $p$ on VIII urotergite and $5+5$ lp on IX abdominal segment; cerci half of body length with 8-11 articles; proximal cercal articles covered in long barbed macrosetae and a few shorter smooth setae, but distal articles having short macrosetae with one distal barb and abundant short smooth setae; small spermatozoid fascicles 25-30 $\mu \mathrm{m}$ in diameter, spiral filament with $2-3$ spirals, $120-180 \mu \mathrm{m}$ long and $1 \mu \mathrm{m}$ diameter.

\section{Habitat and distribution}

Soil-dwelling species well adapted to endogean habitats. It is known from several localities in the northern Anatolian Peninsula (Sendra et al. 2006, 2010). 
Campodea (Dicampa) blancae Sendra \& Moreno, 2006

Campodea (Dicampa) blancae Sendra \& Moreno, 2006: 77, figs 8-9, table VI.

Diagnosis (Sendra \& Moreno 2006)

Body length 2.1-2.4 mm; epicuticle with microdenticles; short, smooth clothing setae; antennae with 18-19 antennomeres; sensillum of third antennomere in ventral position; short ( $\mathrm{ma}$, la) with a few barbs and long barbed $(l p)$ notal macrosetae; short smooth or with a few small apical barbs marginal setae; $2+2$ long $l p$ macrosetae on VIII urotergite and $4+4 l p$ on IX abdominal segment; cerci half of body length covered in long macrosetae with barbs in distal half and a few shorter smooth clothing setae.

\section{Habitat and distribution}

Soil-dwelling species inhabiting in the North of the Iberian Peninsula (Sendra \& Moreno 2006).

Campodea (Dicampa) boneti Silvestri, 1932

Campodea (Dicampa) boneti Silvestri, 1932: 151, fig. XVI.

Diagnosis (Silvestri 1932a; Sendra 1989a)

Body length 1.8-2.4 mm; epicuticle with microdenticles; short, smooth clothing setae; antennae with 15-17 antennomeres; sensillum of third antennomere in dorsal or ventral position; short ( $\mathrm{ma}, \mathrm{la}$ ) poorly barbed and long barbed $(l p)$ notal macrosetae; notal marginal setae short, with apical long barbs; $1+1$ short $m a$ macrosetae on I-VII urotergites, $1+1$ short $m a, 2+2 l p$ on VIII urotergite and $1+1$ short $m a, 4+4$ $l p$ on IX abdominal segment; female with glandular $a_{2}$-setae; cerci less than half of body length with 8-9 articles covered in long barbed in distal half of macrosetae and a few shorter, smooth setae, in adittion to swollen latero-interior macrosetae on the basal article.

\section{Habitat and distribution}

Soil-dwelling species, well adapted to endogean habitats, distributed in the northeastern Iberian Peninsula (Silvestri 1932a; Sendra 1989a; Sendra \& Moreno 2006).

Campodea (Dicampa) campestris Ionescu, 1955

Campodea (Dicampa) campestris Ionescu, 1955: 36, fig. 14.

Diagnosis (Ionescu 1955, Rusek 1965b, Sendra et al. 2012)

Body length 2.1-3.6 mm; epicuticle with microdenticles; short, smooth clothing setae; antennae with 18-25 antennomeres; sensillum of third antennomere in ventral position (dorsal in Bulgarian specimens); short ( $m a, l a)$ with a few barbs and long $(l p)$ barbed notal macrosetae; short, with long apical barbs notal marginal setae; $1+1$ la macrosetae on V-VI urotergites, $1+1 l a, 1+1 l p$ on VII urotergite, $3+3 l p$ on VIII urotergite and $5+5 \mathrm{lp}$ on IX abdominal segment; males without glandular $a_{2}$-setae on the appendages; cerci (in juveniles) with long macrosetae with thin barbs.

\section{Habitat and distribution}

Soil-dwelling species distributed from the southern Carpathians to the Balkan Mountains (Rusek 1965b; Blesić 1984, 1998a, 2000b; Sendra et al. 2012). 
Campodea (Dicampa) catalana Denis, 1930

Figs 1-4, 19-22

Campodea (Dicampa) catalana Denis, 1930: 28, figs 7-13.

Diagnosis (Denis 1930; Condé \& Mathieu 1957; Sendra \& Jiménez 1983; Sendra \& Moreno 2006)

Body length 2.5-4.0 mm; epicuticle with microdenticles; short, smooth clothing setae; antennae with 18-26 antennomeres, with up to 31 in populations inhabiting shallow subsurface habitats, such as the MSS (Sendra et al. 2017a); sensillum of third antennomere in dorsal position, smaller and in ventral position in several populations in the northeast of the Iberian Peninsula; cupuliform organ with four simple olfactory chemoreceptors but increasing in number in specimens from MSS habitats; short ma and $l a$ notal macrosetae with a few barbs and long $l p$ notal macrosetae with barbs along distal half; marginal setae with long apical barbs; $3+3 l p$ macrosetae on VIII urotergite, $5+5 l p$ on IX abdominal segment; cerci shorter than body and covered in long macrosetae with barbs along distal half to twothirds and a few shorter, smooth setae, but in proximal articles with latero-interior macrosetae ending in sharp shape to slightly swollen.

\section{Taxonomic notes}

The studied material (Supplementary file 2) has allowed to photograph some structures under SEM (Figs 2-4, 19-22).

\section{Habitat and distribution}

Soil-dwelling species inhabiting all layers of the soil, and the MSS on scree slopes (Sendra et al. 2017a), from the sea level to the highest mountains of the Iberian Peninsula under Mediterranean climate (Denis 1930; Condé \& Mathieu 1957; Sendra \& Jiménez 1983; Sendra \& Moreno 2006).

\section{Campodea (Dicampa) caucasica Rusek, 1965}

Campodea (Dicampa) cancasica Rusek, 1965a: 1352, figs 7-18.

Diagnosis (Rusek 1965a)

Body length $3.4 \mathrm{~mm}$; short, smooth clothing setae; antennae with 21 antennomeres; short $(\mathrm{ma}, \mathrm{la})$ and long $(l p)$, poorly barbed notal macrosetae; slightly thin pine cone notal marginal setae; $1+1 l a, 1+1 l p$ macrosetae on VII urotergite and $3+3$ lp on VIII abdominal segment.

\section{Habitat and distribution}

Soil-dwelling species found in a forest near Sochi, southwestern Russia (Rusek 1965a).

Campodea (Dicampa) codinai Silvestri, 1932

Campodea (Dicampa) codinai Silvestri, 1932: 146, fig. XIII.

Diagnosis (Silvestri 1932a; Sendra 1989a)

Body length $3.0 \mathrm{~mm}$ short clothing setae; antennae with 22 antennomeres; sensillum of third antennomere in dorsal or ventral position; short barbed ( $m a$, la pronotal) and longer barbed (la mesonotal and $l p$ ) notal macrosetae; short barbed notal marginal setae; $1+1$ short ma macrosetae on I-VII urotergites, $1+1$ la, $1+1 l p$ on V-VII urotergites, $1+1$ short $m a, 3+3 l p$ on VIII urotergite and $1+1$ short $m a, 5+5 l p$ on IX abdominal segment. 


\section{Habitat and distribution}

Soil-dwelling found around in the western Mediterranean region in four localities, three in the east of the Iberian Peninsula and one in Lazio, in central Italy (Silvestri 1932a; Sendra 1989a; Ramellini 1990).

\section{Campodea (Dicampa) condei Rusek, 1965}

Campodea (Dicampa) condei Rusek, 1965a: 1351, figs 3(1-12), 4(1-6).

\section{Diagnosis (Rusek 1965a)}

Body length $3.0 \mathrm{~mm}$; short, smooth clothing setae; antennae with 20-25 antennomeres; sensillum of third antennomere in dorsal position; middle-sized, robust notal macrosetare almost completely covered with short barbs notal macrosetae; short thin pine cone notal marginal setae; $1+1 l p$ macrosetae on VIVII urotergites, $3+3 l p$ on VIII urotergite and $5+5 l p$ on IX abdominal segment; cerci covered in long macrosetae with distal barbs and a few clothing setae.

\section{Habitat and distribution}

Soil-dwelling species distributed in southwestern Russia, near the coast of the Black Sea (Rusek 1965a).

Campodea (Dicampa) crimeaensis Rusek, 1965

Campodea (Dicampa) crimeaensis Rusek, 1965a: 1354, figs 5(3-18), 4(1-6).

\section{Diagnosis (Rusek 1965a)}

Body length 2.8-3.0 mm; short, smooth clothing setae; antennae with 28 antennomeres; short ( $m a$, la) and long $(l p)$ poorly barbed notal; notal marginal setae short, smooth or with a few apical barbs; $1+1$ lp macrosetae on VI-VII urotergites, $3+3 l p$ on VIII urotergite and $5+5 l p$ on IX abdominal segment. The specimens of C. (D.) crimeaensis studied (Sendra et al. 2006) and collected from the Anatolian Peninsula show some differences from the original description such as antennae with 20-25 antennomeres, notal macrosetae with more abundant barbs and thin pine cone notal marginal setae. In addition to small spermatozoid fascicles with 35-45 $\mu \mathrm{m}$ diameter, spiral filament with 5 spirals, 900-1000 $\mu \mathrm{m}$ long and $1 \mu \mathrm{m}$ diameter, as observed.

\section{Habitat and distribution}

Soil-dwelling species found at both sides of the Black Sea, in the Crimean Peninsula (Rusek 1965a) and in the Anatolian Peninsula (Sendra et al. 2006).

Campodea (Dicampa) davidi Condé, 1952

Campodea (Dicampa) davidi Condé, 1952a: 356, fig. 2a-j.

Campodea (Dicampa) davidi crassa Condé, 1952a: 362, fig. Ic-d.

Diagnosis (Condé 1952a, 1953b; Sendra \& Moreno 2006)

Body length 2.0-3.1 mm; short, smooth clothing setae; antennae with 18-24 antennomeres; small sensillum of third antennomere in ventral position; short $(m a, l a)$ with a few and long $(l p)$ barbed notal macrosetae; thin pine cone notal marginal setae; one trochanteral sensillum; $1+1 \mathrm{ma}$ macrosetae on I urotergite, 0 or $1+1$ la on V urotergite; $1+1$ la on VI urotergite, $1+1$ la $1+1$ lp on VII urotergite, $3+3$ lp on VIII urotergite and $5+5 \mathrm{lp}$ on IX abdominal segment; cerci twice shorter than body with 8-10 articles covered in long macrosetae with barbs and a few shorter, smooth setae; spermatozoids fascicles $50 \mu \mathrm{m}$ diameter and $25-30 \mu \mathrm{m}$ of inner diameter. 


\section{Habitat and distribution}

Soil-dwelling species adapted to an endogean life-style, distributed in northern Africa, in Morocco and Algeria (Condé 1952a, 1953b), and in the Grazalema Mountains, in the southern Iberian Peninsula (Sendra \& Moreno 2006).

Campodea (Dicampa) egreria Condé, 1953

Campodea (Dicampa) egreria Condé, 1953b: 367, fig. 2k-q.

\section{Diagnosis (Condé 1953b)}

Body length 2.2-2.8 mm; short, smooth clothing setae or with 1-2 apical barbs, but thick and with 6-8 barbs on IX-X abdominal segments; antennae with 30-32 antennomeres; sensillum of third antennomere in ventral position; short $(m a, l a)$, poorly barbed and long barbed $(l p)$ notal macrosetae; thin pine cone notal marginal setae; $1+1 l a, 1+1 l p$ macrosetae on VI-VII urotergites and $3+3 l p$ on VIII urotergite; cerci shorter than body and covered in long macrosetae with thin barbs along distal half to two-thirds on proximal articles.

\section{Habitat and distribution}

Soil-dwelling species known from a single locality in the West of Morocco (Condé 1953b).

Campodea (Dicampa) escalerai Silvestri, 1932

Campodea (Dicampa) escalerai Silvestri, 1932a: 148, figs XIV-XV.

Diagnosis (Silvestri 1932a; Sendra \& Moreno 2006)

Body length 1.8-3.5 mm; epicuticle with thick microdenticles; short, smooth clothing setae; antennae with 15-24 antennomeres; small sensillum of third antennomere in ventral position, in material from a few localities it occupies a dorsal position; short $(m a, l a)$, poorly barbed and long, barbed $(l p)$ notal macrosetae; marginal setae with long apical barbs; $1+1 \mathrm{ma}$ macrosetae on I-VII urotergites, $3+3 \mathrm{lp}$ on VIII urotergite and 5+5 lp on IX abdominal segment; cerci shorter than body sometimes covered by several kinds of setae distributed in three types of setae: (1) males and females with long macrosetae and a few clothing setae in addition to distal, swollen latero-interior macrosetae on proximal articles; (2) males with long macrosetae and a few clothing setae but females with short macrosetae and abundant short clothing setae; and (3) males and females with short macrosetae and abundant short clothing setae.

\section{Habitat and distribution}

Soil-dwelling species well adapted to endogean habitats, distributed around the eastern half of the Iberian Peninsula influenced by the Mediterranean climate (Silvestri 1932a; Sendra 1989b; Sendra \& Moreno 2006).

\section{Campodea (Dicampa) frenata Silvestri, 1931}

Fig. 53

Campodea (Dicampa) frenata Silvestri, 1931: 97, figs I-II.

Diagnosis (Silvestri 1931b; Rusek 1964; Paclt 1969)

Body length 4.2-4.5 mm; epicuticle with microdenticles; short, smooth clothing setae; antennae with 22-27 antennomeres; sensillum of third antennomere in dorsal position; middle-sized, robust notal macrosetae almost completely covered with barbs (thin and with a few barbs in Slovakian specimens; Rusek 1964); thin pine cone notal marginal setae; $1+1$ la $1+1$ lp macrosetae on VI-VII urotergites, $3+3 l p$ on VIII urotergite and $5+5 l p$ on IX abdominal segment; cerci shorter than body with 12 articles covered in long smooth macrosetae. 


\section{Taxonomic notes}

The studied material (Supplementary file 2) has allowed to draw the nota (Fig. 53).

\section{Habitat and distribution}

Soil-dwelling species occasionally found in caves (Silvestri 1931b; Condé \& Bareth 2001), distributed around the Carpathians Mountains (Ionescu 1955; Rusek 1964), extending towards the south throughout the Balkan Mountains (Paclt 1969; Blesić 1984, 2000b).

Campodea (Dicampa) gestroi Silvestri, 1912

Campodea (Dicampa) gestroi Silvestri, 1912: 130, figs XVII-XVIII.

Diagnosis (Silvestri 1912)

Body length $2.6 \mathrm{~mm}$; short, smooth clothing setae; antennae with 18-21 antennomeres; short ( $\mathrm{ma}$, la), poorly barbed and long, barbed $(l p)$ notal macrosetae; short with a few barbs or smooth notal marginal setae; $1+1$ short $m a$ macrosetae on I-VII urotergites, $1+1$ la on V urotergite (in addition to $1+1 l p$ in a specimen from labelled $C$. aff. gestroi), $1+1 l a, 1+1 l p$ on VI-VII urotergites, $3+3 l p$ on VIII urotergite and 5+5 lp on IX abdominal segment; cerci shorter than body with 11 articles covered in long macrosetae with barbs and a few clothing setae.

\section{Habitat and distribution}

Soil-dwelling species known from two localities, in central and south Italy (Silvestri 1912; Ramellini 1995). The records outside this area are misidentifications (Condé \& Mathieu 1957).

\section{Campodea (Dicampa) imeretinensis Chevrizov, 1976}

Campodea (Dicampa) imeretinensis Chevrizov, 1976: 936, figs 1(1-5), 2(1-6).

Diagnosis (Chevrizov 1976; Sendra et al. 2006)

Body length $4.2 \mathrm{~mm}$; epicuticle with microdenticles; short, smooth clothing setae; thick clothing setae on VIII urotergite and IX-X abdominal segments; antennae with 25 antennomeres (35 in Crimean cave specimens); sensillum of third antennomere in dorsal position; middle-sized, poorly barbed notal macrosetae; slightly barbed marginal setae; $1+1 l p$ macrosetae on VII urotergite; $3+3 l p$ on VIII urotergite, $5+5 \mathrm{lp}$ on IX abdominal segment; cerci with thin macrosetae poorly barbed with a few distal barbs and with short, smooth setae.

\section{Habitat and distribution}

Described from a cave in Georgia, east of the Black Sea (Chevrizov 1976), it is typically a soil-dwelling species, found in the Kars, in northeastern Anatolia (Sendra et al. 2006) and also in a cave in the Crimean Peninsula.

Campodea (Dicampa) insulana Condé, 1952

Campodea (Dicampa) insulana Condé, 1952b: 562, fig. 1.

Diagnosis (Condé 1952b; Bareth 2006)

Body length 2.0-2.2 mm; short, smooth clothing setae; antennae with 21-22 antennomeres; sensillum of third antennomere in ventral position; short $(m a, l a)$ with a few barbs and long, barbed $(l p)$ notal macrosetae, $m a$ and $l p$ macrosetae on pronotum with distal barbs and the others with one apical barb; short with apical long barbs notal marginal setae; $1+1$ short ma macrosetae on I-VII urotergites; $1+1$ la, $1+1 l p$ on VI-VII urotergites, $3+3 l p$ on VIII urotergite and 5+5 lp on IX abdominal segment; cerci shorter than body with 9 articles covered in short macrosetae with barbs and abundant short, smooth clothing setae. 


\section{Habitat and distribution}

Soil-dwelling species inhabiting endogean habitats in the South of Corsica (Condé 1952b).

Campodea (Dicampa) jolyi Condé, 1947

Campodea (Dicampa) jolyi Condé, 1947h: 141, figs a-h.

Diagnosis (Condé 1947h; Bareth 2006)

Body length 2.7-6.3 mm; epicuticle with microdenticles; short, barbed clothing setae with 1-4 barbs along distal half; antennae with 19-29 antennomeres; cupuliform organ with four to five simple olfactory chemoreceptors; sensillum of third antennomere in dorsal position; middle-sized, robust barbed notal macrosetae with barbs almost along entire length; thin pine cone notal marginal setae; $1+1 l p$ macrosetae on VII urotergite, $3+3 l p$ on VIII urotergite and $5+5 l p$ on IX abdominal segment; cerci with 9 articles covered in long thin macrosetae with 1-2 distal barbs and a few shorter smooth setae.

\section{Habitat and distribution}

Soil-dwelling species widely distributed in mountains and forested areas in the French and Italian Alps (Condé 1947h; Bareth \& Condé 1984; Ramellini 2000). The study of further new fresh material will allow to review the record of C. (D.) jolyi in Portugal (Sendra 1990a).

Campodea (Dicampa) kocheri Condé, 1953

Campodea (Dicampa) kocheri Condé, 1953b: 362, fig. 1e-i.

Campodea (Dicampa) kocheri confusa Condé, 1953b: 365, fig. 1j-k.

\section{Diagnosis (Condé 1953b)}

Body length 1.6-3.2 mm; short, smooth clothing setae; antennae with 23-28 antennomeres; sensillum of third antennomere in ventral position (dorsal in one female); short $m a$ and la notal macrosetae with 1-2 distal barbs, long, barbed $l p$ notal macrosetae with barbs along the distal half to two-thirds; short with long apical barbs notal marginal setae; $1+1$ short ma macrosetae on I urotergite; $1+1$ la, $1+1$ lp on V-VII urotergites, $3+3 \mathrm{lp}$ on VIII urotergite and $5+5 \mathrm{lp}$ on IX abdominal segment; cerci half length of body and covered in long macrosetae with barbs along distal half and a few clothing setae.

\section{Habitat and distribution}

Soil-dwelling species well adapted to endogean habitats known from several localities, including one cave, in the Rif and Tell Atlas Mountains, in the northeast of Africa (Condé 1953b).

Campodea (Dicampa) lusitana Wygodzinsky, 1944

Campodea (Dicampa) lusitana Wygodzinsky, 1944a: 506, figs 23-24.

Diagnosis (Wygodzinsky 1944a; Sendra 1990a)

Body length $4.0 \mathrm{~mm}$; epicuticle with microdenticles; short clothing setae, smooth or with 1-2 distal barbs; antennae with 21 antennomeres; sensillum of third antennomere in ventral position; short ma and $l a$ and long barbed $l p$ notal macrosetae all poorly barbed with a few barbs along distal half; thin pine cone marginal setae; $1+1 \mathrm{lp}$ macrosetae on V-VII urotergites, $3+3 \mathrm{lp}$ on VIII urotergite, $5+5 \mathrm{lp}$ on 
IX abdominal segment; cerci with 11 articles covered in long, thin macrosetae with 1-2 thin barbs or smooth and a few shorter smooth setae.

\section{Habitat and distribution}

Rare soil-dwelling species found only in three localities in the Iberian Peninsula (Wygodzinsky 1944a; Condé 1951d; Sendra \& Moreno 2006).

Campodea (Dicampa) malpighii Silvestri, 1912

Campodea (Dicampa) malpighii Silvestri, 1912: 132, fig. XIX.

\section{Diagnosis (Silvestri 1912)}

Body length 2.7-3.0 mm; short, smooth clothing setae; antennae with 20-26 antennomeres; middlesized, thin barbed notal macrosetae, long $l p$ notal macrosetae with barbs along distal two-thirds; short with a few apical barbs notal marginal setae slightly differentiated from clothing setae; $1+1 l a, 1+1 l p$ macrosetae on V-VII urotergites, $3+3$ lp on VIII urotergite and $5+5 l p$ on IX abdominal segment; cerci covered in long macrosetae with barbs and a few clothing setae.

\section{Habitat and distribution}

Soil-dwelling species described from the centre and south of the Italian Peninsula, including Sicily Island (Silvestri 1912), and other Italian localities by Wygodzinsky (1941b) and Ramellini (1990). Fresh material is needed to verify the record of D. malpighii in Serbia (Blesić 1984, 2000b).

\section{Campodea (Dicampa) melici Sendra, 2015}

Figs 29-32

Campodea (Dicampa) melici Sendra, 2015: 194, figs 9-18.

Diagnosis (Sendra et al. 2015)

Cave-adapted species; body length 6.8-9.3 mm; epicuticle without microdenticles; short to middle-sized, smooth clothing setae; antennae with 41-48 antennomeres; sensillum of third antennomere in dorsal position between $a$ and $b$ macrosetae; cupuliform organ with 10-14 rounded olfactory chemoreceptors; long, robust, poorly barbed notal macrosetae with a few tiny distal barbs; long marginal setae with a few tiny distal barbs; $1+1$ long $m a$ macrosetae on I-VII urotergites ( $m a$ much shorter in II and III than on the others); $3+3 l p$ on VIII urotergite and $5+5 l p$ on IX abdominal segment; stylus II-VII urosternites exceptionally long; male without glandular $g_{l}$-setae, subquadrangular appendages with glandular $a l$ and $a 2$-setae; female with long subcylindrical appendages with glandular $a_{1}$ and $a_{2}$-setae; cerci much longer than body with 17-31 articles covered in barbed long macrosetae and long clothing setae; elongated appendages.

\section{Taxonomic notes}

The studied material (Supplementary file 2) allowed illustrating structures under SEM (Figs 29-32).

\section{Habitat and distribution}

Cave-dwelling species located in four caves in the Aragonese Mountains, in the Iberian Peninsula (Sendra et al. 2015). 
Campodea (Dicampa) merceti Silvestri, 1932

Campodea (Dicampa) merceti Silvestri, 1932a: 141, fig. XI.

Diagnosis (Silvestri 1932a; Sendra \& Moreno 2006)

Body length 1.9-2.9 mm; epicuticle with abundant thick microdenticles; short, smooth clothing setae; antennae with 15-22 antennomeres; sensillum of third antennomere in dorsal or ventral position; short $m a$ and $l a$ notal macrosetae with one apical barb, long $l p$ notal macrosetae with barbs along distal half; short with apical long barbs notal marginal setae; $3+3 l p$ macrosetae on VIII urotergite and $5+5 l p$ on IX abdominal segment; cerci shorter than body with 10 articles; females with glandular $a_{2}$-setae on appendages; proximal cercal articles covered in a few clothing setae plus long macrosetae with barbs along distal two-thirds to smooth on latero-interior side; distal cercal articles covered in short, smooth or with one distal barb macrosetae and abundant short clothing setae.

\section{Habitat and distribution}

Soil-dwelling species with a preference for endogean mountain areas. It is known from one locality on Corsica Island (Condé 1956a: 115), two in Algeria (Condé 1947g) and almost 20 localities in the Iberian Peninsula (Silvestri 1932a; Sendra \& Moreno 2006).

\section{Campodea (Dicampa) neuherzi Condé, 1996}

Campodea (Dicampa) neuherzi Condé, 1996: 110, fig. 7.

\section{Diagnosis (Condé 1996)}

Cave-adapted species. Body length 4.8-7.6 mm; epicuticle with fine-grained microdenticles covered in white plates of urate crystals; short, smooth clothing setae; antennae with 34-40 antennomeres; cupuliform organ with eight to ten simple olfactory chemoreceptors; sensillum of third antennomere in dorsal position; thick notal macrosetae and marginal setae with barbs almost from base; $1+1 \mathrm{lp}$ macrosetae on VI-VII urotergites, $3+3$ lp on VIII urotergite and $5+5$ lp on IX abdominal segment; cerci longer than body covered in long macrosetae with distal barbs to smooth in distal articles.

\section{Habitat and distribution}

Cave-dwelling species found in the cave Pesçera de la Movile, Romania, a peculiar chemoautotrophicbased subterranean ecosystem containing high levels of sulphuric acid, near the West coast of the Black Sea (Condé 1996).

Campodea (Dicampa) neusae Sendra \& Moreno, 2006

Campodea (Dicampa) neusae Sendra \& Moreno, 2006: 78, figs 10-11, table VII.

\section{Diagnosis (Sendra \& Moreno 2006)}

Body length 2.4-3.9 mm; epicuticle with microdenticles; short, smooth clothing setae; antennae with 21-24 antennomeres; sensillum of third antennomere in dorsal position; middle-sized, barbed notal macrosetae; short thin pine cone marginal setae; $1+1 l p$ macrosetae on $\mathrm{V}$ urotergite, $1+1 l a, 1+1 l p$ on VI-VII urotergites, $3+3 l p$ on VIII urotergite and $5+5 l p$ on IX abdominal segment; cerci covered in long thin macrosetae with $0-4$ distal barbs and a few clothing setae. 


\section{Habitat and distribution}

Soil-dwelling species inhabiting leaf litter in the Tejera Negra Natural Park (Sendra \& Moreno 2006) and found on scree slopes in the Guadarrama National Park, Spain (Sendra et al. 2017a). These two localities occur separated (one in the Central Massif and another in Iberian Peninsula).

Campodea (Dicampa) pagesi Condé \& Mathieu, 1957

Campodea (Dicampa) pagesi Condé \& Mathieu, 1957: 462, figs X(36-44).

Diagnosis (Condé \& Mathieu 1957; Bareth 2006)

Body length 1.8-2.3 mm; short, smooth clothing setae; antennae with 17-19 antennomeres; sensillum of third antennomere in ventral position; baciliform sensilla on VI-XIV antennomeres; short ma and la notal macrosetae with one apical barb, long pronotal $l p$ macrosetae with 4-10 barbs along distal half; marginal setae slightly thicker than clothing setae and smooth or with a few tiny barbs; $1+1$ short $m a$ on I-VII urotergites, $1+1 l a, 1+1 l p$ on VI-VII urotergites, $3+3 l p$ on VIII urotergite and $5+5 l p$ on IX abdominal segment.

\section{Habitat and distribution}

Soil-dwelling species inhabiting central and eastern French Pyrenees (Condé \& Mathieu 1957).

\section{Campodea (Dicampa) pardoi Silvestri, 1932}

Campodea (Dicampa) pardoi Silvestri, 1932a: 143, fig. XII.

\section{Diagnosis (Silvestri 1932a)}

Body length $4.2 \mathrm{~mm}$; short clothing setae; antennae with 26-27 antennomeres; middle-sized notal macrosetae with barbs; long and well-differentiated marginal setae; $1+1$ middle sized $m a$ on I-VII urotergites, $1+1$ la, $1+1$ lp on IV-VII urotergites, $3+3$ lp on VIII urotergite; cerci with 14 articles covered in long macrosetae with a few barbs and smooth clothing setae.

\section{Habitat and distribution}

Soil-dwelling species known from a single locality in eastern Iberian Peninsula (Silvestri 1932a).

Campodea (Dicampa) plagiaria Silvestri, 1932 Table 2

Campodea (Dicampa) plagiaria Silvestri, 1932b: 83, figs VI-VII.

Diagnosis (Silvestri 1932b)

Body length 4-5 mm; epicuticle with microsenticles; short clothing setae; antennae with 26-28 antennomeres; sensillum in ventral position; short notal macrosetae with a few distal barbs except the long $l p$ macrosetae with barbs along distal two-thirds; short thin pine cone notal marginal; $1+1$ $l a$ macrosetae on V urotergite; $1+1 l a, 1+1 l p$ on VI-VII urotergites, $3+3 l p$ on VIII and $5+5 l p$ on IX abdominal segment; cerci with 12 articles covered with long macrosetae with barbs and a few clothing setae.

\section{Taxonomic notes}

A cave-adapted population of $C(D)$ aff. plagiaria found in a cave in the northeast of Morocco (Supplementary file 2) has a body length of 4.3-6.4 mm; epicuticle with microdenticles; clothing setae with a tiny distal barb; up to 49 antennomeres with up to 12 complex olfactory chemoreceptors in its cupuliform organ; sensillum of third antennomere in ventral position; short $(m a, l a)$ and long $(l p)$ barbed 
Table 2. Measurements of body, antennae, metathoracic leg and cerci in $\mathrm{mm}$, including the number of antennomeres and cercal articles in a cave-adapted form of Campodea (Dicampa) aff. plagiaria Silvestri, 1932 from Kef Pigeons (Takebous, Morocco).

\begin{tabular}{|c|c|c|c|c|c|c|}
\hline \multicolumn{2}{|c|}{ Specimen } & \multicolumn{2}{|l|}{ Antennae } & \multirow{2}{*}{$\begin{array}{l}\text { Metathoracic leg } \\
\text { Length }\end{array}$} & \multicolumn{2}{|c|}{ Cerci (all incomplete) } \\
\hline Sex & Body length & Antennomere number & Length & & Article number & Length \\
\hline$\hat{0}$ & 4.3 & 47 & 5.1 & 1.9 & - & - \\
\hline$\hat{0}$ & 4.3 & 47 & 5.3 & 2.1 & - & - \\
\hline$q$ & 4.7 & - & - & 1.8 & 27 & 5.3 \\
\hline$\hat{0}$ & 4.9 & - & - & 2.3 & - & - \\
\hline$q$ & 5.0 & - & - & 2.4 & - & - \\
\hline$\hat{\sigma}$ & 5.3 & 45 & 5.8 & 2.3 & - & - \\
\hline o & 5.7 & 49 & 6.1 & 2.4 & - & - \\
\hline 우 & 5.7 & 49 & 6.0 & 2.4 & 28 & 12.6 \\
\hline o & 5.9 & - & - & 2.5 & 26 & 9.0 \\
\hline 우 & 6.4 & - & - & 2.8 & - & - \\
\hline
\end{tabular}

notal macrosetae; long thin pine cone notal marginal setae; more than 27 articles in an incomplete cercus; elongated appendages (see Table 2). A non-cave-adapted population of $C$. (D.) plagiaria was found at the entrance of a cave in the extreme south of the Iberian Peninsula that allows to complete the original description with some unknown taxonomic features.

\section{Habitat and distribution}

Soil-dwelling species found at a single locality in the Rif Mountains, Morocco (Silvestri 1932a). A caveadapted form and a non-cave-adapted population have been found at the entrance of a cave in the Sierra de Grazalema Natural Park, southern Iberian Peninsula (250 km from the type locality in North Africa).

Campodea (Dicampa) propinqua Silvestri, 1932

Campodea (Dicampa) propinqua Silvestri, 1932a: 138, fig. X.

\section{Diagnosis (Silvestri 1932a)}

Body length $2.6 \mathrm{~mm}$; short clothing setae; antennae with 23 antennomeres; short $m a$ and la notal macrosetae with 1-4 distal barbs, long, well-barbed $l p$ notal macrosetae; short thin pine cone notal marginal setae; $1+1 l a, 1+1 l p$ macrosetae on VI-VII urotergites, $3+3 l p$ on VIII urotergite and $5+5 l p$ on IX abdominal segment; cerci shorter than body with 10 articles covered with long barbed macrosetae and a few smooth clothing setae. Specimens from a scree slope in Sierra Guadarrama (Central System Range in the central Iberian Peninsula) (Sendra et al. 2017a) show antennae with 27 and 29 antennomeres and seven olfactory chemoreceptors inside cupuliform organ.

\section{Habitat and distribution}

Soil-dwelling species known from a unique locality in the western Subbaetic Mountains, southern Iberian Peninsula (Silvestri 1932a), and inhabiting colluvial scree slopes in central Iberia. The quotations of this species in Romania (Ionescu 1951, 1955) and Italy (Ramellini 1990) should be carefully revised with new material.

\section{Campodea (Dicampa) silvicola Ionescu, 1955}

Campodea (Dicampa) silvicola Ionescu, 1955: 36.

Diagnosis (Ionescu 1955)

Body length $2.3 \mathrm{~mm}$; antennae with 16-18 antennomeres; thin and long notal setae and macrosetae; $3+3$ lp macrosetae on VIII urotergite; cerci covered in long macrosetae. 


\section{Habitat and distribution}

Soil-dwelling species known from a few localities in southern Carpathians (Ionescu 1955; Blesić 1984).

Campodea (Dicampa) sprovieri sprovieri Silvestri, 1933

Campodea (Dicampa) sprovieri sprovieri Silvestri, 1933a: 64, fig. III.

Diagnosis (Silvestri 1933a; Wygodzinsky 1940; Rusek 1965b; Sendra et al. 2006, 2010, 2012)

Body length 3-3.5 mm; epicuticle with microdenticles; short clothing setae with apical barbs; antennae with 22-30 antennomeres; sensillum of third antennomere in dorsal or ventral position; middle-sized notal macrosetae well barbed, ma/la macrosetae approx. 0.5 on mesonotum (in adults); long thin pine cone notal marginal setae; $1+1 l a, 1+1 l p$ macrosetae on VI-VII urotergites, $3+3 l p$ on VIII urotergite and 5+5 lp on IX abdominal segment; cerci shorter than body with 8-10 articles covered with long macrosetae with barbs and a few clothing setae.

\section{Campodea (Dicampa) sprovieri vardousiae Condé, 1984}

Campodea (Dicampa) sprovieri vardousiae Condé, 1984: 187, table VII.

Differential diagnosis from the f. typ. (Condé 1984)

Antennae with 19-22 antennomeres.

\section{Habitat and distribution}

Soil-dwelling species widely spread around the Balkan (Ionescu 1955; Rusek 1965b; Condé 1984; Sendra et al. 2012) and Anatolian peninsulas (Sendra et al. 2006, 2010), several Aegean islands included (Silvestri 1933a; Condé 1984). Campodea (D.) sprovieri vardousiae was found in Phocis, southern Balkan Peninsula (Condé 1984).

Campodea (Dicampa) taurica Silvestri, 1949

Campodea (Dicampa) taurica Silvestri, 1949: 27, fig. 1.

Diagnosis (Silvestri 1949)

Cave-adapted species; body length 4.2-6.0 mm; epicuticle with thin microdenticles to smooth; smooth clothing setae or with one distal barb; thick clothing setae on IX-X abdominal segments; antennae with 32-40 antennomeres; cupuliform organ with 12 to 14 complex olfactory chemoreceptors; coniform sensillum on third antennomere in dorsal position; long, poorly barbed notal macrosetae; long notal marginal setae with $1-3$ thin distal barbs; tibia with one (two exceptional) ventral macrosetae; $1+1 l p$ macrosetae on VII urotergite and $3+3 \mathrm{lp}$ on VIII urotergite and $5+5 \mathrm{lp}$ on IX abdominal segment; cerci covered in long, thin and smooth macrosetae or with distal barbs in basal articles, and shorter, smooth clothing setae.

\section{Habitat and distribution}

Cave-dwelling species known from four caves in Crimea (Silvestri 1949).

Subgenus Monocampa Silvestri, 1932

Monocampa Silvestri, 1932a: 116.

Diagnosis (Silvestri 1932a; Condé 1956a)

Notal formula with $1+1 \mathrm{ma}, 1+1 \mathrm{la}, 1+1 \mathrm{lp}$ macrosetae on pronotum and $1+1$ la on mesonotum; epicuticle with microdenticles, in some species thick and grained; without dorsal femoral macrosetae; one short ventral tibial macrosetae; subequal smooth, slightly curved claws; setiform smooth telotarsal process; 
$0+0$ or $1+1$ lp macrosetae and $0+0$ or $1+1$ la macrosetae on VI-VII urotergites; $3+3$ lp macrosetae on VIII urotergite; $5+5$ lp macrosetae on the IX abdominal segment; without medial anterior or posterior macrosetae on urotergites and VIII abdominal segment; first urosternite with $6+6$ macrosetae, $4+4$ on II-VII urosternites, $1+1$ on VIII urosternite; first urosternite of male with glandular $g_{1}$-setae, enlarged or round appendages with glandular $a_{1}$ and usualy $a_{2}$-setae; female with subcylindrical appendages with glandular $a_{1}$-setae.

\section{Habitat and distribution}

If the synonyms of C. (M.) devoniensis Bagnall, 1918 are taken for granted as Paclt (1966) suggested, species of Monocampa are limited to the Western European and Mediterranean Regions, where seven described species inhabit soil environments (Fig. 60). Four of these species share the same island, Sardinia, where C. (M.) denisi Wygodzinsky, 1941, C. (M.) aurunca Ramellini, 1990, C. (M.) emeryi Silvestri, 1912 and C. (M.) devoniensis seem to occupy the soil from upper horizons (O and A) to endogean (B) habitats except for the subspecies M. emeryi spelaea Condé, 1978 found inside a cave (Condé 1978a).

\section{Taxonomic key for species of the subgenus Monocampa}

1. Lateral posterior macrosetae of the sixth urotergite $1+1$ 2

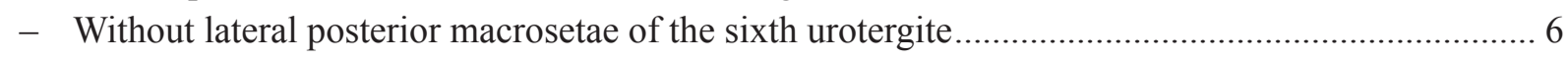

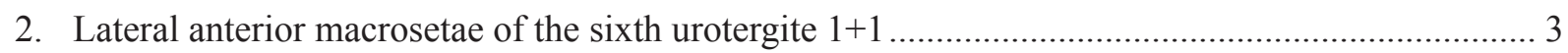

- Without lateral anterior macrosetae of the sixth urotergite .............................................................. 4

3. Clothing setae short well barbed; notal macrosetae long and completely barbed.

Campodea (Monocampa) goursati Condé, 1950

- Clothing setae short smooth or with a small apical barb; notal macrosetae long and barbed

Campodea (Monocampa) navasi Condé, 1932

- Clothing setae short, thick and mooth or with a small apical barb; notal macrosetae middle sized and barbed Campodea (Monocampa) denisi Wygodzinsky, 1941

4. Lateral anterior macrosetae of the seventh urotergite 1+1; clothing setae short, thick, smooth or with a small apical barb; cerci pilosity with long, barbed macrosetae and a few smooth setae in addition to swollen latero-interior macrosetae in proximal articles; marginal setae thin pine cone.

Campodea (Monocampa) aurunca Ramellini, 1990

- Without lateral anterior macrosetae of the seventh urotergite; clothing setae short, smooth or with a small apical barb; cerci pilosity with long, barbed macrosetae and a few smooth setae; marginal setae sligthly thin pine cone

5. Notal macrosetae thin, long and barbed ......Campodea (Monocampa) emeryi spelaea Condé, 1978

- Notal macrosetae long and barbed............. Campodea (Monocampa) emeryi emeryi Silvestri, 1912

6. Lateral posterior macrosetae of the seventh urotergite 1+1; marginal setae thin pine cone shape; dorsal sensillum of the third antennomere...... Campodea (Monocampa) devoniensis Bagnall, 1918

- Without lateral posterior macrosetae of the seventh urotergite; marginal setae short with long apical barbs; ventral sensillum of the third antennomere. 
Campodea (Monocampa) aurunca Ramellini, 1990

Campodea (Monocampa) aurunca Ramellini, 1990: 18, figs 3-13, tables 1-2.

Diagnosis (Ramellini 1990)

Body length 1.5-3.0 mm; epicuticle with microdenticles; thick smooth clothing setae or with a small apical barb; antennae with 18-23 antennomeres; sensillum of third antennomere in dorsal position; middle-sized pronotal macrosetae with one distal barb ( $m a$ macrosetae) or barbed along distal half (la, $l p$ macrosetae), thin pine cone marginal setae; $1+1 l p$ macrosetae on VI urotergite; $1+1 l a, 1+1 l p$ on VII urotergite, $3+3 \mathrm{l} p$ on VIII urotergite and $5+5 \mathrm{l} p$ on IX abdominal segment; cerci shorter than body with 9 articles covered with long swollen macrosetae on proximal articles.

\section{Habitat and distribution}

Soil-dwelling species known from several localities in central Italy (Ramellini 1990) and in Sardinia.

Campodea (Monocampa) denisi Wygodzinsky, 1941

Campodea (Monocampa) denisi Wygodzinsky, 1941: 131, figs 54-60, table 4. Campodea (Monocampa) denisi aequalis Condé, 1947: 283, fig.

Diagnosis (Wygodzinsky 1941a; Condé 1947e; Bareth 2006)

Body length 3.5-4.5mm; thick, smooth clothing setae; antennae with 19-25 antennomeres; sensillum of third antennomere in ventral or dorsal position; middle-sized $m a$, la macrosetae on pronotum with thin barbs along distal half, long la macrosetae on mesonotum with barbs along distal two-thirds; marginal setae longer than clothing setae with $1-5$ short barbs; $1+1$ la, $1+1$ lp macrosetae on VI-VII urotergites, $3+3 l p$ on VIII urotergite and $5+5 l p$ on IX abdominal segment; cerci $0.5 \times$ body length with 10 articles covered with long macrosetae with short tiny barbs and a few clothing setae; proximal cercal articles having latero-interior macrosetae with one long distal barb (without this barb in Corsican specimens); small spermatozoid fascicles with $33-36 \mu \mathrm{m}$ in diameter and $10 \mu \mathrm{m}$ wide, spiral filament with 1-2 spirals, $95-150 \mu \mathrm{m}$ long and $1 \mu \mathrm{m}$ diameter.

\section{Habitat and distribution}

Soil-dwelling species widely distributed in Central Europe (Condé 1947d, 1954; Rusek 1964), in northern and central Italy (Ramellini 1990), and in Sardinia and Corsica (Condé 1947e; Bareth 1980).

Campodea (Monocampa) devoniensis Bagnall, 1918

Figs 14-16, 25-26

Campodea (Monocampa) morgani Silvestri, 1911: 13, figs 5-6.

Campodea (Monocampa) devoniensis Bagnall, 1918c: 277.

Campodea (Monocampa) barnardi Silvestri, 1932c: 55, fig. I.

Campodea (Monocampa) quilisi Silvestri, 1932a: 156, fig. XVIII.

Campodea (Monocampa) tonnoiri Womersley, 1937: 167, fig. I.

Diagnosis (Silvestri 1932a; Paclt 1966; Bareth 1980; Sendra 1988)

Body length 1.5-3.0 mm; epicuticle with microdenticles; short, smooth clothing setae; antennae with 18-23 antennomeres; sensillum of third antennomere in dorsal position; long notal macrosetae well barbed; thin pine cone pronotal marginal setae; $1+1 l p$ macrosetae on VII urotergite, $3+3 l p$ on VIII urotergite and $5+5 \mathrm{l} p$ IX abdominal segment; cerci shorter than body with 9 articles covered in long barbed macrosetae and a few clothing setae, latero-interior swollen macrosetae; small spermatozoid fascicles 33-36 $\mu \mathrm{m}$ and $10 \mu \mathrm{m}$ wide, spiral filament with $1.5-2$ spirals, $93-150 \mu \mathrm{m}$ long and $1 \mu \mathrm{m}$ diameter. 
We follow the suggestion of Paclt (1966) to propose as synonyms of C. (M.) devoniensis: Campodea (Monocampa) quilisi Silvestri, 1932 from the west Mediterranean region, Campodea (Monocampa) barnardi Silvestri, 1932 from South Africa, Campodea (Monocampa) morgani Silvestri, 1911 from North America and Campodea (Monocampa) tonnoiri Womersley, 1937 from Australia. Nevertheless, a more accurate revision should be carried out in the future to untangle this taxonomic uncertainty.

\section{Taxonomic notes}

Some specimens studied from localities in Sardinia Island and Genova (Supplementary file 2) have 1+1 la macrosetae on VII urotergite. In Granarolo (Genova, Italy) specimens with and without la macrosetae on VII urotergite have been observed. The studied material (Supplementary file 2) has also allowed to take photographs of some structures with SEM (Figs 14-16, 25-26).

\section{Habitat and distribution}

Soil-dwelling species distributed in the Atlantic archipelagos of the Canaries (Sendra 1989a) and Azores (Condé \& Barbier 1965), although the main distribution area are the West Mediterranean regions: Iberian Peninsula (Condé \& Mathieu 1957; Sendra et al. 1986; Sendra \& Moreno 2006), Morocco (Condé 1953b), Sardinia (Bareth 1980), Corsica (Condé 1947e) and the Italian Peninsula (Ramellini 1990). It has also been found at several localities in England (Bagnall 1918c), Austria (Christian 1992), Slovakia (Paclt 1966) and Croatia (Blesić 1996), perhaps due to its wide colonization capability, and it is a potential invasing species of other distant localities in Australia, South Africa and North America (Paclt 1966).

Campodea (Monocampa) emeryi emeryi Silvestri, 1912

Table 3

Campodea (Monocampa) emeryi emeryi Silvestri, 1912: 137, figs XXIII-XXIV.

Diagnosis (Silvestri 1912; Condé 1978a; Bareth 1980)

Body length 1.3-4.1 mm; epicuticle with microdenticles; short, smooth clothing setae; antennae with 19-24 antennomeres; sensillum of third antennomere in dorsal position; long, barbed notal macrosetae; slightly thin pine cone marginal setae with long barbs and slightly longer than clothing setae; smooth subapical setae of tarsus; $1+1$ lp macrosetae on VI-VII urotergites, $3+3$ lp on VIII urotergite and 5+5 lp IX abdominal segment; cerci shorter than body with 10 articles covered in long macrosetae with barbs and a few clothing setae (latero-interior macrosetae slightly swollen in Corsican specimens); small spermatozoid fascicles, 33-36 $\mu \mathrm{m}$ in diameter and $10 \mu \mathrm{m}$ wide, spiral filament with 1.5-2 spirals, 93-150 $\mu \mathrm{m}$ long and $1 \mu \mathrm{m}$ diameter.

\section{Taxonomic notes}

Condé (1947e, 1978a) used the ratio between la mesonotal length macrosetae and the separation of their basis ( $($ ) to propose subspecies. The study of 20 specimens from Sardinia Island (Supplementary file 2) shows that the $l a / \varepsilon$ length ratio is variable during the growth, consequently it has no solid taxonomic value (Table 3).

\section{Campodea (Monocampa) emeryi spelaea Condé, 1978}

Campodea (Monocampa) emeryi spelaea Condé, 1978a: 263, table I.

Differential diagnosis from the f. typ. (Condé 1978a)

Body length 4-5.2 mm; epicuticle with grained surface; antennae with 26-28 antennomeres; four to five simple olfactory chemoreceptors in cupuliform organ; thin, long notal macrosetae with thin barbs almost from their basis except ma macrosetae with 2-4 distal barbs. 
Table 3. Measurements of la macrosetae and distance between la basis $(\varepsilon)$ on mesonotum of Campodea (Monocampa) emeryi emeryi Silvestri, 1912 from Sardinia Island.

\begin{tabular}{cccc}
\hline $\begin{array}{c}\text { Body length } \\
(\mathbf{m m})\end{array}$ & $\begin{array}{c}\boldsymbol{l a} \text { mesonotal macrosetae } \\
\text { length }(\boldsymbol{\mu m})\end{array}$ & $\begin{array}{c}\boldsymbol{\varepsilon}, \text { length between } \boldsymbol{l a} \text { mesonotal macro- } \\
\text { setae basis }(\boldsymbol{\mu m})\end{array}$ & $\boldsymbol{\varepsilon} / \boldsymbol{l a}$ \\
\hline 1.3 & 110 & 33 & 3.3 \\
1.4 & 72 & 25 & 2.9 \\
1.5 & 122 & 32 & 3.8 \\
1.6 & 150 & 40 & 3.8 \\
1.6 & 140 & 40 & 3.5 \\
1.7 & 162 & 48 & 3.4 \\
1.8 & 145 & 35 & 4.1 \\
2.2 & 165 & 40 & 4.1 \\
2.3 & 225 & 55 & 4.1 \\
2.5 & 180 & 52 & 3.5 \\
2.8 & 258 & 75 & 3.4 \\
2.9 & 200 & 50 & 4.0 \\
3.0 & 250 & 70 & 3.6 \\
3.1 & 250 & 55 & 4.6 \\
3.2 & 272 & 68 & 4.0 \\
3.4 & 262 & 58 & 4.5 \\
3.4 & 255 & 55 & 4.6 \\
3.7 & 310 & 70 & 4.4 \\
3.9 & 330 & 68 & 4.9 \\
4.1 & 280 & 55 & 5.1 \\
\hline
\end{tabular}

Campodea (Monocampa) emeryi algira Condé 1947

Campodea (Monocampa) emeryi algira Condé, 1947g: 144, fig. g.

Differential diagnosis from the f. typ. (Condé 1947g, 1978a)

Antennae with 18-21 antennomeres; la macrosetae on mesonotum stronger and shorter than f. typ.; 2-3 long barbs on subapical setae of the tarsus.

\section{Habitat and distribution}

Soil-dwelling species widely distributed in soil habitats of Sardinia (Bareth 1980), Corsica (Condé 1978a) and Sicily (Wygodzinsky 1941b). Furthermore, it was found in the South of Italy (Silvestri 1912). Campodea (M.) emeryi algira was collected at a single locality (garden in Ramdane Djamel city, northeast of Algeria), although this subspecies should be reviewed as suggested by Condé (1978) against the Corsican specimens. Finally, the subspecies C. (M.) emeryi spelaea was found in the deepest zone of a cave near Sassari, northeast Sardinia; with moderate cave-adapted traits (Condé 1978a).

Campodea (Monocampa) goursati Condé, 1950

Campodea (Monocampa) goursati Condé, 1950a: 129, figs a-i.

Diagnosis (Condé 1950a; Bareth 2006)

Body length 5.0-6.0 mm; epicuticle with microdenticles; clothing setae with barbs almost from base; antennae with 36-37 antennomeres; small sensillum of third antennomere in ventral position; long notal macrosetae and marginal setae with barbs form base; barbed subapical setae of tarsus; $1+1 l a, 1+1$ lp 
macrosetae on VI-VII urotergites; $3+3 l p$ on VIII urotergite and $5+5 l p$ on IX abdominal segment; first urosternite of male with round appendages without glandular $a_{2}$-setae; cerci covered in long thin macrosetae with 1-4 barbs in proximal articles and a few clothing setae.

\section{Habitat and distribution}

Soil-dwelling species known from a unique locality in the Maures massif (Condé 1950a) and in the Haut-Languedoc, southeast France.

\section{Campodea (Monocampa) hauseri Condé, 1978}

Fig. 54

Campodea (Monocampa) hauseri Condé, 1978a: 266, table I.

Diagnosis (Condé 1978a)

Body length 2.0-2.6 mm; epicuticle with microdenticles; short, smooth clothing setae; antennae with 18-22 antennomeres; sensillum of third antennomere in ventral position; middle-sized notal macrosetae with thin long barbs along distal half; marginal setae with long apical barbs; smooth subapical setae of tarsus; $3+3$ lp macrosetae on VIII urotergite and $5+5$ lp on IX abdominal segment; cerci covered in long macrosetae with barbs along distal half to two-thirds and a few clothing setae.

\section{Taxonomic notes}

The studied material (Supplementary file 2) has allowed to draw the nota (Fig. 54).

\section{Habitat and distribution}

Soil-dwelling species found in the forest in Cephalonia and Ithaca, two of the Ionian islands of Greece (Condé 1978a).

Campodea (Monocampa) navasi Silvestri, 1932

Campodea (Monocampa) navasi Silvestri, 1932a: 153, fig. XVII.

Diagnosis (Silvestri 1932a; Sendra 1988; Bareth 2006; Sendra \& Moreno 2006)

Body length 3.0-4.5 mm; epicuticle with microdenticles; short, smooth clothing setae or with distal barb; antennae with 25-29 antennomeres; sensillum of third antennomere in dorsal position; long notal macrosetae well barbed; marginal setae thicker than clothing setae and with several barbs; $1+1 l a, 1+1$ lp macrosetae on VI-VII urotergites; $3+3 l p$ on VIII urotergite and $5+5$ lp on IX abdominal segment; male with seasonal variation in glandular $a_{2}$-setae; cerci shorter than body with 9 articles covered in long macrosetae with 1-2 distal barbs and a few clothing setae.

\section{Habitat and distribution}

Soil-dwelling species with a preference for the upper layers of the soil ( $\mathrm{O}$ and $\mathrm{A}$ horizons). Its distribution is restricted to the central area of the Pyrenees (Condé \& Mathieu 1957; Sendra \& Moreno 2006).

Subgenus Paurocampa Silvestri, 1932

Paurocampa Silvestri, 1932a: 115.

Diagnosis (Silvestri 1932a; Condé 1956a, 1974)

Notal formula with $1+1 \mathrm{ma}, 1+1$ la, $1+1$ lp macrosetae on pronotum; cupuliform organ with rounded or multi-finger shape olfactory chemoreceptors; without dorsal femoral macrosetae; one short ventral tibial macrosetae; subequal smooth slightly curved claws; setiform smooth telotarsal process; $0+0$ or 

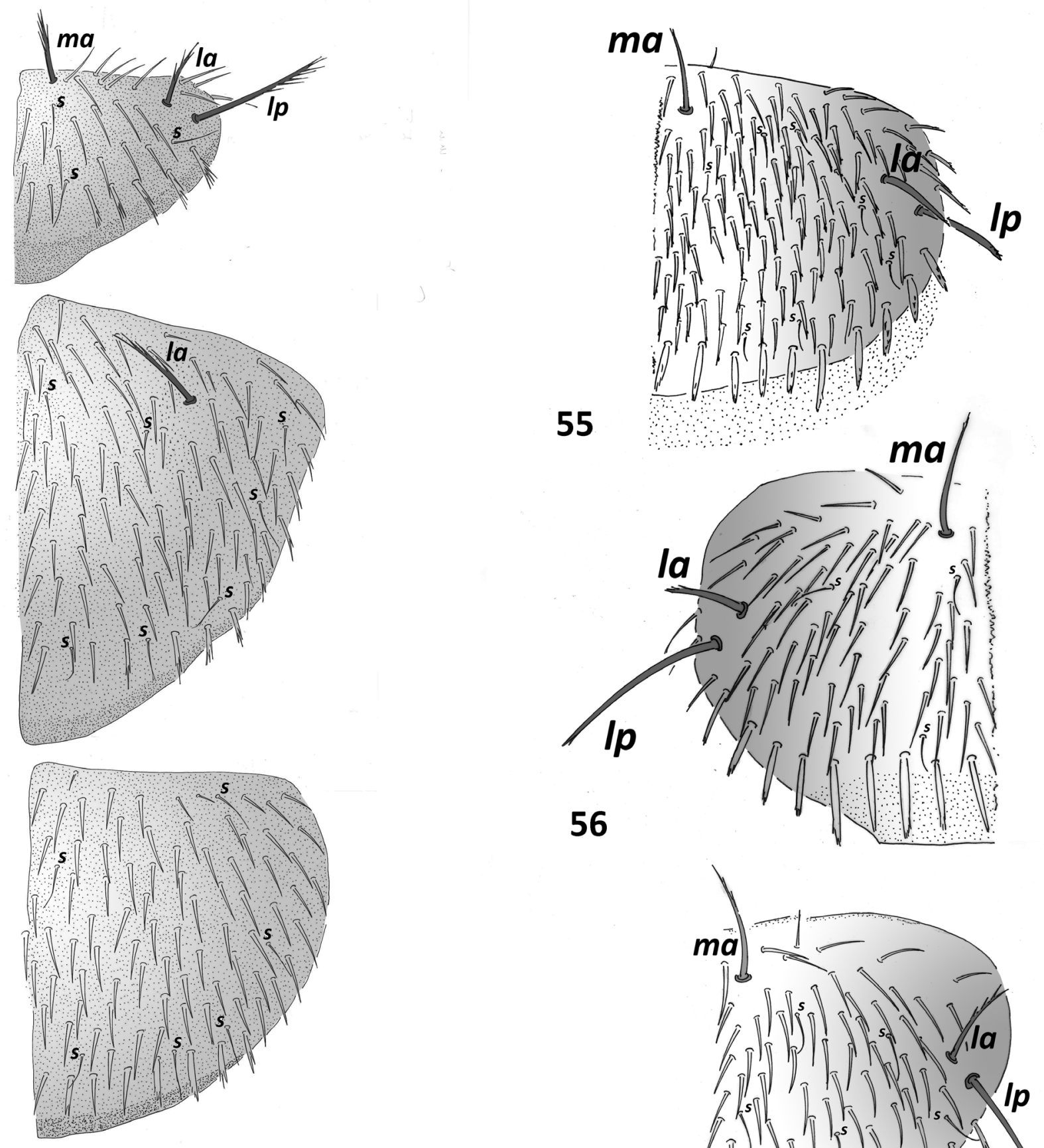

56

54
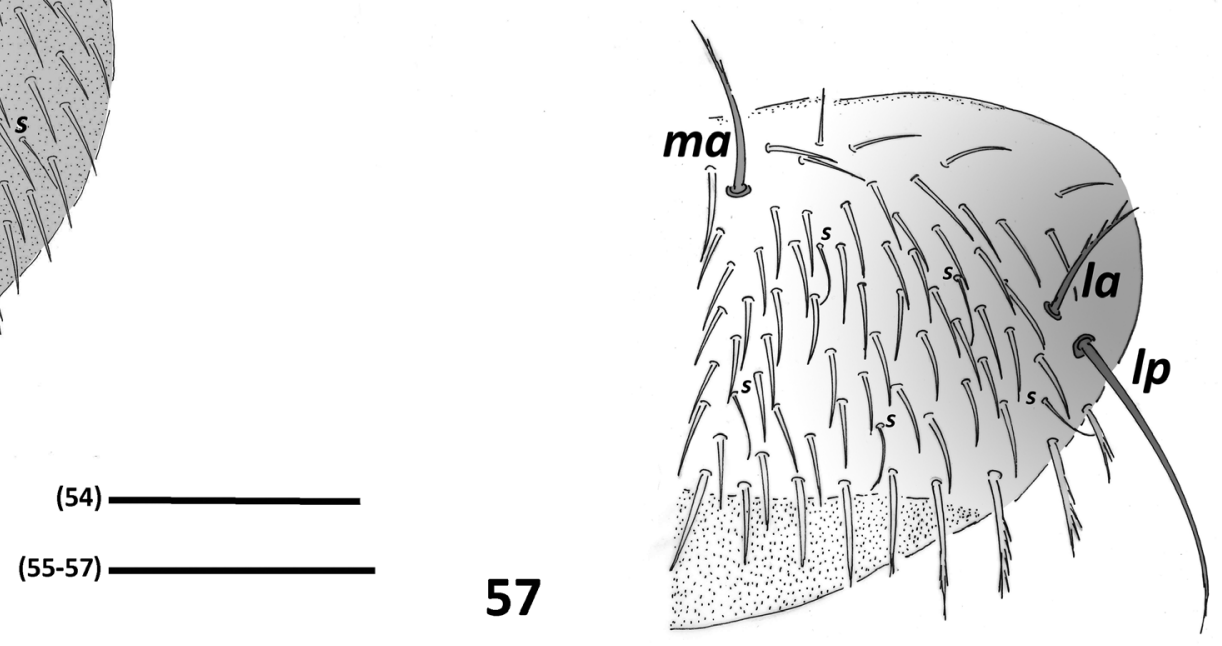

Figs 54-57. - 54. Campodea (Monocampa) hauseri Condé, 1978, +, paratype 70/32, Geneva Zoological Museum, pronotum, mesonotum and metanotum. - 55. Campodea (Paurocampa) aff. pretneri I Condé, 1974,, , 6.1 mm, from Vračka Zijalka, Čreta, Dobrovlje, Slovenia, pronotum. - 56. Campodea (Paurocampa) aff. pretneri II Condé, 1974,,, $8.0 \mathrm{~mm}$, from Grotta Azzurra di Sarratorza, Trieste, Italy, pronotum. - 57. Campodea (Paurocampa) suensoni Tuxen, 1930,,$+ 4.5 \mathrm{~mm}$, from Valle di Skamnéli, Greece, pronotum. Abbreviations: see Material and methods. Scale bars: $54=0.1 \mathrm{~mm} ; 55-57=0.2 \mathrm{~mm}$. 
$1+1$ lp macrosetae and $0+0$ or $1+1$ la macrosetae on VI-VII urotergites; $3+3(2+2) l p$ macrosetae on VIII urotergite; $5+5 \mathrm{lp}$ macrosetae on the IX abdominal segment; without medial anterior or posterior macrosetae on urotergites and VIII abdominal segment; first urosternite with $6+6$ macrosetae, $4+4$ on II-VII urosternites, $1+1$ on VIII urosternite; first urosternite of male with glandular $g_{1}$-setae, round appendages with glandular $a_{1}$ and with or without $a_{2}$-setae; female with subcylindrical appendages with glandular $a_{1}$-setae, in a couple of species with $a_{2}$-setae.

\section{Habitat and distribution}

Seven species belong to the subgenus Paurocampa in the Euro-Mediterranean area (Campodea (Paurocampa) pagei Silvestri, 1931 from China excluded). Five of them can be considered soil-dwelling species with a high preference for living at high altitudes in the mountain ranges of the European alpine orogeny, i.e., Cantabrian, Basque Mounts, Pyrenees; the Alps including the Dinaric and the Carpathian Mountains. The two remaining species live in cave environments; $C$. (P.) spelaea and $C$. (P.) pretneri Condé, 1974, a remarkable cave-adapted species occurring in the Julian Alps and in the north of the Dinaric Mountains (Condé 1974) (Fig. 61).

\section{Taxonomic key for species of the subgenus Paurocampa}

1. Lateral posterior macrosetae of the eighth macrosetae $3+3$

- Lateral posterior macrosetae of the eighth macrosetae $2+2$

Campodea (Paurocampa) ruseki Condé, 1966

2. Lateral posterior macrosetae of the seventh urotergite 1+1; lateral anterior macrosetae of the seventh urotergite $1+1$

- Without lateral posterior and lateral anterior macrosetae of the seventh urotergite ............................. 5

3. Lateral posterior macrosetae of the sixth urotergite $1+1$; pronotal macrosetae middle sized, poorly barbed; clothing setae short, thick and smooth or with a few distal barbs

Campodea (Paurocampa) ribauti Silvestri, 1912

- Without lateral posterior macrosetae of the sixth urotergite; pronotal macrosetae middle sized, barbed; clothing setae short, smooth or with a small apical barb.

4. Lateral anterior macrosetae of the sixth urotergite $1+1$; cerci pilosity with long, barbed macrosetae and short, smooth setae, the latero interior proximal marcoetae swollen with distal pubescence; marginal setae slightly short thin pine cone; male $a_{2}$ glandular setae absent

Campodea (Paurocampa) corsica Condé, 1946

- Without lateral anterior macrosetae of the sixth urotergite; cerci covered in middle-sized macrosetae with barbs along the distal half on the proximal articles with abundant short, smooth setae, but on distal articles there are only abundant setae; marginal setae thin pine cone; male $a_{2}$ glandular setae present.

Campodea (Paurocampa) rocasolanoi Silvestri, 1932

5. Marginal setae thin pine cone

Campodea (Paurocampa) suensoni Tuxen, 1930

- Marginal setae thick with a few distal barbs

- Marginal setae slightly short thin pine cone

Campodea (Paurocampa) aff. pretneri I Condé, 1974

Campodea (Paurocampa) aff. pretneri II Condé, 1974

\section{Campodea (Paurocampa) corsica Condé, 1946}

Campodea (Paurocampa) pachychaeta Condé, 1946a: 1, fig. Ia-i.

Campodea (Paurocampa) corsica Condé, 1946a: 145, fig. 1b-m.

Diagnosis (Condé 1946a, 1946b; Ramellini 1998; Bareth 2006)

Body length 2.0-4.0 mm; slightly thick, short clothing setae mostly smooth but some with one distal barb; antennae with 19-22 antennomeres; sensillum of third antennomere in dorsal position; middle- 
sized barbed notal macrosetae with short or long barbs almost from basis, some specimens with $m a$ and la pronotal macrosetae with a few distal barbs; thin pine cone marginal setae; $1+1$ la macrosetae on VI urotergite, $1+1 l a, 1+1 l p$ on VII urotergite, $3+3 l p$ on VIII urotergite and $5+5 l p$ on IX abdominal segment; male without glandular $a_{2}$-setae; cerci shorter than body with 9 articles covered in long swollen macrosetae, mostly latero-interior ones, remarkable hairy on swollen zone of macrosetae.

\section{Habitat and distribution}

Soil-dwelling species, seems well adapted to endogean habitats in high mountain areas. It has been collected at more than $1000 \mathrm{~m}$ a.s.l. on Corsica Island (Condé 1946a, 1946b), and is also known from three localities at the Abruzzo National Park and Monti Aurunci, Lazio, Italy (Ramellini 1990, 1998).

\section{Campodea (Paurocampa) pretneri Condé, 1974}

Figs 55-56

Campodea (Paurocampa) pretneri Condé, 1974: 564, figs a-e.

Diagnosis (Condé 1974; Bareth 1988)

Body length 3.2-7.5 mm; epicuticle smooth, rarely with micridenticles visible up to high optical magnifications; short smooth to thick with a short distal barb clothing setae; antennae with 30-37 antennomeres; sensillum of third antennomere in ventral position; apical antennomere three times as long as wide; cupuliform organ with 12-20 olfactory chemoreceptors each with tiny long digits cooped up in small cup; robust long to short notal macrosetae with a few small distal barbs or smooth; thick with a few short distal barbs to slightly thin pine cone marginal setae; $3+3$ lp macrosetae on VIII urotergite; $5+5$ lp on IX abdominal segment; male with round big appendages without glandular $a_{2}$-setae; cerci longer than body with 17-18 articles, subdivided in two, three and four from proximal to distal articles, covered in short macrosetae usually with apical barb on proximal articles and smooth on distal ones, all of them with a few clothing setae.

\section{Taxonomic notes}

The specimens studied in this contribution have been sorted out using the morphology of notal marginal setae due to the absence of antennae in almost all the specimens, many completely broken from their bases. A variety of setae shapes among the studied material has been observed (Supplementary file 2), allowing to differentiate two main morphotypes: $C$. $(P$.) aff. pretneri I with short and smooth notal clothing setae and thick with a short apical barbs notal marginal setae (Fig. 55); and $C$. (P.) aff. pretneri II with short notal clothing setae with a small distal barb and slightly pine cone with short small barbs (Fig. 56). Several specimens of Jama Kevderc and Klemenškov (Slovenia) have microdenticles visible at $400 \times$ magnification, smooth in all the other studied material.

\section{Habitat and distribution}

Cave-dwelling species limited to some karst areas in the Julian Alps and the Dinaric Mountains, in Italy and Slovenia (Condé 1974; Bareth 1988).

\section{Campodea (Paurocampa) ribauti Silvestri, 1912}

\section{Campodea (Paurocampa) ribauti Silvestri, 1912: 139, figs XXV-XXVI.}

\section{Diagnosis (Silvestri 1912; Denis 1932b; Bareth 2006)}

Body length 1.5-5.0 mm; epicuticle with microdenticles; short clothing setae with 1-3 distal barbs; antennae with 20-26 antennomeres; sensillum of third antennomere in dorsal position; cupuliform organ with four to five simple olfactory chemoreceptors; short $m a$ and $l a$ pronotal macrosetae with barbs along 
distal half, long $l p$ pronotal macrosetae with barbs almost from basis to distal two-thirds (Bareth (2006) noted that the middle-sized macrosetae on the pronotum are poorly barbed); marginal setae thick and with short barbs; $1+1$ la, $1+1$ lp macrosetae on VI-VII urotergites, $3+3$ l $p$ on VIII urotergite and $5+5$ lp on IX abdominal segment; cerci shorter than body with 11 articles covered in long macrosetae with barbs and a few clothing setae; small spermatozoid fascicles 20-25 $\mu \mathrm{m}$ in diameter and $3 \mu \mathrm{m}$ wide, spiral filament with $1.5 \times, 100 \mu \mathrm{m}$ long and $0.5-1 \mu \mathrm{m}$ in diameter.

\section{Habitat and distribution}

Soil-dwelling species with a preference for the upper layer of the soil in humid habitats, also found in caves. It has a limited distribution in the central area of the Pyrenees (Denis 1932b; Condé 1948a, Condé \& Mathieu 1957).

\section{Campodea (Paurocampa) rocasolanoi Silvestri, 1932}

Campodea (Paurocampa) rocasolanoi Silvestri, 1932: 159, fig. XIX.

Diagnosis (Silvestri 1932a; Condé 1947c; Condé \& Mathieu 1957; Bareth 2006)

Body length 2.0-4.0 mm; epicuticle with microdenticles; short clothing setae with small distal barb; antennae with 16-21 antennomeres; sensillum of third antennomere in dorsal position; middle-sized, barbed pronotal macrosetae; thin pine cone marginal setae; $1+1 l a, 1+1 l p$ macrosetae on VII urotergite; $3+3 l p$ on VIII urotergite and $5+5 l p$ on IX abdominal segment; cerci shorter than body with 10-15 articles covered in middle-sized macrosetae with barbs along distal half on proximal articles with abundant short smooth setae, but on distal articles only abundant setae.

\section{Habitat and distribution}

Soil-dwelling species with a preference for the upper layers of the soil but also found in its distribution area on colluvial scree slopes habitats (Sendra et al. 2017a). It is distributed in the western half of the Pyrenees Mountains (Condé 1947c; Condé \& Mathieu 1957), extending towards to the Cantabrian and Iberian Mountains (Sendra \& Moreno 2006). The record from the Dinaric Mountains (Blesić 2000a) should be carefully revised with new material from those localities.

\section{Campodea (Paurocampa) ruseki Condé, 1966}

Campodea (Paurocampa) ruseki Condé, 1966: 167, figs a-b.

Diagnosis (Condé 1954, 1966)

It was described based on thirteen badly preserved specimens from the Austrian Alps, but Condé (1954) was able to discover two features that do not fit with its closest congener $C$. (P.) suensoni Tuxen, 1930: the existence of one bacilliform sensillum on the trochanter and the remarkable presence of only $2+2 l p$ macrosetae, well barbed on the VIII urotergite.

\section{Habitat and distribution}

Soil-dwelling species known from two localities in the Austrian Alps (Condé 1954).

Campodea (Paurocampa) spelaea Ionescu 1955

Campodea (Paurocampa) spelaea Ionescu 1955: 39, fig. 16a-b.

Differential diagnosis from C. (P.) suensoni (Condé 1974; Ionescu 1955)

Smooth and thinner notal marginal setae, antennae with 28 antennomeres and slightly thicker sensillum of third antennomere are the only features to differentiate $C$. $(P)$. spelaeae from $C$. $(P$.$) suensoni$ 


\section{Habitat and distribution}

Cave-dwelling species collected from several caves in the Romanian Carpathians (Ionescu 1955; Condé 1974; Sendra et al. 2012).

\section{Campodea (Paurocampa) suensoni Tuxen, 1930}

Fig. 9-10, 17, 57

Campodea (Paurocampa) suensoni Tuxen, 1930: 221, figs 1-2.

Diagnosis (Bareth 1978; Condé 1966, 1974)

Body length 1.4-6.0 mm; smooth epicuticle; short, smooth clothing setae with distal barb; antennae with 24-33 antennomeres; sensillum of third antennomere in dorsal or ventral position; cupuliform organ with four round simple olfactory chemoreceptors; notal macrosetae with a few thin distal barbs; thin pine cone marginal setae; $3+3 l p$ macrosetae on VIII urotergite and $5+5 l p$ on IX abdominal segment; male with round appendages without glandular $a_{2}$-setae; cerci with thin smooth macrosetae or with a few distal tiny barbs; small spermatozoid fascicles $28-30 \mu \mathrm{m}$ in diameter, spiral filament with half to one spiral, $50 \mu \mathrm{m}$ long and $0.5 \mu \mathrm{m}$ diameter.

\section{Taxonomic notes}

Based on the newly available material (Supplementary file 2), this species was studied in the SEM (Figs 9-10, 17) and its pronotum is illustrated (Fig. 57).

\section{Habitat and distribution}

Soil-dwelling species found also at the entrance of caves and in their deep zones when abundant organic matter is available (Condé 1974; Sendra et al. 2012). It is common and well distributed in central and eastern Europe (Tuxen 1930; Paclt \& Rusek 1961; Condé 1956a; Rusek 1965b; Paclt 1969; Blesić 1984, 1997a, 2001; Christian 1992; Sendra et al. 2012), extending its distribution southerly towards central Italy (Condé 1966; Ramellini 2000).

Genus Edriocampa Silvestri, 1933

Fig. 62

Edriocampa Silvestri, 1933a: 69.

Diagnosis, habitat and distribution (Condé 1984; Sendra et al. 2010; Silvestri 1933a)

Notal formula with $1+1 m a, 1+1$ la, $1+1$ lp macrosetae on pronotum; without dorsal femoral macrosetae; without tibial ventral macrosetae; subequal claws without lateral crests slightly curved from their base; long and large laminar telotarsal process with barbs on both sides; $2+2$ lp macrosetae on VIII urotergite; first urosternite with $7+7$ macrosetae; $6+6$ on II-VII urosternites, $1+1$ on VIII urosternite; first male urosternite with large area of glandular $g_{1}$-setae and square short appendages; female with subcylindrical appendages with glandular $a_{1}$-setae. Edriocampa is a monospecific genus proposed for a soil-dwelling species, found on the southern Aegean islands and the Anatolian Peninsula (Fig. 62), closely related with Eutrichocampa Silvestri, 1902 and Libanocampa Condé, 1955 (Condé 1984) that need a taxonomical revision (Condé 1956a). 

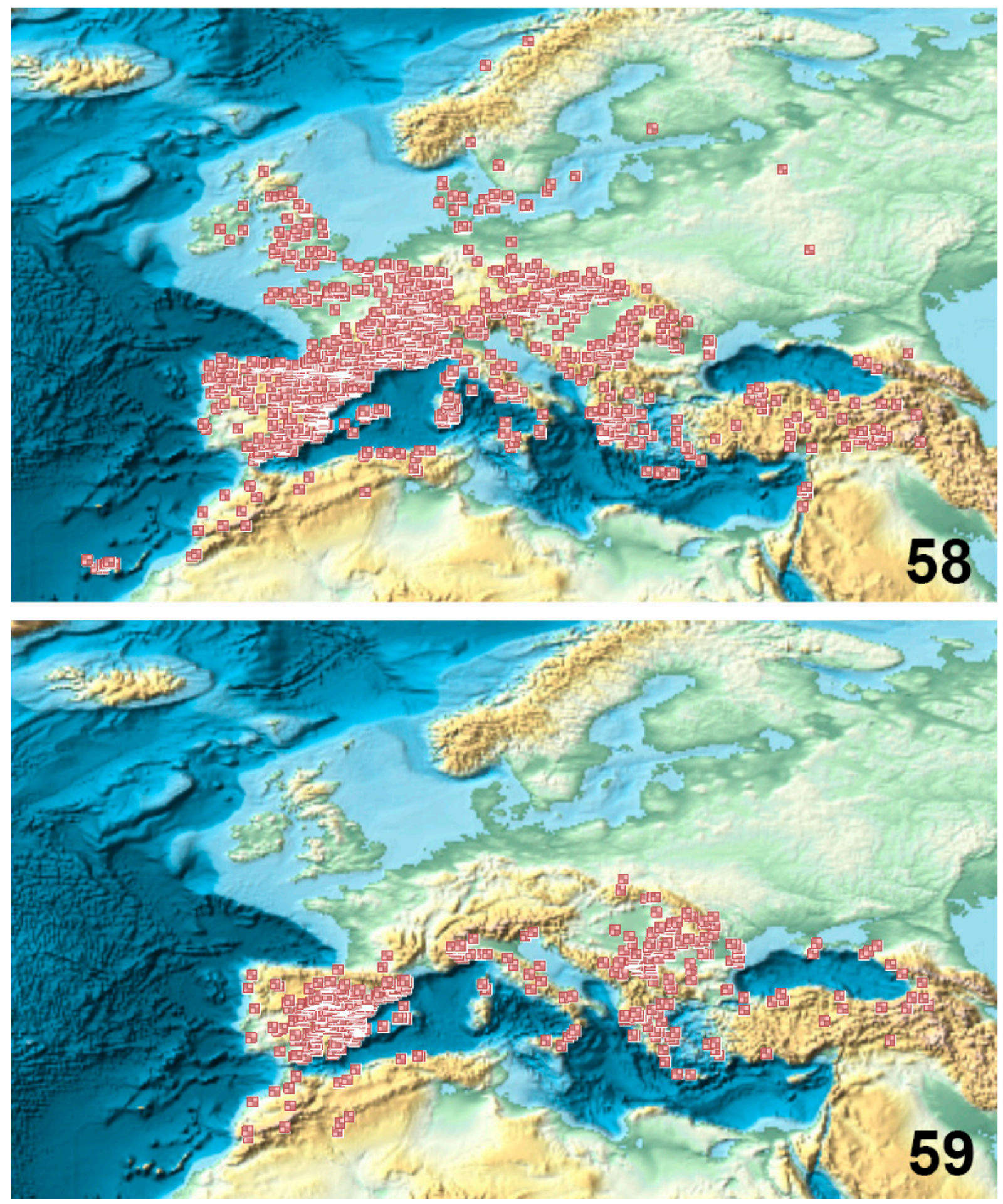

Figs 58-59. Distribution in the Euro-Mediterranean region, including Azores and Canaries. 58. Subgenus Campodea s. str. Silvestri, 1932. 59. Subgenus Dicampa Silvestri, 1932. 

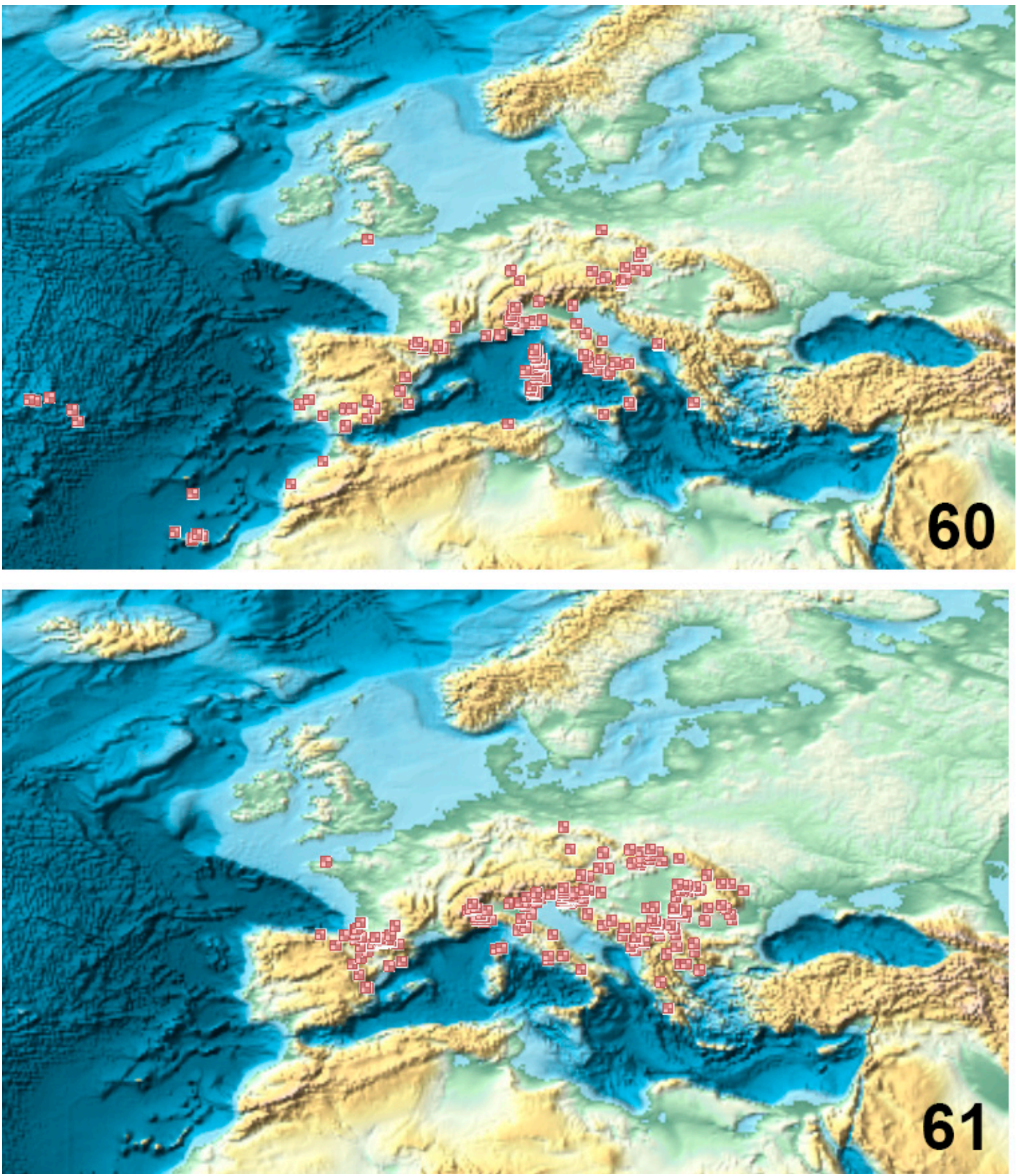

Figs 60-61. Distribution in the Euro-Mediterranean region, including Azores and Canaries. 60. Subgenus Monocampa Silvestri, 1932. 61. Subgenus Paurocampa Silvestri, 1932. 


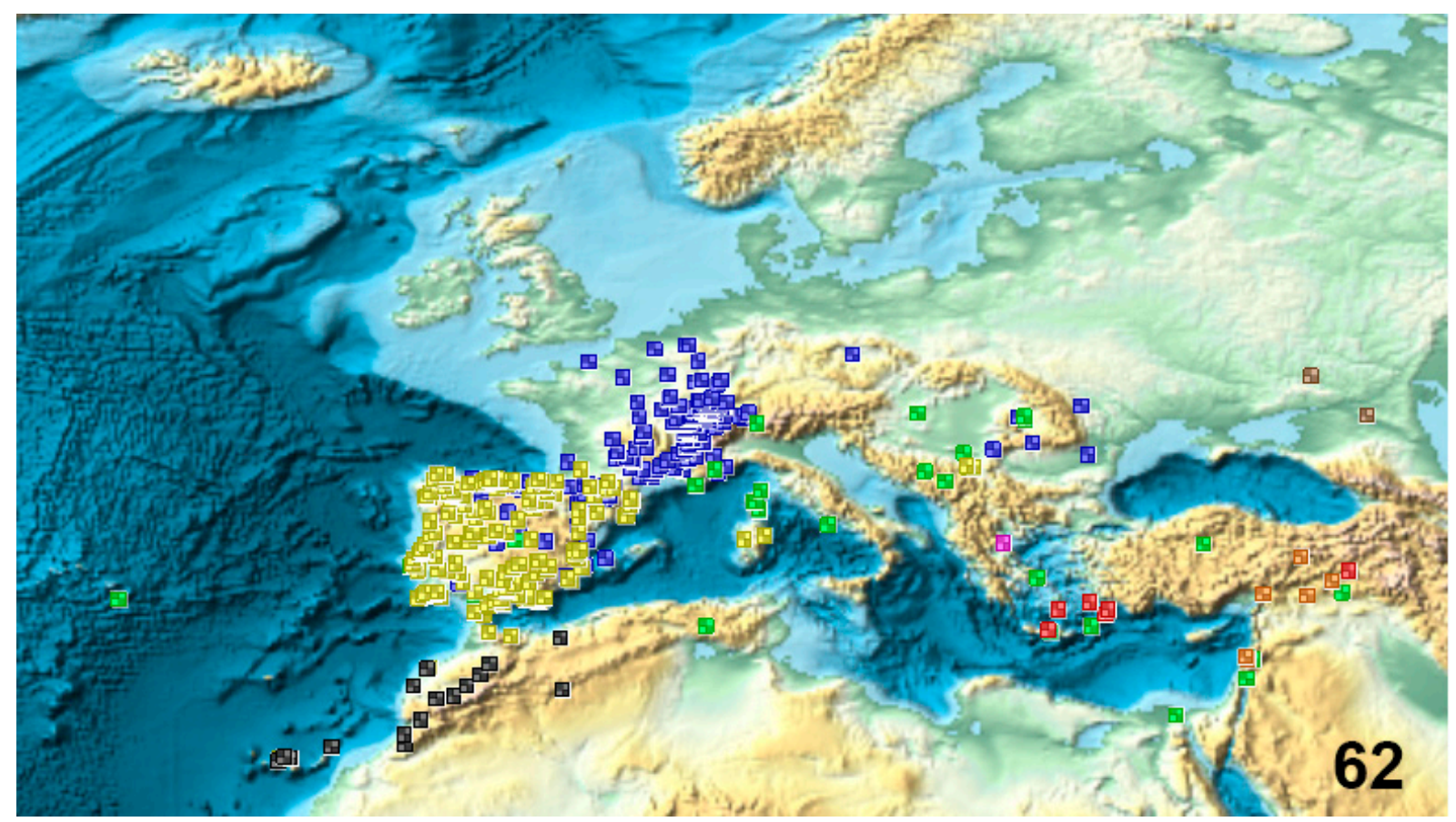

Fig. 62. Distribution in the Euro-Mediterranean region, including Azores and Canaries of Eutrichocampa Silvestri, 1932 (green), Remycampa Condé, 1952 (black), Podocampa Silvestri, 1932 (yellow), Litocampa Silvestri, 1933 (blue), Edriocampa Silvestri, 1933 (red), Libanocampa Condé, 1955 (black brown) and Oreocampa Condé, 1950 (light brown).

\section{Edriocampa ghigii Silvestri, 1933}

Edriocampa ghigii Silvestri, 1933a: 69, figs VI-VII.

Diagnosis (Silvestri 1933a; Condé 1984; Sendra et al. 2010)

Body length 2.5-3.0 mm; epicuticle with microdenticles; short clothing setae; antennae with 23-31 antennomeres; sensillum of third antennomere in dorsal (Anatolian Peninsula) or ventral (Crete Island) positions; $1+1 \mathrm{ma}, 1+1$ la, $1+1 \mathrm{lp}$ macrosetae on pronotum; $m a$ and la short pronotal macrosetae but long $l p$; marginal setae similar to clothing setae; calcars with some barbs; subequal claws with long and large laminar telotarsal process with barbs in both sides; $2+2$ lp macrosetae on VIII urotergite; first urosternite with $7+7$ macrosetae; $6+6$ on II-VII urosternite, $1+1$ on VIII urosternite; first male urosternite with large area of glandular $g_{1}$-setae and squares short appendages; female with subcylindrical appendages with glandular $a_{1}$-setae; cerci shorter than body with 11 articles covered in long macrosetae with barbs and a few clothing setae.

\section{Habitat and distribution}

Soil-dwelling species known from South Aegean islands (Silvestri 1933a; Condé 1984) and in the Anatolian Peninsula (Sendra et al. 2010). 
Genus Eutrichocampa Silvestri, 1902

Eutrichocampa Silvestri, 1902: 240.

\section{Diagnosis, habitat and distribution}

In spite of the effort made by Condé (1956a) to maintain the genus Eutrichocampa, the eleven species of Eutrichocampa described show a staggering variability in different characters, which led Paclt (1957) to propose five subgenera and a genus for them. Species of Eutrichocampa (in a wide sense) have been found on four continents: South America, Africa, Asia and Europe. The laminar or subcylindrical telotarsal process with abundant barbs is the only, presumably synapomorphic, feature to gather all these soil dwelling species. The claws are smooth and have no lateral crests. In the present monograph, we follow the criteria of Condé (1956a) for Eutrichocampa, meaning that in Europe and in the Mediterranean regions seven species have been described (Fig. 62).

Eutrichocampa aegea Silvestri, 1933

Eutrichocampa aegea Silvestri, 1933a: 66, figs IV-V.

Diagnosis (Silvestri 1933a; Sendra et al. 2006, 2010)

Body length $3 \mathrm{~mm}$; short clothing setae; antennae with 22-28 antennomeres; sensillum of third antennomere in ventral position; $1+1 \mathrm{ma}, 1+1 \mathrm{la}, 1+1 \mathrm{lp}$ macrosetae on pronotum and mesonotum, $1+1$ $m a$ on metanotum; long barbed notal macrosetae; marginal setae slightly longer than clothing setae; without dorsal femoral macrosetae; one ventral tibial macroseta; calcars with some barbs; subequal claws slightly curved from base; laminar telotarsal process with barbs on ventral side; $1+1 l a, 1+1$ $l p$ macrosetae on V-VII: $3+3$ lp macrosetae on VIII urotergite and $5+5$ lp on IX abdominal segment; urosternite I with 6+6 macrosetae, urosternites II-VII with 4+4; urosternite VIII with 1+1 macrosetae; first male urosternite with glandular $g_{I}$-setae and subcylindrical appendages; female with subcylindrical appendages with glandular $a_{l}$-setae; cerci covered in long macrosetae with barbs and a few clothing setae.

\section{Habitat and distribution}

Soil-dwelling species inhabiting the southeastern Mediterranean region, from the Aegean Islands, southeastern Mediterranean to the Anatolian Peninsula (Silvestri 1933a; Wygodzinsky 1942; Condé 1955a; Sendra et al. 2006, 2010).

Eutrichocampa collina Ionescu, 1955

Eutrichocampa collina Ionescu, 1955: 46, figs 20-21.

Diagnosis (Ionescu 1955; Condé 1984; Sendra et al. 2012)

Body length $2.7 \mathrm{~mm}$; epicuticle without microdenticles; short, smooth clothing setae; antennae with 22 antennomeres; sensillum of third antennomere in ventral position; cupuliform organ with four simple olfactory chemoreceptors; $1+1 \mathrm{ma}, 1+1 \mathrm{la}, 1+1 \mathrm{lp}$ macrosetae on pronotum; pronotal macrosetae poorly barbed; marginal setae similar to clothing setae; without dorsal femoral macrosetae; calcars with 1-2 thin barbs; one ventral tibial macroseta with one thin distal barb; smooth subapical tarsal setae; subequal smooth claws slightly curved from base; laminar telotarsal process with long barbs on ventral side; $1+1$ la macrosetae on V-VII urotergites, $3+3 l p$ on VIII urotergite and $5+5 l p$ on IX abdominal segment; first urosternite with $4+4$ macrosetae, $3+3$ on II-VII urosternites, $1+1$ on VIII urosternite; female subcylindrical appendages with glandular $a_{1}$-setae; cerci covered in long macrosetae with barbs and a few clothing setae. 
Eutrichocampa collina ithacesia Condé, 1984

Eutrichocampa collina ithacesia Condé, 1984: 189.

Differential diagnosis from the f. typ. (Condé 1984)

Antennae with 23-25 antennomeres; without la macrosetae on V-VII urotergites.

\section{Habitat and distribution}

Soil-dwelling species found at several localities in the east of the Balkan Peninsula (Blesić 1996, 1997c; Ionescu 1955), and E. collina ithacesia on Ithaca Island (Condé 1984).

Eutrichocampa helvetica Wygodzinsky, 1941

Eutrichocampa helvetica Wygodzinsky, 1941: 123, figs 25-33, table 3.

Leniwytsmania helvetica Paclt, 1957: 30, fig. 19.

Diagnosis (Wygodzinsky 1941a)

Body length $3.5 \mathrm{~mm}$; thin, smooth clothing setae; antennae with 24 antennomeres; $1+1 \mathrm{ma}, 1+1 \mathrm{la}$, $1+1$ l $p$ on pronotum; pronotal macrosetae poorly barbed; long, thin marginal setae with 2-3 thin distal barbs; one dorsal femoral macrosetae; short ventral tibial macrosetae with a distal barb; subequal smooth claws slightly curved from base; setiform telotarsal process covered with long barbs; $1+1$ la macrosetae on V-VII urotergites; $3+3$ lp on VIII urotergite; urosternite I with 7+7 macrosetae; urosternite VIII with 1+1 macrosetae; female subcylindrical appendages with glandular $a_{1}$-setae; cerci half of body length with 9 articles covered in long macrosetae with 1-4 distal barb and a few clothing setae.

\section{Habitat and distribution}

Soil-dwelling species known from a single locality in Switzerland (Wygodzinsky 1941a).

Eutrichocampa hispanica Silvestri, 1932

Eutrichocampa hispanica Silvestri, 1932: 161, figs XX-XXI.

Diagnosis (Silvestri 1932a, Condé \& Barbier 1957)

Body length 2.2-3.0 mm; long clothing setae; antennae with 19-24 antennomeres; sensillum of third antennomere in ventral position; cupuliform organ with four simple olfactory chemoreceptors; $1+1 \mathrm{ma}, 1+1 \mathrm{la}, 1+1 \mathrm{lp}$ macrosetae on pronotum and mesonotum, $1+1 \mathrm{ma}, 1+1 \mathrm{lp}$ on metanotum; long, barbed notal macrosetae; smooth marginal setae; one dorsal femoral macrosetae; one short ventral tibial macroseta; sharp ending of tarsus; hook-shaped claws with unguiculus; laminar telotarsal process with long barbs on ventral surface; $1+1$ ma macrosetae on I-VII urotergites, $1+1 l a, 1+1 l p$ on IV-VII urotergites, $1+1 \mathrm{ma}, 3+3 \mathrm{lp}$ on VIII urotergite and $1+1 \mathrm{mp}, 5+5 \mathrm{l} p$ on IX abdominal segment; urosternite I with $6+6$ macrosetae; urosternites II-VII with $4+4$ and urosternite VIII with $1+1$ macrosetae; first male urosternite without glandular $g_{1}$-setae, subtrapezoidal appendages with glandular $a_{l}$ and $a_{2}$-setae; female subcylindrical appendages with glandular $a_{1}$-setae; cerci shorter than body with 11 articles covered in long macrosetae with barbs and a few clothing setae.

\section{Habitat and distribution}

Soil-dwelling species known from several localities in southeastern Iberian Peninsula (Silvestri 1932a; Wygodzinsky 1944a; Sendra \& Jiménez 1986). Its presence in Santa Maria Island (Azores) may be considered as invasive (Condé \& Barbier 1957). 
Eutrichocampa paurociliata Loksa, 1960

Eutrichocampa paurociliata Loksa, 1960: 260, figs 10-17.

Diagnosis (Loksa 1960)

Body length $3.2 \mathrm{~mm}$; short clothing setae; antennae with 20 antennomeres; $1+1 \mathrm{ma}, 1+1 \mathrm{la}, 1+1 \mathrm{lp}$ macrosetae on pronotum and $1+1$ la on mesonotum; notal macrosetae with $1-2$ barbs, except $l p$ with barbs along distal one-third to two-thirds; without dorsal femoral macrosetae; laminar telotarsal process with longs barbs on ventral side; $1+1$ la macrosetae on V-VII urotergites, $3+3$ lp on VIII urotergite and $5+5 \mathrm{lp}$ on IX abdominal segment; cerci shorter than body with 14 articles covered in long macrosetae and a few clothing setae.

\section{Habitat and distribution}

Only known from one cave near Balatonfüred, Hungary (Loksa 1960).

Eutrichocampa remyi Condé, 1947

Eutrichocampa remyi Condé, 1947b: 60, figs a-k.

Diagnosis (Condé 1947b)

Body length $2.0 \mathrm{~mm}$; short clothing setae; antennae with 20-21 antennomeres; $1+1 \mathrm{ma}, 1+1 \mathrm{la}, 1+1 \mathrm{lp}$ macrosetae on pronotum and 1+1 la macrosetae on mesonotum; $m a$ and $l a$ pronotal macrosetae with 1-2 dital barbs, $l p$ pronotal macrosetae with barbs along distal two-thirds and la mesonotal macrosetae with barbs along distal half; marginal setae similar to clothing setae but with 1-2 distal barbs; without dorsal femoral macrosetae; calcars with 2-3 distal barbs; one ventral tibial macroseta with two thin distal barbs; smooth subapical tarsal setae; subequal claws slightly regularly curved; laminar telotarsal process with longs barbs on ventral side; $1+1$ la macrosetae on V-VII urotergites, $3+3$ lp on VIII urotergite and $5+5$ lp on IX abdominal segment; first urosternite with $7+7$ macrosetae, $4+4$ on II-VII urosternites, $1+1$ on VIII urosternite; female with subcylindrical appendages with glandular $a_{l}$-setae; cerci shorter than body with 8 articles covered with long macrosetae with barbs along distal half and a few clothing setae.

\section{Habitat and distribution}

Soil-dwelling species known from several localities in eastern Balkans (Condé 1947b).

Eutrichocampa thamugadensis Condé, 1947

Eutrichocampa thamugadensis Condé, $1947 \mathrm{~g}$ : 145, figs a-f.

Meiocampa thamugadensis Paclt, 1957: 31.

Diagnosis (Condé 1947g, 1952b; Bareth 2006; Sendra et al. 2010)

Body length 2.5-3.0 mm; long, smooth clothing setae; antennae with 22-29 antennomeres; sensillum of third antennomere in dorsal position; $1+1 \mathrm{ma}, 1+1 \mathrm{la}, 1+1 \mathrm{lp}$ macrosetae on pronotum and mesonotum, $1+1 m a, 1+1 l p$ on metanotum; long, thin notal macrosetae with many thin barbs; thin marginal setae similar to clothing setae; calcars with a few barbs; without dorsal femoral macrosetae; one ventral tibial macroseta with distal barb; smooth subapical tarsal setae; subequal claws slightly regularly curved; laminar telotarsal process with very short barbs on ventral side; $1+1 l p$ macrosetae on IV urotergite, $1+1$ $l a, 1+1$ lp on V-VII urotergites, $3+3$ lp on VIII urotergite and 5+5 lp on IX abdominal segment; urosternite I $7+7$ macrosetae; urosternite II-VII 6+6; ursternite VIII 1+1 macrosetae; first male urosternite I with glandular $g_{1}$-setae and appendages with glandular $a_{1}$ and $a_{2}$ setae; female with glandular $a_{1}$-setae; cerci a little bit longer than body covered in long macrosetae with barbs and a few clothing setae. 


\section{Habitat and distribution}

Soil-dwelling species known from a few localities in southeastern France (Condé 1947g), Corsica (Condé 1952b), Algeria (Condé 1947g), the Pontine Islands (Condé 1978b) and Anatolia (Sendra et al. 2010).

Genus Helladocampa Condé, 1984

Helladocampa Condé, 1984: 190, figs 5a-c, 6a-b.

\section{Diagnosis, habitat and distribution (Condé 1984)}

Notal formula with $1+1 \mathrm{ma}, 1+1 \mathrm{la}, 1+1 \mathrm{lp}$ macrosetae on pronotum and mesonotum, $1+1 \mathrm{ma}, 1+1 \mathrm{lp}$ on metanotum; without dorsal femoral macrosetae; with one ventral tibial macroseta ; subequal, smooth and slightly regularly curved claws; setiform smooth telotarsal; $1+1 l a$ and $2+2 l p$ on V-VII urotergites, $3+3 l p$ on VIII urotergite and $5+5 l p$ on IX abdominal segment; first urosternite with $6+6$ macrosetae, $4+4$ on II-VII urosternites and $1+1$ on IX urosternite; first male urosternite with glandular $g_{1}$-setae and squares appendages with glandular $a_{1}$-setae and $a_{2}$-setae. Helladocampa is a monospeciphic genus described from a single young male from Epirus in Greece (Condé 1984).

\section{Helladocampa mahnerti Condé, 1984}

Helladocampa mahnerti Condé, 1984: 190, figs 5a-c, 6a-b.

Diagnosis (Condé 1984)

Body length $2.8 \mathrm{~mm}$; epicuticle without microdenticles; smooth thin clothing setae; sensillum of third antennomere in dorsal position; $1+1 \mathrm{ma}, 1+1 \mathrm{la}, 1+1 \mathrm{lp}$ macrosetae on pronotum and mesonotum, $1+1 \mathrm{ma}, 1+1 \mathrm{lp}$ on metanotum; long, thin notal macrosetae smooth or with 1-2 long barbs, notal $l p$ macrosetae extremely long; smooth or poorly barbed marginal setae longer than clothing setae; smooth subapical tarsal setae; $1+1$ lp macrosetae on IV urotergite, $1+1$ la , 2+2 lp on V-VII urotergites, $3+3$ lp on VIII urotergite, $5+5$ lp on IX abdominal segment; thin long urotergal marcrosetae; apparently described from a juvenile male with a few glandular $g_{1}$-setae on first urosternite and with quadrangular appendages with glandular $a_{1}$ and $a_{2}$-setae.

\section{Habitat and distribution}

Soil-dwelling species known from a single locality in Epirus, Greece (Condé 1984).

Genus Libanocampa Condé, 1955

Libanocampa Condé, 1955a: 404.

Diagnosis, habitat and distribution (Condé 1955a)

Notal formula with $1+1 \mathrm{ma}, 1+1$ lp macrosetae on pronotum, $1+1$ sma (submarcrosetae) on mesonotum; without dorsal femoral macrosetae; one ventral tibial macroseta with distal barb; smooth subequal simple claws slightly regularly curved, with laminar telotarsal process ending in subtrapezoidal enlargement ending, with and without fine pubescence; $2+2 l p$ macrosetae on VIII urotergite and $4+4 l p$ on IX abdominal segment; first urosternite with $6+6$ macrosetae, $4+4$ on II-VII urosternite, $1+1$ on VIII urosternite; first male urosternite with glandular $g_{l}$-setae and subtrapezoidal appendages with glandular $a_{1}$-setae and $a_{2}$-setae; female appendages with glandular $a_{1}$-setae. Libanocampa is a monotypic genus closely related to Edriocampa and living in soil habitats of western Asia: Lebanon (Condé 1955a) and Anatolia (Sendra et al. 2010) (Fig. 62). 
Libanocampa coiffaiti Condé, 1955

Fig. 62

Libanocampa coiffaiti Condé, 1955a: 404, fig. 2.

Diagnosis (Condé 1955a; Sendra et al. 2010)

Body length 2.0-3.0 mm; epicuticle with microdenticles; short clothing setae; antennae with 18-25 antennomeres; small sensillum of third antennomere in ventral position; $1+1 \mathrm{ma}, 1+1 \mathrm{lp}$ macrosetae on pronotum, 1+1 sma (submarcrosetae) on mesonotum; short notal macrosetae except long $l p$ pronotal macrosetae; marginal setae similar to clothing setae; $2+2 l p$ macrosetae on VIII urotergite and $4+4 l p$ on IX abdominal segment; first male urosternite with glandular $g_{l}$-setae and subtrapezoidal appendages with glandular $a_{1}$-setae and $a_{2}$-setae; female appendages with glandular $a_{1}$-setae; genital papilla in male with pair of noticeable curved setae observed in Anatolian specimens; cerci covered in long macrosetae with 3 barbs on proximal and 1 in distal articles and a few clothing setae.

\section{Habitat and distribution}

Soil-dwelling species found in the Lebanon (Condé 1955a) and the Taurus, Anatolia (Sendra et al. 2010) (Fig. 62).

\section{Genus Litocampa Silvestri, 1933}

Litocampa Silvestri, 1933c: 117.

Diagnosis (Silvestri 1933c; Condé 1956a)

Notal formula with $1+1 m a, 1+1 l a, 1+1$ lp macrosetae on pronotum; $1+1 m a, 0+0$ or $1+1 l a, 1+1 l p$ on mesonotum, $0+0$ or $1+1 m a, 0+0$ or $1+1$ l $p$ on metanotum; with or without dorsal femoral macrosetae; one or two ventral tibial macrosetae; subequal to unequal elbow-like claws with small to large sized smooth lateral crests and smooth setiform telotarsal process; $0+0,1+1$ or $2+2$ lp and $0+0$ or $1+1$ la macrosetae on III-VII urotergites; with or without medial anterior or medial posterior macrosetae on urotergites and abdominal segment; urosternite I with 7+7-6+6 macrosetae; II-VII with 6+6-4+4, although variability within each species not yet been studied. Species of Litocampa described outside North America and Europe (Paclt 1957) should be placed in other genera such as Cocytocampa Paclt, 1957 (Condé 1982a) or in new ones. The similarities found between some species of Podocampa is noticeable, the only difference seems to be small lateral claws and their similar distribution areas (Condé, 1956a).

\section{Habitat and distribution}

Among the 33 described species of Litocampa, including the American species, 23 inhabit cave ecosystems in their deep zones and are considered cave adapted. Although there are several soil-dwelling species in Europe, e.g., L. humilis (Condé, 1948), L. cognata (Condé, 1948) or L. tuzetai (Condé, 1948), the main life-style tendency is to inhabit caves as well as MSS (Bareth 1983; Condé 1956a; Condé \& Mathieu 1957; Sendra et al. 2013). Litocampa has a disjunt distribution on both sides of the Atlantic Ocean, it is found in karst territories and the regions surrounding the Appalachian Mountains in the United States (Condé 1949a) and in Europe from the Cantabrian Mountains throughout the Pyrenees towards the Central Massif in France (Condé 1956a; Sendra et al. 2003) in many caves, and reaching central and eastern Europe in moisty habitats, including natural and artificial caves (Condé 1956a; Sendra et al. 2012) (Fig. 62). 
Taxonomic key for species of the genus Litocampa

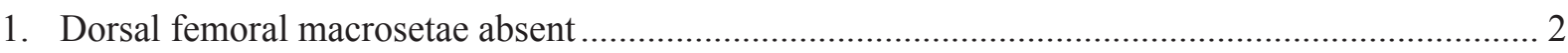

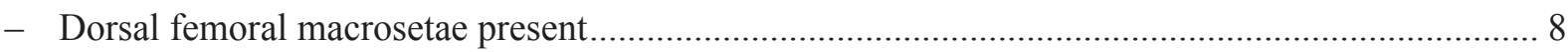

2. Lateral posterior metanotal macrosetae $1+1$; lateral anterior macrosetae of the fifth urotergite $1+1$..

- Without lateral posterior metanotal macrosetae; whithout lateral anterior macrosetae of the fifth urotergite......

3. Male $g_{1}$ glandular setae present in two separated areas; without lateral posterior macrosetae of the fifth urotergite

Litocampa vandeli (Condé, 1947)

- Male $g_{l}$ glandular setae present in a continuous area; lateral posterior macrosetae of the fifth urotergite $1+1$

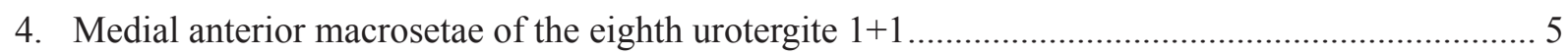

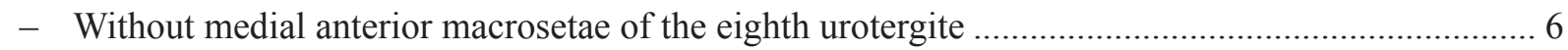

5. Medial posterior macrosetae of the ninth abdominal segment $1+1$; cave-adapted body shape; complex sensillum of the cupuliform organ Litocampa tuzetai (Condé, 1948)

- Without medial posterior macrosetae of the ninth abdominal segment; body shape non-cave-adapted; simple sensillum of the cupuliform organ

Litocampa montana (Ionescu, 1955)

6. Medial anterior macrosetae of the first urotergite 1+1; medial anterior macrosetae of the second urotergite $1+1$; medial anterior macrosetae of the third urotergite $1+1$; medial anterior macrosetae of the fourth urotergite $1+1$

- Without medial anterior macrosetae in first to fourth urotergites

Litocampa cognata (Condé, 1948)

Litocampa humilis (Condé, 1948)

7. Medial anterior metanotal macrosetae $1+1$; lateral anterior macrosetae of the sixth urotergite $1+1$; lateral posterior macrosetae on sixth and seventh urotergites 1+1 Litocampa sollaudi (Denis, 1930)

- Without medial anterior metanotal macrosetae; without lateral anterior macrosetae of the sixth urotergite; without lateral posterior macrosetae on sixth and seventh urotergites.

Litocampa bourgoini (Condé, 1948)

8. Male $g_{1}$ glandular setae absent

- Male $g_{1}$ glandular setae present in a continuous area..

9. Medial anterior macrosetae of the first urotergite $1+1$; medial anterior macrosetae on second to fourth urotergites $1+1$

Litocampa mendesi Sendra \& Reboleira, 2010

- Without medial anterior macrosetae on first to fourth urotergites.....

Litocampa espanoli (Condé, 1949)

10. Lateral anterior pronotal macrosetae $2+2$

Litocampa quadrisetigera Bareth, 2001

- Lateral anterior pronotal macrosetae $1+1$

11. Lateral posterior macrosetae of the fourth urotergite $2+2$

Litocampa zaldivarae Sendra, Salgado \& Monedero, 2003

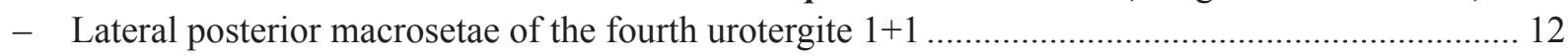

- Without lateral posterior macrosetae of the fourth urotergite........................................................ 13 
12. Lateral posterior macrosetae of the fifth to seventh urotergites $2+2$; medial posterior macrosetae of the eighth urotergite $1+1$

Litocampa hubarti Bareth, 1999

- Lateral posterior macrosetae of the fifth to seventh urotergites 1+1; without medial posterior macrosetae of the eighth urotergite.

Litocampa henryi Condé, 1951

13. Male $a_{2}$ glandular setae absent.

Litocampa drescoi (Condé, 1949)

- Male $a_{2}$ glandular setae present

Litocampa coiffaiti (Condé, 1948)

Litocampa bourgoini (Condé, 1948)

Plusiocampa bourgoini Condé, 1948a: 39, fig. 1g-h.

Diagnosis (Condé 1948a, 1962; Bareth 2006)

Body length 3.0-5.0 mm; epicuticle without microdenticles; smooth clothing setae; antennae with 3034 antennomeres; sensillum of third antennomere in ventral position; slightly prominent frontal process non-tubercular setae; $1+1 \mathrm{ma}, 1+1 \mathrm{la}, 1+1 \mathrm{lp}$ macrosetae on pronotum and $1+1 \mathrm{ma}, 0+0$ or $1+1 \mathrm{la}, 1+1 \mathrm{lp}$ on mesonotum; long, barbed notal macrosetae; barbed marginal setae longer than clothing setae; long metathoracic legs reaching end of abdomen; without dorsal femoral macrosetae; with one ventral tibial setae; calcars with barbs almost from basis; smooth subapical tarsal setae; unequal elbow-like claws with smooth large lateral crests, posterior claw slightly prolonged backwards; $0+0$ or $1+1$ la macrosetae on VII urotergite, $3+3 l p$ on VIII urotergite and $5+5 l p$ on IX abdominal segment; first urosternite with $6+6$ macrosetae, $4+4$ on II-VII urosternites, $1+1$ on VIII urosternite; male with glandular $g_{1}$ setae, subtrapezoidal appendages with glandular $a_{l}$-setae; females with subcylindrical appendages with glandular $a_{1}$-setae; spermatozoid fascicles $60-70 \mu \mathrm{m}$ in diameter and $20 \mu \mathrm{m}$ wide, spiral filament with 5-7 spirals, $1100-1200 \mu \mathrm{m}$ long and $6 \mu \mathrm{m}$ in widest diameter of its elongated section.

\section{Habitat and distribution}

It has been found in caves of the Jura Mountains in France and Switzerland (Condé 1948a, 1962), occasionally syntopic with the more frequent $L$. sollaudi.

\section{Litocampa cognata (Condé, 1948)}

Plusiocampa cognata Condé, 1948b: 49, fig. 1g-i.

Diagnosis (Condé 1948b; Bareth 1983, 2006; Bareth \& Juberthie-Jupeau 1984)

Body length 3.5-6.0 mm; middle-sized, smooth clothing setae; antennae with 30-34 antennomeres; sensillum of third antennomere in ventral position; cupuliform organ with four complex olfactory chemoreceptors; without frontal process; $1+1 \mathrm{ma}, 1+1 \mathrm{la}, 1+1 \mathrm{lp}$ macrosetae on pronotum and mesonotum and 1+1 $\mathrm{ma}, 1+1 \mathrm{lp}$ on metanotum; long notal macrosetae with a few thin barbs; marginal setae slightly longer than clothing setae with 1-2 thin barbs; without dorsal femoral macrosetae but sometimes with a submacroseta in its position; one short ventral tibial macroseta smooth or with an apical barb; calcars with 3-4 barbs; smooth subapical tarsal setae; subequal, smooth, elbow-like claws with small, smooth, lateral crests; $1+1 \mathrm{ma}$ short to gradually longer macrosetae on I-VII urotergites, $1+1 l a, 1+1 l p$ on $\mathrm{V}-$ VII urotergites, $1+1 \mathrm{mp}, 3+3 \mathrm{lp}$ on VIII urotergite and $1+1 \mathrm{mp}, 5+5 \mathrm{lp}$ on IX abdominal segment; male without glandular $g_{1}$ and $a_{2}$-setae.

Litocampa cf. cognata from soil in Cuneo, Maritime Alps, Italy (Rammellini 2000) should be described as a new taxon due to important differences in the insertion of the medial anterior macrosetae on urotergite VIII and abdominal segment IX.

\section{Habitat and distribution}

This species dwells in soil, cave and MSS habitats (Bareth 1983) from the northern slopes of the Ariège Pyrenees to the Cévennes (Condé 1948b). 
Litocampa coiffaiti (Condé, 1948)

Plusiocampa coiffaiti Condé, 1948a: 41, figs 2c-d, 3a-d.

Diagnosis (Condé 1948a, 1949c; Bareth 2006)

Body length 4.7-7.5 mm. long, smooth clothing setae; antennae with 38-45 antennomeres; sensillum of third antennomere in ventral position; cupuliform organ with eight to ten complex olfactory chemoreceptors; $1+1 \mathrm{ma}, 1+1 \mathrm{la}, 1+1 \mathrm{lp}$ macrosetae on pronotum and mesonotum, $1+1 \mathrm{ma}, 1+1 \mathrm{lp}$ on metanotum; thin notal macrosetae with barbs along the distal two-thirds; thick, long, barbed marginal setae; one dorsal femoral macroseta; two ventral tibial macrosetae with one distal barb; calcars barbed one side along their length; smooth apical setae; unequal grooved elbow-like claws with small and smooth lateral crests, but posterior claw slightly prolonged backwards, smooth setiform telotarsal processes; $1+1$ short $m a$ macrosetae on I-VII urotergites; $2+2$ lp on V-VII urotergites; $1+1$ short ma, $3+3 l p$ on VIII urotergite and $1+1 \mathrm{mp}, 5+5 \mathrm{lp}$ on IX abdominal segment; male with continuous area of glandular $g_{1}$-setae, and subcylindrical enlarged appendages with glandular $a_{2}$-setae; cerci longer than body with 8 articles covered in thin macrosetae along distal half in basal articles and with tiny apical barb in basal articles.

\section{Habitat and distribution}

Cave-dwelling species found in several caves along the axial zone of the Pyrenees (Condé 1948a, 1955a; Sendra \& Escolà 2004).

Litocampa drescoi (Condé, 1949)

Plusiocampa drescoi Condé, 1949: 572, fig. 2b.

Litocampa drescoi - Paclt 1957: 26.

Diagnosis (Condé 1949c; Condé \& Mathieu 1957; Sendra 1988)

Body length 3.0-5.0 mm; thick, smooth clothing setae; antennae with 29-36 antennomeres; sensillum of third antennomere in ventral position; cupuliform organ with 6-11 complex olfactory chemoreceptors; $1+1 \mathrm{ma}, 1+1 \mathrm{la}, 1+1 \mathrm{lp}$ macrosetae on pronotum and mesonotum and 1+1 $\mathrm{ma}, 1+1 \mathrm{lp}$ on metanotum; long, barbed notal macrosetae; long with distal barbs notal marginal setae; one dorsal femoral macrosetae; calcars barbed one side along their length; one ventral tibial macroseta; smooth subapical tarsal setae; subequal grooved elbow-like claws with small smooth lateral crests, smooth setiform telotarsal processes; $1+1 m a$ macrosetae on I-VII urotergites, $2+2 l p$ on V-VII urotergites, $1+1 m a, 3+3 l p$ on VIII urotergite and $1+1 \mathrm{mp}, 5+5 \mathrm{lp}$ on IX abdominal segment; male with glandular $g_{l}$-setae, subcylindrical enlarged appendages without glandular $a_{2}$-setae.

\section{Habitat and distribution}

Cave-dwelling species that has also been found in the MSS of scree slopes at high altitude (Condé \& Mathieu 1957). It is distributed throughout caves in the centre of the Pyrenees spreading at low altitudes at both sides of the mountain range (Condé 1949c; Sendra \& Escolà 2004).

Litocampa espanoli (Condé, 1949)

Figs $27-28$

Plusiocampa espanoli Condé, 1949c: 569, fig. 1.

Litocampa espanoli - Paclt 1957: 26. 
Diagnosis (Condé 1949c, 1982b)

Body length 4.0-9.5 mm; epicuticle without microdenticles under optical microscope but visible in SEM; smooth clothing setae; antennae with 40-53 antennomeres; sensillum of third antennomere in ventral position; prominent frontal process; cupuliform organ with seven to eight complex olfactory chemoreceptors; $1+1 \mathrm{ma}, 1+1 \mathrm{la}, 1+1 \mathrm{lp}$ macrosetae on promotum and mesonotum, $1+1 \mathrm{ma}, 1+1 \mathrm{lp}$ on metanotum; thick, long notal macrosetae with barbs along distal two-third to three-fourth; marginal setae longer and thicker than clothing setae with a few distal barbs; one dorsal femoral macroseta; one baciliform trochanteral sensillum; calcars with barbs along length; one but more frequently two ventral tibial machocaetae; smooth subapical tarsal setae; subequal elbow-like claws with small smooth lateral crests, smooth setiform telotarsal processes; $1+1 l p$ on III-IV urotergites; $1+1 l a, 2+2 l p$ on $\mathrm{V}-$ VII urotergites, $1+1 \mathrm{mp}, 3+3 \mathrm{lp}$ on VIII urotergite, $1+1 \mathrm{mp}, 5+5 \mathrm{lp}$ on IX abdominal segment; male without glandular $g_{l}$-setae (with $g_{l}$ in Cantabrian and Salvada Mountain specimens); male with large subtrapezoidal appendages with glandular $a_{1}$ and $a_{2}$ setae; long subcylindrical appendages in females slightly enlarged with glandular $a_{1}$ and $a_{2}$ setae; cerci covered in long macrosetae barbed along distal half and thin barbed clothing setae.

\section{Taxonomic notes}

The studied material (Supplementary file 2) has allowed to photograph some structures under SEM (Figs 27-28).

\section{Habitat and distribution}

Cave-dwelling species widely distributed in the Basque Mountains, Spain (Condé 1982b).

Litocampa aff. espanoli (Condé, 1949)

Differential diagnosis from the f. typ. (Condé, 1982b)

Shorter body; antennae with 25-41 antennomeres; and first urosternite of males with glandular $g_{1}$-setae.

\section{Habitat and distribution}

Cave-dwelling species well spread from the Basque to the Cantabrian Mountains, Spain (Condé 1982b).

Litocampa henryi Condé, 1991

Litocampa henryi Condé, 1991: 244.

Diagnosis (Condé 1991; Bareth 2006)

Body length 4.0-4.8 mm; epicuticle without microdenticles; smooth clothing setae; antennae with 28 antennomeres; thin long sensillum of third antennomere in ventral position; cupuliform organ with four simple olfactory chemoreceptors; without frontal process; $1+1 m a, 1+1 l a, 1+1 l p$ macrosetae on pronotum and mesonotum, $1+1 \mathrm{ma}, 1+1 \mathrm{lp}$ on metanotum; thick, long notal macrosetae with barbs along distal two-third; slightly thin pine cone marginal setae; one dorsal femoral macroseta; one ventral tibial macroseta; smooth apical tarsal setae; subequal grooved elbow-like claws with smooth and small lateral crests; $1+1$ lp macrosetae on IV urotergite, $1+1$ la, $1+1 l p$ on V-VII urotergites, $3+3 l p$ on VIII urotergite and $5+5 \mathrm{lp}$ on IX abdominal segment; male with glandular $g_{l}$-setae, subtrapezoidal appendages with glandular $a_{1}$ and $a_{2}$-setae; female appendages without glandular $a_{2}$-setae; cerci covered in long macrosetae with thin barbs along distal half and a few smooth clothing setae.

\section{Habitat and distribution}

Cave-dwelling species found in a cave in the Bourgogne region, France (Condé 1991). 
Litocampa hubarti Bareth, 1999

Litocampa hubarti Bareth, 1999: 9, figs 1a-1, 2a-e.

Diagnosis (Bareth 1999)

Body length 5.0-5.3 mm; epicuticle without microdenticles; middle-sized to short, smooth clothing setae; antennae with 32-35 antennomeres; sensillum of third antennomere in ventral position; cupuliform organ with four simple olfactory chemoreceptors (large and with one fold in German specimens); slightly prominent frontal process; $1+1 \mathrm{ma}, 1+1 \mathrm{la}, 1+1 \mathrm{lp}$ macrosetae on pronotum and mesonotum, $1+1 \mathrm{ma}, 1+1 \mathrm{lp}$ macrosetae on metanotum; long, thin notal macrosetae with barbs along the distal three-fourth; long marginal setae with some barbs; one dorsal femoral macroseta; one ventral tibial macroseta with one apical barb; calcars barbed on one side along length; smooth subapical tarsal setae; subequal elbow-like claws with small smooth lateral crests; smooth setiform telotarsal processes; $1+1$ lp subsagittal on III urotergite, $1+1$ lp lateral on IV urotergite, $1+1 l a, 2+2 l p$ subsagittal and lateral V-VII urotergites, $1+1 \mathrm{mp}, 3+3 \mathrm{lp}$ on VIII urotergite and $1+1 \mathrm{mp}, 5+5 \mathrm{lp}$ on IX abdominal segment; male with glandular $g_{1}$-setae, slightly subtrapezoidal appendages with glandular $a_{2}$ and $a_{1}$-setae; cerci with long macrosetae with barbs along distal two-thirds; spermatozoid fascicles $80 \mu \mathrm{m}$ diameter and $20 \mu \mathrm{m}$ wide, spiral filament not clearly distinguishable but turns into several spirals.

\section{Habitat and distribution}

Known only from a cave in the Ardennes in Belgium, although it lacks cave-adapted traits (Bareth 1999).

Litocampa humilis humilis (Condé, 1948)

Plusiocampa humilis Condé, 1948a: 43, fig. 4.

Litocampa humilis - Paclt 1957: 27.

Diagnosis (Condé 1948a, 1949b, 1991; Bareth 1966, 1968, 2006)

Body length 4.0-7.0 mm; epicuticle with thin microdenticles; middle-sized, smooth clothing setae; antennae with 24-33 antennomeres; sensillum of third antennomere in ventral position; deep cupuliform organ with four simple olfactory chemoreceptors; $1+1 \mathrm{ma}, 1+1 \mathrm{la}, 1+1 \mathrm{lp}$ macrosetae on pronotum and mesonotum, $1+1 \mathrm{ma}, 1+1 \mathrm{lp}$ on metanotum; middle-sized notal macrosetae with barbs along distal half to two-thirds; well barbed, thick, long marginal setae; without dorsal femoral macrosetae; one short ventral tibial macroseta; calcars with 4-6 barbs; smooth apical tarsal setae; subequal grooved elbow-like claws with small smooth lateral crests; $1+1 l a, 1+1$ lp macrosetae on V-VII urotergites, $3+3 l p$ on VIII urotergite and $5+5 \mathrm{l} p$ on IX abdominal segment; male with glandular $g_{l}$-setae, slightly subtrapezoidal appendages with glandular $a_{2}$ and $a_{1}$-setae; subcylidric appendages in females with glandular $a_{1}$-setae; cerci shorter than body with 12 articles covered in long macrosetae with thin barbs along distal half and a few smooth clothing setae; spermatozoid fascicle 65-70 $\mu \mathrm{m}$ diameter and 14-15 $\mu \mathrm{m}$ wide, spiral filament with 7-10 spirals, $1200-1600 \mu \mathrm{m}$ long and $5.7 \mu \mathrm{m}$ in longest axis of irregular section.

\section{Habitat and distribution}

Cave-dwelling species with moderate cave-adapted traits, frequently found in natural and artificial caves in Central Europe and eastern France (Condé 1991; Bareth 2000a; Sendra et al. 2013), and expanding its distribution towards the eastern Carpathians in Romania (Ionescu 1955). 
Litocampa humilis comani Condé, 1991

Litocampa humilis comani Condé, 1991: 245.

Diferencial diagnosis from the f. typ. (Condé 1991; Sendra et al. 2012)

Antennae with 28-31 antennomeres; cupuliform organ with 12-14 complex olfactory chemoreceptors with finger-like expansions along their edges.

\section{Habitat and distribution}

A cave-adapted subspecies described from the deep zone of an isolated cave in the Romanian Carpathians near Cluj (Condé 1991), at the eastern of the range of the nominate subspecies.

Litocampa mendesi Sendra \& Reboleira, 2010

Litocampa mendesi Sendra \& Reboleira in Reboleira et al., 2010: 51, figs 1-3.

Diagnosis (Reboleira et al. 2010)

Body length 1.9-4.2 mm; epicuticle without ornamentation; thin, smooth clothing setae; antennae with 26-29 antennomeres; sensillum of third antennomere in ventral position; cupuliform organ with five olfactory chemoreceptors with two folds; slightly prominent frontral process; $1+1 \mathrm{ma}, 1+1 \mathrm{la}, 1+1 \mathrm{lp}$ macrosetae on pronotum and mesonotum, $1+1 \mathrm{ma}, 1+1 \mathrm{lp}$ on metanotum; long notal macrosetae with barbs along distal two-thirds; marginal setae poorly differentiated from clothing setae but with $2-8$ thin distal barbs; one dorsal femoral macroseta; one ventral tibial macroseta; calcars with long barbs almost from basis; smooth apical tarsal setae; subequal grooved elbow-like claws with tiny, smooth lateral crests; $1+1$ long ma macrosetae on III-VII urotergites; $1+1$ or $0+0$ la, $1+1$ lp on IV urotergite, $1+1$ la, $1+1 l p$ on V-VII urotergites, $1+1 \mathrm{mp}, 3+3 \mathrm{lp}$ on VIII urotergite and $1+1 \mathrm{mp}, 5+5 \mathrm{lp}$ on IX abdominal segment; thick, long clothing setae on IX-X abdominal segments; first male urosternite without glandular $g_{1}$-setae, slightly thick subcylindrical with glandular $a_{1}$ and $a_{2}$-setae; first female urosternite with thin subcylindrical appendages with only glandular $a_{l}$-setae; cerci twice shorter than body covered with long macrosetae barbed in distal portion and a few clothing setae.

\section{Habitat and distribution}

Cave-dwelling species with moderate cave-adapted traits known from two caves in southern Portugal (Reboleira et al. 2010; unpublished data).

Litocampa montana (Ionescu, 1955)

Campodea (Dicampa) montana Ionescu, 1955: 37, figs a-g.

Diagnosis (Ionescu 1955, Sendra et al. 2012)

Body length 2.0-2.8 mm; epicuticle without microdenticles; short, smooth clothing setae; antennae with 21-23 antennomeres; sensillum of third antennomere in ventral position; cupuliform organ with four simple olfactory chemoreceptors; $1+1 m a, 1+1 l a, 1+1 l p$ macrosetae on pronotum and mesonotum, $1+1 \mathrm{ma}, 1+1 \mathrm{lp}$ on metanotum; short, thin notal macrosetae with one distal barb except $l p$ on pronotum double in length with 3-4 thin barbs along distal half; marginal setae overall not differentiated from clothing setae; without dorsal femoral macrosetae; calcars with barbs almost from their basis; short ventral tibial macrosetae with a small apical barb; smooth apical tarsal setae; subequal elbow-like claws with small smooth lateral crests; $1+1$ short ma macrosetae on I-VII urotergites, $1+1 l a, 1+1 l p$ on $\mathrm{V}-$ VII urotergites, $1+1$ short $m a, 3+3 l p$ on VIII urotergite and $5+5 l p$ on IX abdominal segment; male with glandular $g_{1}$-setae, subtrapezoidal appendages with glandular $a_{2}$ and $a_{1}$-setae; female subcylidric appendages with glandular $a_{l}$-setae; cerci shorter than body with 7 articles covered in long macrosetae with 1-4 long barbs and a few smooth clothing setae. 


\section{Habitat and distribution}

Soil-dwelling species known from a single locality in southern Carpathians, Romania (Sendra et al. 2012).

Litocampa quadrisetigera Bareth, 2001

Litocampa quadrisetigera Bareth, 2001: 41, fig. 1a-1.

Diagnosis (Bareth 2001, 2006)

Body length $6.0 \mathrm{~mm}$; thin, smooth clothing setae; antennae with 40 antennomeres; sensillum of third antennomere in ventral position; cupuliform organ with seven to eight simple olfactory chemoreceptors; without protuberance on frontal process; $1+1 m a, 2+2 l a, 1+1 l p$ macrosetae on pronotum, $1+1 m a$, $1+1 l a, 1+1 l p$ on mesonotum, $1+1 m a, 1+1 l p$ on metanotum; long notal macrosetae with barbs along distal one-third to two-thirds; thin long barbed marginal setae; one dorsal femoral macrosetae; one short ventral tibial macrosetae with apical barb; calcars with barbs along length; smooth subapical tarsal setae; subequal elbow-like claws with small smooth lateral crests, smooth setiform telotarsal processes; long $1+1$ ma macrosetae on I-VII urotergites; $0+0-1+1 l p$ macrosetae on IV urotergite, $2+2$ lp on V-VII urotergites, $1+1 \mathrm{ma}, 3+3 \mathrm{lp}$ on VIII urotergite and $1+1 \mathrm{mp}, 5+5 \mathrm{lp}$ on IX abdominal segment; female with subcylindrical appendages having glangular $a_{l}$-setae.

\section{Habitat and distribution}

Cave-dwelling species described from a single female from a cave of the Arbailles Massif in the western Pyrenees (Bareth 2001).

Litocampa sollaudi (Denis, 1930)

Troglocampa sollaudi Denis, 1930: 34, figs 21-27.

Litocampa sollaudi - Paclt 1957: 27.

Diagnosis (Denis 1930; Condé 1948a; Bareth 1968, 2006)

Body length 5.0-8.0 mm; middle-sized, smooth clothing setae; antennae with 30-34 antennomeres; sensillim in the third antennomere in dorsal position; cupuliform organ with 10-12 complex olfactory chemoreceptors; prominent frontal process; $1+1 \mathrm{ma}, 1+1 \mathrm{la}, 1+1 \mathrm{lp}$ macrosetae on pronotum, $1+1 \mathrm{ma}$, $0+0$ or $1+1 l a, 1+1 l p$ on mesonotum and $1+1 m a$ on metanotum; long notal macrosetae with barbs along distal half to two-thirds; long marginal setae with some barbs along distal two-thirds; long legs reaching end of abdomen; without dorsal femoral macrosetae; calcars barbed almost from basis; one or two ventral tibial macrosetae; smooth apical tarsal setae; subequal elbow-like claws with smooth lateral crests; $1+1 l a, 1+1 l p$ on VI-VII urotergites, $3+3 l p$ on VIII urotergite and $5+5 l p$ on IX abdominal segment; enlarged appendages in males without glandular $a_{2}$-setae, also in females; cerci longer than body with 9-10 articles covered in long thin macrosetae with barbs along distal half to two-thirds and thin barbed clothing setae; spermatozoid fascicles 50-60 $\mu \mathrm{m}$ in diameter and $10 \mu \mathrm{m}$ wide, spiral filament with 7-8 spirals, $1100-1200 \mu \mathrm{m}$ long and 2-3 $\mu \mathrm{m}$ in widest diameter of elliptical section.

\section{Habitat and distribution}

Cave-dwelling species with consistent cave-adapted traits found in more than 100 caves in the Jura and the western Vercors Massifs, in France and Switzerland (Condé 1948a, 1962). 
Litocampa tuzetai (Condé, 1948)

Campodea tuzetai Condé, 1948a: 36, figs 1a-f, 2a-b.

Litocampa tuzetai - Condé 1997: 159.

Diagnosis (Condé 1948a, 1997; Bareth 2006)

Body length 5.0-6.0 mm; short, smooth clothing setae; antennae with 26-35 antennomeres; plain frontal process; cupuliform organ with 7-12 complex olfactory chemoreceptors; $1+1 \mathrm{ma}, 1+1 \mathrm{la}, 1+1$ $l p$ macrosetae on pronotum and mesonotum, $1+1 \mathrm{ma}, 1+1 \mathrm{lp}$ on metanotum; thick middle-sized notal macrosetae with barbs along distal half to two-thirds; thick marginal setae with thin barbs; without dorsal femoral macrosetae; one trochanteral baciliform sensillum; calcars barbed almost from basis; one or two ventral tibial macrosetae; smooth apical tarsal setae; subequal grooved elbow-like claws with small smooth lateral crests; $1+1 \mathrm{ma}$ macrosetae from short to long on I-VII urotergites, $1+1 \mathrm{la}, 1+1 \mathrm{lp}$ on V-VII urotergites, $1+1 \mathrm{ma}, 3+3 \mathrm{lp}$ on VIII urotergite and $1+1 \mathrm{mp}, 5+5 \mathrm{lp}$ on IX abdominal segment; cerci as long as body with 10 articles covered in long barbed macrosetae; spermatozoid fascicles $46 \mu \mathrm{m}$ in diameter and $32 \mu \mathrm{m}$ wide, spiral filament with 11-12 spirals, $1700 \mu \mathrm{m}$ long with elliptical section $7 \mu \mathrm{m}$ in longest diameter.

\section{Habitat and distribution}

Litocampa tuzuetai dwells in soil and cave habitats in the Cévennes, southern France (Condé 1947h, 1997).

\section{Litocampa vandeli (Condé, 1947)}

Plusiocampa vandeli Condé, 1947a: 21, figs 2-3.

Diagnosis (Condé, 1947a; Bareth \& Condé 1981; Bareth 1983, 2006)

Body length 4.0-4.5 mm; short, smooth clothing setae; antennae with 22-27 antennomeres; cupuliform organ with four thick simple olfactory chemoreceptors; $1+1 m a, 1+1$ la, $1+1$ lp macrosetae on pronotum and mesonotum, $1+1 \mathrm{ma}, 1+1 \mathrm{lp}$ on metanotum; short notal macrosetae with 1-5 distal barbs; marginal setae thicker and longer than clothing setae with 2-4 thick barbs; without dorsal femoral macrosetae; calcars with barbs almost from basis; one short ventral tibial macroseta with one apical barb; smooth subapical tarsal setae; subequal smooth elbow-like claws with small, smooth lateral crests; $1+1$ short ma macrosetae on I-VII urotergites, $1+1$ la on V urotergite, $1+1$ la $1+1$ lp on VI-VII urotergites, 1+1 $m p, 3+3 l p$ on VIII tergite and $1+1 \mathrm{mp}, 5+5 \mathrm{l} p$ on IX abdominal segment; male with two separated area of glandular $g_{1}$-setae; cerci shorter than body with 10 articles covered in smooth macrosetae or with 3-4 distal barbs, latero-interior macrosetae with $1 \mathrm{barb}$; spermatozoid fascicles $50-55 \mu \mathrm{m}$ in diameter and 10 $\mu \mathrm{m}$ wide, spiral filament with $1 \frac{1}{2}$ spirals, $150-200 \mu \mathrm{m}$ long and $1-1.5 \mu \mathrm{m}$ in diameter seccion.

\section{Habitat and distribution}

Litocampa vandeli dwells in soil, cave and MSS habitats (Bareth 1983) in the centre of the northern and southern slopes of the Pyrenees (Sendra \& Escolà 2004). It was also found in a cave near the coast in the eastern Iberian Peninsula (Bareth \& Condé 1981).

Litocampa zaldivarae Sendra, Salgado \& Monedero, 2003

Litocampa zaldivarae Sendra, Salgado \& Monedero, 2003: 76, fig. 7, tables 6-9.

Diagnosis (Sendra et al. 2003)

Body length 2.8-6.8 mm; epicuticle without microdenticles, smooth clothing setae; antennae with 3034 antennomeres; cupuliform organ with four to six thick, simple olfactory chemoreceptors; prominent 
frontal process; $1+1 \mathrm{ma}, 1+1 \mathrm{la}, 1+1 \mathrm{lp}$ macrosetae on pronotum and mesonotum, $1+1 \mathrm{ma}, 1+1 \mathrm{lp}$ on metanotum; long, thick notal macrosetae with barbs along distal half; long marginal setae with barbs along distal half; one dorsal femoral macrosetae; calcars barbed almost from basis; one short ventral tibial machoseta; smooth apical tarsal setae; subequal grooved elbow-like claws with small and smooth lateral crests, smooth setiform telotarsal processes; $1+1 l p$ macrosetae on III urotergite, $2+2 l p$ on IV urotergite, $1+1 l a, 2+2 l p$ on V-VII urotergites, $1+1 \mathrm{mp}, 3+3 \mathrm{lp}$ on VIII urotergite and $1+1 \mathrm{mp}, 5+5 \mathrm{lp}$ on IX abdominal segment; enlarged appendages of first urosternite in males with glandular $a_{2}$-setae; subcylindrical appendages on females and also with glandular $a_{2}$-setae; cerci longer than body covered in long macrosetae with barbs along distal one-third to half and smooth long clothing setae.

\section{Habitat and distribution}

Cave-dwelling species found in several caves across the southern slopes in the east of Cantabria towards the Basque Mountains (Sendra et al. 2003).

Genus Oreocampa Condé, 1950

Oreocampa Condé, 1950c: 809.

\section{Diagnosis (Condé 1950c)}

Pronotum and mesonotum with $1+1 m a, 1+1$ la, $1+1$ lp macrosetae; metanotum with $1+1$ ma macrosetae. No dorsal femoral macrosetae nor ventral tibial macrosetae. Smooth angular claws with basal sideshoot sharp instead of telotarsal processs separates this genus from other species of Campodeinae. Without medial anterior and posterios urotergal macrosetae. Urosternal macrosetae starting with $3+3$ lp in urotergite VIII. Urosternite I with $6+6$ macrosetae; urosternites II-VII with 4+4; and urosternite VIII with $1+1$ macrosetae; male without glandular $g_{l}$-setae, short and subcylindrical appendages with glandular $a_{1}$-setae: female appendages similar to male.

\section{Habitat and distribution}

Monotypic genus established for a species from soils on Mount Kenya at 2870 m a.s.l. (Condé 1950c) (Fig. 62).

\section{Oreocampa aff. minutella (Silvestri, 1918)}

\section{Diagnosis (Silvestri 1918; Condé 1950b, 1950c)}

Body length 2.5-2.9 mm; antennae with 17 and 19 antennomeres; sensillum of third antennomere in dorsal position (ventral in Ukrainian specimens); short notal macrosetae with a few barbs; $3+3 l p$ macrosetae on VIII urotergite; thin, long urotergal marcrosetae; apparently described from juvenile male with a few glandular $g_{I}$-setae on first urosternite and with quadrangular appendages with glandular $a_{l}$ and $a_{2}$-setae.

Rusek (1965a) cited three specimens collected in Lugansk, a region in the east of Ukraine, as O. minutella, that differ from the African specimens in body length $(4.8 \mathrm{~mm})$, sensillum of third antennomere in ventral position and $2+2 \mathrm{lp}$ macrosetae on VIII urotergite.

\section{Genus Podocampa Silvestri, 1932}

Podocampa Silvestri, 1932a: 116.

\section{Diagnosis (Silvestri 1932a; Condé 1956a)}

Notal macrosetae 1+1 ma, 1+1 la, $1+1$ lp macrosetae on pronotum and mesonotum and 1+1 ma, 1+1 $l p$ on metanotum; plain frontal process without protruding with one exception in P. simonnini Condé, 
1956; one thick long dorsal femoral macrosetae; subequal slightly curved smooth claws with smooth setiform or laminar telotarsal process; $0+0,1+1$ or $2+2$ lp macrosetae on urotergites III-VII; $0+0$ or $1+1$ la macrosetae on utrotergites IV-VII; with or without medial anterior and medial posterior macrosetae on urotergites and abdominal segment; urosternite I with 7+7-9+9 macrosetae, urosternites II-VII 5+5 and ursoternite VIII with $1+1$ macrosetae; first male urosternite with glandular $g_{1}$-setae, appendages enlarged with glandular $a_{1}$ and $a_{2}$-setae; subcylindrical appendages in female with glandular $a_{1}$ and with or without $a_{2}$-setae. The variability observed in a few species is remarkable, with a telotarsal process from setiform to laminar which has led to some confusion ino this apparently monophyletic taxon, see Paclt (1957), Condé (1959) and Sendra et al. (1986).

\section{Habitat and distribution}

Sixteen species of Podocampa live in the western Euro-Mediterranean region; and six more were described from North America (Allen 1994; Condé \& Geeraert 1962). Five of the 16 western EuroMediterranean species of Podocampa inhabit cave habitats in karst areas from the west of the Iberian Peninsula throughout the Cantabrian region, the Basque Mountains including the Pyrenees (Sendra et al. 2003), in addition to Sardinia (Condé 1975). The rest of the species inhabit a soil environment with a preference for humid spots from the upper horizons of the soil to MSS around the Iberian Peninsula, from the northern slopes of the Pyrenees to the North of Africa (Condé 1956a; Bareth 1983) (Fig. 62).

\section{Taxonomic key for species of the genus Podocampa}

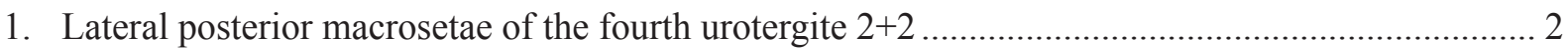

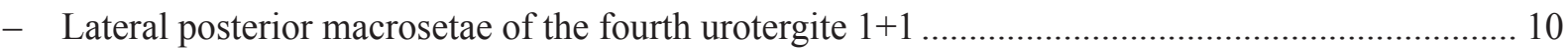

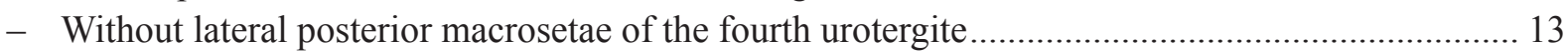

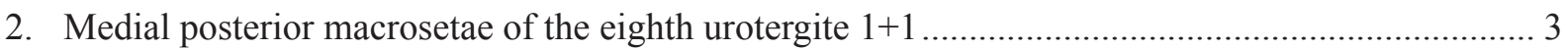

- Without medial posterior macrosetae of the eighth urotergite........................................................ 9

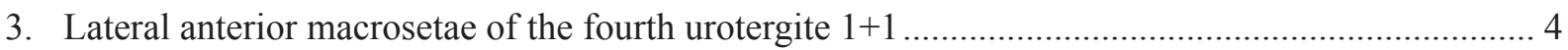

- Without lateral anterior macrosetae of the fourth urotergite............................................................ 7

4. Cerci pilosity with long, barbed macrosetae and short, smooth setae on proximal articles and only

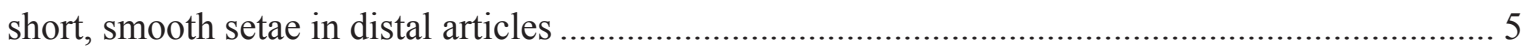

- Cerci pilosity with long, thin, barbed macrosetae with a few short, smooth setae............................ 6

5. Marginal setae long, barbed .............................................Podocampa mauritanica (Silvestri, 1932)

- Marginal setae thick, long, barbed.................................... Podocampa fragiliformis (Condé, 1953)

6. Ventral tibial macrosetae one or two; sensillum of the cupuliform organ complex; body shape caveadapted; notal macrosetae thick, long, barbed

Podocampa asturiana riberiensis Sendra, Salgado \& Monedero, 2003

- Ventral tibial macrosetae one; sensillum of the cupuliform organ simple; body shape non-caveadapted; notal macrosetae long, barbed.

Podocampa moroderi (Silvestri, 1932)

7. Ventral tibial macrosetae one or two; sensillum of the cupuliform organ complex; body shape caveadapted; notal macrosetae thick, long, barbed.

Podocampa asturiana asturiana Sendra, Salgado \& Monedero, 2003

- Ventral tibial macrosetae one; sensillum of the cupuliform organ simple; body shape non-caveadapted; notal macrosetae long barbed. 
8. Telotarsal process setiform; sensillum of the third antennomere dorsal.

Podocampa serbica Karaman \& Blesic, 1983

- Telotarsal process polymorphic; sensillum of the third antennomere ventral

Podocampa fragiloides (Silvestri, 1932)

9. Telotarsal process laminar

Podocampa rifiana (Silvestri, 1932)

- Telotarsal process setiform Podocampa cardini (Silvestri, 1932)

10. Lateral posterior macrosetae of the third urotergite 1+1; marginal setae long and barbed

- Without lateral posterior macrosetae of the third urotergite; marginal setae long and poorly barbed

11. Telotarsal process setiform; cerci pilosity with long, barbed macrosetae and short, smooth setae on proximal articles and only short, smooth setae in distal articles; trochanteral sensillum none.

Podocampa iglesiasi (Silvestri, 1932)

- Telotarsal process polymorphic; cerci pilosity with long, thin, barbed macrosetae with a few short, smooth setae; trochanteral sensillum one

Podocampa ceballosi (Silvestri, 1932)

12. Lateral posterior macrosetae of the fifth urotergite $2+2$; lateral posterior macrosetae of the sixth urotergite 2+2; lateral posterior macrosetae of the seventh urotergite $2+2$; ventral tibial macrosetae two or three.

Podocampa simonini Condé, 1956

- Lateral posterior macrosetae of the fifth urotergite 1+1; lateral posterior macrosetae of the sixth urotergite 1+1; lateral posterior macrosetae of the seventh urotergite 1+1; ventral tibial macrosetae one

Podocampa brolemanni (Denis, 1932)

13. $2+2$ long lateral posterior macrosetae on fifth to seventh urotergites; two or three ventral tibial macrosetae

Podocampa jeanneli (Condé, 1947)

- $2+2$ or 1+1 lateral posterior macrosetae on fifth urotergite, $2+2$ lateral posterior macrosetae om sixth and seventh urotergites (but most lateral macrosetae always shorter in slight anterior position); one ventral tibial macroseta

14. $2+2$ lateral posterior macrosetae on fifth urotergite

Podocampa cerrutti cerrutti Condé, 1975

- $1+1$ lateral anterior macrosetae on fifth urotergite. Podocampa cerrutti kahmanni Condé, 1975

Podocampa asturiana Sendra, Salgado \& Monedero, 2003

Podocampa asturiana Sendra, Salgado \& Monedero, 2003: 70, figs 1-2, 3a-b, 4-5, 6a, tables 1-4.

Diagnosis (Sendra et al. 2003)

Body length 5.1-9.3 mm; epicuticle without microdenticles; clothing setae smooth or with 1-2 small distal barbs; antennae with 35-43 antennomeres; sensillum of third antennomere in dorsal or ventral position; cupuliform organ with seven to eight complex olfactory chemoreceptors; thick, long notal macrosetae with barbs along distal half; thick long marginal setae with thin barbs along distal half to twothirds; without trochanteral sensilla; one or two ventral tibial macrosetae; calcars with barbs extending from base; smooth subapical tarsal setae; smooth setiform telotarsal process; $1+1 l p$ on III urotergite, $2+2 l p$ on IV urotergite, $1+1 l a, 2+2 l p$ on V-VII urotergites, $1+1 \mathrm{mp}, 3+3 l p$ on VIII urotergite and $1+1$ $m p 5+5$ lp on IX abdominal segment; clothing setae on IX-X abdominal segments similar to others; first male urosternite with glandular $g_{1}$-setae (absent in three caves from Laviana, Asturias region); subtrapezoidales appendages with glandular $a_{1}$ and $a_{2}$-setae; appendages of female subcylindric with glandular $a_{1}$ and $a_{2}$-setae; cerci longer than body covered in long, thin macrosetae with thin barbs along distal half and a few shorter smooth setae. 
Podocampa asturiana riberiensis Sendra, Salgado \& Monedero, 2003

Podocampa asturiana riberiensis Sendra, Salgado \& Monedero, 2003: 74, fig. 6b-c, table 5.

Differential diagnosis from the f. typ. (Sendra et al. 2003)

Sensillum of third antennomere in ventral position; one to four trochanteral sensilla; $1+1$ la macrosetae on IV urotergite.

Podocampa aff. asturiana I Sendra, Salgado \& Monedero, 2003

Differential diagnosis from $P$. asturiana asturiana

The males from three caves from Llaviana in the Nalón Basin, the Cantabrian Mountain, show a noticeable frontal process.

Podocampa aff. asturiana II Sendra, Salgado \& Monedero, 2003

\section{Differential diagnosis from P. asturiana asturiana}

Two variable features have been observed in specimens from nine caves in the Galician massif: several specimens show thick clothing setae on VIII urotergite and IX and X abdominal segments and in others there are $1+1 l p$ macrosetae on IV urotergite. These two differential characters occur together in some specimens.

\section{Habitat and distribution}

Cave-dwelling species known from many caves in the North of the Iberian Peninsula, from Galicia to the Basque country throughout the Cantabrian Mountains (Sendra et al. 2003). Podocampa asturiana riberiensis is restricted to caves throughout the Asturian Central Basin (Sendra et al. 2003).

\section{Podocampa brolemanni (Denis, 1932)}

Campodea brolemanni Denis, 1932b: 602, figs 4-11.

Diagnosis (Denis 1932b; Condé \& Mathieu 1957; Condé 1975; Bareth 2006)

Body length 2.1-3.0 mm; long, smooth clothing setae; antennae with 19 antennomeres; sensillum of third antennomere in ventral position; cupuliform organ with 4 simple olfactory chemoreceptors; long, thin notal macrosetae with a few distal barbs; long marginal setae with a few distal barbs; smooth setiform telotarsal process; $1+1 \mathrm{ma}$ short thin macrosetae on I-VII urotergites, $1+1 l a, 1+1$ lp on IV-VII urotergites, $1+1 \mathrm{mp}, 3+3 \mathrm{lp}$ on VIII urotergite and $1+1 \mathrm{mp}, 5+5 \mathrm{lp}$ on IX abdominal segment; first male urosternite with setae glandular $g_{I}$-setae; cerci shorter than body covered in long barbed macrosetae and a few clothing setae.

\section{Habitat and distribution}

Soil-dwelling species known from three localities on the northern slopes of the central Pyrenees (Denis 1932b; Condé \& Mathieu 1957).

Podocampa cardini (Silvestri, 1932)

Campodea (Podocampa) cardini Silvestri, 1932a: 133, fig. VIII.

Diagnosis (Silvestri 1932a)

Body length $5.5 \mathrm{~mm}$; short, smooth clothing setae; very long notal macrosetae with barbs along distal half to two-thirds; long marginal setae barbed along distal two-thirds; one ventral tibial macroseta; 
calcars slightly barbed; setiform smooth telotarsal process; $1+1$ lp macrosetae on III urotergite, $1+1$ la, $2+2 l p$ on IV-VII urotergites and $3+3 l p$ on VIII urotergite.

\section{Habitat and distribution}

Soil-dwelling species found at a unique locality in Aralar massif, Basque Mountains (Silvestri 1932a), and doubtfully reported from caves of Portugal (Condé 1956a).

Podocampa ceballosi (Silvestri, 1932)

Campodea (Podocampa) ceballosi Silvestri, 1932a: 130, fig. VII.

Campodea canariensis Silvestri, 1932a: 133.

Remycampa grassei Condé, 1953: 373.

Meiocampa grassei - Paclt 1957: 31.

Diagnosis (Silvestri 1932a; Sendra 1989a, 1990a, 1990c)

Body length 2.0-3.5 mm; long smooth clothing setae; antennae with 19-25 antennomeres; sensillum of third antennomere in ventral position (dorsal in one female from Benaoján, Spain); thick, short gubia sensilla; long, well barbed notal macrosetae; marginal setae longer and thicker than clothing setae with long, thin barbs; one trochanteral sensillum; thin dorsal femoral macrosetae; one tibial ventral macrosetae; calcars with barbs along distal two thirds; smooth subapical tarsal setae; polymorphic telotarsal process from setiform to laminar shape; $1+1 \mathrm{ma}$ macrosetae on I-VII urotergites, $1+1 \mathrm{la}$, $1+1 l p$ on IV-VII urotergites, $1+1 \mathrm{mp}, 3+3 \mathrm{lp}$ on VIII urotergite and $1+1 \mathrm{mp}, 5+5 \mathrm{lp}$ on IX abdominal segment; clothing setae on $\mathrm{X}$ abdominal segment thicker than other clothing setae; first male urosternite with seasonal presence of glandular $g_{I}$-setae, enlarged appendages with glandular $a_{I}$-setae and seasonal $a_{2}$-setae; subcylindrical appendages with glandular $a_{1}$-setae in females; cerci shorter than body covered in long barbed macrosetae and a few shorter smooth setae.

\section{Habitat and distribution}

Soil-dwelling species occasionally found in caves (Sendra 2013). Distributed mainly across the southwest Iberian Peninsula (Silvestri 1932a; Wygodzinsky 1944a; Sendra et al. 1986), also in Morocco, Algeria (Condé 1953b) and the Canary Islands (Sendra, 1989a, 1990c).

\section{Podocampa cerrutti Condé, 1975}

Podocampa cerrutti Condé, 1975: 348, figs a-d.

Diagnosis (Condé 1975)

Body length $3.0 \mathrm{~mm}$ (juvenile male); antennae with 28-29 antennomeres; sensillum of third antennomere in dorsal position; cupuliform organ with five to six complex olfactory chemoreceptors; long, thin notal macrosetae with barbs along distal half; long, thin marginal setae with barbs along distal half; one ventral tibial macroseta; one thin trochanteral sensillum; calcars with a few barbs along distal half; smooth setiform telotarsal process; $1+1 m a$ macrosetae on I-VII urotergites, $2+2 l p$ (or could also be considered $1+1 l a, 1+1 l p$ ) on V-VII urotergites, $1+1 m a, 3+3 l p$ on VIII urotergite and $1+1 \mathrm{mp}, 5+5$ $l p$ on IX abdominal segment; male with glandular $g_{l}$-setae and slight subtrapezoidel appendages with glandular $a_{1}$-setae and $a_{2}$-setae; female with subcylindrical appendages with glandular $a_{1}$-setae and $a_{2}{ }^{-}$ setae. 
Podocampa cerrutti kahmanni Condé, 1975

Podocampa cerrutti kahmanni Condé, 1975: 350, fig. e.

Differential diagnosis from the f.typ. (Condé 1975)

Urotergite $\mathrm{V}$ with $1+1$ lp macrosetae.

\section{Habitat and distribution}

The type locality is a natural pit in Sardinia. The weak cave-adapted traits suggest, that this is a troglophile form. Podocampa cerrutti kahmanni was collected under stones in Sardinia (Condé 1975).

Podocampa fragiliformis (Condé, 1953)

Campodea fragiliformis Condé, 1953: 371, fig. 3.

\section{Diagnosis (Condé 1953b)}

Body length 2.9-3.0 mm; short, smooth clothing setae; antennae with 24-25 antennomeres; sensillum of third antennomere in ventral position; long, barbed notal macrosetae; long, thick notal marginal setae; one ventral tibial macroseta; calcars with barbs almost from bases; setiform smooth telotarsal process; macrosetae on $1+1 l p$ on III urotergite, $1+1 l a, 2+2 l p$ on IV-VII urotergites, $1+1 m p, 3+3 l p$ on VIII urotergite; first male urosternite with glandular $g_{l}$-setae, appendages enlarged with glandular $a_{l}$ and $a_{2}$-setae; female appendages with glandular $a_{1}$-setae; cerci half of body length with 8 articles covered in long, barbed macrosetae on proximal articles, distal articles without macrosetae but with numerous short clothing setae.

\section{Habitat and distribution}

Soil-dwelling species found at one locality near Casablanca, Morocco (Condé 1953b).

Podocampa fragiloides (Silvestri, 1932)

Figs 12, 33-34

Campodea (Podocampa) fragiloides Silvestri, 1932b: 75, figs I1-18.

Diagnosis (Silvestri 1932a, 1932b; Condé 1956a; Sendra et al. 1986)

Body length 2.5-5.0 mm; long, thin, smooth clothing setae; antennae with 21 to 33 antennomeres; sensillum of third antennomere in ventral position; cupuliform organ with four simple olfactory chemoreceptors; long notal macrosetae with barbs along distal two-thirds; long, thick, barbed marginal setae; one setiform or baciliform trochanteral sensilla; one ventral tibial macroseta; calcars with barbs extending from base; smooth subapical tarsal setae; polymorphic telotarsal process from setiform to laminar shapes; $1+1$ l $p$ on III urotergite, $2+2$ l $p$ on IV urotergite, $1+1$ la, $2+2$ l $p$ on V-VII urotergites, $1+1$ $m p, 3+3 l p$ on VIII urotergite and $1+1 \mathrm{mp}, 5+5 \mathrm{lp}$ on IX abdominal segment; first male urosternite with glandular $g_{l}$-setae and subcylindrical appendages slightly enlarged with glandular $a_{l}$-setae and seasonal $a_{2}$-setae; females subcylindrical appendages with glandular $a_{1}$ and $a_{2}$-setae; cerci slightly shorter than body covered in long macrosetae well barbed on proximal articles and short ones on medial and distal articles with abundant short clothing setae.

\section{Taxonomic notes}

Specimens collected at several localities across the Iberian Peninsula (Sendra 1988) show differential features from the previous diagnosis. These include a setiform telotarsal process in the legs, cerci covered 
with long barbed macrosetae and sparse cloting setae. This variability in $P$. fragiloides shows its close similaritites with $P$. seabrai and P. jorgei that might be considered as synonyms. Aditionally, the studied material (Supplementary file 2) allowed studying structures under SEM (Figs 12, 33-34).

\section{Habitat and distribution}

Soil-dwelling species inhabiting the Rif Mountains in Morocco (Silvestri 1932b) and many areas on the Iberian Peninsula, without reaching the Pyrenees (Silvestri 1932a; Wygodzinsky 1944a; Sendra et al. 1986; Sendra 1990a).

Podocampa iglesiasi (Silvestri, 1932)

Campodea (Podocampa) iglesiasi Silvestri, 1932a: 135, fig. IX.

\section{Diagnosis (Silvestri 1932a)}

Body length 3.5-4.5 mm; long, smooth clothing setae; antennae with 26-29 antennomeres; sensillum of third antennomere in ventral position; cupuliform organ with four simple olfactory chemoreceptors; very long notal macrosetae with barbs along distal half to two thirds; long, well barbed marginal setae; one ventral tibial macroseta; without trochanteral sensillum; calcars with barbs almost from basis; smooth setiform telotarsal process; $1+1 \mathrm{ma}$ macrosetae barbed along distal first third on I-VII urotergites; $1+1$ $l p$ on III urotergite, $1+1 l a, 2+2 l p$ on IV-VII urotergites, $1+1 \mathrm{mp}, 3+3 l p$ on VIII urotergite and $1+1$ $m p, 5+5 \mathrm{lp}$ on IX abdominal segment; clothing setae IX-X abdominal segments as others; first male urosternite with glandular $g_{1}$-setae and subcylindrical appendages slightly enlarged with glandular $a_{I^{-}}$ setae and seasonal $a_{2}$-setae; female appendages subcylindrical with at least glandular $a_{1}$; cerci as long as body length with 14 articles covered in long macrosetae on proximal articles but only clothing setae on distal articles.

\section{Habitat and distribution}

Soil-dwelling species found in moisty habitats such as soils with plenty of leaves in the proximity of springs, across the northeastern Iberian Peninsula (Silvestri 1932a; Condé 1951d).

\section{Podocampa jeanneli (Condé 1947)}

Campodea (Podocampa) jeanneli Condé 1947a: 18, fig. 1.

Diagnosis (Condé 1947a, 1975; Sendra \& Escolà 2004; Bareth 2006)

Body length 3.5-8.0 mm; thin, smooth clothing setae; antennae with 34-40 antennomeres; cupuliform organ with six to seven complex olfactory chemoreceptors (up to 12); sensillum of third antennomere in ventral position; thick, long notal macrosetae with a few barbs along distal one-third to one-fourth; marginal setae longer and thicker than clothing setae with a few tiny barbs; one trochanteral sensillum; two or three tibial ventral macrosetae; calcars with long barbs almost from basis; smooth subapical tarsal setae; setiform telotarsal process; $1+1$ ma macrosetae on I-VII urotergites, $2+2$ lp on V-VII urotergites, $1+1 m a, 3+3 l p$ on VIII urotergite and $1+1 m p, 5+5 l p$ on IX abdominal segment; clothing setae IX-X abdominal segment similar to others; first male urosternite with large area of glandular $g_{I}$-setae, swollen appendages with glandular $a_{1}$ and $a_{2}$-setae; female appendages with glandular $a_{1}$-setae; cerci twice as long as body covered in long, well barbed macrosetae and a few shorter, smooth setae; spiral filament of spermatozoid fascicles with $1 \frac{1}{2}$ to two spirals, $190 \mu \mathrm{m}$ long and $5 \mu \mathrm{m}$ in diameter. 


\section{Habitat and distribution}

Cave-dwelling species found in deep zone of caves, but also in MSS habitats (Bareth 1983) in the central region of the Pyrenees (Condé 1947a, 1948b; Sendra 1985).

Podocampa jorgei (Wygodzinsky, 1944)

Campodea (Podocampa) jorgei Wygodzinsky, 1944: 508, figs 38-50.

Differential diagnosis from P. fragiloides (Wygodzinsky 1944a; Sendra 1990a)

Cerci covered in macrosetae with 2-4 distal barbs on latero-interior proximal articles and short macrosetae with one apical barb on distal articles.

\section{Habitat and distribution}

Soil-dwelling species collected in southern Portugal (Wygodzinsky 1944a; Sendra 1990a).

Podocampa mauritanica (Silvestri, 1932)

Campodea mauritanica Silvestri, 1932b: 78, figs II-III.

Diagnosis (Silvestri 1932b)

Body length $5.1 \mathrm{~mm}$; short, smooth clothing setae; antennae with 25 antennomeres; long, barbed notal macrosetae; long, barbed notal marginal setae; one ventral macroseta on tibia; calcars with barbs from bases; smooth setiform telotarsal process; $1+1 l p$ on III urotergite, $1+1 l a, 2+2 l p$ on IV-VII urotergites and $1+1 \mathrm{mp}, 3+3 \mathrm{lp}$ on VIII; cerci shorter than body with 9 articles covered in long, barbed macrosetae and a few short, smooth setae on proximal articles but with shorter macrosetae on distal articles.

\section{Habitat and distribution}

Soil-dwelling species known only from one locality in the Rif, northern Morocco (Silvestri 1932b).

Podocampa moroderi (Silvestri, 1932)

Campodea (Podocampa) moroderi Silvestri, 1932a: 116, fig. 1.

\section{Diagnosis (Silvestri 1932a)}

Body length 3.5-5.8 mm; short, smooth clothing setae; antennae with 26-34 antennomeres; sensillum of third antennomere in ventral position; thin, short gubia sensilla; long, barbed notal macrosetae; thick, long, barbed marginal setae: one trochanteral sensillum; one ventral tibial macroseta; calcars with barbs from bases; setiform smooth telotarsal process; $1+1 l p$ on III urotergite, $1+1 l a, 2+2 l p$ on IV-VII urotergites, $1+1 \mathrm{mp}, 3+3 \mathrm{lp}$ on VIII urotergite and $1+1 \mathrm{mp}, 5+5 \mathrm{lp}$ on IX abdominal segment; clothing setae on IX-X abdominal segments thicker than others; first male urosternite with glandular $g_{I}$-setae and appendages enlarged with glandular $a_{1}$ and $a_{2}$-setae; subcylindrical appendages in female with glandular $a_{1}$ and $a_{2}$-setae; cerci covered in long macrosetae and a few short smooth setae.

\section{Habitat and distribution}

Soil-dwelling rare species collected at three localities in the southern Iberian Peninsula (Silvestri 1932a). 
Podocampa quadrisetigera Bareth, 2001

Unavailable name proposed after 1999, without explicitly being indicated as intentionally new and with no fixation of a holotype or syntypes, thereby violating Articles 16.1 and 16.4 of the International Code of Zoological Nomenclature.

Podocampa rifiana (Silvestri, 1932)

Campodea rifiana Silvestri, 1932b: 80, figs IV-V.

Meiocampa rifiana - Paclt 1957: 31.

Diagnosis (Silvestri 1932b)

Body length $5.2 \mathrm{~mm}$; short, smooth clothing setae; antennae with 25-29 antennomeres; long, barbed notal macrosetae; long, barbed marginal setae; one ventral tarsal macroseta; calcars with barbs from bases; laminar smooth telotarsal process; $1+1$ lp macrosetae on III urotergite, $1+1$ la in posterior position $(l p), 2+2 l p$ on IV-VII urotergites, $3+3 l p$ on VIII urotergite; cerci half of body length with 10 articles covered in long macrosetae and a few short smooth setae.

\section{Habitat and distribution}

Soil-dwelling species found near Tétouan, in the Rif Mountains, Morocco (Silvestri 1932b).

Podocampa seabrai (Wygodzinsky, 1944)

Campodea (Podocampa) seabrai Wygodzinsky, 1944: 510, figs 51, 53, 55.

Differential diagnosis from P. fragiloides (Wygodzinsky 1944a; Sendra 1990a)

Cerci presumably regenerated with long macrosetae and a few clothing setae.

Habitat and distribution

Soil-dwelling species known from Setúbal, Portugal (Wygodzinsky 1944a).

Podocampa serbica Karaman \& Blesić, 1983

Podocampa serbica Karaman \& Blesić, 1983: 71, figs 1-11.

Diagnosis (Karaman \& Blesić 1983)

Body length 2.1-3.8 mm; antennae with 20-30 antennomeres: sensillum of third antennomere in dorsal position; cupuliform organ with four simples olfactory chemoreceptors; long notal macrosetae with barbs in distal third; one trochanteral sensillum; one tibial ventral macrosetae; setiform smooth telotarsal process; $1+1 l p$ macrosetae on III urotergite; $2+2 l p$ on IV urotergite; $1+1 l a, 2+2 l p$ on V-VII urotergites; $1+1 \mathrm{mp}, 3+3 \mathrm{lp}$ on VIII urotergite, $1+1 \mathrm{mp}, 5+5 \mathrm{lp}$ on IX abdominal segment.

\section{Habitat and distribution}

Soil-dwelling species from the Dinaric Mountains in Serbia (Karaman \& Blesić, 1983, 1984).

Podocampa simonini Condé, 1956

Podocampa simonini Condé, 1956a: 31.

Diagnosis (Condé 1956a, 1982b; Sendra 1988)

Body length 6.5-9 mm; middle-sized, smooth clothing setae; protruding frontal process; antennae with 58-64 antennomeres; sensillum of third antennomere in ventral position; cupuliform organ with 
eight complex olfactory chemoreceptors; long, curved gubia sensilla; long notal macrosetae with barbs along distal two thirds; long marginal setae with barbs along distal half; two or three ventral tibial macrosetae; calcars with a few barbs along distal half; smooth subapical tarsal setae; setiform smooth telotarsal process; $1+1 l p$ on IV urotergite, $1+1 l a, 2+2 l p$ on V-VII urotergites, $1+1 m p, 3+3 l p$ on VIII urotergite, $1+1 \mathrm{mp} 5+5 \mathrm{lp}$ on IX abdominal segment; first male urosternite without glandular $g_{1}$-setae, subtrapezoidal appendages with glandular $a_{1}$ and $a_{2}$ setae; cerci three times as long as body with up to 20 articles covered in long, barbed macrosetae and short, smooth cloting setae; spermatozoid fascicles $70 \mu \mathrm{m}$ in diameter.

\section{Habitat and distribution}

Cave-dwelling species known from several caves in the Basque Mountains, northern Iberian Peninsula (Condé, 1956a, 1982b).

Genus Remycampa Condé, 1952

Remycampa Condé, 1952: 358.

Diagnosis (Condé 1952a, 1953b; Sendra et al. 2020b)

Labium atypical with slight torsion towards right of labial palps, elongated palpiform processes and deep groove in middle labium from posterior border of anterior lobe to middle of submentum, reaching in some species posterior border of labium. Notal formula with $1+1 m a 1+1 l a, 1+1 l p$ macrosetae on pronotum and mesonotum, $1+1 \mathrm{ma}, 0-1+1 \mathrm{lp}$ macrosetae on metanotum; one dorsal femoral macrosetae; one to three ventral tibial macrosetae; subequal curved claws with small lateral crests; laminar telotarsal process ending in subtrapezoidal extreme; urotergites with medial anterior, posterior, lateral anterior and posterior macrosetae; first urosternite with 7+7-6+6 macrosetae, $5+5-4+4$ on II-VII urosternites and $1+1$ on VIII urosternite; first male urosternite with glandular $g_{l}$.

\section{Habitat and distribution}

Two species dwelling in soil habitats, one in northwestern Morocco and the other in a lava cave in Fuerteventura, Canary Islands (Condé 1953b; Sendra et al. 2020b) (Fig. 62).

Remycampa launeyi Condé, 1952

Remycampa launeyi Condé, 1952: 359, fig. 3.

Meiocampa launeyi - Paclt 1957: 31.

Diagnosis (Condé 1952a, 1953b; Sendra 1989a)

Body length 2.2-3.0 mm; sparse thin and smooth clothing setae; antennae with 16-21 antennomeres; sensillum of third antennomere small in ventral position; short, thick gubia sensilla; atypical labium; $1+1$ $m a, 1+1 l a, 1+1$ lp macrosetae on pronotum and mesonotum, $1+1 \mathrm{ma}, 1+1 \mathrm{lp}$ macrosetae on metanotum; thin, barbed notal macrosetae; smooth marginal setae slightly thicker than clothing setae; calcars well barbed; one dorsal femoral macrosetae; one ventral tibial macroseta with a few barbs; subequal, smooth, slightly curved claws; laminar telotarsal process ending in subtrapezoidal extreme; $1+1 \mathrm{ma}$ macrosetae on I-VII urotergites, $1+1 l p$ on III urotergite, $1+1 l a, 1+1 l p$ on IV-VII urotergites, $1+1 \mathrm{mp}, 3+3 \mathrm{lp}$ on VIII urotergite; first urosternite with $7+7$ macrosetae, $5+5$ on II-VII urosternites and $1+1$ on VIII urosternite; first male urosternite with glandular $g_{1}$-setae and subcylindrical appendages with glandular $a_{1}$ and $a_{2}$-setae; female subcylindrical appendages with glandular $a_{1}$ and $a_{2}$-setae; cerci shorter than body with 8 articles covered in long barbed macrosetae and a few clothing setae. 


\section{Habitat and distribution}

Soil-dwelling species recorded from several localities in Morocco and the Canary Islands (Condé 1953b).

Remycampa herbanica Sendra \& Oromí, 2020

Remycampa herbanica Sendra \& Oromí in Sendra et al., 2020b: 44, figs 5-30, tables 1-2.

Diagnosis (Sendra et al. 2020b)

Body length 3.8-4.4 mm; epicuticle smooth and slightly reticulated at high magnifications; scarce short clothing setae with one or two apical barbs; antennae with 36 antennomeres, $2 \times$ as long as wide in apical antennomere; 21 complex olfactory chemoreceptors arranged in two concentric circles, each with a pile of fused plates forming coniform structure; distal and central antennomeres with single distal whorl of 8-12 short, thick gouge sensilla $10 \mu \mathrm{m}$ long; small coniform sensillum on third antennomere in ventral position; moderate protrusion of frontal process covered with very slightly tuberculated setae; atypical labium with slight torsion of labial palps, little elongation of palpiform processes and deep groove in middle of labium; pronotum and mesonotum with $1+1 \mathrm{ma}, 1+1 \mathrm{la}, 1+1 \mathrm{lp}$ macrosetae; metanotum with 1+1 ma macrosetae; all macrosetae short and slightly thick; marginal setae longer and more barbed than clothing setae; legs elongated, metathoracic legs reaching abdominal segment IX; tibia always longer than femur or tarsus; femorae III each with one short, thick dorsal macroseta; tibiae III with two (three) short ventral macrosetae; subequal claws with lateral expansion; smooth laminar telotarsal processes curved along and ending in slight wide expansion with narrow prolongation on one side, unique shape among diplurans; urotergites with $1+1 m a$ on I-IV; $1+1 m a, 1+1$ la on IV, $1+1 m a, 1+1 l a, 1+1 l p_{3}$ on VVII; $1+1 m p, 3+3 l p_{l-3}$ on VIII; and $1+1 m p, 5+5 l p_{1-5}$ on IX abdominal segment; urosternite I with $6+6$ macrosetae; urosternites II to VII with 4+4; urosternite VIII with 1+1; stylus with apical, subapical and ventromedial seta with a few long barbs; cerci more than $2 \times$ as long as body length, with 27 primary articles; female urosternite I with slim cylindrical appendages, with glandular $a_{1}$ setae; male urosternite I with short coniform appendages, with glandular $a_{1}$ setae; posterior edge with narrow field of glandular $g_{1}$ setae.

\section{Habitat and distribution}

Cave-adapted species only known from a lava tube on Fuerteventura, Canary Islands (Sendra et al. 2020b).

Genus Spaniocampa Silvestri, 1933

Spaniocampa Silvestri, 1933e: 210.

\section{Diagnosis (Silvestri 1933e)}

Non-thoracic macrosetae on pronotum, mesonotum and metanotum; femora without macrosetae, tibia with $0-1$ short macrosetae; subequal curved smooth claws with smooth setiform telotarsal process; $1+1-2+2$ lp on urotergite VIII; $2+2-3+3$ lp on abdominal segment IX, urosternites II to VII with 3+3$4+4$; urosternite VIII with 1+1; posterior border of female urosternite with three or four groups of small setiform setae in S. relicta.

\section{Habitat and distribution}

Two soil-dwelling species adapted to deep soil horizons, with a disjunct distribution: one in the Republic of Guinea and the other in Gran Canaria, Canary Islands (Silvestri 1933; Sendra et al. 2020b). 
Spaniocampa relicta Sendra \& López, 2020

Spaniocampa relicta Sendra \& López in Sendra et al., 2020b: 51, figs 31-34.

Diagnosis (Sendra et al. 2020b)

Body length 3.4-4.1 mm; epicuticle with small microdenticles; smooth clothing setae; bacilliform sensillum on third antennomere in ventral position; non-thoracic macrosetae on pronotum, mesonotum and metanotum; short, slightly thick marginal setae, smooth or with small barbs; femora and tibiae without macrosetae; subequal claws, slightly wider at base and regularly curved; smooth setiform telotarsal processes; $1+1 l p_{3}$ on urotergite VIII; $3+3 l p_{3-5}$ on abdominal segment IX, and $4+4$ macrosetae on abdominal segment X; urosternite I with $5+5$ macrosetae; urosternites II to VII with $3+3$; urosternite VIII with 1+1; stylus with apical, subapical and ventromedial seta with a few thin, long, distal barbs, more abundant on ventromedial setae; female urosternite I with short subcylindrical appendages with glandular $a_{l}$ setae; posterior border of female urosternite with three or four groups of small setiform setae; male urosternite I with short, thick appendages with glandular $a_{l}$ setae and posterior edge with a glandular glandular $g_{l}$ setae.

\section{Habitat and distribution}

In deep soil horizons of Gran Canaria Island (Sendra et al. 2020b).

\section{Discussion}

The Euro-Mediterranean fauna of Campodeinae comprises 10 genera, 161 species, 14 subspecies and 19 affinis forms. These 194 taxa comprise 20\% of known Diplura (Table 1).

Campodea is the richest genus with 116 species. It is divided into four subgenera: Campodea s. str. (68 spp plus $7 \mathrm{ssp}$ ), Dicampa (34 spp plus $1 \mathrm{ssp}$ ), Monocampa (7 spp plus $2 \mathrm{ssp}$ ) and Paurocampa (7 spp). Other genera have considerably less species in the Euro-Mediterranean: Podocampa (16 spp, 2 ssp), Litocampa (15 spp, $1 \mathrm{ssp})$, the clearly polyphyletic Eutrichocampa (7 ssp, $1 \mathrm{ssp})$, Remycampa (2 spp) and Spaniocampa (1 sp.). Edriocampa, Libanocampa, Oreocampa, and Helladocampa are monotypic.

In the absence of copulatory structures, which provide solid taxonomic characters in other groups of arthropods, it is difficult to clearly understand the phylogeny of Campodeinae. The taxonomy of this subfamily relies on a few morphological characters with considerable variability, such as the macrosetal chaetotaxy, the pretarsal structures, and the secondary sexual characters on the first urosternite (Condé 1956a, 1959; Sendra et al. 1986). Thus, 19 affinis forms are proposed to preclude the description of unclear species or subspecies, as happened previously.

The SEM study of Campodeinae provides consistent taxonomical characters related to the shape, abundance and distribution of microdenticles on the cuticle (Figs 2-12), as for the subfamily Plusiocampinae (Sendra et al. 2020a). A molecular phylogeny with extensive taxa coverage will shed light on the evolution of the group.

Campodeinae inhabit all horizons of soils and cave ecosystems (Sendra et al. 2020c). Some Campodeinae are of high biogeographic and paleobiogeographic interest. Within the subgenera of Campodea, Campodea s. str. is the widest distributed subgenus at both sides of the North Atlantic Ocean, reaching the northernmost latitude distribution of all diplurans; Dicampa is limited to the Mediterranean basin enduring dry environments with a preference for the B horizon of soils. Paurocampa has a more restricted distribution in some mountain areas of the Mediterranean region; in addition to two cave-adapted species in the Dinaric Mountains. Monocampa is limited to western Europe with the exception of the invasive M. devoniensis that also occurs in cities of South Africa, Australia and North America (Paclt 1966). 
Podocampa and Litocampa are close-related genera with overlapping distribution areas. They share an amphi-Atlantic distribution, presumably a result of the tectonic drift in the Late Mesozoic with poor dispersal capabilities (Sendra 2020c). This distribution pattern is similar to that of the tachycampoids, a dipluran group incertae sedis (Sendra et al. 2020a) and also of other arthropods such as Syarinidae pseudoscorpions from America and the Iberian Peninsula (Zaragoza 2017).

Campodeinae is a group well represented in terrestrial ecosystems and significantly contributing to the biomass of soil biota. They play an important role in the decomposition of organic matter at the surface, within and below the soil, providing an ecosystem service of relevant socio-economical value.

\section{Acknowledgements}

We are grateful for the sampling efforts of Loles Beltrán, Pablo Barranco, Špela Borko, Erhard Christian, Teo Delić, Bogdan Dehelean, Floren Fadrique, Carles Fontxivel, Fulvio Gasparo, Pier Mauro Giachino, Dilian Georgiev, Sabrina Joye, Christian Komposch, Lubomir Kováč, Josiane Lips, Sergio Montagud, Guiseppe Nicolosi, Pedro Oromí, Vicente M. Ortuño, Slavko Polak, Carlos Prieto, D. Rodríguez, José María Salgado, Santiago Teruel, Peter Trontelj, Illya Turbanov, Mateo Vadell and Dante Vailati. Thanks go to the whole wonderful staff of the Universitat de València; to Ferran Palero for support on the production of the distribution maps, to Katie Marzen for the English revision of the manuscript; to Sergio Montagud for the permission to reproduce the photographs, and to Thomas Pape, Natural History Museum of Denmark, for kind advice on nomenclatural issues. AS is personally grateful to Cyrille d'Haese for hosting him at his lab in the MNHN-Paris during the SYNTHESYS stay. This study was supported by the SYNTHESYS Project FR-TAF-4960 / Muséum national d'histoire naturelle, financed by the European Community Research Infrastructure Action under the FP7 Capacities Program and by a research and grant (15471) from VILLUM FONDEN. Finally we are very grateful for the effort made by Erhard Christian and Pedro Oromí in their valuable revisions.

\section{References}

Agrell I. 1944. Die schwedischen Thysanuren. Opuscula entomologica 9: 23-36.

Allen R.T. 1994. An annotated checklist and distribution records of the subfamily Campodeiinae in North America (Insecta: Diplura: Rhabdura: Campodeidae). Transactions of the American Entomological Society 120 (3): 181-208.

Allen R.T. 1995. Key to the species of Campodea (Campodea) from eastern North America and description of a new species from Virginia (Diplura: Campodeidae). Annals of the Entomological Society of America 88 (3): 255-262. https://doi.org/10.1093/aesa/88.3.255

Arevad K. 1957. Danske Diplura (Insecta, Apterygota). Entomologiske Meddelelser 28: 127-144.

Azadbakhsh S. \& Nozari J. 2016. First faunistic study of Diplura in north of Iran with records of two species of Campodea (Campodeidae). Entomologica Fennica 27: 53-56.

Bagnall R.S. 1915. Preliminary notes on British Campodeidae (Thysanura) and a plea for material. The Entomologist's Monthly Magazine 1915: 261-263.

Bagnal R.S. 1918a. On two new species of Campodea. The Entomologist's Monthly Magazine 54: 157159.

Bagnall R.S. 1918b. Records and descriptions of some British Campodeidae. The Entomologist's Monthly Magazine 54: 109-113.

Bagnall R.S. 1918c. On a new species of Campodea (C. devoniensis, sp.n.) from South Devon. The Entomologist's Monthly Magazine 54: 277-278. 
Bareth C. 1963. À propos des pontes et des éclosions chez Campodea (C.) remyi Denis. Bulletin Société zoologique de France 88 (5-6): 663-671.

Bareth C. 1966. Ėtude comparative des spermatophores chez les Campodéidés. Comptes rendus de l'Académie des sciences Paris série D 262: 2055-2058.

Bareth C. 1968. Biologie sexuelle et formations endocrines de Campodea remyi Denis (Diploures Campodéidés). Revue d'Écologie et de Biologie du sol 5 (3): 303-426.

Bareth C. 1978. Acquisitions récentes sur l'anatomie et la biologie d'un groupe de microarthropodes du sol, les Diploures Campodéides (Insecta Apterygota). 103 Congrès national des Sociétés savantes, Nancy, 1978, Sciences 3: 215-226.

Bareth C. 1980. Campodéidés endogés de Sardaigne recoltés par R. Dallai (Insecta Diplura). Redia 63: 121-135.

Bareth C. 1983. Diploures Campodéidés du milieu souterrain superficiel de la Region Ariegeoise. Mémoires de Biospéologie 10: 67-71.

Bareth C. 1985. Campodea (C.) leclercin. sp. de la grotte de Puechredon(Gard) (Diploures Campodéidés). Note présentée au Colloque de Biospéologie de Nancy (Mai 1985). Spelunca 14: 47-48.

Bareth C. 1986. Acquisitions récentes sur l'écologie et la biologie des Diploures Campodéidés (Insectes Apterygota). $2^{e}$ International Seminar on Apterygota, Sienna, Italy 1986: 99-103.

Bareth C. 1988. Campodés cavernicoles de la Vénétie orientale (Frioule, Vénétie Julienne) et de la Calabre (Insecta, Aprtérygota Diplura). Atti e Memorie della Commissione Grotte "E. Boegan" 27: $45-55$.

Bareth C. 1992. Diploures Campodéidés du Nord-Est de Madagascar (Insecta Apterygota). Journal of African Zoology 106 (6): 489-497.

Bareth C. 1999. Une nouvelle espèce de Litocampa découverte dans une grotte de Belqique (Diploures Campodeidae). Bulletin des Chercheurs de la Wallonie 39: 9-13.

Bareth C. 2000a. Les Diploures Campodéidés des grottes de Belgique. Bulletin des Chercheurs de la Wallonie 60: 5-6.

Bareth C. 2000b. Ultrastructure du faisceau de spermatozoïdes de Campodea sensillifera Condé et Mathieu, 1958: Étude comparative (Insecta Diplura). Bulletin de l'Académie lorraine des Sciences 39: 33-39.

Bareth C. 2001. Litocampa quadrisetigera n.sp. (Campodeidae Diplura) de la grotte de Bidalunia. Bulletin de l'Académie lorraine des Sciences 40 (4): 41-44.

Bareth C. 2006. Les Campodes de France (Diploures Campodéidés). Mémoires de Biospéologie, numéro hors série: $2-108$.

Bareth C. 2007a. Remarques sur les cerques de Campodea lubbockii Silvestri, 1912 (Diplura: Campodeidae). Notes faunistiques de Gembloux, Comumnications brèves 60 (1) : 53-54.

Bareth C. 2007b. In memoriam: Notice sur Bruno Condé et son oeuvre scientifique. Bulletin Société zoologique française 132 (3): 225-228.

Bareth C. \& Condé B. 1958. Campodéidés endogés de l'ouest des États-Unis (Washington, Oregon, Californie, Arizona). Bulletin de la Société linnéenne de Lyon 27 (8): 226-48.

Bareth C. \& Condé B. 1965. La prélarve de Campodea (C.) remyi. Revue Écologie et Biologie du sol 2(3): 397-401. 
Bareth C. \& Condé B. 1977. Diploures Campodéidés de Cuba. Résultats des Expéditions biospéologiques cubano-roumaines à Cuba 2: 313-316.

Bareth C. \& Condé B. 1981. Nouveaux Campodéidés de grottes d'Espagne. Revue suisse de Zoologie 88 (3): 775-786.

Bareth C. \& Condé B. 1984. Nouveaux Plusiocampa cavernicoles d'Italie Continentale (Diplura Campodeidae). Bollettino della Società entomologica Italiana 116 (8-10): 132-147.

Bareth C. \& Condé B. 1985. Campodéidés endogés de Ligurie (Diplura). Annali del Museo Civico di Storia Naturale “Giacomo Doria” 85: 251-258.

Bareth C. \& Condé B. 1998. Diploures Campodéidés de France continentale. Revue française d'Entomologie (nouvelle sèrie) 20 (3): 95-102.

Bareth C. \& Juberthie-Jupeau J. 1984. Les organes sensoriels des diploures campodeidés (insectes apterygotes). Étude ultrastructurale. Annales de la Société royale zoologique de Belgique 114 (1): 9-20.

Bareth C. \& Juberthie-Jupeau J. 1996. Ultrastructure of the formations of the cuticle of Campodea kervillei Denis (Insecta: Diplura). Bulletin des Academie \& Société lorraines des Sciences 35 (4): 231241.

Bernard E.C. 2008. Reappraisal of the Stachia-stachiomella-Pseudostachia complex (Collembola: Odontellidae), redescriptions of Stachia minuta and Stachiomella oxfordia, and Stachia tasgola, new species. Proceeding of the Biological Society of Washington 21: 106-116.

Bitsch J. 1952. Recherches anatomiques sur le labium des Diploures (Insectes Aptérygotes). Publications de l'Université de Dijon nouvelle série 9: 5-26.

Blanke A. \& Machida R. 2016. The homology of cephalic muscles and endoskeletal elements between Diplura and Ectognatha (Insecta). Organisms Diversity \& Evolution 16 (1): 241-257.

https://doi.org/10.1007/s13127-015-0251-5

Blesić B. 1984. Fauna Diplura (Insecta) Sr Srbije. Collection of Scientific Papers of the Faculty of Science Kragujevac 5: 91-96.

Blesić B. 1987. The dynamics of the fauna of Campodeidae (Insecta, Diplura) in the surroundings of Kragujevac. Collection of Scientific Papers of the Faculty of Science Kragujevac 8: 35-49.

Blesić B. 1988. Prilog Poznavanja Faune Campodeidae (Diplura, Apterygota) Istocne Srbije. Collection of Scientific Papers of the Faculty of Science Kragujevac 9: 39-41.

Blesić B. 1992. Apterygota (Diplura i Protura) u Blizini Pozarevca. Collection of Scientific Papers of the Faculty of Science Kragujevac 13: 99-101.

Blesić B. 1996. Diplura of Western Balkan. BIOS (Macedonia, Grecia), Scientific Annals of the School of Biology 4: 23-27.

Blesić B. 1997a. Knowledge of Protura and Diplura of Montenegro. The Montenegrin Academy of Sciences and Arts Glasnik of the Section of Natural Sciences 12: 63-70.

Blesić B. 1997b. Knowledge of Campodeidae (Diplura, Insecta) of Vojvodina. Proceedings for Natural Sciences Matica Srpska 92: 65-67.

Blesić B. 1997c. Eutrichocampa species (Diplura Campodeidae) in Balkan Peninsula. Acta entomológica serbica 2 (1/2): 141-144.

Blesić B. 1998a. Investigations of Protura and Diplura of South Serbia. Proceedings for Natural Sciences Matica Srpska 94: 87-90. 
Blesić B. 1998b. Knowledge of Protura and Diplura of Montenegro. The Montenegrin Academy of Sciences and Arts Glasnik of the Section of Natural Sciences 12: 63-70.

Blesić B. 2000a. Of the Subgenus Paurocampa Silvestri, 1932 (Insecta: Diplura) on the Balkans and the rest of Europe. BIOS (Macedonia, Greece), Scientific Annals of the School of Biology 5: 23-26.

Blesić B. 2000b. Investigation of Diplura and Protura in western Serbia. Proceedings for Natural Sciences 99: 69-79.

Blesić B. 2001. Protura and Diplura (Insecta: Apterygota) of the Republic of Macedonia. 75 years Macedonian Museum Natural History: 157-162.

Bockmühl J. 1956. Die Apterygoten des Spitzberges bei Tübingen, eine faunistisch-ökologische Untersuchung. Zoologische Jahrbücher (Systematik, Ökologie und Geographie der Tiere) 84: 113-194.

Börset E. 1968. Some records of Diplura from the Oslo area. Norsk Entomologisk Tidsskrift 15 (2): 141-143.

Carpenter A. 1988. The biology of Campodea staphylinus (Campodeidae: Diplura) in a grassland soil. Pedobiologia 32: 31-38.

Chevrizov B.P. 1976. A new species of the genus Campodea (Campodeidae, Diplura) from a cave in west Georgia. Zoologichesky Zhurnal 55 (6): 936-938.

Christian E. 1992. Verbreitung und Habitatpräferenz von Doppel- und Zangenschwänzen in der Großstadt Wien (Diplura: Campodeidae, Japygidae). Entomologia Generalis 17 (3): 195-205.

Christian E. 2003. Checklist of the Diplura of Germany. Entomofauna Germanica 6: 26-32.

Christian E. \& Bauer T. 2005. Food acquisition and processing in entral European Diplura (Hexapoda). $8^{\text {th }}$ Central European Workshop on Soil Zoology, České Budéjovice: 15-18.

Coiffait H. 1958. Les coléoptères de sol. Vie et Milieu 7 supplément: 1-204.

Condé B. 1946a. Diploures récoltes en Corse par P. Remy (première note). Bulletin de la Société entomologique de France 51 (10): 145-148.

Condé B. 1946b. Diploures recoltés en Corse par P. Remy (deuxième note). Collections du Musée de Zoologie de Nancy 1: 1-6.

Condé B. 1947a. Description de deux Campodeidae de la grotte de Bas-Nistos. Bulletin de la Société des Sciences de Nancy nouvelle série 6 (1): 18-24.

Condé B. 1947b. Eutrichocampa remyi n. sp. (Diploures Campodéidés). Bulletin Société des Sciences de Nancy nouvelle série 6 (1): 60-62.

Condé B. 1947c. Quelques campodéidés des Landes et du Pays Basque (Aptérygotes, Diploures). Bulletin du Muséum national d'histoire naturelle $2^{\text {ème }}$ série 19: 185-186.

Condé B. 1947d. Quelques campodéidés du nord-est de la France. Bulletin Société Sciences Nancy nouvelle série 6: 85-92.

Condé B. 1947e. Diploures récoltés en Corse par P. Remy (3e note). Bulletin Muséum national d'histoire naturelle $2^{\text {ème }}$ série 19: 282-285.

Condé B. 1947f. Diploures du Liban. Bulletin Société Sciences de Nancy nouvelle série 7 (4): 122.

Condé B. 1947g. Campodéidés d'Algérie. Bulletin de la Société entomologique de France 52 (9): 144146.

Condé B. 1947h. Nouvelles stations françaises de campodéidés avec description d'une forme nouvelle. Annales des Sciences naturelles Zoologie 11 ìme série (9): 139-144. 
Condé B. 1948a. Contribution a la connaissance des campodéidés cavernicoles de France. Notes biospéologiques 2: 35-48.

Condé B. 1948b. Addition a la Faune des campodéidés cavernicoles de France. Bulletin Société des Sciences de Nancy nouvelle série 7 (2): 45-54.

Condé B. 1948c. Campodéidés hypogés de Corse. Bulletin de la Société Sciences de Nancy nouvelle série 7 (3): 62-68.

Condé B. 1949a. Campodéidés cavernicoles de la région des Appalaches. Notes biospéologiques 4: $125-137$.

Condé B. 1949b. Présence de Campodéidés cavernicoles en Lorraine et en Champagne. Bulletin de la Société des Sciences de Nancy nouvelle série 8 (2/3): 31-34.

Condé B. 1949c. Description préliminaire d'un Campodéidé cavernicole du Pays Basque Espagnol. Bulletin du Muséum national d'histoire naturelle $2^{\text {ème }}$ série 21: 569-573.

Condé B. 1950a. Campodéidés du Var et des Alpes-Maritimes. Bulletin de la Société linnéenne de Lyon 6: $128-132$.

Condé B. 1950b. Note sur le genre Oreocampa (Diploures Campodéidés). Revue française d'Entomologie 17: 283-284.

Condé B. 1950c. Campodeidae (Insecta Diplura) d'Afrique du Sud récoltés par le Dr. R.F. Lawrence. Proceedings of the Zoological Society of London 119 (4): 807-815.

Condé B. 1951a. Campodea (C.) meinerti Bagnall et ses affinites (Diploures Campodéidés). Bulletin de la Société linnéenne de Lyon 4: 88-91.

Condé B. 1951b. Campodéidés cavernicoles de Catalogne. Speleon 2: 51-62.

Condé B. 1951c. Campodéidés de la région d'Orédon (Hautes-Pyrénées). Bulletin de la Société entomologique de France 56 (6): 91-95.

Condé B. 1951d Campodéidés du Portugal récoltés par M.A. de Barros Machado. Memórias e Estudos do Museu Zoológico da Universidade de Coimbra 204: 1-8.

Condé B. 1952a. Contribution à la Faune Endogée du Sahara. Diplopodes Pénicillates, Protoures, Diploures Campodéidés. Bulletin du Société zoologique de France 76 (5-6): 349-365.

Condé B. 1952b. Diagnoses de nouvelles Campodéidés Corses. Bulletin du Muséum national d'histoire naturelle $2^{\text {ème }}$ série 25: 562-567.

Condé B. 1953a. Le Diploure Campodea monspessulana n.sp. hôte de la grégarine Lepismatophila campodeae Tuzet, Manier et Ormières. Bulletin du Muséum national d'histoire naturelle $2^{\text {ème }}$ série 2 (4): 406-409.

Condé B. 1953b. Campodéidés endogés d'Afrique septentrionale. Bulletin de la Société zoologique de France 78 (5-6): 358-377.

Condé B. 1953c. Campodéidés de la grotte de San Giovanni (Sardaigne). Notes biospéologiques 8: 33-37.

Condé B. 1954. Ordnung: Entotropha (Diplura). In: Franz H. (ed.) Die Nordost-Alpen im Spiegel ihrer Landtierwelt: 644-649. Universitätsverlag Wagner, Innsbruck.

Condé B. 1955a. Mission Henri Coiffait au Liban (1951). 4. Protoures et Diploures Campodéidés. Biospeologica 75: 397-412.

Condé B. 1955b. Campodéidés Cavernicoles des Baléares. Notes biospéologiques 9: 121-132. 
Condé B. 1955c. Sur la faune endogée de Majorique (Pénicillates, Protoures, Diploures Campodéidés, Palpigrades). Bulletin du Muséum d'histoire naturelle $2^{\text {ème }}$ série 26 (6): 674-677.

Condé B. 1956a. Matériaux pour une monographie des Diploures Campodéidés. Mémoires du Muséum national d'histoire naturelle Série A - Zoologie 12: 1-202.

Condé B. 1956b. Campodéidés des grottes de Sardaigne (Insecta Diplura). Atti VII Congresso Nazionale di Speleologia Memoria III: 199-202.

Condé B. 1957. Campodéidés récoltés en Sicile par P.Strinati. Fragmenta Entomologica 2 (14): 137141.

Condé B. 1959. Métamorphose des processus télotarsaux d'un Campodéidé (Insecte Diploure) au cours d'une postpubérale. Comptes rendus de l'Académie des Sciences, Séance du 2 Mars 1959 248: 1402 1405.

Condé B. 1960. Protoures et Diploures Campodéidés des alluvions de la Moselle. Bulletin de la Société des Sciences de Nancy 19: 123-127.

Condé B. 1961. Sur la microfaune du sol de Grande-Bretagne. II Diploures Campodédidés. Annales and Magazine of Natural History série 13 4: 149-154.

Condé B. 1962. Géonémie des Diploures troglobies du Jura et du Vercors. Spelunca Mémoires 2: 119127.

Condé B. 1966. Campodéidés de la région de Recoaro (Vénétie). Revue d'Écologie et de Biologie du sol 3 (1): 166-169.

Condé B. 1973. Campodéidés Endoges de l'Est des États-Unis. Bulletin de la Société linnéenne de Lyon $n^{o}$ spécial: $17-29$.

Condé B. 1974. Les Paurocampa du groupe de suensoni Tuxen dans les grottes d'Europe centrale (Diploures Campodéidés). Revue suisse de Zoologie 81 (2): 561-567.

Condé B. 1975. Présence, en Sardaigne, du genre Podocampa (Diploures Campodéidés). Annales de Spéléologie 30 (2): 347-350.

Condé B. 1978a. Le sous-genre Monocampa dans les grottes de Sardaigne (Diploures Campodéidés). Bulletin Société zoologique de France 103 (3): 263-267.

Condé B. 1978b. Diplopodes Pénicillates, Diploures Campodéidés et Palpigrades des îles Ponziane. Revue d'Écologie et de Biologie du sol 15 (2): 273-277.

Condé B. 1980. Diploures Campodéidés des grottes de Nouvelle-Caledonie. Revue suisse de Zoologie 87 (1): 193-200.

Condé B. 1982a. Diploures Campodéidés de Papouasie. Revue suisse de Zoologie 89 (3): 731-748.

Condé B. 1982b. Un extraordinaire Campodéidé troglobie des Picos de Europa (Santander), Espagne. Revue suisse de Zoologie 89 (1): 69-76.

Condé B. 1984. Diploures Campodéidés (Insectes) de Grèce (1 $1^{\text {ere }}$ note). Revue suisse de Zoologie 91 (1): 173-201.

Condé B. 1991. Campodéidés des Grottes de Bourgogne (Insectes, Diploures). Mémoires de Biospéologie 18: 243-246.

Condé B. 1996. Diploures Campodéidés de la Pestera de la Movile (Movile Cave), Dobroudja méridionales (Roumanie). Revue suisse de Zoologie 103 (1): 101-114. 
Condé B. 1997. Campodéidés des grottes du Parc Naturel Régional des Grands Caussess (Insecta, Diplura). Mémoires de Biospéologie 24: 157-162.

Condé B. \& Barbier G. 1965. Diploures Campodéidés des Açores et de Madère. Boletim do Museu Municipal do Funchal 19: 63-87.

Condé B. \& Bareth C. 1970. La faune terrestre de l'Ile de Sainte-Hélène (première partie). Annals of the Royal Museum for Central Africa $8^{\text {ème }}$ Zoology 181: 149-152.

Condé B. \& Bareth C. 1998. Diploures Campodéidés de France continentale. Revue française d'Entomologie nouvelle série 20 (3): 95-102.

Condé B. \& Bareth C. 2001. Campodéidés des grottes de Bulgarie (Insecta: Diplura). Mémoires de Biospéologie 28: 9-27.

Condé B. \& Geeraert P. 1962. Campodéidés endogés du centre des Etats-Unis. Archives de Zoologie expérimentale et générale 101 (3): 73-160.

Condé B. \& Mathieu A. 1957. Campodéidés endogés de la région Pyrénéenne. Vie et Milieu 8 (4): 439-472.

Condé B. \& Pagés J. 1991. Diplura. In: Naumann I.D. (ed.) The Insects of Australia. A Textbook for Students and Research Workers, $2^{\text {nd }}$ edition, 2 volumes: 269-271. Melbourne University Press, Carlton.

Dallwitz M.J. 2005. DELTA - DEscription Language for TAxonomy.

Available from http://www.delta-intkey.com [accessed 3 Nov. 2020].

Denis J.R. 1924. Contribution à la connaissance des Diploures. Bulletin scientifique de Bourgogne Supplement 9: 1-97.

Denis J.R. 1930. Sur la faune française des Aptérygotes XIe note: Diploures avec tableau de détermination des espèces françaises. Bulletin Société zoologique de France 55: 19-41.

Denis J.R. 1932a. Sur la faune française des Aptérygotes. XIII. Bulletin de la Société entomologique de France 37 (5): 75-77.

Denis J.R. 1932b. Campodés Pyrénéens récoltés par H. Gadeau de Kerville. Société entomologique de France Livre Centenaire 1932: 597-614.

Denis J.R. 1949. Ordre des Diploures. In: Grassé P.P. (ed.) Traité de Zoologie IX: 160-185. Masson, Paris.

Good J.A., Blackith R.E. \& Higgins D.G. 1989. Campodea lankestri Silvestri, a soil apterygote new to Ireland. Irish Naturalist's Journal 23 (4): 154.

Gunn A. 1992. The ecology of Campodea lankesteri (Silvestri) (Diplura). The Entomologist 111 (4): 201-209.

Husson R. 1946. Sur quelques récoltes de Diploures Campodéidés. Revue française d'Entomologie 13: 90-92.

Ionescu M.A. 1951. Contribuţiuni la studiul Campodeidelor din Republica Populara Romana. Buletin ştiinţific, Secţiunea de ştiinţe biologice, agronomice, geologice şi geografice 3 (3): 525-532.

Ionescu M.A. 1955. Diplura. Fauna Republicii Populare Române, Insecta VII (2): 1-48. Rumanian Academy, Bucharest.

Juberthie-Jupeau L. \& Bareth C. 1980. Ultrastructure des sensilles de l'organe cupuliforme de l'antenne des Campodés (Insecta: Diplura). International Journal of Insect Morphology and Embryology 9: 255268. 
Karaman M. \& Blesić B. 1983. The first finding of the genus Podocampa (Insecta, Diplura) on the Balkan peninsula. Drugi simpozijum o fauni SR Srbije, Zbornik: 71-74.

Karaman M. \& Blesić B. 1984. Fauna Diplura (Insecta) SR Srbije. Collection of Scientific Papers of the Faculty of Science Kragujevac 5: 91-96.

Kühnelt W. 1957. Biologia del Suelo. Consejo Superior de Investigaciones Científicas, Madrid.

Marten W. 1939. Zur Kenntis von Campodea. Zeitschrift für Morphologie und Ökologie der Tiere 36: $41-88$

Meinert F. 1865. Campodea: en familie af Thysanurernes orden. Naturhistorisk Tidsskrift 3: 400-440.

Leleup M.N. 1948. Thysanoures nouveaux pour la faune belge. Bulletin et Annales Société entomologique de Belgique 84 (1-2): 12.

Lie-Pettersen O.J. 1898. Apterygogenea in Sogn und Nordfjord 1897 u. 98 eingesammelt. Bergens Museums Aarbog 1898 (VI): 1-17.

Loksa I. 1960. Faunistisch-Systematische und Ökologische Untersuchungen in der Lóczy-Höhle bei Balatonfüred (Biospeologica Hungarica XL). Annales Universitatis Scientiarum Budapestinensis, Sectio Biologica 3: 253-266.

Olsen K.M. 1996. Tohalen Campodea lubbockiii Silvestri, 1912, "kranstohale". Insekt-Nytt 21 (4): 7-8.

Orelli M.v. 1956. Untersuchungen zur postembryonalen Entwicklung von Campodea (Insecta, Apterygota). Verhandlungen der Naturforschenden Gesellschaft in Basel 67 (3): 501-574.

Paclt J. 1951. Contribution à l'étude de notre faune du domaine principalement endogé I. Entomolgické listy 14: 161-164.

Paclt J. 1954. Ein zoogeographisches Problem: Campodea augens Silv. (Apterygota, Diplura). Entomologisches Nachrichtenblatt Österreichischer und Schweizer Entomologen 6: 7-10.

Paclt J. 1956. Diplura Slovenska a prilahlych oblasti. Biologické práce SAV 2 (6): 5-25.

Paclt J. 1957. Diplura. Genera Insectorum 212E. P. Wytsman, Crainhem.

Paclt J. 1961a. Campodeidae des Senckenberg-Museums (Ins.-Diplura). Senckenbergiana biologica 42 (5/6): 455-458.

Paclt J. 1961b. Über eine neue Campodea-Art aus der Ostslowakei (Ins., Diplura). Senckenbergiana biologica 42 (5/6): 451-453.

Paclt J. 1965. Neue Beiträge zur Kenntnis der Apterygoten-Sammlung des Zoologischen Staatsinstituts und Zoologischen Museums Hamburg. Entomologische Mitteilungen aus dem Zoologischen Staatsinstitut und Zoologischen Museum Hamburg 3 (54): 93-104.

Paclt J. 1966. Über die Identität, geographische Verbreitung und Synonymie von Campodea (Monocampa) devoniensis Bagnall (Ins., Diplura). Senckenbergiana biologica 47 (2): 125-129.

Paclt J. 1969. Über zwei verkannte Campodea-Arten (Insecta, Diplura) aus dem Witoscha bei Sofia. Zoologischer Anzeiger 182 (3/4): 285-287.

Paclt J. \& Rusek J. 1961. Campodea suensoni Tuxen (Insecta, Diplura) clenem beskydské. Publications Faculty of Science University of Brno 415: 279-283.

Pagés J. 1951. Contribution à la connaissance des Diploures. Supplément du Bulletin scientifique de Bourgogne 9: 1-97.

Pagés J. 1959. Remarques sur la classification des diploures. Travaux du Laboratoire de Zoologie et de la Station aquicole Grimaldi de la Faculte des sciences de Dijon 26: 1-25. 
Pagés J. 1961. Comparaison et interprétation des papilles génitales femelles des Diploures. Comptes rendus de l'Académie des sciences, séance du 27 mars 1961 252: 2001-2003.

Pagés J. 1967a. Données sur la Biologie de Dipljapyx humberti (Grassi). Revue d'Écologie et de Biologie du sol 4 (2): 187-281.

Pagés J. 1967b. La notion de territoire chez les diploures japygidés. Annales de la Société entomologique de France nouvelle série 3 (3): 715-719.

Palacios-Vargas J. \& Garcia-Gómez A. 2014. Biodiversidad de Diplura (Hexapoda: Entognatha) en México. Revista Mexicana de Biodiversidad 85: 236-242.

Palissa A. 1964. Apterygota. Die Tierwelt Mitteleuropas IV(1) 1A: 324-349. Quelle \& Meyer, Leipzig. Ramellini P. 1990. I Diplura dei Monti Ausoni e Aurunci (Lazio): Fauna ed Ecologia. Bollettino dell'Associazione Romana di Entomologia 44: 13-28.

Ramellini P. 1995. Materiali per un catalogo topografico dei Dipluri Italiani. Fragmenta entomologica 27 (1): 15-50.

Ramellini P. 1998. Note sui Dipluri del Parco Nazionale d'Abruzzo (Diplura). Bolletino dell'Associazione Romana di Entomologia 53 (1-4): 19-25.

Ramellini P. 2000. Note su Campodeidi del Piemonte (Diplura, Campodeidae). Rivista Piemontese di Storia Naturale 21: 103-114.

Reboleira A.S., Sendra A., Gonçalves F. \& Oromí P. 2010. The first hypogean dipluran from Portugal: description of a new species of the genus Litocampa (Diplura: Campodeidae). Zootaxa 2728: 50-56.

Reuter O.M. 1895. Apterygogenea Fennica Finlands Collembola och Thysanura. Acta Societatis pro Fauna et Flora Fennica 2 (4): 1-35.

Rusek J. 1964. Über die Diplura (Apterygota) der Tschechoslowakei. Acta Societatis Zoologicae Bohemoslovenicae 28 (2): 134-154.

Rusek J. 1965a. Campodeids (Campodeidae, Diplura) of South-Eastern Europe. Zoologichesky Zhurnal 44 (6): 1345-1356.

Rusek J. 1965b. Zur Kenntnis der Campodeidae(Diplura) Bulgariens. Acta entomologica Bohemoslovaca 62: 92-97.

Rusek J. 1965c. Zur Kenntnis der Apterygoten-Fauna des Gebirges Krupinská vrchovina in der MittelSlovakei. Acta faunistica entomologica Musei Nationalis Pragae 11: 151-164.

Rusek J. 1966. Einige neue und interessante Proturen- und Dipluren-Arten aus der Tschechoslowakei (Apterygota). Acta entomologica Bohemoslovaca 63: 348-372.

Sendra A. 1985.Campodéidos (Insecta:Diplura) cavernícolas de Cataluña y Huesca I. Géneros Plusiocampa Silv, Litocampa Silv. y Podocampa Silv. Butlletí Institució Catalana d'Història Natural 52 (Zoologia 6): 119-128.

Sendra A. 1988. Taxonomía, Filogenia y Biogeografía de la Fauna de Campodeidos Ibérica, Balear y Canaria (Hexapoda, Diplura, Campodeidae). PhD thesis, Biological Science Faculty, València University, Spain.

Sendra A. 1989a. Datos sobre Campodéidos del Museo Nacional de Ciencias Naturales de Madrid (Insecta, Diplura, Campodeidae). Eos 65 (1): 115-123.

Sendra A. 1989b. Nuevas aportaciones a la fauna de Campodeidos edáficos de la Península Ibérica e Islas Baleares (Diplura, Campodeidae). Boletín de la Asociación española de Entomología 13: 35-51. 
Sendra A. 1990a. Campodeidos del Museu Bocage, Lisboa (Insecta, Diplura, Campodeidae). Arquivos do Museu Bocage nouvelle série 1 (31): 465-474.

Sendra A. 1990b. Campodeidos (Insecta:Diplura) cavernícolas de Cataluña y Huesca, II. Géneros Campodea Westwood y Paratachycampa Wygodzinsky. Butlletí de la Institució Catalana d'Història Natural 58 (Secció Zoologia 8): 31-36.

Sendra A. 1990c. Campodeidos del Archipielago Canario (Insecta, Diplura). Actas IV Congreso Ibérico de Entomologia. Asociación española de Entomología, Granada.

Sendra A. 2013. Dipluros del medio subterráneo de Jaén. In: Pérez Fernández T. \& Pérez Ruiz A. (coord.) Los invertebrados de hábitats subterráneos de Jaén: 115-116. Grupo de Espeleología de Villacarrillo (G.E.V.), Jaén.

Sendra A. 2015. Orden Diplura. IDE@-SEA 35: 1-11.

Available from http://sea-entomologia.org/IDE@/revista_35.pdf [accessed 12 Mar. 2019].

Sendra A. \& Baez M. 1986. Nota sobre los Dipluros Campodéidos de la Isla de Tenerife (Islas Canarias) (Diplura Campodeidae). Fragmenta Entomologica 19 (1): 95-98.

Sendra A. \& Condé B. 1987. Un nouveau Campodéidé troglobie de l'Est de l'Espagne (Insecta, Diplura). Revue suisse de Zoologie 94 (1): 55-59.

Sendra A. \& Escolà O. 2004. Campodéidés cavernicoles du nord-est de la péninsule Ibérique. Revue suisse de Zoologie 111 (4): 889-914.

Sendra A. \& Jiménez R. 1983. Contribución al conocimiento de los Campodeidae endógeos de la Península Ibérica (Campodeidae, Diplura). I Congreso Ibérico de Entomología II: 749-757.

Sendra A. \& Jiménez R. 1986. Contribución al conocimiento de los Campodéidos endogeos de España Peninsular (Insecta, Diplura). Eos 62: 277-284.

Sendra A. \& Moreno A. 2004. El subgénero Campodea s.str. en la Península Ibérica (Hexapoda: Diplura: Campodeidae). Boletin de la Sociedad Entomológica Aragonesa 35: 19-38.

Sendra A. \& Moreno A. 2006. Los subgéneros Dicampa, Monocampa y Paurocampa en la Península Ibérica e Islas Baleares (Diplura: Campodeidae). Boletín de la Sociedad Entomológica Aragonesa 39: 69-82.

Sendra A. \& Weber D. 2018. An unexpected discovery of a new subgenus and a species of Plusiocampa (Campodeidae, Diplura) alongside an overview of Central European subterranean campodeids. European Journal of Taxonomy 428: 1-21. https://doi.org/10.5852/ejt.2018.428

Sendra A., Bach C. \& Gaju M. 1986. Contribución al conocimiento de los Campodeidae de Sierra Morena central (Hex.: Diplura). Boletín de la Asociación española de Entomología 10: 35-43.

Sendra A., Salgado J.M. \& Monedero E. 2003. Dos nuevas especies y una subespecie de campodeidos cavernícolas de la cornisa cantábrica (Diplura Campodeidae). Animal Biodiversity and Conservation 26.2: 69-80.

Sendra A., Satar A. \& Montagud S. 2006. Première contribution à la faune de Diploures Campodéidés de la Péninsule d'Anatolie, Turquie (Diplura: Campodeidae). Revue suisse de Zoologie 113 (3): 693-709.

Sendra A., Teruel S., Satar A., Tusun S. \& Özbay C. 2010. New species, new records, and distribution of Campodeidae (Diplura) in Anatolia. Zootaxa 2639: 40-52.

Sendra A., Nitzu E. \& Sanjuan A. 2012. Half a century after Ionescu's work on Romanian Diplura - A faunal contribution based on material collected from karst areas. Travaux de l'Institut de Spéologie "Émile Racovitza" 51: 37-66. 
Sendra A., García Y. \& Weber D. 2013. Campodeidae (Hexapoda, Diplura) from caves of the Grand Duchy of Luxembourg. In: Weber D. (ed.) Die Höhlenfauna Luxemburgs: 216-226. Ferrantia 69, Musée national d'histoire naturelle, Luxembourg.

Sendra A., Beltran M.D. \& Sanchez J.M. 2015. Descripción de un sorprendente dipluro nuevo (Diplura: Campodeidae) de las cavidades de la Cordillera Ibérica (Aragón, España). Boletín de la Sociedad Entomológica Aragonesa (S.E.A.) 57: 189-199.

Sendra A., Palacios J., Garcia A. \& Montejo M. 2016. New species of Campodeidae (Diplura) from Mexican caves. Zootaxa 4072 (5): 540-558. https://doi.org/10.11646/zootaxa.4072.5.2

Sendra A., Jiménez-Valverde A., Gilgado J.D., Ledesma E., Baquero E., Pérez-Suárez G., Cuesta E., Herrero-Borgoñón J.J., Jordana R., Tinaut A., Barranco P. \& Ortuño V.M. 2017a. Diplurans of subsurface terrestrial habitats in the Iberian Peninsula, with a new species description (Diplura: Campodeidae). Zootaxa 4291 (1): 61-80. https://doi.org/10.11646/zootaxa.4291.1.4

Sendra A., Jiménez-Valverde A., Rochat J., Legros V., Gasnier S. \& Cazanove G. 2017b. A new and remarkable troglobitic Lepidocampa Oudemans, 1890 species from La Réunion Island, with a discussion on troglobiomorphic adaptations in campodeids (Diplura). Zoologischer Anzeiger 266: 95104. https://doi.org/10.1016/j.jcz.2016.11.005

Sendra A., Sket B. \& Stoev P. 2017c. A striking new genus and species of troglobitic Campodeidae (Diplura) from Central Asia. Subterranean Biology 23: 47-68. https://doi.org/10.3897/subtbiol.23.14631

Sendra A., Yoshizawa K. \& Ferreira R.L. 2018. New oversize troglobitic species of Campodeidae in Japan (Diplura). Subterranean Biology 27: 53-73. https://doi.org/10.3897/subtbiol.27.28575

Sendra A., Antić D., Barranco P., Borko Š., Christian E., Delić T., Fadrique F., Faille A., Galli L., Gasparo F., Georgiev D., Giachino P.M., Kováč L., Lukić M., Marcia P., Miculinić K., Nicolosi G., Palero F., Paragamian K., Pérez T., Polak S., Prieto C.E., Turbanov I., Vailati D. \& Reboleira A.S.P.S. 2020a. Flourishing in subterranean ecosystems: Euro-Mediterranean Plusiocampinae and tachycampoids (Diplura, Campodeidae). European Journal of Taxonomy 591: 1-138.

https://doi.org/10.5852/ejt.2020.591

Sendra A., López H., Selfa J., Oromí P. 2020b. Two new dipluran species unearthed from subterranean habitats of the Canary Islands (Arthropoda, Hexapoda, Entognatha). Subterranean Biology 34: 39-59. https://doi.org/10.3897/subtbiol.34.50231

Sendra A., Palero F., Jiménez-Valverde A. \& Reboleira A.S.P.S. 2020c. Diplura in caves: diversity, ecology, evolution and biogeography. Zoological Journal of the Linnean Society: zlaa116.

https://doi.org/10.1093/zoolinnean/zlaa116

Silvestri F. 1911. Nuovi generi e nuove specie di Campodeidae (Thysanura) dell'America settentrionale. Bolletino del Laboratorio di Zoologia generale e agraria in Portici 6: 5-25.

Silvestri F. 1912. Contribuzione alla conoscenza dei Campodeidae (Thysanura) d'Europa. Bolletino del Laboratorio di Zoologia generale e agraria in Portici 6: 110-147.

Silvestri F. 1918. Insectes Aptérygogéniens, I, Thysanoures. Voyage de Ch. Alluaud et R. Jeannel en Afrique Orientale (1911-1912). Résultats scientifiques: 3-27.

Silvestri F. 1931a. Campodeidae (Insecta, Thysanura) di Cuba. Bolletino del Laboratorio di Zoologia generale e agraria della R. Scuola superiore d'agricoltura in Portici 24: 299-318.

Silvestri F. 1931b. Contributo alla conoscenza dei Campodeidae (Thysanura) delle grotte della Bulgaria. Bulletin des Institutions royales d'histoire naturelle à Sofia 4: 97-107. 
Silvestri F. 1931c. Campodeidae (Insecta Thysanura) dell'estremo Oriente. Bolletino del Laboratorio di Zoologia generale e agraria della R. Scuola superiore d'agricoltura in Portici 25: 286-320.

Silvestri F. 1932a. Campodeidae (Thysanura) de España (primera parte). Eos 8: 115-164.

Silvestri F. 1932b. Descripción de cinco nuevas Campodea (Thys.) de Marruecos. Boletín de la Sociedad española de Historia Natural 32 (1): 75-87.

Silvestri F. 1932c. Campodeidae (Insecta, Thysanura) dell'Unione dell'Africa Meridionale. Bollettino del Laboratorio di Zoologia generale e agraria in Portici 26: 54-86.

Silvestri F. 1933a. Nuovi contributi alla conoscenza della fauna delle isole Italiane dell'Egeo. Bolletino del Laboratorio di Zoologia generale e agraria della R. Scuola superiore d'agricoltura in Portici 27: 61-111.

Silvestri F. 1933b. Quarto contributo alla conoscenza dei Campodeidae (Thysanura) del Nord America. Bolletino del Laboratorio di Zoologia generale e agraria della R. Scuola superiore d'agricoltura in Portici 27: 156-204.

Silvestri F. 1933c. Spedizione del Prof. Nello Beccari nella Guiana Britannica I. Thysanura (Insecta). Bolletino del Laboratorio di Zoologia generale e agraria della R. Scuola superiore d'agricoltura in Portici 27: 114-124.

Silvestri F. 1933d. First contribution to the knowledge of the Indo-Malayan Campodeidae (Thysanura Entotropha). Records of the Indian Museum 35: 379-392.

Silvestri F. 1933e. Primo contributo allá conoscenza dei Campodeidae dell'Africa occidentale. Bolletino del Laboratorio di Zoologia generale e agraria della R. Scuola superiore d'agricoltura in Portici 27: 205-218.

Silvestri F. 1936. Eine neue Campodea von Kärnten. Festschrift für Prof. Dr. Embrik Strand 1: 529-531.

Silvestri F. 1949. Descrizione di due specie nuove cavernícole di Campodeidae (Insecta Diplura) della regione del Monte Tauro. Bolletino del Laboratorio di Entomologia agraria in Portici 9: 27-31.

Stach J. 1920. Vorarbeiten zur Apterygoten-Fauna Polens. Teil II: Apterygoten aus den Pieniny. Bulletin International de l'Académie Polonaise des Sciences et des Lettres, série B: Sciences naturelles (1919): $133-233$.

Stach J. 1928. Verzeichnis der apterygogenea Ungarns. Annales Musei Nationalis Hungarici 26: 269274.

Stach J. 1959. The Apterygotan Fauna of the Polish Tatra National Park. Acta Zoologica Cracoviensia 4: $1-102$.

Stach J 1964. Katalog Fauny Polski. XV. Apterygota. Polska Akademia Nauk, Instytut Zoologiczny, Warszawa.

Szeptycki A. 1974. Diplura (Campodeidae) of the Ojców National Park in Poland. Bulletin entomologique de Pologne 46: 745-748.

Tuxen S.L. 1930. Einige Apterygoten aus Südeuropa nebst Beschreibung zwei neuer Arten von Thysanura. Entomologiske Meddelelser 17: 219-227.

Vadell M., Jordana R., Sendra A. \& Moraza M.L. 2007. Primeros datos sobre la fauna cavernícola terrestre de la Cova des Pas de Vallgornera (Llucmajor, Mallorca, Baleares). Endins 31: 117-124.

Valentine B.D. \& Glorioso M.J. 1978. Grooming behavior in Diplura (Insecta: Apterygota). Psyche 85 (2-3): 191-200. 
Westwood J.O. 1842. Description of a new genus of apterous hexapod insects found near London. The Annals and Magazine of Natural History 10: 231-234. https://doi.org/10.1111/j.1365-2311.1842.tb03276.x

Weyda F. 1976. Histology and ultrastructure of the abdominal vesicles of Campodea franzi (Diplura, Campodeidae). Acta entomologica Bohemoslovaca 73 (4): 237-242.

Womersley H. 1927. The Apterygota of the South-West of England. Proceedings of the Bristol Naturalists'Society, series 4 6: 372-379.

Wygodzinsky P.W. 1940. Beiträge zur Kenntnis der Dipluren und Thysanuren der Schweiz. Verhandlungen der Naturforschenden Gesellschaft in Basel 51: 40-64.

Wygodzinsky P.W. 1941a. Beiträge zur Kenntnis der Dipluren und Thysanuren der Schweiz. Denkschriften der Schweizerischen Naturforschenden Gesellschaft 74 (2): 113-223.

Wygodzinsky P.W. 1941b. Zur Kenntnis einiger europäischen Dipluren und Thysanuren. Verhandlungen der Naturforschenden Gesellschaft in Basel 52: 63-100.

Wygodzinsky P.W. 1941c. Über eine neue Campodea und eine neue Lepismachilis aus Südeuropa. Entomologiske meddelelser 22: 137-141.

Wygodzinsky P.W. 1942. Second contribution towards the knowledge of Diplura and Thysanura from Palestina. Revista Brasileira de Biologia 2 (1): 29-46.

Wygodzinsky P.W. 1944a. Contribuiçâo ao conhecimento dos "Entotrophi" e "Thysanura" (Apterygota, Insecta) de Portugal. I. Introdução. Família "Campodeidae". Revista Brasileira de Biologia 4 (4): 501512.

Wygodzinsky P.W. 1944b. Contribuçao ao conhecimento da familia Campodeidae (Entotrophi, Insecta) do Mexico. Anales de la Escuela Nacional de Ciéncias Biológicas 3 (3-4): 367-404.

Zaragoza J.A. 2017. Revision of the Ephippiochthonius complex (Pseudoscorpiones, Chthoniidae) in the Iberian Peninsula, Balearic Islands and Macaronesia, with proposed changes to the status of the Chthonius subgenera. Zootaxa 4246: 1-221. https://doi.org/10.11646/zootaxa.4246.1.1

Manuscript received: 24 February 2020

Manuscript accepted: 21 September 2020

Published on: 9 December 2020

Topic editor: Nesrine Akkari

Desk editor: Kristiaan Hoedemakers

Printed versions of all papers are also deposited in the libraries of the institutes that are members of the EJT consortium: Muséum national d'histoire naturelle, Paris, France; Meise Botanic Garden, Belgium; Royal Museum for Central Africa, Tervuren, Belgium; Royal Belgian Institute of Natural Sciences, Brussels, Belgium; Natural History Museum of Denmark, Copenhagen, Denmark; Naturalis Biodiversity Center, Leiden, the Netherlands; Museo Nacional de Ciencias Naturales-CSIC, Madrid, Spain; Real Jardín Botánico de Madrid CSIC, Spain; Zoological Research Museum Alexander Koenig, Bonn, Germany; National Museum, Prague, Czech Republic. 


\section{Supplementary material}

Supplementary file 1: Localities of all Euro-Mediterranean species and subspecies of Campodeinae. https://doi.org/10.5852/ejt.2020.728.1181.3287

Supplementary file 2: List of studied material, Euro-Mediterranean Campodeinae fauna.

https://doi.org/10.5852/ejt.2020.728.1181.3289 